
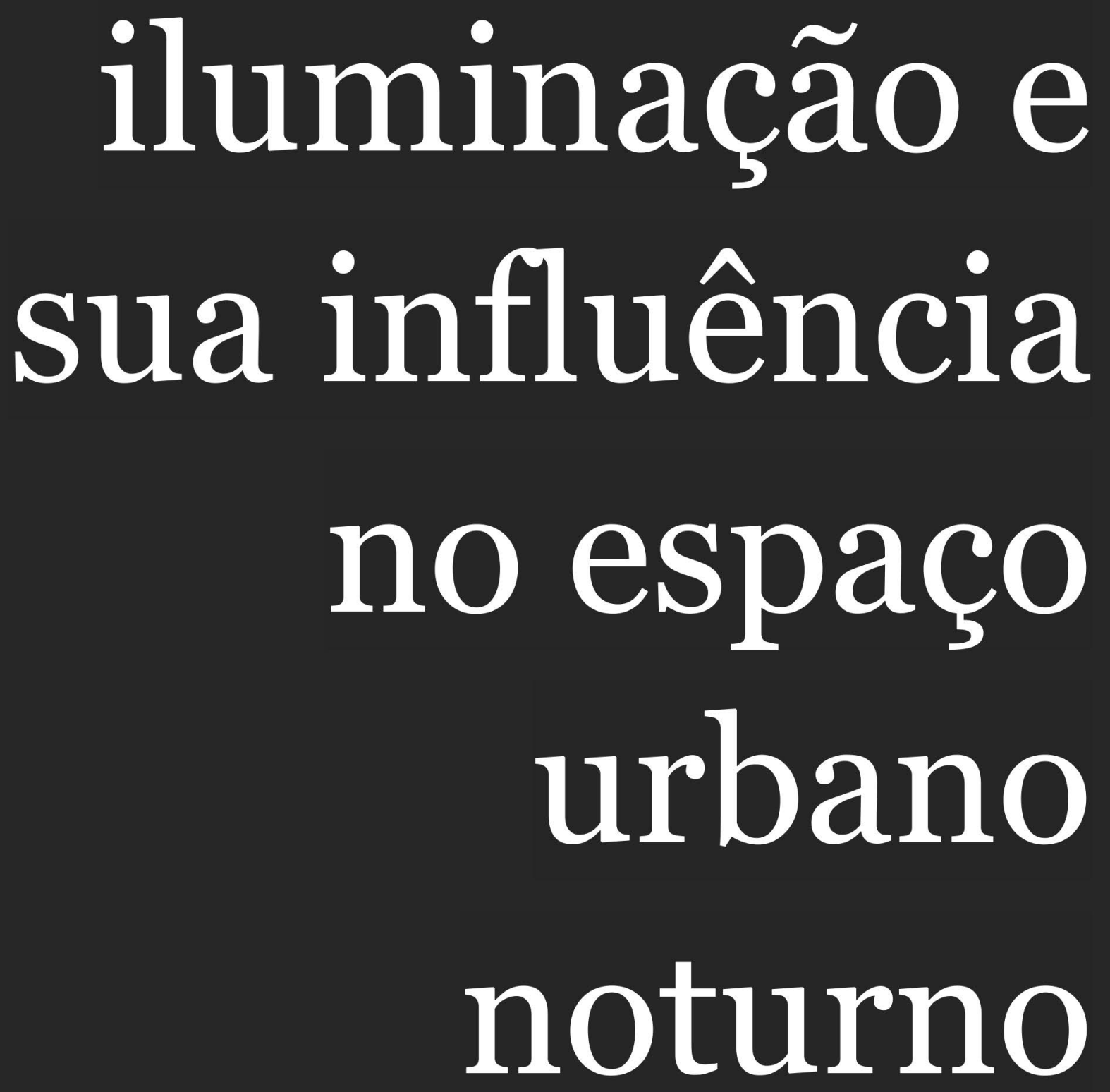

as impressões do usuário no processo de planejamento da luz 
ÍTALO PEREIRA FERNANDES

Iluminação e sua influência no espaço urbano noturno: as impressões do usuário no processo de planejamento da luz 


\section{Iluminação e sua influência no espaço urbano noturno: as impressões do usuário no processo de planejamento da luz}

Dissertação apresentada à Faculdade de Arquitetura e Urbanismo da Universidade de São Paulo - FAUUSP, para obtenção do título de Mestre em Arquitetura e Urbanismo.

Área de Concentração: Tecnologia da Arquitetura

Linha de Pesquisa: Conforto, Eficiência Energética e Ergonomia

Orientador: Prof. Dr. Norberto Corrêa Da Silva Moura

Coorientador: Prof. Dr. António Aguiar Costa 
Autorizo a reprodução e divulgação total ou parcial deste trabalho, por qualquer meio convencional ou eletrônico, para fins de estudo e pesquisas, desde que citada a fonte.

EMAIL DO AUTOR: italo@live.com

Fernandes, Ítalo Pereira

F363i Iluminação e sua influência no espaço urbano noturno: as impressões do usuário no processo de planejamento da luz / Ítalo Pereira Fernandes. -- São Paulo, 2017.

150 p. : il.

Dissertação (Mestrado - Área de Concentração: Tecnologia da Arquitetura) - FAUUSP.

Orientador: Norberto Corrêa da Silva Moura

Co-orientador: António Aguiar Costa

1.lluminação 2.Percepção ambiental 3.Realidade virtual I.Título

CDU 628.9 
FERNANDES, I. P. Iluminação e sua influência no espaço urbano noturno: as impressões do usuário no processo de planejamento da luz. 2017. 150 f. Dissertação (Mestrado) - Faculdade de Arquitetura e Urbanismo, Universidade de São Paulo, 2017.

Aprovado em:

Banca Examinadora

Prof. Dr.

Instituição:

Julgamento:

Assinatura:

Prof. Dr.

Instituição:

Julgamento:

Assinatura:

Prof. Dr.

Instituição:

Julgamento:

Assinatura: 
A Maria de Lourdes Coutinho Pereira (in memoriam) 
Agradecimentos

Agradeço a Deus e Nossa Senhora pela luz constante no caminho da vida.

Aos meus pais Dona Lêda e Seu Itamar, pela confiança, incentivo, amor e força desde quando decidi pesquisar a 2818 quilômetros de distância.

À minha irmã Itamara, pelo apoio forte e meu cunhado Júnior pela exaltação das qualidades desta cidade que me acolheu.

Às minhas sobrinhas Maria Eduarda e Marina, pela compreensão da minha ausência e por me receberem com felicidade e a alegria do mundo.

À minha vovó Lourdes (in memoriam), a pessoa mais feliz que já conheci, que partiu no dia em que cheguei na cidade e que hoje olha lá de cima todas as nossas conquistas. À família Negreiros, Dona Elizabete e Seu Ovídio, pelo apoio e confiança, onde me sinto numa segunda família.

À Dona Fátima e Seu Ribamar, pela compreensão, confiança e apoio incondicional. Ao ceder um espaço em casa, me senti acolhido como nunca poderia imaginar. Acharam pouco e me ajudaram a encontrar um lugar só meu. Agradeço ainda à Lourdinha, Adelmo, Djonata, Daniel, Dona Chiquinha e Maria, pelo carinho em me acolher como um filho na cidade de São Paulo.

Ao meu orientador, Professor Dr. Norberto Corrêa da Silva Moura, pelas contribuições e aprendizados ao longo deste período, pelo comprometimento e dedicação inesgotável, imprescindível para a realização do trabalho.

Ao meu coorientador, Professor Dr. António Aguiar Costa, pelas contribuições e sugestões a respeito da pesquisa, sem os quais não seria possível sua execução.

À Faculdade de Arquitetura e Urbanismo da Universidade de São Paulo (FAUUSP) pela oportunidade, confiança e ensinamentos.

À todos os participantes da pesquisa, pelas contribuições e observações ao trabalho. À Professora Dra. Cláudia Torres, pela amizade, confiança, apoio ao incentivar e sugerir voos mais longes na certeza de que eu seria capaz.

Ao grande amor da minha vida, Ísis de Negreiros, que me acompanha no sufoco ou no sossego, pelo amor, apoio, paciência e carinho neste período contínuo de encontros e despedidas. Ao seu lado suporto adversidades, compartilho felicidades e transformo sonhos em realidade. 
"Se quiséssemos começar com as primeiras causas da percepção visual, um exame da luz devia ter precedido todos os outros porque sem luz os olhos não podem observar nem forma, nem cor, nem espaço ou movimento. Mas a luz é mais do que apenas a causa física do que vemos. Mesmo psicologicamente, ela continua sendo uma das experiências humanas mais fundamentais e poderosas" 
Resumo

FERNANDES, I. P. Iluminação e sua influência no espaço urbano noturno: as impressões do usuário no processo de planejamento da luz. 2017. 150 f. Dissertação (Mestrado) - Faculdade de Arquitetura e Urbanismo, Universidade de São Paulo, 2017.

Pesquisas no âmbito da iluminação focam no aspecto quantitativo e físico dos efeitos lumínicos e seu desempenho na relação usuário-ambiente. Estudos sobre os aspectos subjetivos da luz e sua influência na percepção e usufruto do espaço são crescentes, porém, existem poucos experimentos para avaliar impressões subjetivas dos espaços urbanos à noite. O intuito da pesquisa, portanto, é procurar inverter a pergunta: quanto de luz as pessoas precisam? para como as pessoas interpretam o espaço iluminado em que estão inseridas? e respondê-la através de avaliações visuais dos ocupantes inseridos em diferentes cenários de iluminação. Assim, a pesquisa tem por objetivo verificar a influência da iluminação na percepção do espaço urbano e na relação do usuário com o ambiente noturno. Neste sentido, a pesquisa concentra-se em duas vertentes, uma teórica e outra experimental. Primeiro, a partir da revisão da literatura, investiga-se as impressões dos usuários em ambientes iluminados a partir de conceitos como atmosfera, cunhada por Vogels (2008), e questões relacionadas a variáveis da iluminação e sua influência na percepção visual. Por fim, o estudo contempla um viés experimental, no sentido de formular recursos aparatos e procedimentos - para avaliação dos cenários pelos usuários. Sob à luz dos conceitos selecionados e, utilizando o ambiente virtual como suporte à criação de cenários noturnos, os resultados mostram que existem qualidades subjetivas diferentes nos espaços, relacionadas com questões de segurança e sociabilidade do ambiente, o que reflete a importância destas avaliações, além de apontar possibilidades de investigação sobre a relação entre intenções do projetista e as necessidades e expectativas dos usuários, além de futuros desenvolvimentos em outros contextos onde a iluminação desempenha papel fundamental na vivência e percepção do espaço.

Palavras-chave: Iluminação. Percepção ambiental. Realidade Virtual. 


\begin{abstract}
FERNANDES, I. P. Lighting and its influence on the urban night space: user's impressions in the lighting planning process. 2017. 150 f. Dissertação (Mestrado) - Faculdade de Arquitetura e Urbanismo, Universidade de São Paulo, 2017.
\end{abstract}

Researches in the field of lighting focuses on the quantitative and physical aspects of light effects and their performance in the user-environment relationship. Studies on the subjective aspects of light and its influence on the perception and usufruct of space are increasing; however, there are few experiments to evaluate subjective impressions of urban spaces at night. The aim of research, therefore, is to try to reverse the question: how much light do people need? to How do people interpret the enlightened space in which they are inserted?, and respond to it through visual assessments of occupants in different lighting scenarios. Thus, the research aims to verify the influence of lighting in the perception of urban space and the relationship of the user with the nocturnal environment. In this sense, the research focuses on two aspects: theoretical and experimental. First, from the literature review we investigate the impressions of users in illuminated environments based on concepts such as atmosphere, coined by Vogels (2008), and questions related to lighting variables and their influence on visual perception. Finally, the study contemplates an experimental phase, in the sense of formulating resources - devices and procedures - to evaluate the scenarios by users. Using the selected concepts and through the virtual environment as support for the creation of night scenarios, the results show that there are different subjective qualities in the spaces, related to safety issues and the sociability of the environment, which reflects the importance of these evaluations. Besides that, the research aims to point out possibilities about the relation between the designer's intentions and the user's needs and expectations, as well as future developments in other contexts where lighting planning plays a fundamental role in the experience and perception of space.

Keywords: Lighting design. Environmental Psychology. Virtual Reality. 
FIGURA 1 - PARÂMETROS PARA QUALIDADE DA ILUMINAÇ̃̃O 25

FigURA 2 - OITO ADJETIVOS DISTRIBUíDOS DE MANEIRA CIRCULAR (MODELO CIRCUNFLEXO)

Figura 3 - MODELO CIRCUNFLEXO UTILIZADO NA AVALIAÇÃO DE ESPAÇOS URBANOS NOTURNOS ..33

FIGURA 4 - SALA DE CONFERÊNCIAS UTILIZADA NO EXPERIMENTO. 34

FIGURA 5 - DADOS ANALISADOS A PARTIR DE PROCEDIMENTOS ESTATÍSTICOS 36

FIGURA 6 - FOTOGRAFIAS DO SETOR RUAS E AVENIDAS, CADA UMA REPRESENTANDO UM ATRIBUTO DE ILUMINAÇÃO. 43

FIGURA 7 - FOTOGRAFIAS DA ÁREA DE PEDESTRE INVESTIGADA NO ESTUDO. 45

FiguRA 8 -ILUMINAÇ̃̃o NO ESPAÇO EM PLANTA (A). RUAS ILUMINADAS COM DUAS ALTURAS, QUATRO (B) E SEIS METROS (C) 48

FIGURA 9 - FACHADA DA IGREJA ILUMINADA COM TRÊS OPÇÕES: DOIS (A), TRÊS (B) OU CINCO FACHOS (C) 49

FIGURA 10 - ÁRVORES, CAMINHOS E BANCOS ILUMINADOS 50

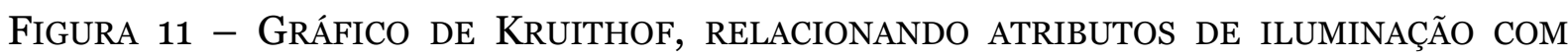
QUALIDADE DO AMBIENTE .52

FigURA 12 - RUAS DA CIDADE DE GRANADA, OBJETO DE ESTUDO DOS AUTORES 55

FigURA 13 - GRÁFICOS DESENVOLVIDOS A PARTIR DA PERGUNTA “ESTE É UM BOM EXEMPLO DE ILUMINAÇÃO PARA SEGURANÇA”. NA ESQUERDA, A COMPARAÇÃO ENTRE DUAS CIDADES, E À DIREITA ENTRE GÊNEROS 57

FIGURA 14 - SOLUÇÃO PARA ILUMINAÇÃO DE ESCADAS 59

Figura 15 - MUSEU DE ARTE KimbeLL 59

Figura 16 - EXEMPloS DE ARQUitetura DA NOITE, BASEAdOS NO CONTRASTE ENTRE SUPERFÍCIES E A ILUMINAÇÃO 60

FIGURA 17 - EXEMPLOS DE ARQUITETURA DA NOITE, BASEADOS NO CONTRASTE ...................61

FIGURA 18 - TRÊS ELEMENTOS DA ILUMINAÇÃO POR RICHARD KELLY ................................. 62

FIGURA 19 - TRÊS ELEMENTOS DA ILUMINAÇÃO POR RICHARD KELLY …………………...... 63

FIGURA 20 - ETAPAS DO PROCESSO DE DESIGN CENTRADO NO USUÁRIO ................................65

FiguRA 21 - USO DE AMBIENTES VIRTUAIS IMERSIVOS NO PROCESSO DE PROJETO EM

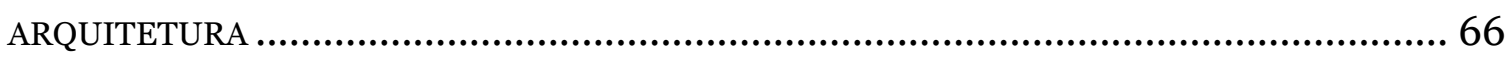

FIGURA 22 - USO DE AMBIENTES VIRTUAIS IMERSIVOS DURANTE EXPERIMENTO PRÁTICO ...67 
FIGURA 23 - GRÁFICOS HIERARQUIA ESTRUTURADA QUANTO A DISPONIBILIDADE DE INFORMAÇÃO EXISTENTE EM CADA MEIO DE REPRESENTAÇÃO....................................70

FIGURA 24 - EXEMPLOS DE MOCKUPS REALIZADOS NA ÁREA HOSPITALAR......................... 71 Figura 25 - À DIREITA, IMAGENS DO MOCKUP DO METRÔ EM WASHINGTON. A ESQUERDA, QUARTO DE ESTUDOS, OBJETO DE PESQUISA EM LAU (1972) ...................................73

FIGURA 26 - MODELO EM ESCALA 1:7.5 COM DIFERENTES POSIÇÕES DE LUMINÁRIAS .........74

FIGURA 27 - VARIAÇÕES DE ILUMINAÇÃO NO CENÁRIO URBANO NOTURNO .........................76

FIGURA 28 - DiFERENTES ALGORITMOS DESEMPENHAM CÁLCULO DE ILUMINAÇÃO PRECISO.

OS MAIS UTILIZADOS SÃO RAYTRACING (A), RADIOSITY (B) E PHOTON MAP (C) . ............. 77

FIGURA 29 - DIFERENTES CENÁRIOS GERADOS POR COMPUTADOR. .................................79

FIGURA 30 - IMAGENS DIGITAIS COM CONFIGURAÇÕES DE ILUMINAÇÃO DIFERENTES. ........79

FigURA 31 - AMBIENTE GENÉRICO UTILIZADO PARA AVALIAÇÃO DA ATMOSFERA EM

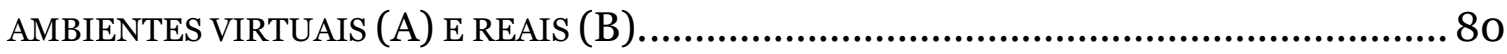

FIGURA 32 - MEIOS DE REPRODUÇÃO E INTERAÇÃO EM AMBIENTES VIRTUAIS, COMO O CAVE (A), VERSÃO NÃO-IMERSIVA (B) E VERSÃO IMERSIVA (C). 82

FIGURA 33 - DiAGRAMA MOSTRANDO OS PROCEDIMENTOS UTILIZADOS PARA A CAPTAÇÃO DE ÁUDIO E REPRODUÇÃO EM AMBIENTES VIRTUAL IMERSIVO..................................... 82 FIGURA 34 - AMBIENTES VIRTUAIS IMERSIVOS UTILIZADOS PARA ENSINO DE ARQUITETURA (A, B), EXPLORAÇÃO DO ESPAÇO (C) E AVALIAÇÃO DE REDESENHO EM PROJETO (D). 84 Figura 35 - PROCESSO DE PROJETO DE PRAÇA UTILIZANDO-SE AMBIENTES VIRTUAIS IMERSIVOS 84

Figura 36 - MODELO DA SALA OBJETO DE ESTUdO. AO LADO, OS PARTICIPANTES UTILIZANDO O APARATO TÉCNICO 85

FIGURA 37 - AMBIENTES VIRTUAIS UTILIZADOS PARA PROJETO DE ILUMINAÇÃO DO TRECHO DE RIO URBANO NO JAPÃO. 86

FIGURA 38 -MAPA CONCEITUAL DO EXPERIMENTO DESCREVENDO AS ROTINAS METODOLÓGICAS DESENVOLVIDAS NO TRABALHO 89

FIGURA 39 -LOCALIZAÇÃO DO OBJETO DE ESTUDO 92

Figura 40 - Imagens do Largo de SÃo Frei Pedro GonçAlves. (A) vista AÉrea do MODELO VIRTUAL TRIDIMENSIONAL E (B) VISTA A PARTIR DA IGREJA........................ 93

FIGURA 41 - WORKFLOW E RECURSOS DE IMERSÃO VIRTUAL DO EXPERIMENTO................. 94 FIGURA 42 - UTILIZAÇÃO DO COMANDO “RENDER TO TEXTURE” GERA UM ÚNICO MATERIAL. NA IMAGEM, O PAVILHÃO DE BARCELONA FOI UTILIZADO COMO OBJETO DE TESTES..... 94 
FIGURA 43 -MODELO TRIDIMENSIONAL E DISPOSITIVOS AUXILIARES UTILIZADOS NO EXPERIMENTO

FiguRA 44 -MODELO TRIDIMENSIONAL E DISPOSITIVOS AUXILIARES UTILIZAdOS NO EXPERIMENTO

Figura 45 - IMAGEM do LARgo de SÃo Frei PEDRo GONÇALVES NOS CENÁRIOS DESCRITOS. EM PLANTA BAIXA A INDICAÇÃo DO PONTO DE VISTA. (A) CENÁRIO o; (B) CENÁRIO 1; (C) CENÁRIO 2 98

Figura 46 - Vista AÉREa do LaRgo de SÃo Frei PEdro GonçAlves DEMONSTRANdo o PERCURSO BÁSICO DE APREENSÃO DO ESPAÇO URBANO. À DIREITA IMAGENS DOS PARTICIPANTES DO EXPERIMENTO. 100

FIGURA 47 - VISUALIZAÇÃO DOS CENÁRIOS NOTURNOS A PARTIR DE DOIS PONTOS: COM VISTA PARA A CASA VERDE (A) E COM VISTA PARA A IGREJA (B). 103

FIGURA 48 - CARACTERÍSTICAS DEMOGRÁFICAS DOS PARTICIPANTES E NÍVEIS DE FAMILIARIDADE COM O LOCAL E TECNOLOGIA .106

FIGURA 49 - UTILIZAÇÃO DO APARATO TECNOLÓGICO E TRAJETO BÁSICO DE EXPLORAÇÃO DO ESPAÇO 107

FIGURA 50 - QUESTIONÁRIO UTILIZADO COM OS TERMOS DE ATMOSFERA PERCEBIDA E ESCALA LIKERT 109

FIGURA 51 - QUESTIONÁRIO DA QUALIDADE AMBIENTAL E QUALIDADE DA ILUMINAÇÃO.... 110 FIGURA 52 - OPINIÕES SOBRE O ASPECTO MAIS IMPORTANTE PARA MELHOR USO DOS ESPAÇOS À NOITE 112

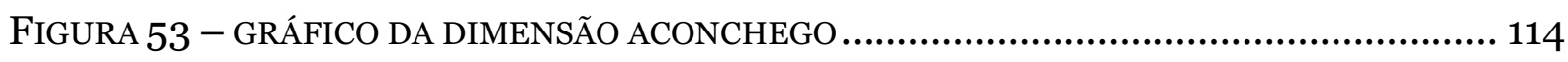

FIGURA 54 - GRÁFICO DA DIMENSÃO ÂNIMO ..................................................... 116

FIGURA 55 - GRÁFICO DA DIMENSÃO TENSÃO ..................................................117

FIGURA 56 - GRÁFICO DA DIMENSÃO IDENTIDADE/PERTENCIMENTO ........................... 118

FIGURA 57 - GRÁFICO DA DIMENSÃO IDENTIDADE/PERTENCIMENTO.............................. 119

FIGURA 58 - GRÁFICO SÍNTESE DA ATMOSFERA PERCEBIDA.........................................120

FIGURA 59 - GRÁFICO CORRESPONDENTE AOS TERMOS AGRADÁVEL/DESAGRADÁVEL .......122 FigURA 60 - GRÁFICOS CORRESPONDENTES AOS TERMOS ATRAENTE/NÃO ATRAENTE E

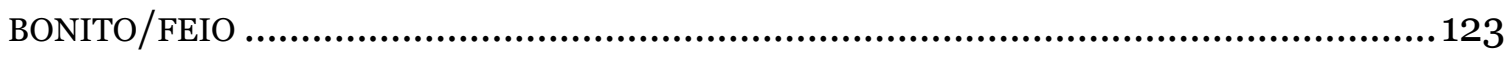

FIGURA 61 - GRÁFICO CORRESPONDENTE AOS TERMOS CLARO/ESCURO..........................124

FIGURA 62 - GRÁFICO CORRESPONDENTE AOS TERMOS INTERESSANTE/MONÓTONO ..........125

FIGURA 63 - GRÁFICO CORRESPONDENTE AOS TERMOS QUENTE/FRIO.............................126 
Lista de tabelas

TABELA 1 - TERMOS AGRUPADOS PELOS PESQUISADORES NAS OITO DIMENSÕES ......................27

TABELA 2 - MATRIZ DE TERMOS DO AMBIENTE PELO VIÉS INFORMACIONAL .......................... 28

TABELA 3 - VARIAÇÕES EMOCIONAIS RELACIONADOS AO MODELO PAD............................... 32

TABELA 4 - RESULTADOS A PARTIR DE VARIAÇÕES NA ILUMINAÇÃO DO AMBIENTE...................37

TABELA 5 - TABELA DE ESCALAS E DIMENSÕES PROPOSTAS POR VEITCH E NEWSHAM ........... 39

TABELA 6 - TERMOS DA ATMOSFERA PERCEBIDA DE VOGELS. ................................................. 41

TABELA 7- SETORES URBANOS E ATRIBUTOS DE ILUMINAÇÃO ESTUDADOS ……………….... 42

TABELA 8 - RELAÇÕES ENTRE ATRIBUTOS E RESPOSTAS EMOCIONAIS ................................... 44

TABELA 9 - TERmos DA ATMOSFERA PERCEBIDA DE VOGELS. (EM NEgRITO OS SELECIONADOS

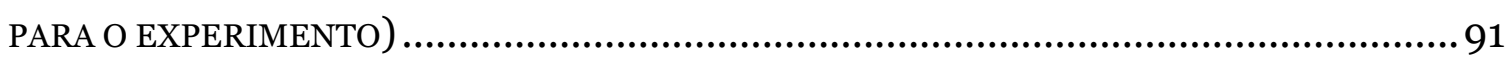

TABELA 10 - RESUMO DAS QUATRO DIMENSÕES E RESPECTIVA ABRANGÊNCIA DE TERMOS .104

TABELA 11 - ROTINA DE EXECUÇÃO DO EXPERIMENTO........................................................105

TABELA 12 - RESUMO DAS QUATRO DIMENSÕES E DISTRIBUIÇÃO ENTRE TABELAS .................108 
SUMÁRIO

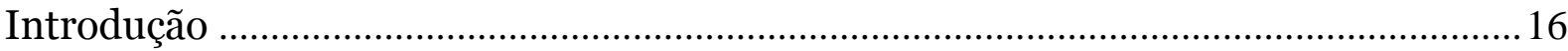

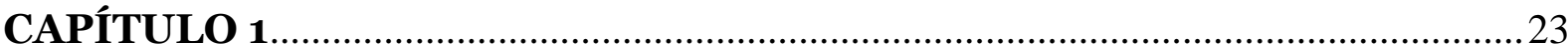

(re)produção de significados em iluminação …………………………………....23

1.1. Avaliações subjetivas na interação com o ambiente ......................................26

Descrição semântica do ambiente em Küller e Acking ...........................................2 26

Teoria da preferência ambiental Stephen Kaplan .................................................2

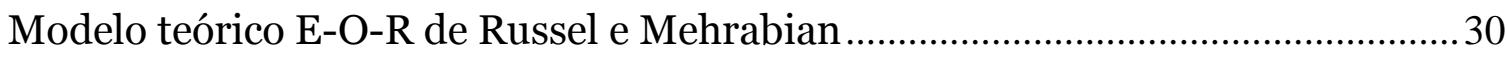

Efeitos da iluminação na impressão do usuário de Flynn, Spencer, Martyniuk,

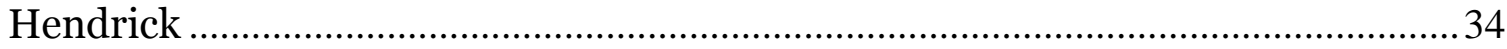

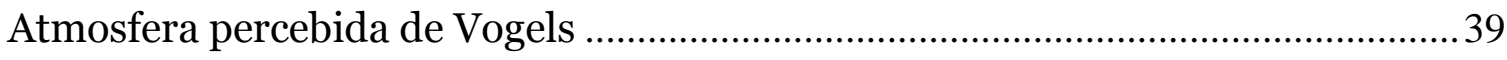

Avaliação qualitativa da iluminação urbana de Ünver ............................................ 42

Avaliação da qualidade ambiental em Johansson $(2011,2014)$.............................. 45

Iluminação e percepção espacial em Lindh (2012) ................................................ 47

1.2. Iluminação como indicador de qualidade ambiental ...................................51

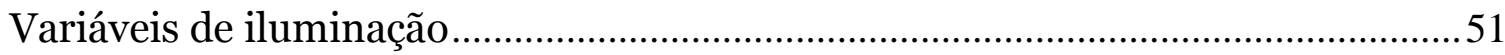

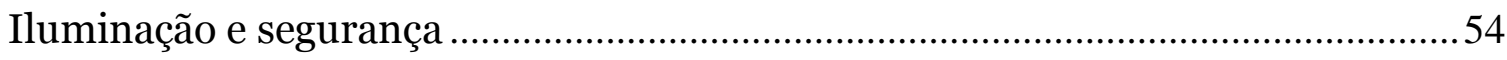

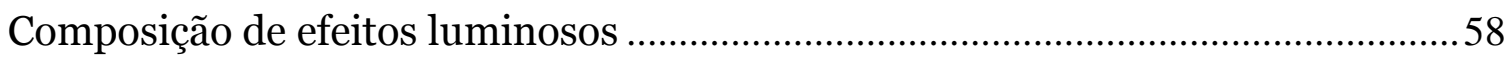

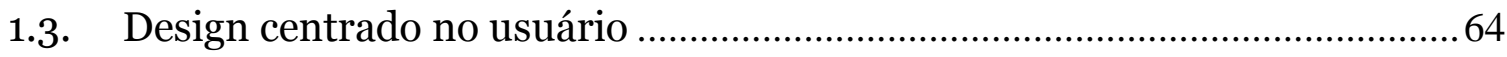

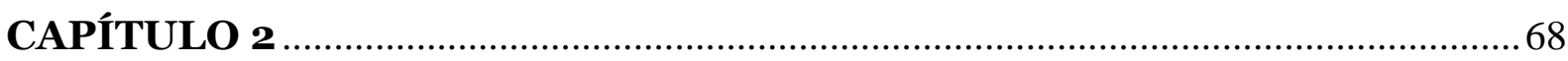

Modos de interação/representação do ambiente simulado............................6

2.1. Mockups e modelos em escala ................................................................... 71

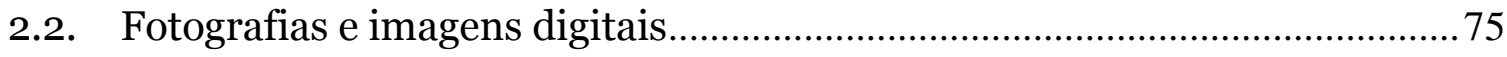

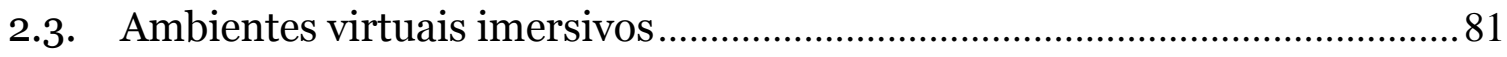

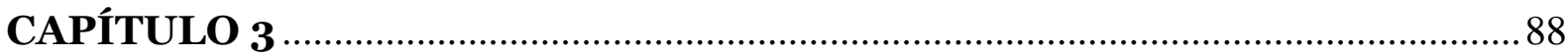

Investigação sobre a percepção do espaço urbano: material, método e

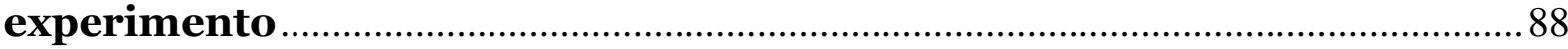

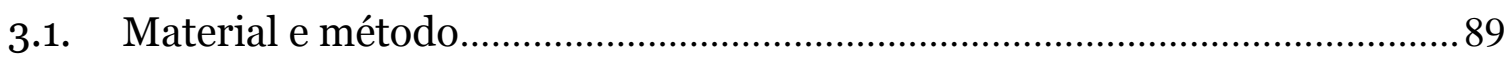

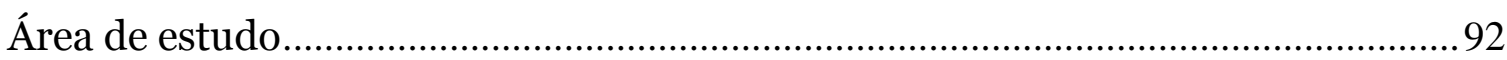

Modelo e recursos de imersão virtual .................................................................. 93

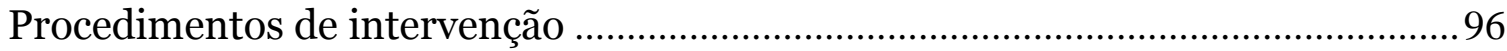

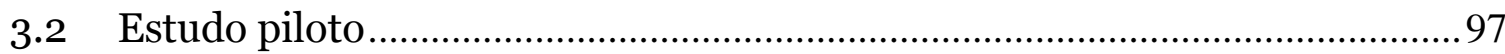

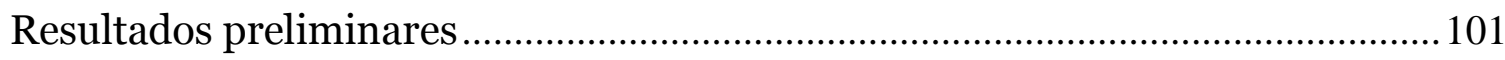

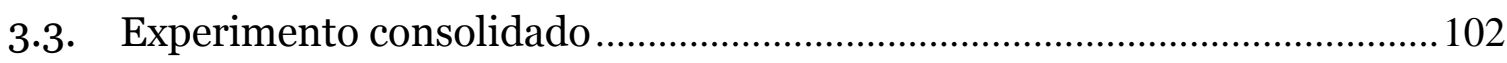

Caracterização do experimento e critérios de amostragem................................... 104 


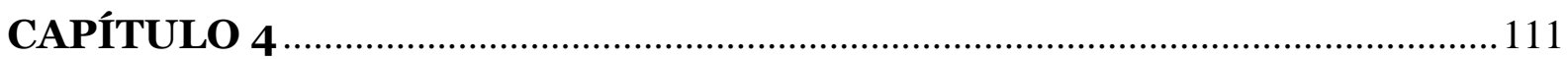

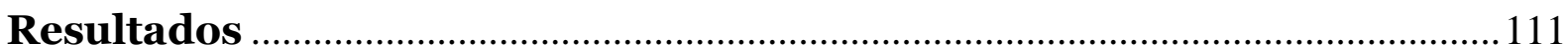

4.1. Procedimentos preliminares..................................................................112

4.2. Atmosfera percebida (Vogels) ....................................................................... 113

4.2.1. Primeira dimensão: Aconchego …………………………………………....... 113

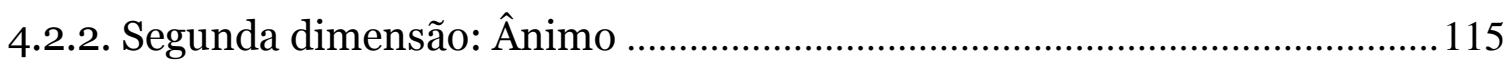

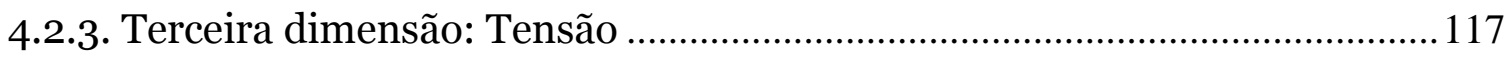

4.2.4. Quarta dimensão: Identidade/Pertencimento ………………….................... 118

4.2.5. Síntese da Atmosfera percebida ..................................................................... 120

4.3. Qualidade ambiental dos cenários estudados ................................................ 122

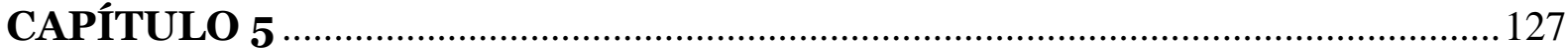

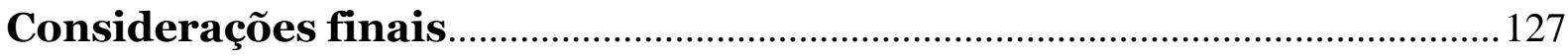

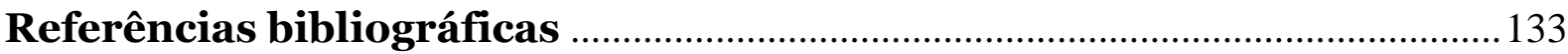

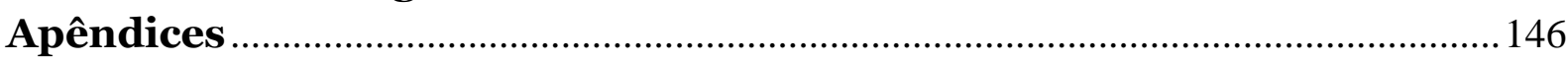

APÊNCIDE A - Termo de Consentimento Livre e Esclarecido ................................ 147

APÊNCIDE B - Questionário Socioeconômico........................................................... 148

APÊNCIDE C - Questionário da atmosfera percebida ........................................... 149

APÊNCIDE D - Questionário da qualidade ambiental e da iluminação................150 


\section{Introdução}


A iluminação urbana transforma a paisagem noturna. É capaz de valorizar patrimônios importantes da cidade, contar sua história através dos percursos, promovendo o turismo, comércio, lazer e cultura.

Também gera economia de energia no adequado planejamento de luz, satisfazendo necessidades dos habitantes na realização de atividades, como caminhadas e exercícios físicos. Iluminação beneficia o meio ambiente ao evitar seu excesso, chamado poluição luminosa, mais conhecido quando olhamos para o céu e não conseguimos ver as estrelas.

Desde a década de 1960 a cultura do automóvel vem ditando as normas e recomendações a respeito de como deve ser iluminado o espaço urbano, abordando questões econômicas das fontes de luz (MASCARÓ, 2006). Assim, a velocidade e escala dos carros em detrimento dos pedestres nestes locais é a abordagem mais recorrente, desconsiderando diferenças e particularidades em prol da eficiência e baixo custo. $\mathrm{O}$ resultado deste cenário foi uma iluminação uniforme e pouco refinada, cuja luz incide sempre nas vias carroçáveis, causando impactos como sombras projetadas sobre as calçadas - gerando impressão de insegurança física e psicológica aos pedestres - e também problemas ambientais, como a poluição luminosa e ofuscamento.

O desenvolvimento de políticas de iluminação sob o ponto de vista qualitativo, priorizando as necessidades funcionais e emocionais dos usuários que circulam pelos espaços urbanos, começa a ser estimulado a partir do potencial turístico e econômico das cidades de Lyon e Paris, como consequência de um plano diretor de iluminação em fins da década de 1980 e a relação entre os habitantes e os locais da cidade (HONG, 2007; BASSO, 2008).

Assim, o planejamento da luz em espaços urbanos passa a ser entendido não só como iluminação de pontos isolados e vias de tráfego, mas um espaço organizado arquitetonicamente, que privilegia ambiências e atmosferas - um meio físico, estético e psicológico - ou seja, refletindo o modo de viver, as necessidades e os valores produzidos pela cidade e identificados pela comunidade (GONÇALVES, 2005). A cidade noturna é capaz de promover ambientes em que a percepção do espaço estimule o uso e o prolongamento das atividades também para o período da noite.

Ao passo que os aspectos subjetivos e a influência da iluminação na relação entre a cidade e o usuário são relevantes neste processo, acredita-se que os ambientes para 
os quais um projeto luminotécnico deverá ser concebido podem se beneficiar das impressões das pessoas ainda nos primeiros estágios de design, através da participação coletiva e avaliações centradas nas necessidades dos usuários no espaço (HEYDARIAN, 2015a, 2015b), a fim de melhorar o produto final, promovendo a identificação dos valores e modos de vida da população.

Conforme será abordado no decorrer deste trabalho, que visa analisar a relação da interação sujeito-ambiente em ambientes noturnos, busca-se investigar como as pessoas apreendem o espaço em que estão inseridas. Desta forma, foi possível gerar reflexões críticas a respeito do processo metodológico desenvolvido e seus resultados, o que pode contribuir a longo prazo para a disciplina da iluminação, ao focar na possibilidade de utilização dos dados da participação coletiva como forma de auxiliar no processo de planejamento do projeto - batizado de iluminação urbana 2.0 por Bessete (2011 apud CASCIANI; ROSSI, 2012), em referência a WEB 2.o.

\section{Objeto e objetivos}

O objeto da presente pesquisa são as impressões subjetivas dos usuários inseridos em espaços urbanos noturnos.

Objetivo geral

Verificar a influência da iluminação na percepção do espaço urbano e na relação do usuário com o ambiente noturno.

Objetivos específicos

- Investigar de que forma a luz exerce influência na percepção visual do espaço urbano;

- Sistematizar o conhecimento existente sobre percepção em iluminação e seu registro;

- Estudar como dados de percepção visual podem alimentar o processo de projeto em iluminação centrado no usuário;

- Refletir como os estudos qualitativos sobre iluminação em ambientes noturnos tem relação com a melhoria da paisagem urbana brasileira. 


\section{Justificativa}

Reconhecendo a importância do patrimônio cultural e arquitetônico para identidade urbana, a iluminação funciona como fator de promoção e valorização de aspectos importantes na imagem da cidade. Aliado às questões técnicas e subjetivas, o cenário iluminado valoriza patrimônios históricos, embeleza a paisagem natural, conta história através dos seus percursos e traz uma melhor imagem da cidade, com benefícios ao usuário do espaço, podendo ser fator de atratividade do turismo, comércio, lazer e cultura.

O objetivo do planejamento da luz na cidade não é mais iluminar apenas as vias de tráfego, os passeios públicos, os prédios e os referenciais culturais, mas sim as ambiências -o espaço arquitetonicamente organizado e animado que constitui, sob essa perspectiva, um meio físico, estético e psicológico, especialmente aparelhado que reflita o modo de viver, fazer e pensar das comunidades. [...] Áreas e elementos super iluminados, bem acima dos níveis recomendáveis de iluminação, são uma tônica em algumas cidades brasileiras, ocasionando o desequilíbrio entre as ambiências e o bem valorizado e seu entorno. (GONÇALVES, 2006, p. 11).

Priorizando as necessidades funcionais e emocionais dos usuários que circulam pelos espaços urbanos, passa-se a estimular o desenvolvimento de políticas de iluminação sob o ponto de vista qualitativo, visando sobretudo destacar a paisagem no período noturno, ao privilegiar ambiências e respeitando valores produzidos pela cidade. Características qualitativas dos espaços iluminados provocam sensações e estabelecem conexões com quem se apropria deles numa troca de informações entre usuário e o ambiente. Neste sentido, são pesquisas que se propõem a entender como as pessoas percebem e avaliam o espaço, bem como sua relação com o ambiente iluminado, a partir de uma abordagem em termos psicológicos, sociais, subjetivos (VEITCH, 2001; CUSTERS et al., 2010).

Estudos relacionados com a psicologia ambiental sugerem que a iluminação exerce influência no comportamento e emoções dos usuários, como tensão, relaxamento, prazer e desconforto (VOGELS, 2008; KAPLAN, 1987). Os efeitos de luz também são capazes de gerar diferentes impressões visuais e espaciais, como impressões de altura, profundidade, ordem e imponência (FLYNN et al., 1973; LINDH, 2012).

Ainda assim, pesquisas sobre avaliações subjetivas em ambientes noturnos iluminados são incipientes e dispersas. Parte deste problema está na dificuldade de 
catalogar impressões e padronizá-las universalmente. Apesar de procedimentos semelhantes - procedimentos estatísticos, questionários e entrevistas - os resultados encontrados e metodologias aplicadas são diferentes entre si, pelas variáveis estudadas, características individuais e contextos cultural e social dos estudos.

Outro motivo deve-se ao fato de pesquisas que abordam este outro prisma da área da iluminação estão embasadas fortemente em outras disciplinas, como psicologia ambiental, cuja contribuição ao entendimento da relação entre o ser humano, suas emoções e o espaço em que está inserido é sobremaneira importante (KNEZ, 1995; RUSSEL; MEHRABIAN, 1974; KAPLAN, 1985; KAPLAN, 1987; ACKING; KULLER, 1973).

As pesquisas recorrentes na área de iluminação estão inseridas no âmbito quantitativo e físico dos efeitos da luz e seu desempenho (KNIGHT, 2010; FOTIOS et al, 2005) em detrimento dos aspectos subjetivos da iluminação e sua influência na percepção e usufruto do ambiente construído.

O panorama brasileiro é voltado predominantemente à análise do sistema de iluminação pública vigente e seus parâmetros quantitativos, seu desempenho e eficiência energética, embora estudos problematizem a influência da iluminação na percepção do usuário. Roizenblatt (2009) e Basso (2008) descrevem a situação da iluminação urbana em São Paulo, quando analisam edifícios e espaços urbanos distintos como praças, calçadões e largos durante o dia e a noite. Concluem que o planejamento da luz urbana não satisfaz as necessidades dos usuários, além das estratégias serem voltadas à escala do automóvel em detrimento do pedestre.

Fonseca, Duarte e Rosa D'Ávila (2015) avaliam os espaços públicos de conjuntos habitacionais em Porto Alegre segundo critérios de desempenho entre tecnologias e possíveis impactos da iluminação na segurança do ambiente, como altura das luminárias, conflito com paisagismo e vandalismo.

O intuito da pesquisa, portanto, é procurar inverter a pergunta quanto de luz as pessoas precisam? para como as pessoas interpretam o espaço iluminado em que estão inseridas? e respondê-la através de avaliações visuais dos ocupantes inseridos em diferentes cenários de iluminação. Os resultados se transformam em dados que poderão expor tendências e expectativas dos usuários quanto ao projeto, e se as intenções do projetista foram atendidas ao longo do processo. 
Propondo uma melhoria da qualidade do espaço urbano a partir do seu sistema de iluminação, e estabelecendo relações de memória e identidade com os habitantes, esta pesquisa diz respeito a avaliação qualitativa do sistema de iluminação urbana a partir da percepção do usuário.

\section{Procedimentos metodológicos}

O estudo em questão é referente ao que Silva e Menezes (2005) descrevem como pesquisa aplicada, onde há o interesse de gerar conhecimentos para solucionar problemas, utilizando-se procedimentos científicos e sistemáticos. De caráter quantitativo-qualitativo, a interpretação dos fenômenos e atribuição de significados são parte integrante da análise do pesquisador, assim como a classificação e sistematização de dados, a fim de demonstrar tendências observáveis (MINAYO; SANCHES, 1993), o projeto de pesquisa tem em foco a análise e registro da percepção do usuário no espaço urbano noturno. Assim, a questão central da pesquisa diz respeito a avaliação qualitativa da iluminação urbana a partir da percepção do usuário.

Envolve o levantamento e organização de referências bibliográficas sobre o tema da iluminação e sua influência nas impressões dos usuários, que vão desde livros, artigos, teses e dissertações. Tem por finalidade a delimitação da questão da pesquisa, além da definição de estratégias para melhor respondê-las e procedimentos metodológicos a serem aplicados.

A pesquisa concentra-se em duas vertentes, uma teórica e outra experimental. Primeiro, a partir da revisão da literatura, investiga-se as impressões percebidas em ambientes iluminados a partir de conceitos como atmosfera, cunhada por Vogels (2008), e questões relacionadas a variáveis da iluminação e sua influência na percepção. Por fim, o estudo contempla um viés experimental, no sentido de formular recursos - aparatos e procedimentos - para avaliação dos cenários pelos usuários.

Conforme revisão de literatura, a realidade virtual mostrou-se recurso fundamental para criação de cenários com diferentes configurações de iluminação. Considerando a característica diversa e inovadora da realidade virtual, tanto em seus aspectos físicos como digitais, os experimentos foram programados em fases de desenvolvimento, a fim de avaliar conceitos retirados da revisão bibliográfica, validação e ajustes da metodologia, além de interpretação e compreensão do espaço virtual pelo usuário. 


\section{Estrutura do trabalho}

O presente trabalho está estruturado em cinco capítulos. O referencial teórico é abordado nos capítulos 1 e 2, enquanto o desenvolvimento de procedimentos metodológicos e execução dos experimentos são descritos nos capítulos subsequentes.

O capítulo 1 contém uma revisão bibliográfica a partir da análise de trabalhos que estudam a avaliação subjetiva dos ambientes a partir dos usuários. Intitulada de avaliações subjetivas na interação usuário-ambiente, é traçado um panorama do estado da arte desde a década de 1970 para serem definidas as diretrizes para a próxima seção, intitulada iluminação como indicador de qualidade ambiental. Este trecho versa sobre como características fotométricas possuem relação com impressões dos usuários, desde respostas emocionais até sensação de segurança e bem-estar, além de conceitos relacionados a composição dos efeitos de luz. Concluindo, a seção design centrado no usuário é contemplada através de conceitos e sua aplicabilidade a arquitetura e urbanismo, a fim de compreender como as expectativas dos usuários são utilizadas como ferramenta no processo de projeto em iluminação.

O capítulo 2 contempla os processos de representação do ambiente simulado para apresentação do projeto de iluminação, desde mockups e modelos em escala, imagens renderizadas por computadores e fotografias, até ambientes virtuais imersivos, auxiliando na interação entre o projeto simulado e o usuário.

O terceiro capítulo é dedicado a parte experimental da pesquisa, cujos métodos e conceitos foram extraídos da revisão bibliográfica vista anteriormente. A partir do desenvolvimento de aparatos técnicos para viabilidade dos experimentos, os estudos exploraram as impressões subjetivas dos usuários inseridos em espaços urbanos noturnos com suporte da realidade virtual, cuja avaliação foi realizada através de questionários sobre a percepção do ambiente. Aqui estão descritos o estudo piloto e o experimento consolidado cujos resultados são discutidos no capítulo 4.

Por fim, o capítulo 5 trata das considerações finais, cujas reflexões sobre o processo de pesquisa e seus resultados são discutidos à luz do atendimento aos objetivos propostos, além de destacar dificuldades ou limitações no decorrer da investigação. São abordadas potencialidades e questões a serem discutidas futuramente, visando contribuir para novos estudos na área, além quatro apêndices com documentação relativa ao experimento e sua execução. 


\section{CAPÍTULO 1 \\ (re)produção de significados em \\ iluminação}


O processo de projeto em iluminação ocorre através de associações mentais das intenções do lighting designer ${ }^{1} \mathrm{e}$ as possibilidades que a iluminação pode causar em dado ambiente. A iluminação urbana é capaz de aliar as perspectivas da promoção da paisagem noturna com índices adequados de luz, visando economia de energia e baixo custo a partir de fontes mais eficientes que satisfaçam as necessidades dos usuários. Entretanto, com o crescimento das cidades, a referência do pedestre como protagonista do espaço foi aos poucos deixada de lado, enquanto a parte técnica e funcional da iluminação predominou sobre o subjetivo e estético.

Nas pesquisas científicas, os aspectos técnicos da luz e seu desempenho são bastante estudados. São trabalhos onde a performance do usuário e a influência da iluminação são investigados a fim de minimizar efeitos indesejáveis, como fadiga visual, para realização de atividades em ambientes de escritórios (VEITCH, 2001), hospitais, entre outros, além de configurações luminosas adequadas para dirigir em espaços urbanos externos (BOYCE, 2003; FOTIOS; GOODMAN, 2012; FOTIOS; UNWIN; FARRALL, 2014).

Exemplos destas pesquisas são comparações entre as diversas fontes luminosas disponíveis e seu eventual benefício energético e econômico (REA, 2000; KNIGHT, 2010; KUHN, 2013) até pesquisas relacionadas às características fotométricas como a influência do aspecto luminoso e quantidade de iluminação para desempenho visual (VEITCH; NEWSHAM, 1998).

Segundo Cauwerts (2013) a definição da qualidade da iluminação em espaços arquitetônicos deve levar em consideração aspectos funcionais, estruturais e estéticos - inspirado na tríade de Vitruvius, utilitas, firmitas e venustas, respectivamente - para a criação de ambientes certificados pelos métodos expostos, inclusive no uso de iluminação natural no processo (FIG. 1).

${ }^{1} \mathrm{O}$ termo lighting designer refere-se ao projetista de iluminação, responsável pela criação, através da luz, de "sensação de lugar e atmosfera, além de satisfazer as necessidades práticas de um projeto, qualquer que seja o programa [...], misturado perfeitamente com a arquitetura, muitas vezes com o risco de não ser visto. Trata-se de dar definição a um espaço." (DONOFF, 2013, tradução nossa). Será utilizado neste trabalho por estar consolidado nesta área de conhecimento. 
Figura 1 - Parâmetros para qualidade da iluminação

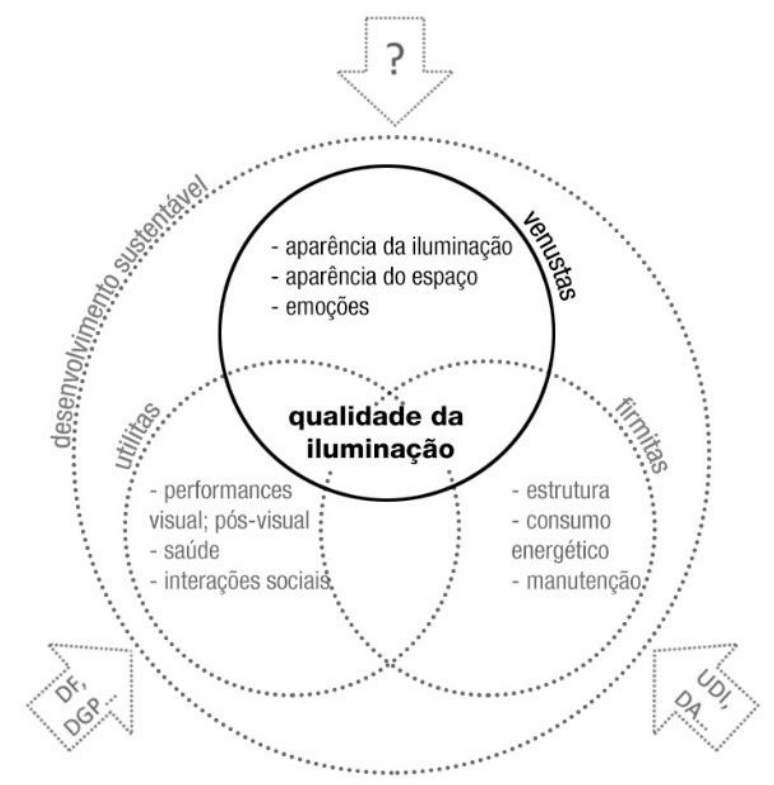

Fonte: Cauwerts (2013), tradução nossa

Para cada área é atribuída uma série de dimensões que abarcam a teoria da qualidade, desde métodos específicos para avaliação do ambiente em iluminação natural, como o Fator de Luz do Dia (Daylight Factor - DF) ou Autonomia de Luz Natural (Daylight Autonomy - DA), até dimensões funcionais de performance visual, saúde e interações sociais.

Entretanto, a dimensão estética, cujo foco está na avaliação da iluminação sob o ponto de vista da percepção e criação de emoções, não possui indicadores válidos e aplicáveis a diferentes contextos. Com vistas à qualidade do espaço em prol dos usuários, suas interações entre pessoas e o ambiente, é necessário também a abordagem deste outro lado da iluminação, caracterizada por ambiências e atmosferas que são fruto da percepção sob o ponto de vista qualitativo.

Estudos que propõem métodos para avaliar a influência da iluminação no ambiente sob o ponto de vista do usuário utilizam técnicas de outras áreas de pesquisa, como a psicologia ambiental. O objetivo do presente capítulo é demonstrar as principais pesquisas realizadas que guiam esta área subjetiva da iluminação e que servem de base para pesquisas recentes. A principal crítica em relação à avaliação destes aspectos são as contradições recorrentes entre os métodos utilizados e os resultados encontrados, dificultando a comparação entre estudos e o correto dimensionamento da qualidade da iluminação em diferentes contextos. 


\subsection{Avaliações subjetivas na interação com o ambiente}

\subsubsection{Pesquisas em psicologia ambiental}

\section{Descrição semântica do ambiente em Küller e Acking}

O trabalho de Acking e Küller (1973) - revisado por Küller (1991) - considera aspectos relacionados a descrições das percepções visuais do ambiente construído. Baseado nos estudos de Osgood, Suci e Tannenbaum (1957), cuja descrição semântica de um ambiente é feita a partir de avaliações estéticas e subjetivas aplicáveis em diferentes áreas, os autores buscam compreender um método para interpretação da interação entre as pessoas e o ambiente arquitetônico em si, utilizando-se de questionário onde são atribuídas escalas semânticas unipolares com cerca de 200 descritores, selecionados pelos pesquisadores (ACKING; KULLER, 1973; KULLER, 1991).

Assim, o autor conduziu uma série de estudos onde era solicitado aos participantes a avaliação de diversos ambientes, como salas de estar e escritórios, paisagens e habitações, através de fotografias e ambientes reais, culminando na identificação de oito dimensões, possível de descrever o espaço arquitetônico. São elas: agradabilidade (pleasantness), complexidade (complexity), unidade/harmonia (unity), enclausuramento (enclosedness), potencia/poder (potency), status social (social status), afeição (affection) e originalidade (originality).

No total 36 termos foram agrupados nestas dimensões, sendo distribuídos apropriadamente para cada escala. Cada dimensão possui quatro termos, com exceção da agradabilidade (pleasantness) que tem oito termos (TAB. 1). O modelo de questionário ficou conhecido como SMB (em sueco Semantisk Miljo Beskrivning), ou descrição semântica do ambiente, ao considerar o ponto de vista do usuário no processo de avaliação do ambiente em que esteja exposto. 
Tabela 1 - termos agrupados pelos pesquisadores nas oito dimensões

\begin{tabular}{|c|c|c|c|}
\hline agradabilidade & complexidade & unidade/harmonia & enclausuramento \\
\hline feio (-) & heterogêneo (+) & funcional $(+)$ & fechado $(+)$ \\
\hline estimulante $(+)$ & subjugado (-) & estilo $(+)$ & aberto (-) \\
\hline seguro $(+)$ & animado $(+)$ & coerente $(+)$ & demarcado $(+)$ \\
\hline tedioso (-) & alegre & completo $(+)$ & arejado (-) \\
\hline idílico $(+)$ & complexo $(+)$ & & \\
\hline bom $(+)$ & & & \\
\hline agradável (+) & & & \\
\hline brutal (-) & & & \\
\hline potência/poder & status social & afeição & originalidade \\
\hline másculo $(+)$ & custoso $(+)$ & moderno (-) & curioso $(+)$ \\
\hline frágil (-) & bem cuidado $(+)$ & atemporal $(+)$ & ordinário (-) \\
\hline potente $(+)$ & simples (-) & envelhecido $(+)$ & surpreendente $(+)$ \\
\hline feminino (-) & generoso $(+)$ & novo (-) & especial $(+)$ \\
\hline
\end{tabular}

Fonte: adaptado de Küller (1991, apud CAUWERTS, 2013)

Apesar de pesquisas subsequentes sobre impressões de ambientes se basearem nos estudos de Küller, desde avaliação de interiores residenciais e escritórios, ambientes urbanos e interiores de automóveis (KULLER, 1988 apud FERNANDEZ, 2012), a metodologia encontra algumas limitações.

Segundo Fernandez (2012), o entendimento atribuído às palavras pode confundir os usuários do experimento. Há também a necessidade de certo grau de conhecimento específico à disciplina arquitetônica, podendo gerar interpretações errôneas, por exemplo nas palavras frágil e brutal. Como o trabalho dos autores serve para descrição do ambiente arquitetônico de maneira geral, as especificidades da avaliação em ambientes iluminados podem causar a ausência de palavras importantes e imprecisão de termos existentes no questionário, a depender dos objetivos da pesquisa. A próxima pesquisa aborda o problema de maneira diferente, desta vez do ponto de vista informacional.

\section{Teoria da preferência ambiental Stephen Kaplan}

Desde a década de 1970 Stephen Kaplan estuda o conceito de preferência no contexto da psicologia ambiental. É com a teoria da preferência ambiental que o autor busca compreender, de maneira holística, o ambiente a partir da quantidade de informação existente e sua capacidade de influenciar o ser humano a partir de 
processos psicológicos, cognitivos e/ou afetivos (vale salientar a pesquisa de Rachel Kaplan (1985) sobre paisagens naturais e sua sistematização para avaliação de preferência). Kaplan (1987) incorpora a teoria evolucionista como fator importante na interpretação dos resultados, mostrando ser possível a existência de condições adaptativas vinculados ao ambiente.

Há uma inclinação dos seres vivos por escolhas que conduzam ao afastamento de espaços inapropriados e busquem ambientes desejáveis, baseados em processos cognitivos, conscientes ou não, de processamento de informações. Assim, o estudo da preferência - uma expressão intuitiva de comportamento - é uma das alternativas para avaliação do impacto da evolução sobre o comportamento humano.

Uma inclinação em preferir ambientes que tornam a adaptação bem-sucedida e provável não é exclusivo da nossa espécie. Entre os vertebrados, a seleção do habitat é uma tendência generalizada (WOODCOCK, 1982)². O que isto significa é que os animais demonstram preferência por tipos de ambientes onde sua espécie prospera. (KAPLAN, 1987, p. 12, tradução nossa).

O conceito de preferência está relacionado a um processo de percepção das informações do ambiente, compreendidas em características para apreensão do espaço: a) quantidade de informação recebida pelo usuário quando exposto a um ambiente; b) grau de familiaridade e conhecimento, relacionados a orientação e familiaridade neste espaço; c) componentes de novidade no processamento de informação do ambiente, gerando as preferências do usuário quanto ao ambiente em questão. Para sistematizar a teoria, Kaplan define uma matriz de quatro termos que descrevem o ambiente e sua situação informacional, afetando o usuário no que diz respeito à preferência ambiental (TAB. 2).

Tabela 2 - matriz de termos do ambiente pelo viés informacional

\begin{tabular}{l|rr}
\hline & $\begin{array}{r}\text { Compreensão } \\
\text { (Understanding) }\end{array}$ & $\begin{array}{r}\text { Exploração } \\
\text { (Exploration) }\end{array}$ \\
\hline $\begin{array}{l}\text { Imediato } \\
\text { (Immediate) }\end{array}$ & $\begin{array}{r}\text { Coerência } \\
\text { (Coherence) }\end{array}$ & $\begin{array}{r}\text { Complexidade } \\
\text { (Complexity) }\end{array}$ \\
\hline $\begin{array}{l}\text { Inferido } \\
\text { (Inferred, } \\
\text { Predicted) }\end{array}$ & $\begin{array}{r}\text { Legibilidade } \\
\text { (Legibility) }\end{array}$ & $\begin{array}{r}\text { Mistério } \\
\text { (Mystery) }\end{array}$ \\
\hline
\end{tabular}

Fonte: traduzido de Kaplan (1987)

${ }^{2}$ WOODCOCK, D. M. A functionalist approach to environmental preference. 1982. $\mathrm{Ph}$. D. Thesis (Psychology) - College of Literatura, Science, and the Arts, University of Michigan, Michigan, 1982 
Dois destes termos correspondem à capacidade de compreensão do ambiente (understanding), ou à capacidade de fazer sentido: são os termos coerência e legibilidade. O termo legibilidade sugere um grau de informação que valoriza a compreensão e, baseado no conceito de Lynch (1960), é utilizado com fins de orientação no espaço. Um cenário tem coerência quando seus elementos, ou pedaços de cena, são organizados de tal sorte para facilitar a compreensão imediata em um todo coerente.

A coerência relaciona-se com a nossa capacidade de dar sentido ao ambiente - o ambiente nos fornece pistas que permitem uma interpretação adequada? Existem elementos familiares suficientes no ambiente que nos permitam fazer correspondências mentais com nossas experiências anteriores? (DAVIS, 2013, n.p., tradução nossa).

Os outros dois termos são relacionados à capacidade de exploração da cena (exploration), ou seja, ser atraído por sugestões de informações adicionais: mistério e complexidade. O termo mistério sugere a dedução de informações presentes no cenário, indicando que informações adicionais podem ser adquiridas ao aprofundarse nestes ambientes. Há complexidade quando o usuário percebe uma variedade de elementos e estímulos presentes no cenário de forma imediata, induzindo o usuário a um engajamento para obter mais informações sobre o ambiente.

Segundo o autor, os quatro termos de preferência podem ser aplicados a uma variedade de contextos ambientais, desde paisagens naturais até ambientes urbanos. Apesar de limitações, envolvendo o processo evolutivo do ser humano na escolha de paisagens preferíveis em detrimento de outras, Kaplan relata que alguns componentes da paisagem ambiental possuem grande influência no julgamento dos usuários. Chamados de qualidades primárias, cenários contendo água e árvores são elementos que favorecem a sobrevivência do ser humano, sendo assim melhor avaliados.

Do ponto de vista da arquitetura e urbanismo, esta tendência pode dificultar a comparação de espaços urbanos, notadamente parques, praças e espaços litorâneos. Davis (2013) faz conexão entre iluminação e a teoria da psicologia ambiental, a partir da composição entre claro/escuro e atenção/destaque de algo no cenário iluminado. Assim, a ênfase dada em algo importante ou de fácil apreensão pode fazer com que o ambiente tenha níveis maiores de coerência. O oposto também acontece, caso o destaque na iluminação seja relacionado a algo não importante, reduzindo a preferência do usuário e prejudicando a percepção da coerência. 
É importante notar que uma mudança na textura ou brilho na matriz visual está associada com algo importante acontecendo na cena. Em outras palavras, algo que chama a atenção dentro da cena deve se tornar um objeto ou limite importante [...] Se o que atrai a atenção e o que vale a pena se visto são propriedades diferentes, então a cena não tem coerência. (KAPLAN, 1988 apud DAVIS, 2013, tradução nossa).

Olascoaga (2003) escreve que a teoria de Kaplan é limitadora em alguns aspectos, como o próprio conceito central da teoria evolucionista enquanto suporte a preferência ambiental.

\footnotetext{
"A beleza de um pôr-do-sol pode ser altamente associada ao mistério; mas este mistério pode estar mais relacionado ao mistério da existência humana e da existência em geral do que meramente em função da exploração ou da promessa de novas informações." (OLASCOAGA, 2003, p. 20, tradução nossa).
}

Segundo o autor, a teoria evolucionista não pode explicar todos os tipos de preferência, como a escolha por cores e do sentido dos termos descritos por Kaplan. Entretanto, é correto afirmar que os ambientes, cujas qualidades ambientais favoreçam uma melhor compreensão do espaço e sua exploração a partir dos quatro termos de preferência, são mais bem avaliados, contribuindo para uma categorização entre espaços adequados para o usuário.

\section{Modelo teórico E-O-R de Russel e Mehrabian}

Os autores descrevem o meio ambiente como um espaço dotado de atributos físicos e atividades humanas, cujos processos cognitivo e emocional desempenham papel fundamental na percepção deste ambiente, estabelecendo um fluxo de informações geradas pelo ambiente ao usuário. Segundo Mehrabian e Russell (1974), variáveis ambientais, características individuais e externas influenciam os estados emocionais das pessoas, induzindo-os a comportamentos de aproximação ou afastamento.

Esta relação entre o ambiente e o usuário é determinada pelo modelo E-O-R Estímulo-Organismo-Resposta ( $S-O-R$ Stimulus-Organism-Response). O processo se desenvolve através dos estímulos proporcionados pelos aspectos ambientais (E), gerando reações emocionais de maior ou menor grau (O) - representadas em dimensões básicas denominadas prazer, ativação e dominância - e definindo o comportamento do usuário (R), que pode ser positivo (desejo, aproximação) ou negativo (afastamento). 
De acordo com a teoria, o estímulo pode ser difícil de ser definido devido à variedade de ambientes existentes. Os autores propõem uma forma de medição genérica aplicável a situações diversas: a quantidade de informação existente no ambiente.

Esta quantidade é definida a partir do grau de novidade e complexidade, envolvendo "o inesperado, o surpreendente, o novo, o não-familiar" e o "número de elementos ou características que se referem a mudanças em um ambiente", estando ligados diretamente ao grau de ativação do usuário, mediado por suas características individuais na maneira de responder a essas informações externas.

Em arquitetura e urbanismo os estímulos podem ser caracterizados pela interação do sujeito com o ambiente por meio da forma urbana, cores, ruídos, iluminação, entre outros, gerando respostas emocionais.

O modelo teórico também estipula que qualquer ambiente, seja ele urbano, rural, interno ou externo, deverá produzir uma reação emocional que pode ser categorizada em termos das três dimensões que mediam o comportamento do usuário: prazer-ativação e dominância (pleasure-arousal-dominance - PAD).

De acordo com a teoria de Mehrabian e Russell (1974), estas dimensões são consideradas bipolares, ou seja, compreendidas numa gama de descritores que variam desde os extremos. Por exemplo, a dimensão prazer-desprazer pode se situar desde desprazer extremo até prazer extremo, enquanto a ativação descreve o estado emocional desde sonolência até excitação frenética e a dominância é relacionada a sensação de controle a submissão.

Na prática, cada uma destas dimensões possui adjetivos que correspondem a estados emocionais, os quais são avaliados pelo usuário ao serem expostos a situações e eventos onde a interação com o ambiente acontece. Assim, um ambiente considerado agradável pode apresentar nível alto de prazer e de ativação - sensação de excitação, alerta - induzindo um comportamento de aproximação (TAB. 3). 
Tabela 3 - variações emocionais relacionados ao modelo PAD

\begin{tabular}{cc|cc} 
PAD & adjetivos & PAD & adjetivos \\
\hline +P+A+D & exuberante & -P-A-D & chato \\
+P+A-D & dependente & $\mathbf{- P + A + D}$ & desprezo \\
+P-A-D & dócil & $\mathbf{- P + A + D}$ & hostil \\
+P-A+D & relaxado & $\mathbf{- P + A - D}$ & ansioso
\end{tabular}

Fonte: adaptado de Vieira (2008)

Utilizado como modelo teórico desde a década de 1970, ao longo do tempo alguns autores propuseram modificações e novos significados aos termos das dimensões citadas. Por exemplo, Russel (1980) sugere a exclusão da variável dominância, pois esta dimensão requer uma interpretação cognitiva pelo usuário, não sendo aplicada a respostas afetivas/emocionais. Assim, produzem o "modelo circunflexo", atribuindo 8 variáveis distribuídas em espaço bidimensional, onde as reações emocionais provenientes do ambiente podem ser caracterizadas como vetores neste espaço (FIG. 2). Por exemplo o termo "excitação" pode ser definida como a combinação entre alto nível de prazer e ativação (primeiro quadrante).

Figura 2 - oito adjetivos distribuídos de maneira circular (modelo circunflexo)

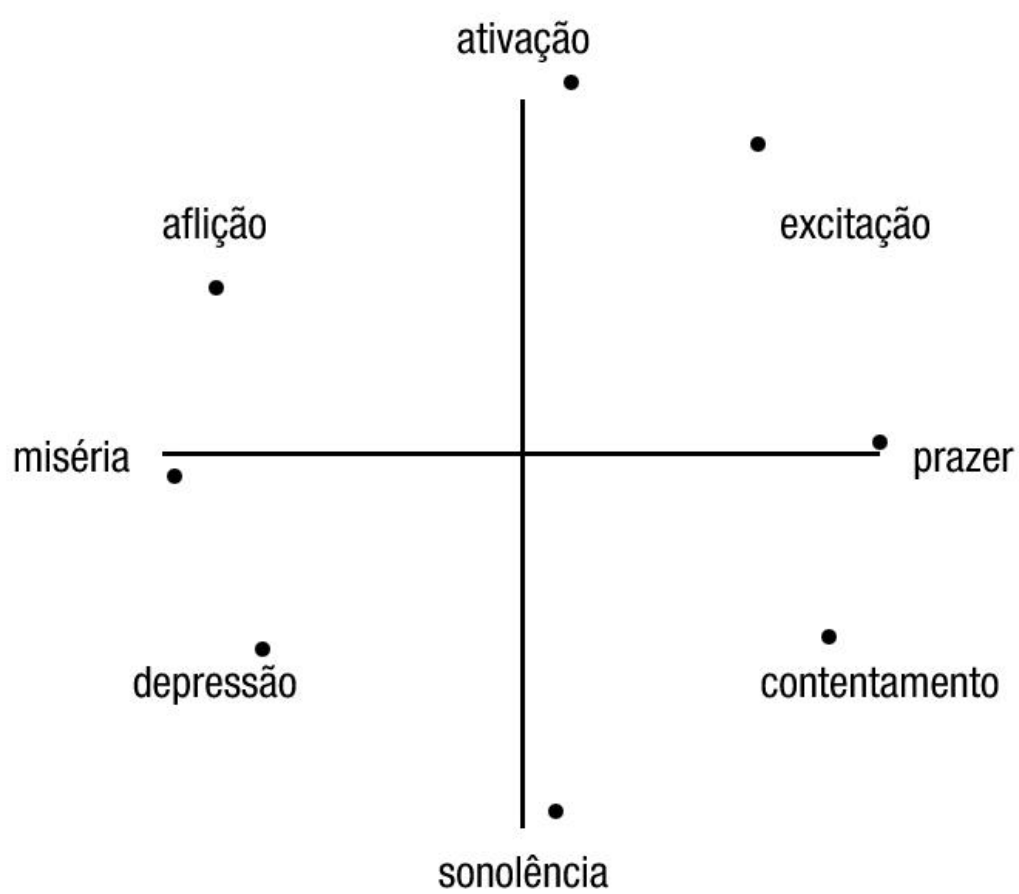

Fonte: Russell (1980), tradução nossa 
Bakker et al. (2014) apresentam uma revisão da literatura referente ao uso dos termos das três dimensões ao longo do tempo, relatando a dificuldade de comparações de resultados entre pesquisas devido a diferentes adjetivos utilizados para descrever as respostas emocionais dos ambientes. Baseado neste trabalho, os autores concluem que a teoria original das dimensões de Russell e Mehrabian (1974) ainda é útil, sugerindo a utilização do modelo tridimensional como forma de compreender as emoções e definindo as dimensões prazer, ativação e dominância como dimensões afetivas, cognitivas e conativas, respectivamente.

A teoria desenvolvida por Russell e Mehrabian (1974) para avaliação de experiências entre ambiente e respostas emocionais dos usuários é usada com frequência em contextos diversos. No trabalho de Donovan e Rossiter (1982), aplicaram o modelo da psicologia ambiental no ambiente de lojas comerciais e a fim de pesquisar a influência do espaço no comportamento dos consumidores e poder de compra, assim como o estudo de Casciani e Rossi (2012) que também a utiliza como base metodológica para desenvolver questionário online visando investigar a percepção das pessoas quanto a cenários urbanos noturnos pré-selecionados (FIG. 3). Incluem-se ainda, pesquisas em marketing (LIN, 2010) e ciência da computação (COLOMO-PALACIOS et al. 2011).

Figura 3 - modelo circunflexo utilizado na avaliação de espaços urbanos noturnos
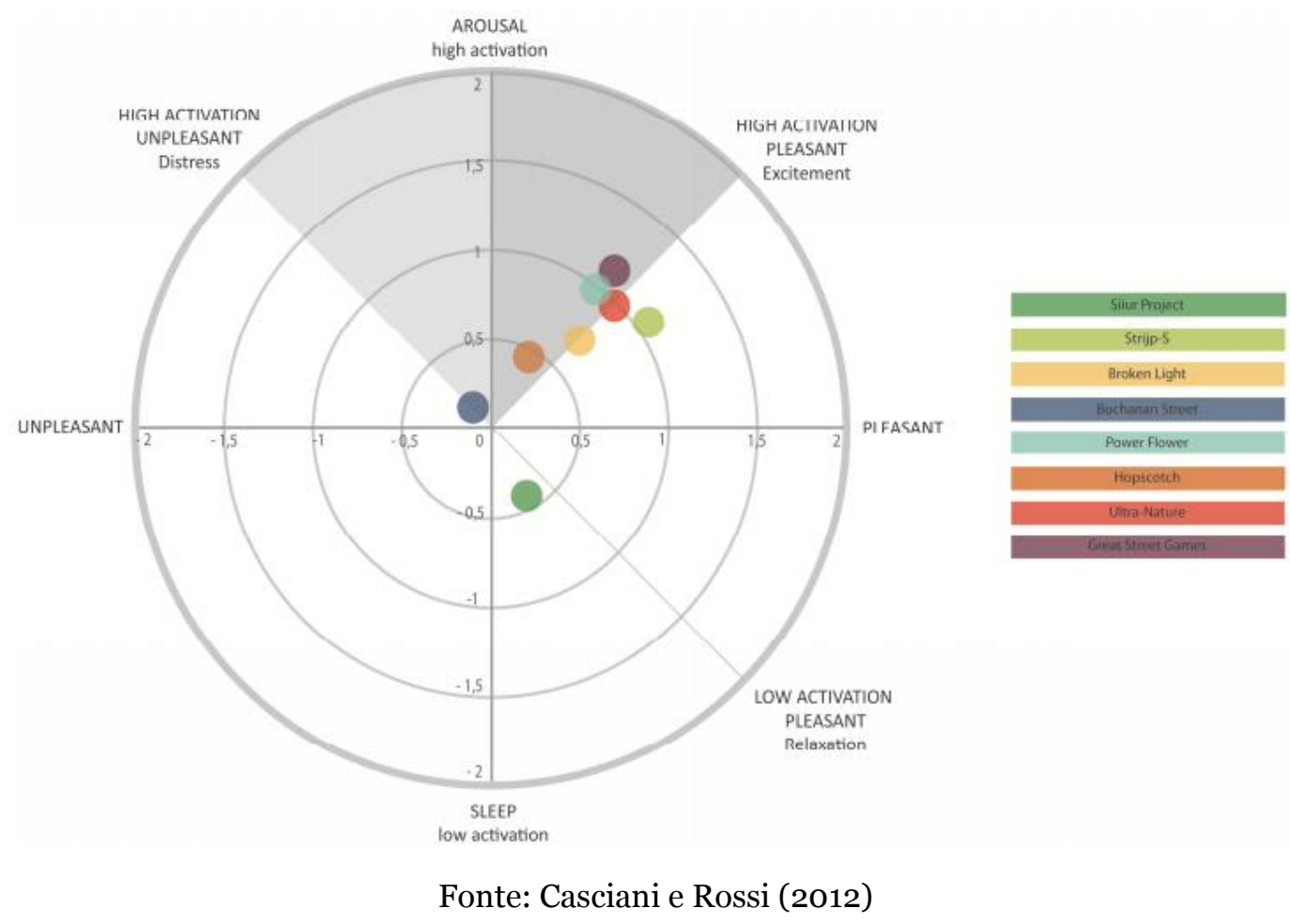


\subsection{2. avaliações em espaços iluminados}

\section{Efeitos da iluminação na impressão do usuário de Flynn, Spencer, Martyniuk, Hendrick}

A pesquisa realizada por Flynn et al. (1973) aborda aspectos relacionados a interação de parâmetros fotométricos e sua influência no indivíduo, ao investigar as suas reações em resposta a diferentes cenários de iluminação realizados em um ambiente genérico, cujos resultados foram compilados em forma de relatório preliminar, para mais tarde evoluir à guia de recomendações pela IES (Illuminating Engineering Society)

Uma das contribuições mais importantes deste estudo é a utilização de pesquisas em psicologia ambiental e técnicas estatísticas - então desenvolvidas há pouco tempo - como meio de mapear impressões subjetivas e entender como o estímulo visual gerado pela iluminação influencia a avaliação da qualidade do ambiente a partir da perspectiva do usuário. Utilizaram-se escalas de diferencial semântico para realizar analise fatorial dos resultados, escalonamento multidimensional e também aspectos relacionados a observação comportamental dos usuários quando inseridos em ambientes iluminados.

Para tanto, são convidados 96 participantes, separados em 12 grupos. Informações sócio demográficas não são mencionadas no artigo e o contexto da pesquisa é uma sala de conferências no Instituto de Iluminação da GE (General Eletric) em Cleveland/EUA, onde usuários são expostos a seis cenários de iluminação, a partir de parâmetros de iluminação como posicionamento (central ou periférica), intensidade e uniformidade (direta ou difusa) das fontes luminosas (FIG. 4)

Figura 4 - sala de conferências utilizada no experimento
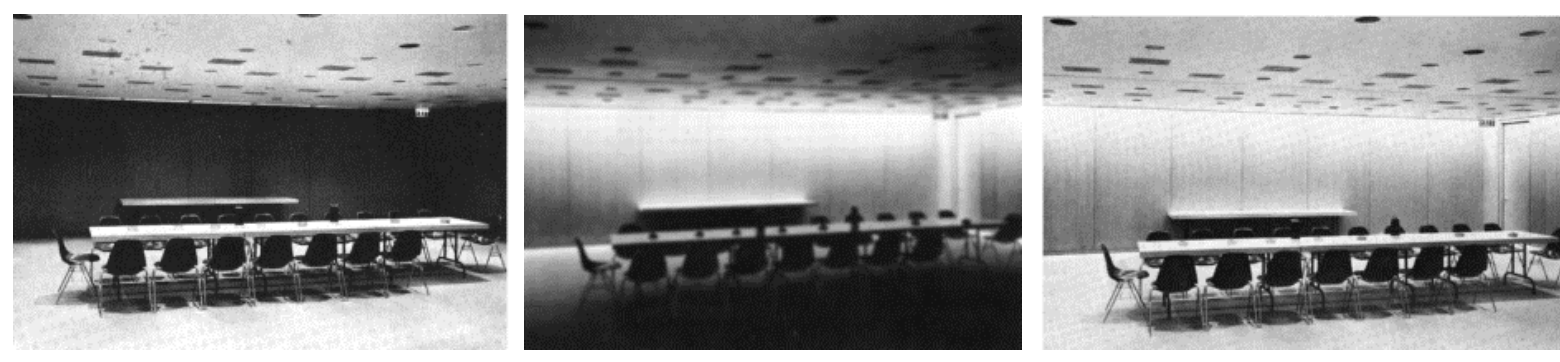

Fonte: Flynn e Mills (1962) 
A coleta de dados é feita em duas etapas: questionários contendo escalas avaliativas de diferencial semântico (bonito/feio, relaxante/tenso, escuro/claro) aplicados quando os grupos - um de cada vez - adentram no ambiente iluminado por um dos cenários, etapa chamada de avaliações iniciais; em seguida, os seis cenários criados pelos pesquisadores são analisados comparativamente através do mesmo questionário, etapa chamada de avaliações comparativas.

Nesta segunda etapa de avaliação, os cenários eram apresentados todos de forma rápida e sucessiva. Em seguida, era mostrado um de cada vez por um período de tempo maior, para permitir aos participantes darem suas contribuições através do questionário de 34 escalas semânticas diferenciais.

Segundo os autores, do total de escalas apresentadas, 17 demonstraram diferenças significativas entre os cenários de iluminação estudados a partir da perspectiva do usuário. Através da análise fatorial, categorizaram-se as impressões em três dimensões: a) avaliação global, cujas variáveis importantes são a uniformidade e posicionamento; b) clareza percebida, determinada pela quantidade de luz no ambiente; e c) espaço percebido, definido pelas variáveis.

Com os resultados coletados e analisados estatisticamente, pode-se comparar diversos cenários de maneira gráfica. Os autores compararam o desempenho de cenários com características luminosas diferentes e sua performance perante as três dimensões citadas anteriormente. Os cenários 1 e 4, por exemplo (em negrito), são comparados para investigação da influência da luz na percepção do usuário. Assim, as configurações no cenário 1 é definida pela iluminação no plano horizontal da mesa, enquanto que elementos verticais e periféricos (paredes) são também destacados no cenário quatro.

A partir dos questionários pode-se avaliar se esta diferença causa impressões no espaço estudado. Neste caso, percebe-se que o cenário 4 apresentou condições mais favoráveis nas dimensões encontradas ao ser comparado com o cenário 1 (FIG. 5). $\mathrm{Na}$ dimensão avaliação global, o cenário foi considerado mais agradável, sociável e interessante, enquanto que na dimensão clareza percebida, o destaque de elementos verticais e periféricos promoveu maior percepção de brilho, nitidez e claridade. Por fim, o espaço foi percebido como sendo mais amplo e espaçoso. 
Figura 5 - dados analisados a partir de procedimentos estatísticos
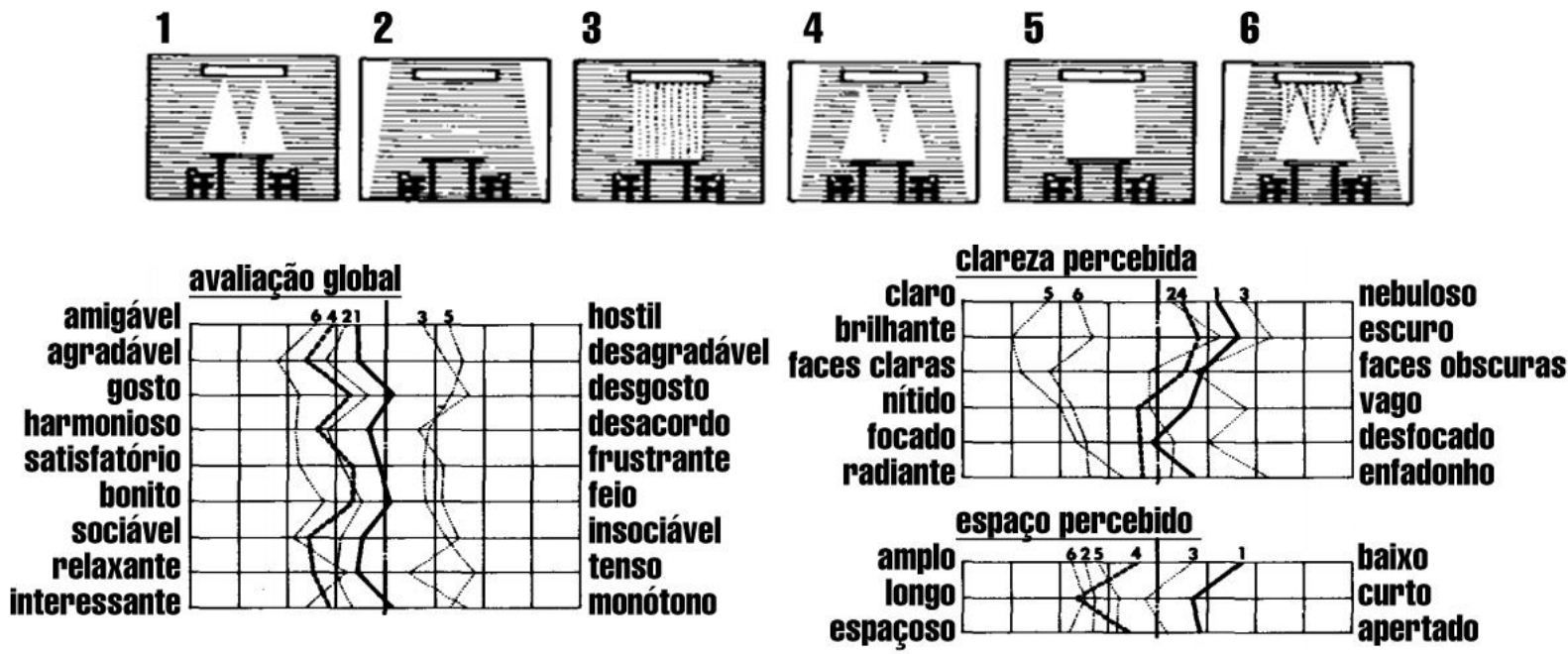

Fonte: Flynn et al. (1973), tradução nossa.

Em seguida, os pesquisadores procuraram utilizar uma segunda técnica de classificação das impressões subjetivas, sendo a escala multidimensional. Para tanto, e utilizando-se dos mesmos cenários de iluminação propostos no primeiro estudo, era solicitado aos participantes a apreciação de semelhança ou diferença entre pares de cenários, atribuindo um número de o a 10, onde o representava "sem mudança" e 10 "mudança muito grande". Os participantes adotaram critérios próprios ao fazer este julgamento, ao contrário das escalas semânticas que já especificavam impressões para avaliação, como claro-escuro, interessante-monótono.

O resultado dos 46 participantes a 38 pares de cenários foi submetido a análise computacional (INDSCAL), que identificou três dimensões, chamadas de lighting modes: a) claro/escuro, b) uniforme/não-uniforme, c) periférica/direta.

A partir deste trabalho, foi aprovado na IES um guia de recomendações criado pelo mesmo grupo de pesquisadores, cujo objetivo era a divulgação de uma metodologia padrão para medir impressões subjetivas em espaços iluminados, capaz de comparar estudos realizados por outros pesquisadores da comunidade científica (FLYNN et al. 1979).

Em suma, o guia detalha os procedimentos para condução da pesquisa, desde o encontro com os participantes, tempo de exposição, ordem sugerida dos cenários até a coleta de dados e análises estatísticas das técnicas mencionadas anteriormente. Apesar 
disto, ainda há confusão quanto à padronização e utilização das escalas semânticas aplicadas em pesquisas subsequentes.

Os resultados da pesquisa são úteis também para profissionais diretamente envolvidos na criação de ambientes iluminados, ao considerar os diferentes efeitos subjetivos que a iluminação é capaz de criar em um espaço, como relaxamento, intimidade e amplitude, ao se modificar apenas parâmetros fotométricos (TAB. 4). O trabalho dos autores também foca em aspectos relacionados à observação de comportamentos dos usuários. Em uma pesquisa informal, os autores iluminaram um bar de duas maneiras e gravaram suas reações, identificando que a iluminação influencia decisões como onde sentar e para onde olhar.

Tabela 4 - resultados a partir de variações na iluminação do ambiente

\begin{tabular}{|c|c|}
\hline impressão subjetiva & variação na iluminação existente \\
\hline \multirow[b]{2}{*}{ claridade visual } & iluminação uniforme \\
\hline & $\begin{array}{l}\text { acentuação em elementos } \\
\text { periféricos, tais como paredes com } \\
\text { alta refletância, "wallwashing" }\end{array}$ \\
\hline \multirow{2}{*}{ grandeza } & iluminação uniforme \\
\hline & iluminação periférica \\
\hline \multirow[b]{2}{*}{ relaxamento } & iluminação não uniforme \\
\hline & $\begin{array}{l}\text { acentuação da iluminação em } \\
\text { elementos periféricos, preferíveis no } \\
\text { plano vertical (paredes) }\end{array}$ \\
\hline \multirow[b]{2}{*}{ privacidade } & iluminação não uniforme \\
\hline & $\begin{array}{l}\text { baixa intensidade de luz ao redor do } \\
\text { usuário e brilho em locais de } \\
\text { destaque }\end{array}$ \\
\hline
\end{tabular}

Fonte: Fernandez (2012), tradução nossa

Entretanto, este trabalho mostra algumas limitações, sendo objeto de críticas por vários pesquisadores ao longo do tempo (VEITCH, 2001; FERNANDEZ, 2012). Alguns exemplos são relacionados ao local do experimento realizado, que por ser em um instituto de iluminação, os participantes já teriam sido influenciados indiretamente pelos objetivos do estudo; também, aspectos como a falta de clareza no processo inicial de escolha das escalas semânticas e sua validade; amostragem considerada pequena para uma análise fatorial confiável - pesquisadores estabelecem 
um mínimo de 10 pessoas para cada escala, resultando num total de 340 pessoas (KERLINGER, 1986, apud VEITCH, 2001).

Além disto, há críticas quanto a validade das recomendações inseridas no Lighting Handbook (REA, 2000), editado pelo IES, por serem baseadas na pesquisa dos autores que na época configurava apenas como um relatório preliminar. Ou seja, a metodologia não foi replicada nem refinada, disseminando-se resultados que podem não ser aplicáveis em contextos distintos do original.

Apesar da falta de informações e consistência em seus resultados, os procedimentos do trabalho do grupo de Flynn (1973 e 1979) serviram de referência para novos estudos, predominantemente ambientes de escritório, como Hawkes, Loe e Rowlands (1979), que estudaram 18 configurações de iluminação em um escritório e encontraram duas dimensões através das escalas semânticas: brilho percebido e interesse. Entretanto não conseguiram resultados conclusivos através da análise multidimensional.

Os estudos subsequentes encontraram mais evidencias da interação entre iluminação e o ser humano nos espaços estudados, como a contribuição da luminância média e do contraste, dentro de uma faixa de visão de um observador sentado, para o aumento da sensação de brilho percebido e interesse no ambiente, ou seja, o grau de uniformidade pode estabelecer hierarquias no ambiente iluminado (LOE; MANSFIELD; ROWLANDS, 1994).

Também Veitch e Newsham (1998), baseados na metodologia desenvolvida por Flynn et al. (1973), aumentaram a quantidade de participantes no experimento a fim de investigar a influência da iluminação na avaliação subjetiva do ambiente. Assim, utilizando-se 292 pessoas em um ambiente de escritório com nove configurações de iluminação e 27 escalas semânticas diferenciais, chegaram a uma solução mais robusta, onde definiram três componentes como complexidade, atração visual e brilho percebido (TAB. 5). 
Tabela 5 - tabela de escalas e dimensões propostas por Veitch e Newsham

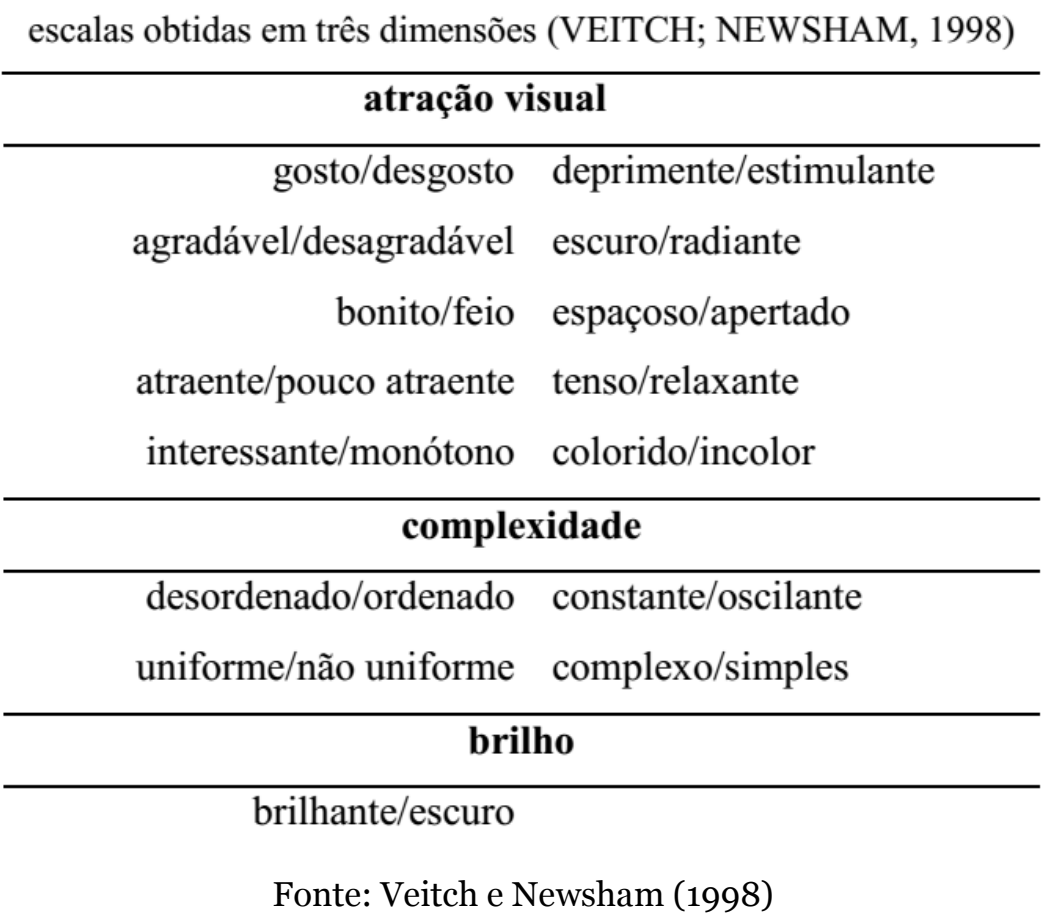

\section{Atmosfera percebida de Vogels}

Focando em questões relacionadas aos efeitos subjetivos esperados que o ambiente iluminado pode gerar na interação entre o usuário e o espaço, a pesquisa de Vogels (2008) parte da noção da percepção como uma avaliação do ambiente relacionado ao efeito esperado que dado espaço exerce, não necessariamente correspondendo ao real estado emocional. Esta autora justifica que, apesar das emoções flutuarem de forma repentina, as qualidades projetadas sobre o ambiente permanecem mais estáveis.

Em outras palavras, o ambiente pode ser considerado relaxante mesmo quando o usuário esteja se sentindo o oposto. A possibilidade de o ambiente afetar nossas emoções faz parte de uma perspectiva fenomenológica da qualidade arquitetônica dos lugares (ZUMTHOR, 2009) e a iluminação desempenha papel fundamental nesta sinergia.

Para desenvolver o conceito de atmosfera, a autora desenvolve um método para medir esta variável e destacar qualidades percebidas pelos usuários em um dado ambiente. Assim, 43 usuários participaram de uma primeira etapa do processo, a coleta de termos que as pessoas recorrentemente utilizam para descrever um ambiente. 
As instruções eram imaginar vários lugares, tais como a sala de estar, loja favorita ou consultório odontológico e descrever a atmosfera do local com o máximo de termos possíveis. No total 184 palavras foram recolhidas, separadas a partir de categorias semânticas como: a) termos relacionados a emoções sentidas pelo sujeito, por exemplo, "aterrorizado"; b) palavras atribuídas de acordo com a atmosfera do lugar, como "aconchegante, ou seja, uma descrição subjetiva do espaço; c) termos objetivos do lugar, como "claro" ou "escuro".

A palavras da primeira categoria relacionada a emoções foram transformadas em adjetivos como "aterrorizante", enquanto que termos objetivos que descrevem o ambiente foram suprimidos devido ao foco da pesquisa. Assim, termos com significados semelhantes foram agrupados e, por fim, foram selecionados 38 termos de percepção da atmosfera.

Em seguida, tratou-se de verificar a validade destes termos em um questionário e uma série de experimentos. Os termos foram avaliados em ambientes internos simulados, como salas genéricas que imitam lojas e ambientes vazios, iluminados somente com os efeitos de luz nas superfícies desejados pelos pesquisadores.

Através de análise fatorial, os termos foram categorizados em quatro dimensões: aconchego, ânimo, tensão e distanciamento (coziness, liveliness, tenseness e detachment). Para a dissertação, foi realizada a adequação dos termos da língua original em Holandês para o Português (TAB. 6), tendo em vista a tradução feita pela autora apenas para o Inglês. 
Tabela 6 - Termos da atmosfera percebida de Vogels.

\begin{tabular}{lll|rrr} 
Holandês & Inglês & Português & Holandês & Inglês & Português \\
\hline afstandelijk & detached & inamistoso & levendig & lively & vivaz \\
beangstigend & terrifying & assustador & luxueus & luxurious & luxuoso \\
bedompt & musty & abafado & mysterieus & mysterious & misterioso \\
bedreigend & threatening & intimidador & ongedwongen & uninhibited & desinibido \\
behaaglijk & cozy & acolhedor & ongemakkelijk & uncomfortable & desconfortável \\
beklemmend & oppressive & opressivo & onrustig & restless & agitado \\
deprimerend & depressed & deprimido & ontspannen & relaxed & relaxado \\
enerverend & exciting & excitante & persoonlijk & personal & intimo \\
formeel & formal & exclusivo & omantisch & romantic & romântico \\
gastvrij & hospitable & acolhedor & ruimtelijk & spatial & amplo \\
geborgen & safe & seguro & rustgevend & tranquil & tranquilo \\
gemoedelijk & pleasant & agradável & saai & boring & tedioso \\
gespannen & tense & estressante & sloom & lethargic & apático \\
gezellig & pleasant & sociável & stimulerend & stimulating & estimulante \\
inspirerend & inspiring & inspirador & toegankelijk & accessible & acessível \\
intiem & intimate & familiar & vijandig & hostile & hostil \\
Kil & chilly & ermo & vrolijk & cheerful & alegre \\
Knus & cozy & aconchegante & warm & warm & caloroso \\
Koud & cool & frio & zakelijk & business & pragmático
\end{tabular}

Fonte: Vogels (2008), adaptado pelo autor.

O objetivo da autora é descrever adequadamente atmosferas de diferentes ambientes submetidos a diferentes configurações de iluminação. A partir desta metodologia, pesquisas subsequentes procuraram avaliar os espaços de forma subjetiva, desde lojas a supermercados e bancos (CUSTERS et al. 2010; CASCIANI, 2014).

Vale destacar a importância da continuidade das pesquisas no grupo do qual a autora faz parte (Visual Experiences na Universidade Tecnológica de Eindhoven em parceria com a Philips Research) na busca de resultados cada vez mais consistentes na interação entre variáveis de iluminação e percepções de atmosfera. Van Erp (2008) descreve como o aumento da intensidade da fonte de luz, em conjunto com baixa temperatura de cor, tem relação com uma atmosfera menos aconchegante e mais animada, além da contribuição da distribuição luminosa, difusa ou direcionada, na percepção da atmosfera do lugar. Em um novo experimento, o autor busca condensar 
em um espaço genérico, e juntando os dados dos participantes de estudos anteriores, procura dar consistência e robustez nos resultados e validação da metodologia.

\section{Avaliação qualitativa da iluminação urbana de Ünver}

O autor sistematiza parâmetros de estudo para viabilizar a aplicação da metodologia desenvolvida. Assim, categoriza os diversos elementos do espaço urbano em setores - edifícios, ruas e avenidas, áreas de pedestre/praças e parques - e identifica atributos de iluminação recorrentes encontrados na revisão bibliográfica.

Os termos mais comuns aplicados aos setores são utilizados na pesquisa, totalizando cinco atributos, aqui descritos como brilho, contraste, direção, legibilidade e cor (TAB. 7). O mesmo procedimento é realizado para identificar as respostas emocionais dos usuários inseridos no espaço noturno. Deste modo, os termos recorrentes aos setores urbanos são preferência, interesse, conforto e segurança.

Tabela 7- setores urbanos e atributos de iluminação estudados

\begin{tabular}{lccccc}
\hline $\begin{array}{l}\text { setores } \\
\text { urbanos }\end{array}$ & edifícios & ruas e avenidas & $\begin{array}{c}\text { áreas de } \\
\text { pedestre/praças }\end{array}$ & \multicolumn{2}{c}{ parques } \\
\hline $\begin{array}{l}\text { atributos de } \\
\text { iluminação }\end{array}$ & brilho & contraste & direção & legibilidade & cor \\
\hline
\end{tabular}

Fonte: Elaboração própria, adaptado de Ünver (2009)

Participaram do experimento 30 estudantes universitários da Universidade Técnica do Oriente Médio (Middle East Technical University - METU), desenvolvido na cidade de Ankara, Turquia. Para sistematizar as questões da pesquisa - investigar qual a avaliação do usuário quanto à iluminação urbana e a relação entre atributos de iluminação e respostas emocionais - dois métodos foram propostos: a primeira seção visa sistematizar a relação entre variáveis de iluminação e as respostas emocionais utilizando-se da escala Likert e procedimentos estatísticos; a segunda parte busca identificar questões relacionadas a preferência do usuário - fazendo o usuário escolher o melhor e o pior cenário de cada setor urbano - a partir da análise de conteúdo.

A cada respondente foi mostrado 20 fotografias, uma por uma na primeira seção, e era solicitado avaliar 9 declarações através de escala Likert. [...] As primeiras cinco afirmações visam testar as fotografias que representam determinadas variáveis em termos de suficiência de "brilho", eficiência de "distribuição de luz", "legibilidade", efeito de "contraste" e uso suficiente de "Cor" na iluminação. As outras quatro declarações têm por objetivo testar as reações emocionais das pessoas a determinadas variáveis. Essas variáveis 
emocionais são "gostar", "interesse", "conforto" e "segurança". [...] Na segunda seção, os entrevistados foram solicitados a escolher as cenas urbanas que mais gostaram e também as que não gostaram dentre todas as categorias de seções urbanas. Como resultado da segunda seção, cada entrevistado escolheu um total de 4 fotografias preferidas e 4 não preferidas. (ÜNVER, 2009, p.123, tradução nossa).

A representação da imagem da cidade noturna foi viabilizada através de fotografias tiradas pelo pesquisador da cidade de Ankara. Para cada setor urbano são apresentadas cinco fotografias, cada uma representando um dos cinco atributos de iluminação - brilho, contraste, direção, legibilidade e cor - totalizando 20 imagens (FIG. 6). O autor reconhece a coexistência de mais de um atributo, pois as fotografias estão inseridas no contexto urbano real, portanto complexo per si. Entretanto, o processo de seleção das fotografias selecionou as imagens que contém aspectos predominantes de cada variável.

Figura 6 - fotografias do setor ruas e avenidas, cada uma representando um atributo de iluminação.
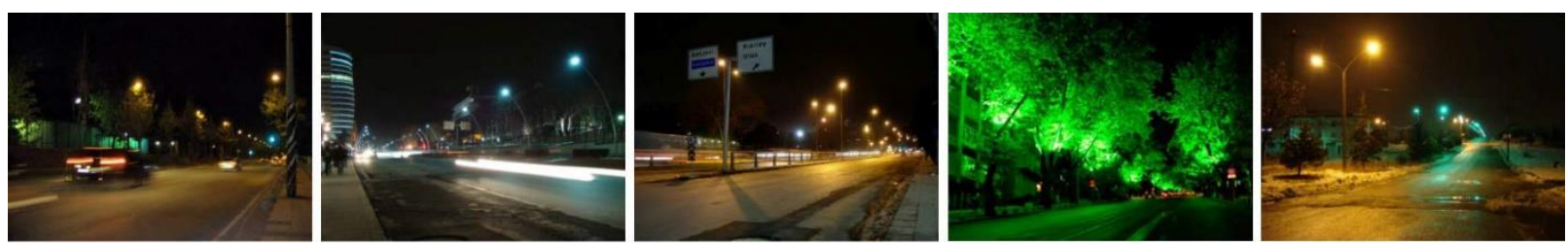

Fonte: Ünver (2009)

Ünver também justifica o uso de fotografias como forma de representar imagens noturnas e coletar informações emocionais dos participantes. Segundo o autor, os estudos de Hendrick et al. (1977) investigaram as diferenças entre os resultados das apreensões dos usuários em espaços iluminados a partir de dois grupos de estimulo: a experiência do real e fotografias contendo diferentes configurações de iluminação. Concluíram que os estudos apresentam resultados idênticos, sendo confiáveis na avaliação de um julgamento e apreciação do espaço (ÜNVER, 2009)

Após análises estatísticas e de conteúdo das preferências dos usuários quanto aos espaços iluminados, o autor estabelece relações entre os atributos de iluminação brilho, contraste, legibilidade, cor, distribuição da luz - que influenciam nas respostas emocionais dos usuários - preferencia, conforto, interesse e segurança - de cada setor urbano, categorizado em edifícios, ruas e avenidas, áreas de pedestre/praças e parques. 
A Tabela 8 mostra os atributos mais relevantes para cada setor urbano, separados pelas respostas emocionais do usuário. De acordo com os resultados, o autor relata a variável contraste sendo significativa na avaliação da iluminação, tendo em vista sua capacidade de revelar a tridimensionalidade dos objetos.

Tabela 8 - Relações entre atributos e respostas emocionais

\begin{tabular}{|c|c|c|c|c|}
\hline \multirow{2}{*}{$\begin{array}{l}\text { respostas } \\
\text { emocionais }\end{array}$} & \multicolumn{4}{|c|}{ categorias urbanas segundo ÜNVER (2009) } \\
\hline & edifícios & ruas/avenidas & áreas pedestre/praças & parques \\
\hline preferência & cor & contraste & cor & contraste \\
\hline conforto & cor & distribuição da luz & contraste & contraste \\
\hline interesse & cor & contraste & cor & contraste \\
\hline \multirow[t]{2}{*}{ segurança } & distribuição da luz & contraste & contraste & contraste \\
\hline & \multicolumn{4}{|c|}{ atributos de iluminação } \\
\hline
\end{tabular}

Fonte: Elaboração própria, adaptado de Ünver (2009)

O uso da cor como fator para qualidade da iluminação urbana noturna também é relevante. De um lado, entende-se que a introdução de elementos luminosos coloridos promove vivacidade e variedade no cenário urbano.

Ao mesmo tempo, é criticado devido a mudanças dramáticas na aparência das estruturas, modificando o espaço urbano e gerando um cenário de confusão. As respostas emocionais no estudo de Ünver demonstram que o uso da cor afeta positivamente os usuários inseridos nos espaços noturnos.

\begin{abstract}
A pesquisa revela que quando a iluminação proporciona um uso eficaz da cor, as pessoas não se aproximaram da iluminação de forma conservadora e sentiram-se positivas sobre o resultado do projeto. No entanto, a cor também pode ser a principal razão pela qual as pessoas não gostam da iluminação de maneira geral. Estes resultados mostram que o uso da cor na iluminação traz certos riscos que, o resultado do projeto pode ter um apelo limitado no público. (ÜNVER, 2009, p.170, tradução nossa).
\end{abstract}

Do ponto de vista da escolha dos ambientes mais preferidos ou rejeitados pelos usuários, o autor utiliza a análise de conteúdo para agrupar os comentários subjetivos em categorias como "nível de complexidade e variedade”, “cor”, "legibilidade”, “emocional/comportamental”.

A categoria "Emocional/Comportamental" foi a mais citada entre as respostas dos 30 participantes. Inclui descrições envolvendo segurança, calma, relaxamento e 
admiração: "É muito natural e confortante."; "Eu sinto que com esta luz este local seria o local mais seguro para um pedestre."

O mesmo procedimento foi realizado para a análise dos ambientes não preferidos pelos participantes. A categoria "Emocional/Comportamento" foi a mais citada entre as respostas dos 30 participantes. Inclui descrições envolvendo insegurança, ameaça, atratividade e tédio: "Não se sentiria seguro aqui."; "Não há um arranjo especial para a iluminação desta área, não parece estético. ”.

Apesar de ser bastante difundido o uso de fotografias - em psicologia ambiental, Russel e Mehrabian (1974) e Kaplan (1987) utilizam fotografias como estímulo na investigação dos seus estudos - a possibilidade de interação com o ambiente permanece estático, no sentido da não interação do usuário ao explorar o espaço. Esta interação pode ser realizada no ambiente real, entretanto torna-se problemático a criação de diversos cenários, tanto do ponto de vista burocrático como logístico e financeiro.

\section{Avaliação da qualidade ambiental em Johansson (2011, 2014)}

Johansson, Rosen e Küller (2011) descrevem um processo de avaliação da qualidade do ambiente externo a partir da percepção de usuários específicos mulheres jovens, idosos e deficientes visuais - ao caminharem em um trajeto para pedestres (FIG. 7). Encontram dimensões relacionadas à percepção/alcance visual, percepção de perigo. Além disto, as influências de características individuais, como impressões subjetivas da iluminação e o grau de confiança no ambiente, são estudadas a fim de entender suas relações.

Figura 7 - fotografias da área de pedestre investigada no estudo
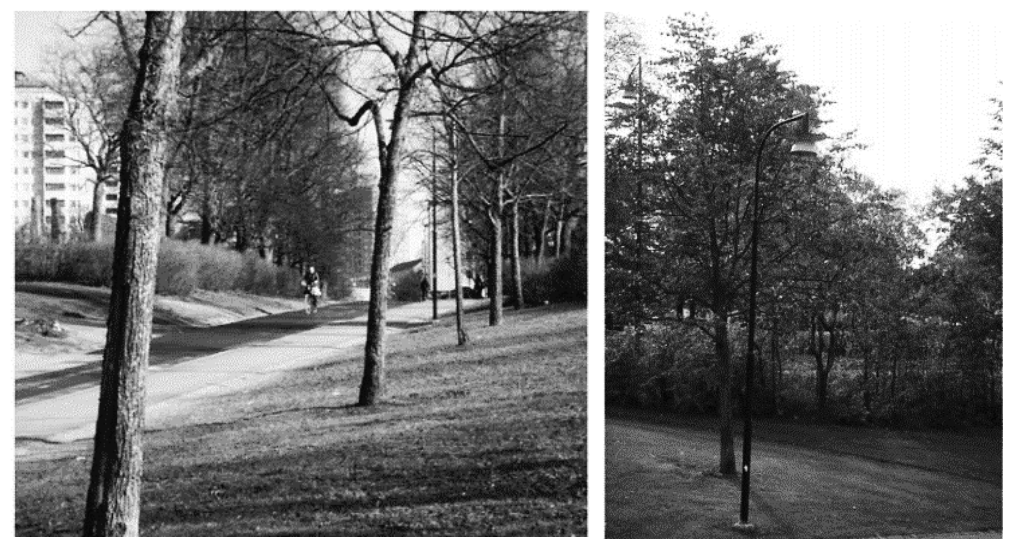

Fonte: Johansson, Rosen e Küller (2011) 
Para os autores, a percepção de perigo e o alcance visual de ambientes externos com a mesma configuração de iluminação podem ser diferentes, a depender das características individuais como percepções, atitudes e personalidade. Neste caso, os autores utilizam como ferramenta a dimensão de confiança no ambiente, desenvolvida por Johansson em estudos anteriores, cuja confiabilidade nos espaços, sejam naturais ou construídos, é resultado de fatores individuais, como memória e preferência.

Portanto, a pesquisa se desenvolve na relação entre as impressões subjetivas da iluminação (descritas aqui pelo brilho e pela agradabilidade) e a confiança no ambiente, de um lado, e a percepção de perigo e acessibilidade visual de outro. Em outras palavras, um maior nível de confiança e qualidade da iluminação pode levar a um melhor alcance visual - facilidade em reconhecer pessoas e detectar obstáculos, por exemplo - e uma melhor percepção de segurança.

A seleção de participantes levou em consideração pessoas que são mais vulneráveis aos efeitos da iluminação no espaço público e seus possíveis danos físicos e emocionais, sendo os idosos, mulheres jovens e deficientes visuais com pouca visibilidade. Assim, desenvolveu-se a pesquisa com 81 participantes em uma calçada para pedestres na Suécia, onde os usuários realizavam o procedimento padrão de andar sozinho por um trajeto determinado até encontrar-se com o instrutor.

Em seguida, respondiam um questionário sobre aspectos subjetivos da iluminação, acessibilidade e percepção de perigo, confiança ambiental e questões sócio demográficas. Todos os itens utilizaram escalas de avaliação semânticas unipolares e bipolares, computadas estatisticamente para os resultados finais. Também foram realizadas medições fotométricas de iluminância em locais-chave do trajeto, como no início e no fim.

Os resultados indicaram que os participantes expressaram baixa confiança no ambiente estudado. Idosos e mulheres reportaram uma acessibilidade visual suficiente para as condições de iluminação, com exceção dos deficientes visuais, representando um risco, tendo em vista a segurança física do usuário. $\mathrm{Na}$ análise do alcance visual, o campo de visão do usuário é considerado importante, em conjunto com a percepção de brilho do ambiente. Já sobre a percepção de perigo, a sensação de agradabilidade foi fator fundamental na qualidade, ou seja, um ambiente monótono e desagradável trará pouca segurança e conforto. 
Em pesquisas mais recentes, Johansson et al. (2014) desenvolvem um método para avaliação da qualidade ambiental do espaço urbano noturno e iluminado calçadas para pedestres na Suécia - a partir do usuário, baseados em 10 escalas semânticas bipolares, desenvolvidas por Küller e Wetterberg (1993) ao analisarem as qualidades percebidas do espaço no estudo entre diferentes fontes luminosas.

Assim, áreas residenciais para pedestres, como calçadas, foram avaliadas em dez diferentes configurações luminosas, desde instalações com lâmpadas LED e vapor de sódio de alta pressão variando aspectos como iluminância, temperatura e reprodução de cor em cada um dos cenários. Os resultados foram calculados estatisticamente através de fatores de análise, onde encontraram duas dimensões que descrevem o ambiente luminoso: Força da Qualidade Percebida (Perceived Strength Quality - PSQ) e Qualidade Percebida de Conforto (Perceived Comfort Quality - PCQ).

Estes indicadores são relacionados diretamente com iluminação como fator primordial da qualidade do espaço urbano, sendo o PSQ responsável pela percepção de brilho e distribuição luminosa, enquanto o PCQ leva em consideração aspectos hedonísticos, como prazer e suavidade do ambiente iluminado, percebido através de escalas como caloroso (warm), sombreado (shaded), calmo (mild).

Segundo os autores, os dois indicadores contribuem para a melhoria do ambiente urbano noturno, considerando a importância das tarefas desenvolvidas. Valores altos indicam que o lugar é considerado seguro e claro, no sentido de detecção de obstáculos e reconhecimento facial.

\section{Iluminação e percepção espacial em Lindh (2012)}

A pesquisa de Lindh (2012) foca no aspecto da influência da iluminação na percepção do espaço, e consequentemente na interpretação deste pelo usuário. A partir de três contextos em diferentes escalas, sendo o primeiro estudo uma maquete em escala 1:7.5, o segundo um auditório e por fim um espaço público, todos na Suécia, a autora desenvolve uma série de conceitos relacionados à experiência espacial, como sensação de enclausuramento, vastidão, atenção, inclusão e exclusão, além de hierarquia das dimensões arquitetônicas e sua percepção de forma e tamanho.

Representando uma ordem sequencial, as pesquisas desenvolvem métodos variados em cada situação, mas sempre se referindo a percepções qualitativas do 
espaço. Segundo Lindh (2012), "os estudos quantitativos concentram-se em controlar todos os aspectos da situação experimental, mas raramente discutem a interpretação dos conceitos e compreensões dos sujeitos envolvidos". Portanto, os questionários aplicados são seguidos de entrevistas ou grupo focal, de forma a obter uma compreensão holística.

De especial interesse para os estudos de avaliação da qualidade dos espaços noturnos, a autora selecionou um espaço em escala real, servindo de laboratório a fim de compreender as questões de pesquisa levantadas, como influência da altura da luminária (chamada de topografia da luz) na percepção de segurança.

Outras questões da pesquisa buscam compreender como certos elementos iluminados podem transformar a experiência do espaço e sua coerência, por exemplo a relação entre direção da luz e hierarquia de edifícios, delimitação espacial como mediador de segurança, abrigo, conforto e aconchego.

A montagem da iluminação foi resultado das questões levantadas acima. Lindh selecionou uma praça na cidade de Alingsås, cujo período de instalação das luzes coincidiu com um evento de iluminação da cidade, facilitando procedimentos logísticos. Sendo assim, o espaço público é cercado por edificações residenciais e institucionais, com ruas para automóveis. A praça é o espaço central da área, voltada aos pedestres, onde existem caminhos que cruzam o espaço em "X", árvores caducifólias e uma igreja em uma de suas extremidades (FIG. 8).

Figura 8 -Iluminação no espaço em planta (A). Ruas iluminadas com duas alturas, quatro (B) e seis metros (C).
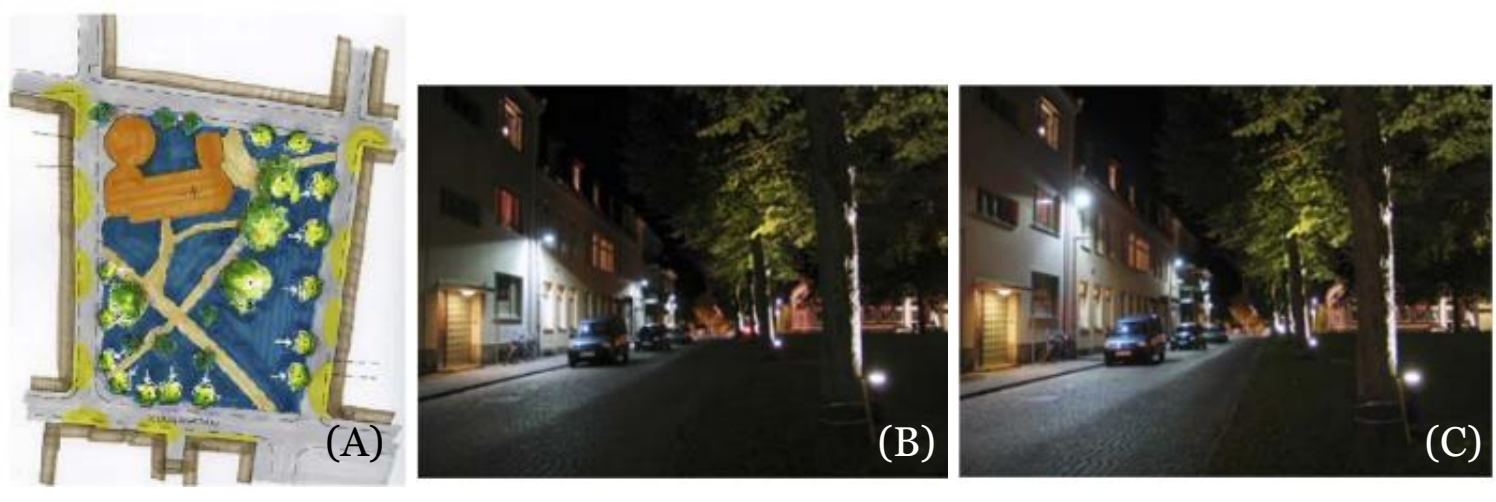

Fonte: Lindh (2012) 
O projeto de iluminação privilegiou cinco pontos considerados importantes pela autora, sendo ruas, fachada da igreja e prefeitura, árvores e um pequeno túnel que liga a praça ao espaço interno da quadra. A iluminação das ruas possuía duas alturas quatro e seis metros - e intensidades que eram modificadas a cada cinco minutos. O objetivo é avaliar a percepção dos usuários quanto à delimitação, tamanho e sensação de segurança do espaço.

Luminárias de piso com foco voltado para cima (uplighting) foram utilizadas para iluminar as fachadas da igreja e a prefeitura que estão voltadas para a praça. A igreja possuía três opções de iluminação, sendo 5, 3 ou 2 fachos em sua fachada, modificados a cada três minutos (FIG. 9). Segundo a autora, devem ser estudadas as relações entre profundidade, largura, delimitação e coerência do espaço. Na fachada da prefeitura, o objetivo é compreender o impacto da iluminação na impressão de altura e imponência do edifício, tendo em vista sua função.

Figura 9 - fachada da igreja iluminada com três opções: dois (A), três (B) ou cinco fachos (C).
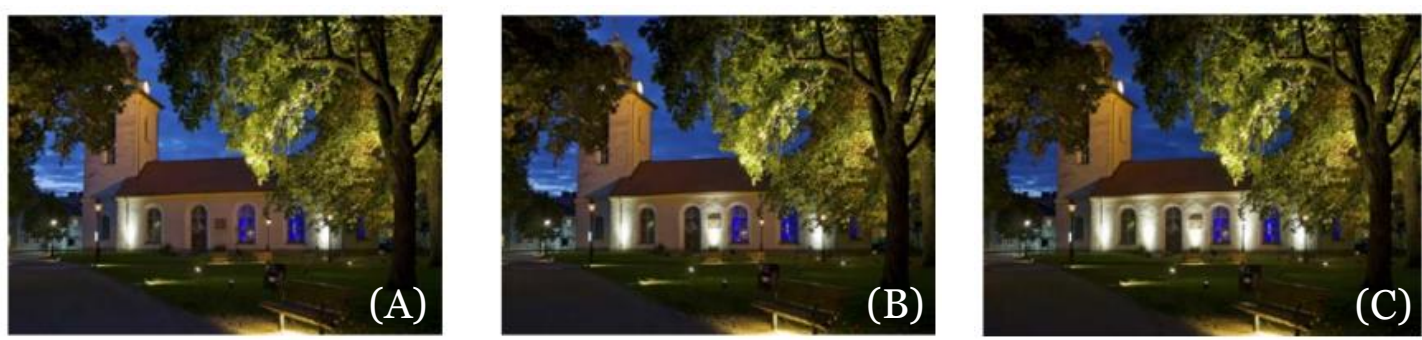

Fonte: Lindh (2012)

As árvores foram iluminadas de duas maneiras: de baixo - com luminárias de diferentes temperaturas de cor e intensidades, a fim de enfatizar os volumes das copas - e com iluminação rasante nos troncos, a fim de enfatizar a textura. Eram desligadas a cada 15 minutos durante o evento. Também foram iluminados os caminhos da praça, a fim de compreender a percepção do usuário quanto à delimitação espacial e percepção de segurança. A fim de melhorar a qualidade do espaço urbano, alguns detalhes foram destacados pela iluminação, como uma velha cabine elétrica vermelha, bancos e pedras que contam a história da cidade (FIG. 10). 
Figura 10 - Árvores, caminhos e bancos iluminados
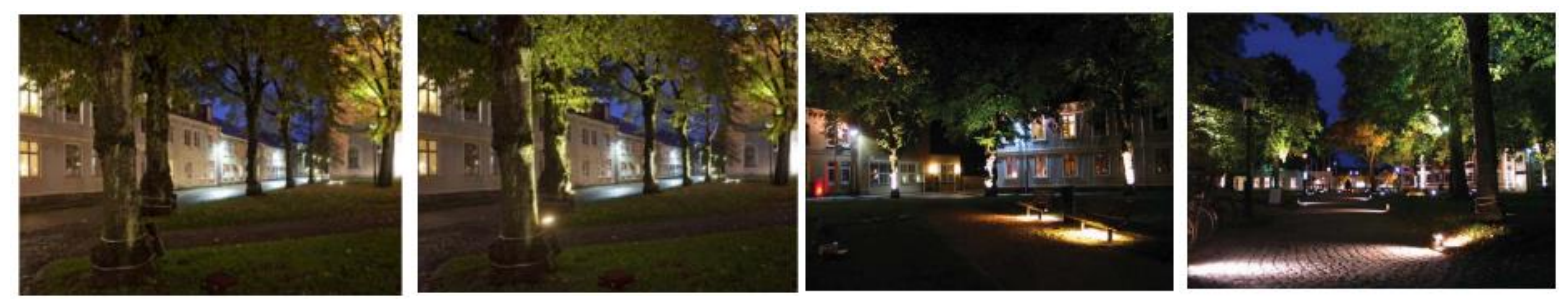

Fonte: Lindh (2012)

A pesquisa durou cinco semanas, e as respostas foram coletadas através de 222 questionários, contendo 11 questões direcionadas a pessoas que presenciaram a instalação no local e que poderiam responder rapidamente. Também foram realizadas 39 entrevistas, sendo 27 gravadas em vídeo. Segundo a autora, o objetivo desta etapa era detectar impressões espontâneas sobre o espaço e atmosfera do lugar, verificar se as pessoas entenderam os conceitos envolvidos e também compreender o porquê das respostas recebidas.

Baseados nas questões da pesquisa, os resultados demonstraram que a altura da luminária em 4 metros contribui mais para a sensação de segurança do que a de 6 metros, afetando a percepção de altura. As entrevistas sugerem que esta configuração está mais próxima à escala do pedestre, favorecendo a sensação de segurança, além de prover mais iluminação nas superfícies verticais.

De acordo com os questionários coletados, a questão da delimitação do espaço com luminárias em altura mais baixa foi considerada importante devido ao seu contexto local, pois a cidade estudada é pequena e possui a morfologia urbana bastante modesta, com prédios de até três andares, o que pode ter contribuído para os resultados. Segundo os entrevistados, esta questão pode ser compreendida pela comparação com o ambiente interior, onde o teto promove a delimitação do espaço, cuja impressão de altura transforma a percepção do usuário quanto ao seu conforto e vulnerabilidade.

Outros resultados dizem respeito à percepção de forma e dimensão da igreja ao ser iluminada de três maneiras diferentes, sendo considerada mais extensa a fachada iluminada por completo (com 5 fachos), enquanto que a iluminada com três fachos foi considerada mais estreita e alta. A prefeitura foi considerada mais alta e imponente quando iluminada, redefinindo através da iluminação hierarquias no espaço público e 
o conceito de poder relacionada a percepção da importância deste edifício no contexto local.

A delimitação do espaço pela iluminação das árvores foi considerada um fator importante para a percepção da qualidade espacial, mas produzindo efeitos contraditórios pela capacidade de diminuir a altura do ambiente e alarga-lo, a depender do local analisado. A legibilidade entendida como fruto da delimitação clara do ambiente é tida como benéfica ao usuário, pois contribui para a percepção de segurança e demonstra a importância da distribuição da luz na compreensão da experiência visual do espaço.

\subsection{Iluminação como indicador de qualidade ambiental}

Os usuários inseridos em um dado espaço são influenciados por processos psicológicos, emocionais, e até variações fisiológicas, satisfazendo necessidades, gerando sensação de segurança física e reconhecimento facial, além da possibilidade de interações sociais e capacidade de realizar tarefas em ambientes noturnos, onde a iluminação é uma das variáveis mais importantes neste aspecto.

Esta seção apresenta pesquisas relacionadas às características da luz - sendo elas intensidade, temperatura de cor e distribuição - que exercem influência na percepção visual e no processo de avaliação de ambientes urbanos noturnos (afastamento ou atratividade). Também são apresentados estudos sobre iluminação e segurança e composição de efeitos luminosos.

\section{Variáveis de iluminação}

A avaliação perpassa por preferencias ambientais (quantidade e cor da luz), variáveis de contexto e cultura (onde atribuição de significados pela memória e pelos hábitos do lugar são importantes), respostas emocionais aos ambientes iluminados (processos psicológicos e cognitivos) a apreciações inconscientes (parâmetros fisiológicos do olho humano desempenham papel fundamental por exemplo na percepção de diferença de brilho entre fontes luminosas de temperatura de cor diferentes). Vale salientar a predominância de produção científica em ambientes internos - notadamente escritórios - em detrimento dos espaços externos.

Existem pesquisas que relacionam variáveis de iluminação e a influência na preferência do usuário inserido em um dado ambiente, sendo um dos primeiros o 
trabalho de Kruithof (1941). Este trabalho demonstrou que um ambiente iluminado é julgado agradável a partir da combinação de duas variáveis: temperatura de cor e quantidade de luz. Assim, o autor apresenta o gráfico com recomendações para a criação de cenários de luz.

O gráfico mostra como as combinações das duas variáveis de iluminação podem ser encontradas a fim de gerar ambientes agradáveis (FIG. 11): a área em branco indica as variações recomendadas dentro do limite do agradável; na área abaixo do limite inferior, o autor descreve o ambiente como sendo quente, monótono e sombrio, enquanto que a área acima do limite superior o ambiente é percebido como muito frio, desagradável e pouco natural.

Figura 11 - Gráfico de Kruithof, relacionando atributos de iluminação com qualidade do ambiente

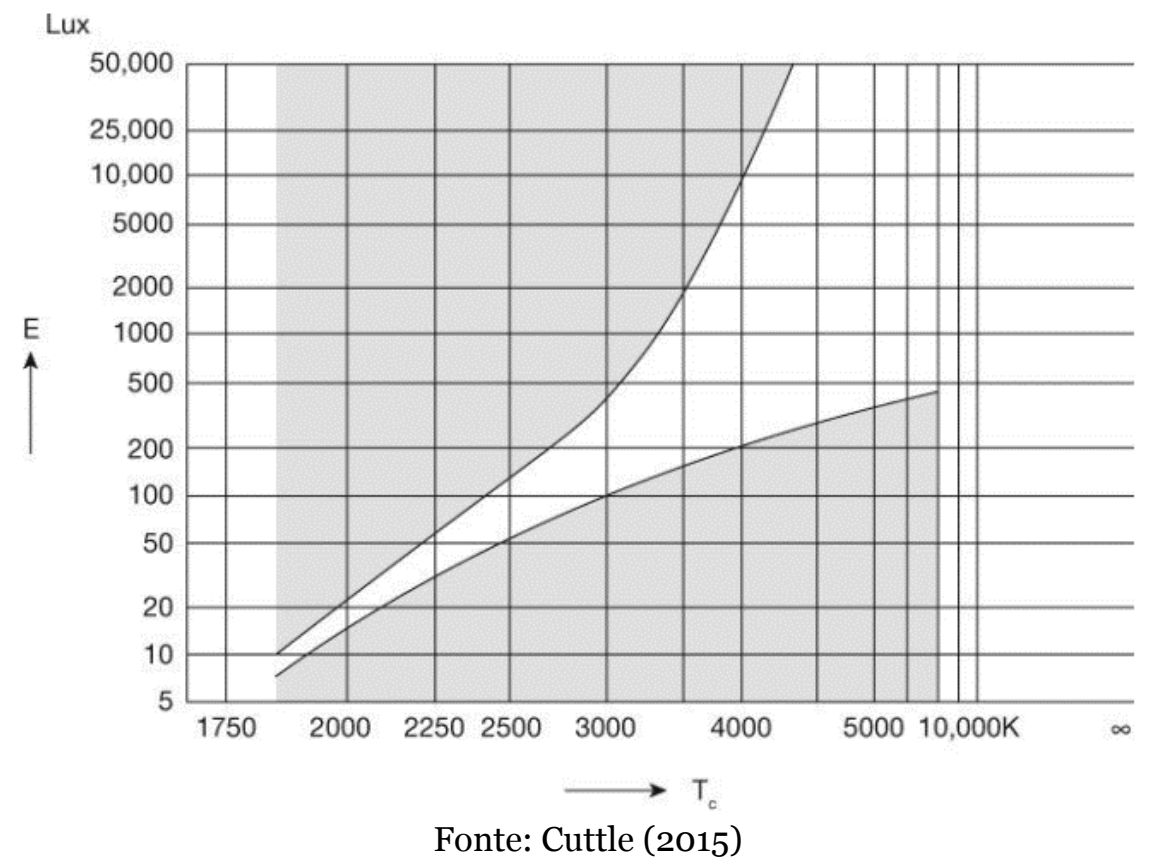

Uma série de pesquisas foram desenvolvidas para validação das condições do gráfico apresentado, organizadas em revisões bibliográficas produzidas por Fernandez (2012) e Van Erp (2008), cuja pesquisa também investiga os mesmos parâmetros de Kruithof e de certa forma, valida os resultados em laboratório.

Boyce e Cuttle (1990) testaram a hipótese de Kruithof ao avaliar a percepção dos usuários inseridos em um ambiente laboratorial, assemelhando-se a um escritório, com configurações de iluminação diferentes (temperatura de cor de $2700 \mathrm{~K}$ e $6500 \mathrm{~K}$ e 
quatro iluminâncias, 30, 90, 225 e 60olx). Os resultados mostraram que as preferências dos entrevistados foram influenciadas mais pela variação da quantidade de luz do que a temperatura de cor.

Os pesquisadores demonstraram que ambientes com níveis altos de iluminância tendem a ser mais agradáveis, confortáveis e uniformes. A ausência do efeito da temperatura de cor foi explicada pelo fenômeno de adaptação cromática do sistema visual (os participantes ficaram cerca de vinte minutos no ambiente, adaptando-se ao lugar). Os autores destacam que o contexto pode ter influência nos resultados, ao comparar a temperatura de cor recorrente em ambientes de escritórios e de residências. Outras pesquisas encontram resultados semelhantes, evidenciando que a preferência por cenários de luz é dependente do contexto e das características individuais dos ocupantes do espaço (NAKAMURA; KARASAWA, 1999 apud ERP, 2008; KULLER; WETTERBERG, 1993 apud FERNANDEZ, 2012).

A noção de contexto tem predominância em ambientes internos, onde os usos são diversos e a iluminação desempenha papel fundamental e específico para cada função. Por exemplo, a qualidade da iluminação em escritórios visa a performance, produtividade e a redução da fadiga (VEITCH, 2001), enquanto que em ambientes como hotéis, a qualidade ambiental se traduz o oposto do escritório, visando o relaxamento e prazer (FERNANDEZ, 2012).

Em espaços urbanos, a cultura e memória coletiva exercem influência na compreensão do espaço, tendo em vista lugares que contam a história da cidade, ou foram pontos importantes em algum momento (GONÇALVES, 2006). Estudos como Bonaiuto, Fornara e Bonnes (2003), Tu e Lin (2008) e Tejera (2012) buscam investigar a influência de qualidades psicossociais em espaços públicos, desde praças a bairros residenciais. $\mathrm{O}$ primeiro desenvolve um índice - qualidade do ambiente residencial percebida (Perceived Residential Environment Quality - PREQ) - capaz de medir a satisfação dos habitantes em relação a sua vizinhança (suas características sociais, físicas e ambientais) na cidade de Roma. Tu e Lin (2008) analisam a qualidade da vizinhança em bairros de Taipei, enquanto Tejera investiga se há diferenças no comportamento e ocupação de usuários de praças públicas em bairros com diferentes perfis econômicos na cidade de Barcelona, relacionando-se com a qualidade do espaço e sensação de segurança. 
Do ponto de vista de processos psicológicos e sua influência no humor (mood) do usuário inserido em ambientes iluminados, Van Erp (2008) relata a existência de múltiplos estudos sobre o impacto das características de iluminação. Entretanto, são difíceis de serem comparados e validados por conta de diferentes procedimentos metodológicos, questionários e configurações ambientais. Estas pesquisas são baseadas nos trabalhos descritos anteriormente no capítulo 1, como Flynn et al. (1973), Mehrabian e Russel (1974) e Acking e Küller (1973), onde variações são realizadas a fim de se adaptar a questões de pesquisa e condições culturais.

Alguns exemplos são os trabalhos de Baron, Rea e Daniels (1992) e Knez (1995). Ambos os estudos são desenvolvidos a partir do conceito de PANAS (Positive Affect \& Negative Affect) formulado por Watson, Clark e Tellegen (1988). Este conceito, tomando como base o trabalho de Mehrabian e Russel (1974), é baseado nas duas dimensões de afeto, contendo 20 descritores como alerta, determinação, culta e tristeza, a fim de medir afeto positivo ou negativo.

\section{Iluminação e segurança}

A iluminação de ambientes urbanos deve obedecer a critérios relacionados à quantidade de luz necessária e sua uniformidade para o adequado deslocamento dos usuários pelo espaço, garantindo conforto visual e segurança física. Existem várias associações responsáveis por estudos relacionados às normas, como a CIE (Committee Internationale de Eclairage) e a ABNT (Associação Brasileira de Normas Técnicas) no contexto brasileiro. Entretanto, é recorrente a aplicação de elevados níveis de iluminação, ultrapassando as recomendações e causando desperdícios de energia e impactos ambientais (poluição luminosa) em prol de sensação de segurança e bemestar dos usuários.

A relação entre quantidade de luz e segurança faz parte do escopo de pesquisa em iluminação desde a década de 1970, onde são desenvolvidos estudos a fim de compreender este impasse e buscar soluções. O trabalho mais emblemático é a pesquisa de Tien et al. (1977), cuja revisão bibliográfica destaca que melhorias na iluminação pública reduzem a vulnerabilidade de crimes em certas regiões, ao mesmo tempo que a iluminação não é um fator significativo estatisticamente para reduzir a incidência de crimes. Em outras palavras, níveis elevados de iluminação não 
necessariamente irão reduzir o crime. A analogia com o período diurno é mais evidente, tendo em vista a ocorrência de crimes mesmo na luz do dia.

Peña-García, Hurtado e Aguilar-Luzón (2015) destacam que a diferença está na mudança de paradigma, ao indicar que "melhor iluminação" - ao invés de "mais iluminação" - evidencia melhor sensação de segurança. Os autores buscam investigar o impacto da intensidade de luz e temperatura de cor na percepção de segurança e bemestar do usuário em espaços públicos da Espanha.

Para tanto, aplicam questionário com 11 questões - relacionadas a preferencias e percepções - com 275 participantes distribuídos em cinco ruas na cidade de Granada (FIG. 12). As ruas possuem lâmpadas instaladas variando de vapor de sódio (cor amarelada) e vapor metálico (luz branca).

Figura 12 - ruas da cidade de Granada, objeto de estudo dos autores
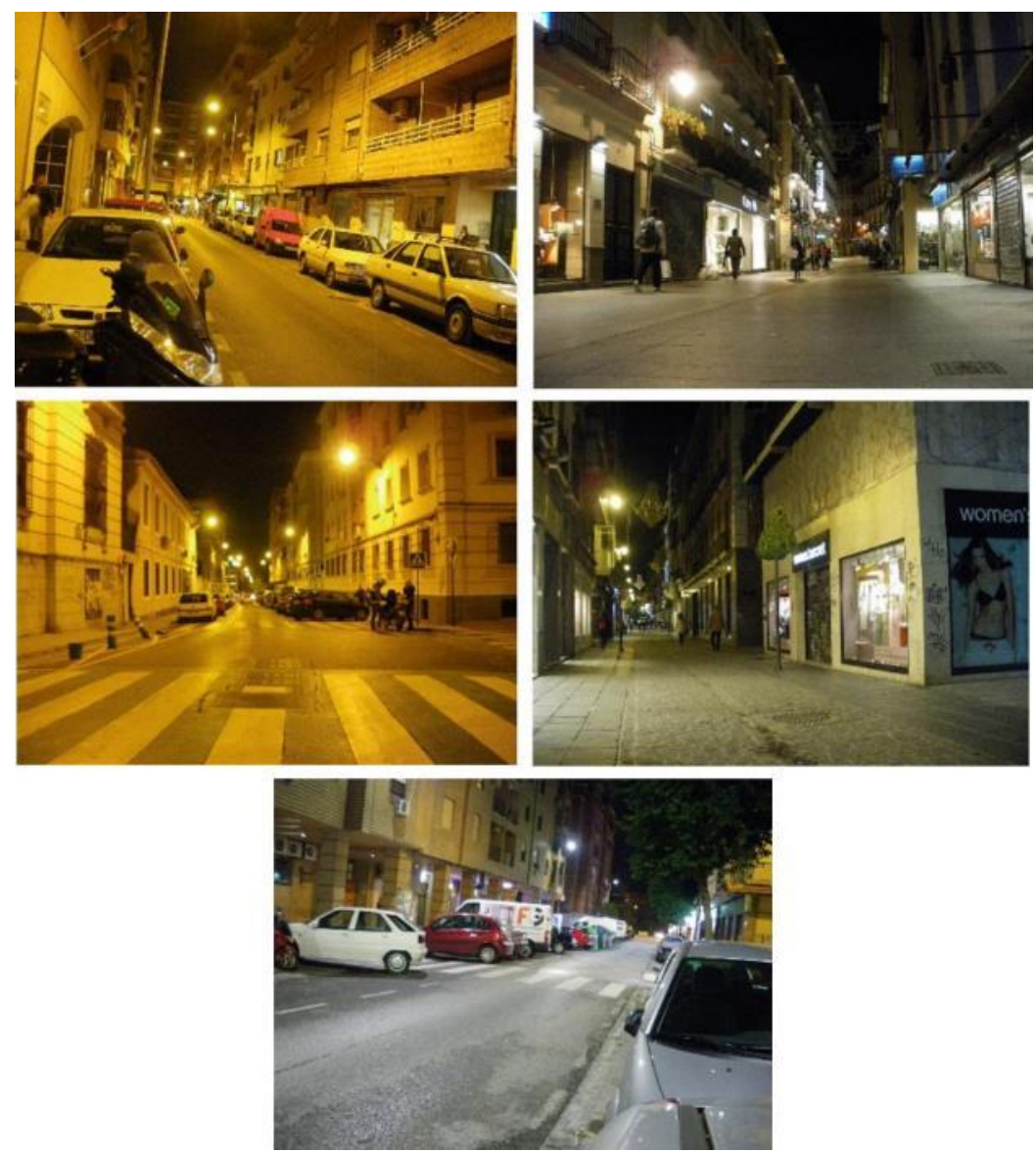

Fonte: Peña-García, Hurtado e Aguilar-Luzón (2015) 
Os resultados demonstram que a quantidade de luz é mais elevada que o recomendado nas normas em todos os espaços estudados, e as pessoas preferem as ruas com maior quantidade de luz. Em especial, luzes com temperatura de cor fria foram preferidas no quesito percepção de segurança, devido a melhor reprodução de cor para reconhecimento facial.

Boyce et al. (2000) estabelecem parâmetros para poderem trabalhar questões relacionadas a iluminação e segurança ao estudarem áreas predominantemente públicas nas cidades de Albany, Nova York e Clifton Park. Estudos de campo são analisados, comparando percepções de segurança entre áreas urbanas e suburbanas, e também se há influência da temperatura de cor no espaço urbano.

O primeiro estudo é desenvolvido em dois espaços urbanos de Nova York e Albany. Em cada local, os participantes eram divididos em dois grupos e realizavam um procedimento padronizado: andavam pelo local e então ficavam numa posição prédeterminada e olhavam em determinada direção, e em seguida preenchiam o questionário, contendo escalas semânticas bipolares de 5 pontos, considerando palavras como bom/ruim, claro/escuro, uniforme/não uniforme, confortável/desconfortável, ofuscante/não ofuscante, amplo em área/limitado em área, desadequado ao lugar/adequado ao lugar.

Além disto, há uma série de perguntas a respeito do grau de segurança e visibilidade nos espaços analisados, como este é um bom exemplo de iluminação $\underline{\text { segura, }}$ cujo usuário respondia a partir de parâmetros de concordância em uma escala de 1 a 5 (não concordo e concordo, respectivamente). Dos resultados, os autores chegam à conclusão de que os ambientes tendem a serem avaliados de maneira semelhante quanto às escalas de conforto, brilho e estética.

Quanto ao entendimento da relação entre variáveis de iluminação e características demográficas, os resultados demonstram que há maior nível de concordância quando a quantidade de luz é aumentada. Da mesma forma, Boyce relata o gênero como fator importante na mudança de percepção de uma boa iluminação, ao constatar que mulheres requerem maior iluminância em relação aos homens. Assim, estabelece uma medida prática de iluminância média entre 35 lx e 60 lx (FIG.13). 
Figura 13 - gráficos desenvolvidos a partir da pergunta "este é um bom exemplo de iluminação para segurança”. Na esquerda, a comparação entre duas cidades, e à direita entre gêneros
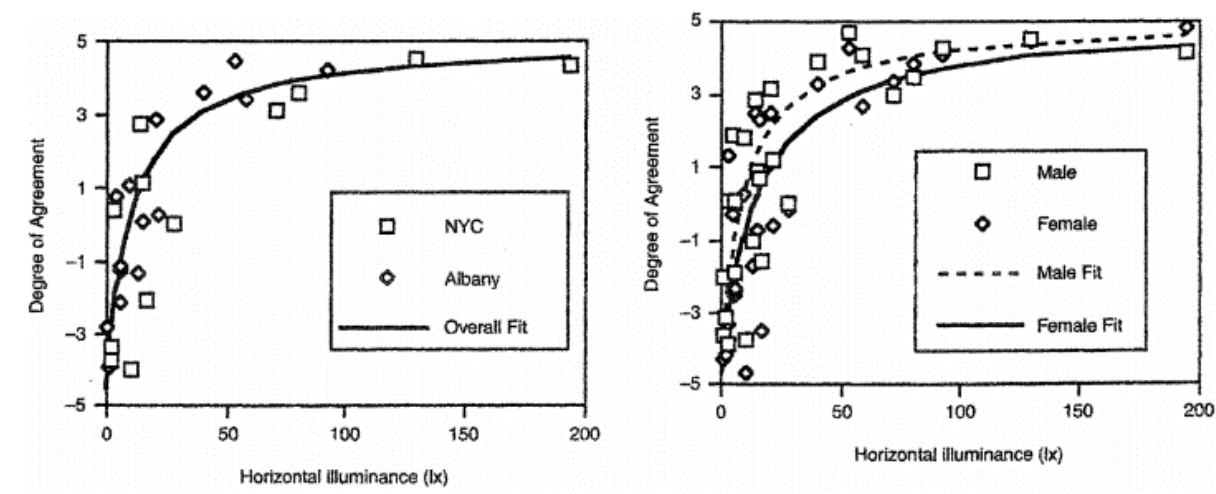

Fonte: Boyce et al. (2000)

O autor continua seus estudos ao comparar a percepção de segurança em espaços abertos, no caso estacionamentos localizados em área urbana e no subúrbio (Albany e Clifton Park), a fim de entender se a percepção de segurança é a mesma para ambos os casos ou não.

A diferença neste estudo é que o autor compara cenários diurnos com noturnos, ao utilizar um questionário contendo perguntas relacionadas à sensação de segurança, como andar sozinho no estacionamento e estacionar o carro no local. Os resultados mostram que a segurança percebida durante o dia é maior do que à noite. A qualidade da iluminação no subúrbio é considerada mais segura, com quantidade de luz de 10 lux, enquanto que é necessário 20 lux para o estacionamento estudado em áreas urbanas.

Os autores descrevem que algumas percepções durante os estudos anteriores podem ter sido geradas pelos diferentes tipos de lâmpadas utilizadas, como vapor de sódio de alta pressão a vapores metálicos. Portanto, propõem-se a estudar um estacionamento-laboratório para a criação de cenários com diferentes fontes luminosas. São criadas três áreas no estacionamento com lâmpadas de diferentes tipos e intensidades, por onde 15 pessoas iriam atravessar. Também era solicitado responder a questionários e medição do grau de acuidade visual.

O objetivo da pesquisa era identificar se o espectro das lâmpadas influencia a percepção de segurança, identificação facial, brilho e conforto do espaço noturno. Os 
resultados demonstraram que a iluminância continua sendo fator de melhoria da qualidade do ambiente, recomendando níveis de iluminação para o espaço estudado.

Vale salientar estudos que comprovam que fontes luminosas com diferentes características espectrais mudam a percepção de brilho e percepção de segurança, principalmente aquelas que possuem comprimento de onda variando entre 510nm, notadamente fontes mais azuladas (KNIGHT, 2010; PENA-GARCÍA, HURTADO e AGUILAR-LUZON, 2015). Entretanto, suas descobertas demonstram como a mudança de quantidade de luz afeta o ambiente em certas faixas de iluminância. Por exemplo, para a faixa de 0-10 lux, pequenos aumentos resultam em uma maior percepção de segurança. Enquanto que na próxima faixa acima de 50 lux, a percepção tem pouca diferença com o aumento da iluminância.

\section{Composição de efeitos luminosos}

Segundo Skarlatou (2010), lighting designers planejam projetos a partir da composição de efeitos de luz, seguindo uma série de princípios no processo de concepção e desenho, sendo eles: direção e posição da fonte luminosa, geometria da luz, perspectiva de iluminação, relações sintáticas entre os recursos disponíveis e as superfícies do espaço e abstração. Este processo gera composições de iluminação, cujo objetivo é variado, desde atender a condições técnicas, valorizar o ambiente iluminado, seja interno ou externo, até gerar respostas emocionais agradáveis aos usuários inseridos no espaço. Assim, coloca-os a prova durante a pesquisa, na qual é solicitado a uma série de lighting designers a realização hipotética de um projeto de iluminação em uma residência.

A autora define os conceitos a partir de referências bibliográficas que perpassam pelas artes, teatro, história da iluminação doméstica e arquitetura moderna. $\mathrm{O}$ primeiro conceito coloca o problema da posição da fonte luminosa e sua influência no aspecto estético e funcional da arquitetura. Usa como exemplos os candelabros e lustres da época vitoriana, ao descrever que sua posição era determinada por efeitos funcionais - baseados em medidas antropométricas e utilizados no cotidiano o mais próximo possível das tarefas a serem realizadas - e visuais, ao expor texturas através dos materiais do ambiente (FIG.14). 
Figura 14 - solução para iluminação de escadas
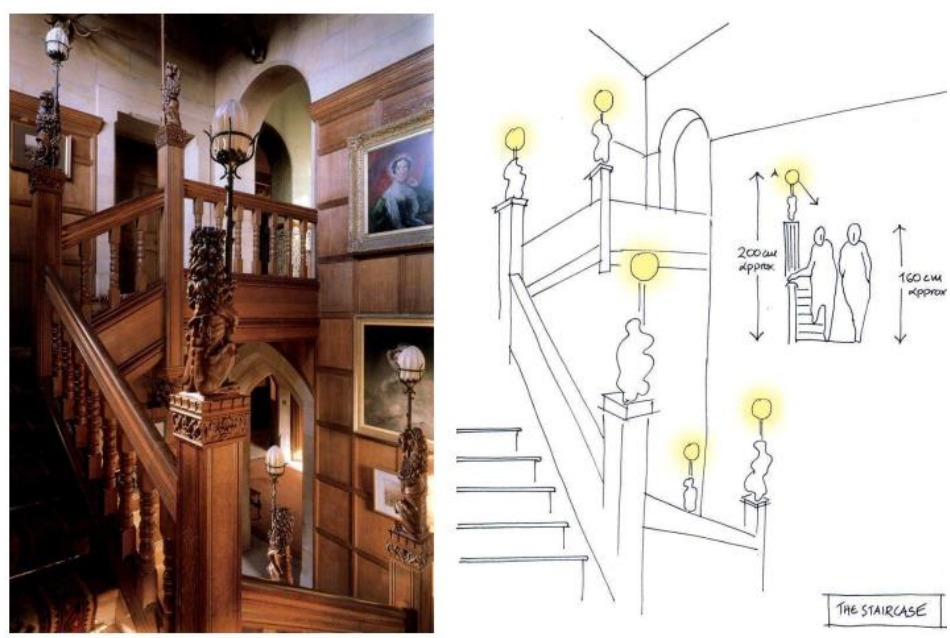

Fonte: Dillion³ (2002, apud SKARLATOU, 2010)

O conceito de geometria da luz está associado à distribuição da luz ao ser associada a refletores e difusores, dispositivos importantes na relação entre a superfície que recebe a luz e o efeito desejado. A autora relata o caso do Museu de Arte Kimbell, de Louis Kahn (FIG. 15) e a Igreja de Santo Inácio, por Steven Holl, e seus sistemas de captação de luz natural.

Figura 15 - Museu de Arte Kimbell
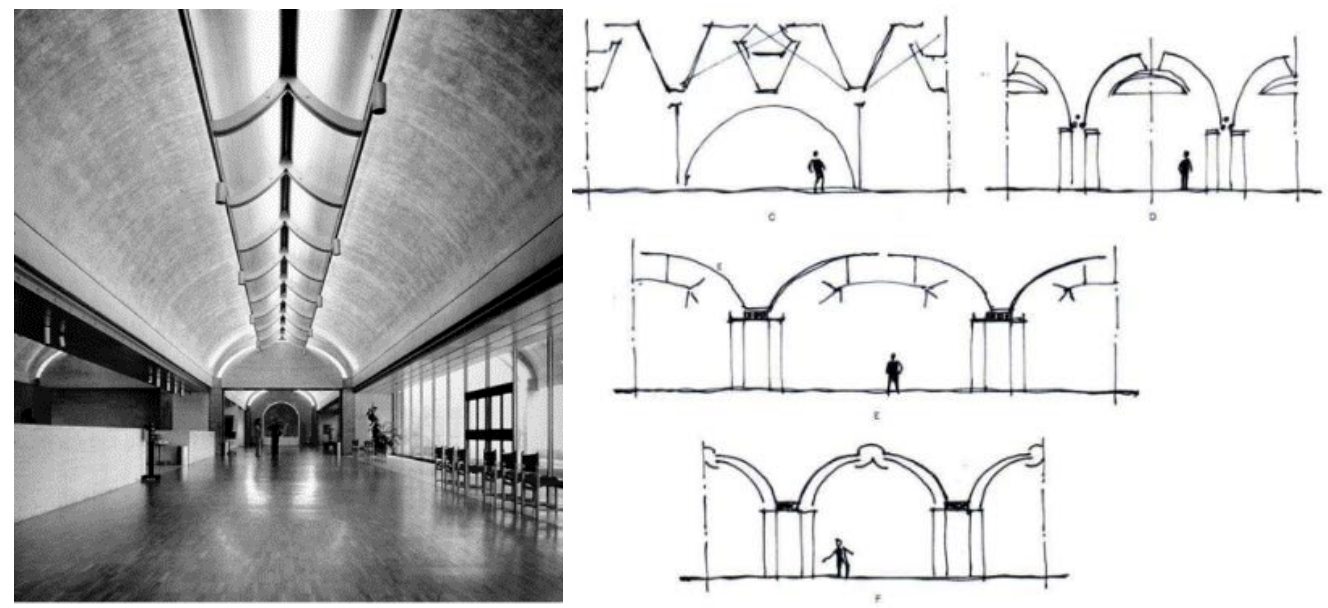

Fonte: Skarlatou (2010)

A iluminação de perspectiva, terceiro conceito, diz respeito à gradação da luz e sua relação com a figura-fundo - contraste - do lugar. Muito associado ao

3 DILLION, M. Artificial Sunshine: A Social History of Domestic Lighting. 1 ed. London: National Trust, 1999. 
expressionismo alemão e ao movimento architecture of the night, a autora justifica seu uso por conter elementos que causam sensação de profundidade, por exemplo em uma sequência de espaços ou uma fachada alongada (FIG.16).

O primeiro e mais óbvio efeito que um designer gostaria de alcançar com a luz
em uma sequência de espaços ou através de um espaço longo é revelar sua
profundidade tanto por razões funcionais - conhecimento da profundidade
fornece uma sensação de segurança - e estéticas - o mais provável é que a
profundidade de um espaço em comprimento ou em altura não seja
consequente, mas intencional pelo arquiteto [...] Uma vez que a perspectiva
pressupõe profundidade ou uma sequência de espaços, não se trata apenas da
imagem estática de um espaço, mas também sobre a imagem dinâmica e como
ela muda para o usuário que a processa através de uma sequência de espaços.
(SKARLATOU, 2010, p.103, tradução nossa).

Figura 16 - Exemplos de arquitetura da noite, baseados no contraste entre superfícies e a iluminação
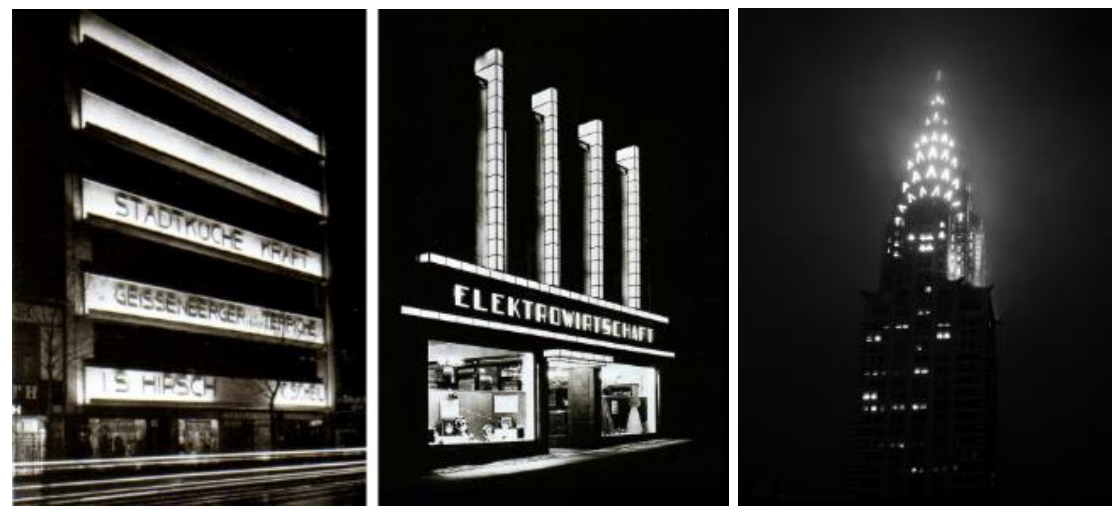

Fonte: Skarlatou (2010)

A relação sintática entre superfície e fonte é o quarto conceito, o qual é percebido através de ambiguidades entre intenção do projeto e intenção da iluminação. Aqui a autora descreve como efeitos de luz considerados ambíguos - materiais auto iluminados (backlighting) - fazem parte do processo de projeto e tem a capacidade de mudar percepções de volumes, ao serem vistos como leves ou flutuantes ao invés de sólidos e pesados (FIG.17), e isto deve estar conectado com a intenção do projeto, ao tentar desmaterializar certos elementos ou denotar outra característica a eles. 
Figura 17 - Exemplos de arquitetura da noite, baseados no contraste

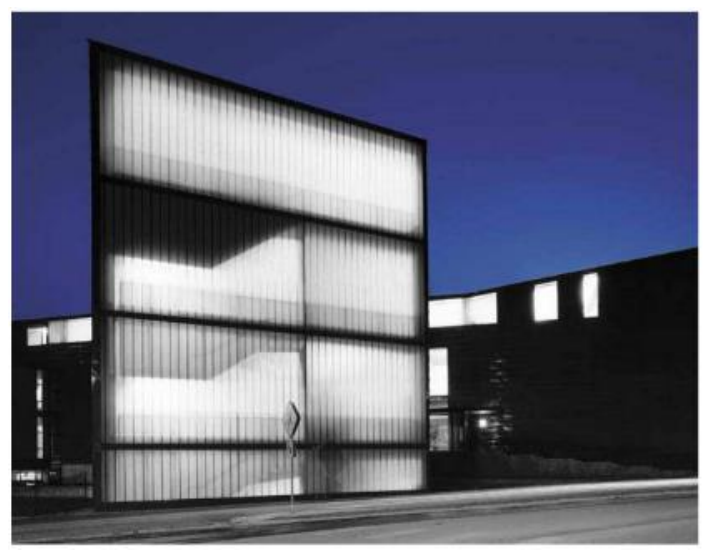

Fonte: Skarlatou (2010)

Em abstração dos espaços iluminados, quinto e último conceito, a autora utiliza como base o trabalho de Richard Kelly, dos três elementos da iluminação, cujos conceitos serão expostos em seguida. A autora defende o uso da abstração ao descrever que os projetistas se utilizam deste recurso como forma de explicar conceitos e ambiências, através de metáforas e exemplos existentes na natureza, principalmente em versão textual. Aqui, Kelly exerce grande influência, ao dissociar a iluminação do espaço em questão e tentar explicar o efeito no sentido abstrato e imaginativo.

Conceitos são concebidos por lighting designers como ideias preliminares sem detalhes, mas cheios de significado e que são então implementados com o uso de técnicas em um processo mais ou menos linear. Sem a presença de conceitos, meras técnicas de iluminação estão preenchendo as lacunas de 'novidade em design de iluminação' de forma desajeitada e sem sentido. (SKARLATOU, 2010, p.112, tradução nossa).

Esta visão fenomenológica do processo de concepção pelo projetista faz parte da busca de explicar e descrever um conceito que deve nortear todo o projeto. Arquitetos como Peter Zumthor, Steven Holl e Juhani Pallasmaa utilizam-se deste recurso, ao relacionar aspectos sensoriais na criação de ambiências e atmosferas.

Após ler a passagem [...] escrita por Peter Zumthor, pode-se perceber um outro ponto de vista. A descrição permite levar alguém a reconstruir mentalmente a situação e o contexto em que o arquiteto se encontrava. Apesar disso, porém, é impossível sequer redesenhá-la em escala num papel. [...] O que se apreende da descrição é uma percepção quase poética do momento, que, genérica, é delineada apenas por aspectos subjetivos do contexto. (GUILHERMINO, 2015, p. 30) 
Os conceitos relacionados a Richard Kelly dizem respeito a três elementos que devem estar presentes no projeto de iluminação, sendo eles: brilho focal, luminescência ambiente e jogo de brilhos (FIG. 18 e 19).

Utilizando-se de explanações textuais, onde o conceito do projeto se materializava na imaginação através de metáforas com a natureza, o autor produziu a teoria que pode ser descrita em qualquer lugar e entendida por qualquer pessoa, tendo em vista seus exemplos ordinários.

Figura 18 - três elementos da iluminação por Richard Kelly
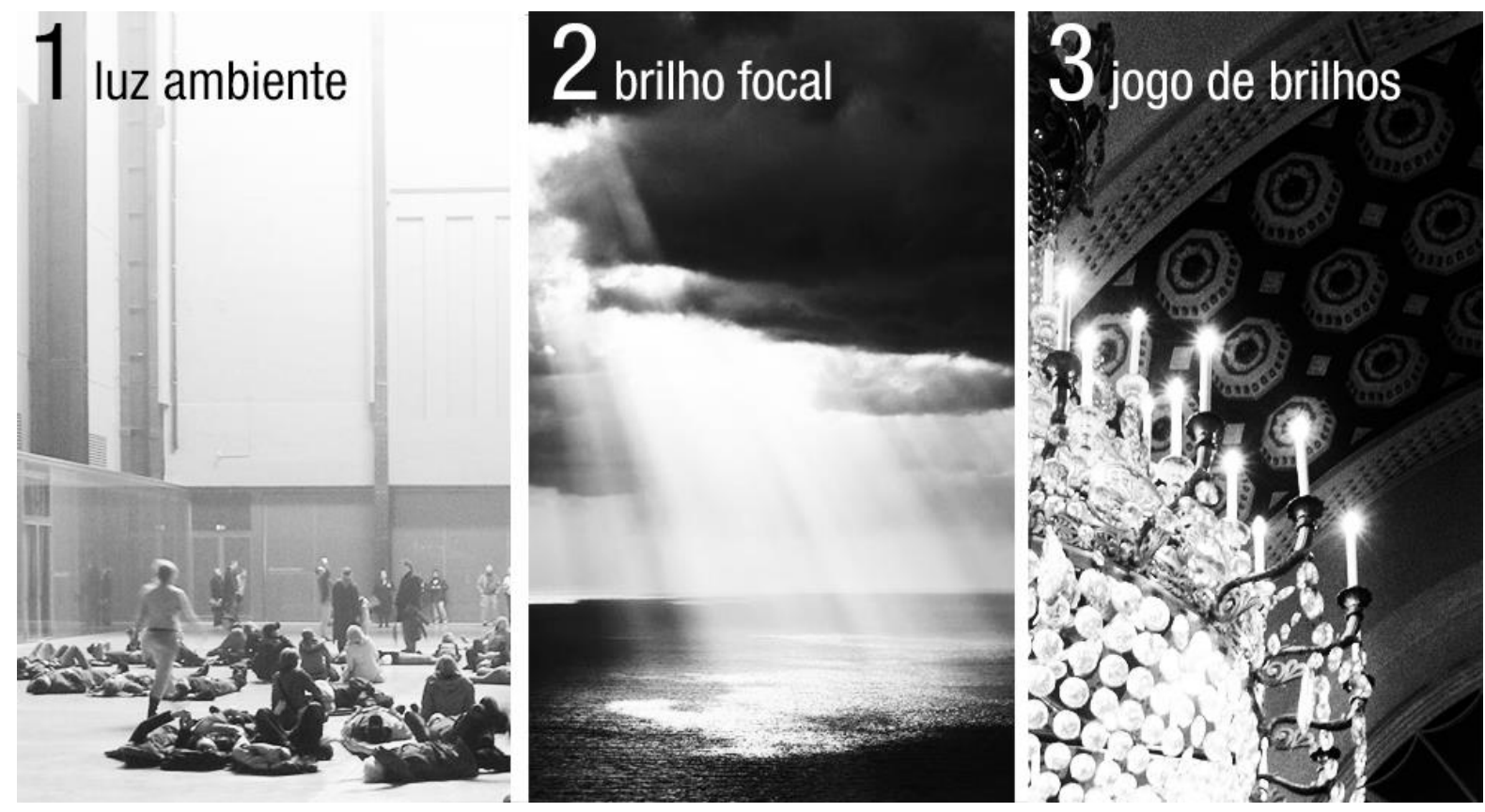

Fonte: adaptado de SKARLATOU (2010)

Assim, o primeiro conceito, brilho focal, é uma forma de atrair atenção e separar o importante do não importante.

Brilho focal é a fogueira de todos os tempos. É spot na fase moderna. É a luz em sua cadeira de leitura favorita. Ele é o eixo da luz do sol que aquece o final do vale. É a luz da vela no rosto e uma lanterna em uma escada... brilho focal chama a atenção, reúne diversas partes, vende mercadoria, ajuda as pessoas a ver. (KELLY, $1952^{4}$ apud SKARLATOU, 2010, p. 111, tradução nossa).

Luminescência ambiente diz respeito a iluminação geral e difusa, reduzindo à calmaria o espaço iluminado, sendo a versão oposta do brilho focal.

\footnotetext{
${ }^{4}$ KELLY, R. Lighting as Integral Part of Architecture. College Art Journal, v. 12, n. 1, p. 24-30, 1952.
} 
Luminescência ambiente é a luz ininterrupta de uma manhã de neve a céu aberto. É o reflexo do sol no mar em um pequeno barco, é a névoa do crepúsculo em um rio largo, onde terra, água e céu são indistinguíveis. É, em qualquer galeria de arte, as paredes iluminadas, teto translúcido, e piso branco. [...] A luz ambiente produz iluminação sem sombras. (KELLY, 1952 apud SKARLATOU, 2010, p. 112, tradução nossa).

Por fim, o jogo de brilhos é descrito como estimulante, informativa, no sentido de aguçar a curiosidade.

O jogo de brilhos é a Times Square à noite. É o salão de baile do século XVIII, com lustres de cristal e muitas chamas de velas. É a luz solar em uma fonte ou um riacho ondulante. $\mathrm{O}$ jogo de brilhos estimula os nervos ópticos e, assim, estimula o corpo e o espírito. (KELLY, 1952 apud SKARLATOU, 2010, p. 112, tradução nossa).

Figura 19 - três elementos da iluminação por Richard Kelly
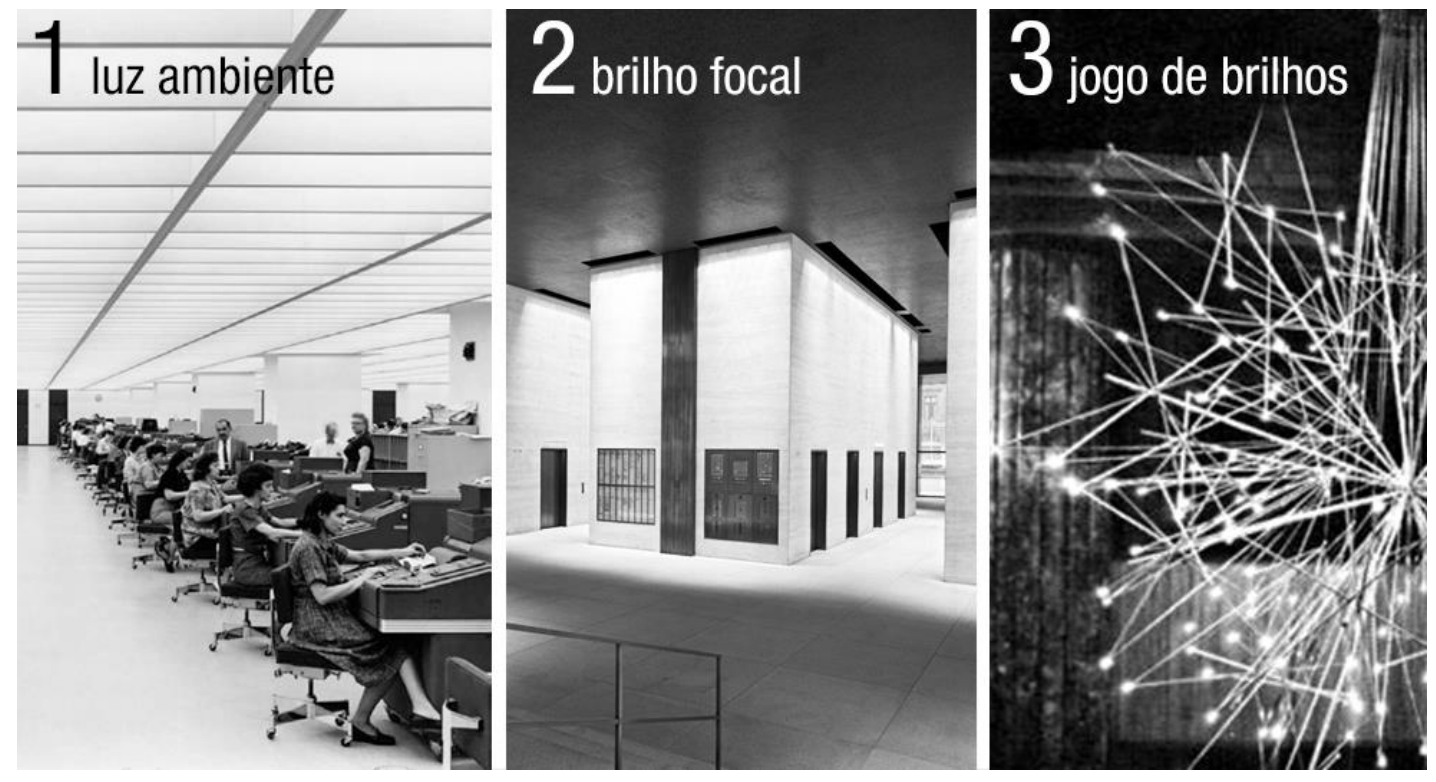

Fonte: adaptado de SKARLATOU (2010)

Richard Kelly foi um dos pioneiros na profissão de lighting designer, ao ser responsável pelos projetos de iluminação de grande parte da arquitetura moderna americana e seu Estilo Internacional. Seus projetos incluem o Museu de Arte Kimbell (Louis Kahn), o edifício Seagram (Mies van der Rohe), aeroporto JFK (Eero Saarinen), casa de vidro (Philip Johnson) e a iluminação urbana do Parque do Flamengo (Afonso E. Reidy e Roberto Burle Marx), no Rio de Janeiro. 


\subsection{Design centrado no usuário}

O processo de design, seja de objetos, comunicação, espaços e sistemas, deve levar em consideração requisitos como usabilidade, estética agradável e fácil compreensão dos mecanismos a fim de atingir os objetivos de quem utiliza tal produto.

Existem formas de abordagem categorizadas a partir do nível de participação ou não de agentes que podem influenciar na tomada de decisão, como usuários, projetista, administrador, contratante (no caso da arquitetura e urbanismo). Alguns exemplos são: a) design participativo (participatory design - PD) e b) design centrado no usuário (user-centered design - UCD).

Design participativo é uma abordagem colaborativa multidisciplinar, onde todos os stakeholders - aqui inserem-se desde os habitantes de uma cidade, designers e construtores - estão envolvidos de maneira semelhante a fim de garantir que o produto final atenda as expectativas de todos. Segundo Kang et al. (2015) este método permite aos usuários a sensação de pertencimento e identidade com o local, tendo em vista sua participação, cuja implementação pode ocorrer de diversas maneiras, como workshops e etnografia.

O design participativo pode ser implementado de várias maneiras, incluindo workshops, etnografias, protótipos cooperativos, mockups, classificação de cartões e design do usuário. Em um workshop, as partes interessadas e designers colaboram para criar visão, projetos ou até mesmo uma simples compreensão dos problemas atuais na busca de uma solução. (KANG et al., 2015, p.831, tradução nossa).

Abras, Maloney-Krichmar e Preece (2004) descrevem que o termo design centrado no usuário é originário de pesquisas realizadas por Donald Norman na Universidade da California em San Diego. Mais tarde, o termo ficou conhecido pela publicação do livro User-Centered System Design: New Perspectives on HumanComputer Interaction, por Norman e Draper (1986, apud ABRAS; MALONEYKRICHMAR; PREECE, 2004).

As aplicações deste processo se caracterizam por colocar o usuário no cerne do contexto, à medida em que suas expectativas e necessidades sejam atendidas, além de ações e tarefas facilmente compreendidas. Assim, o designer atua como um mediador e intérprete das condições impostas a fim de otimizar a eficiência e satisfação no uso do produto final pelo usuário (SANDERS, 2002). 
Figura 20 - etapas do processo de design centrado no usuário

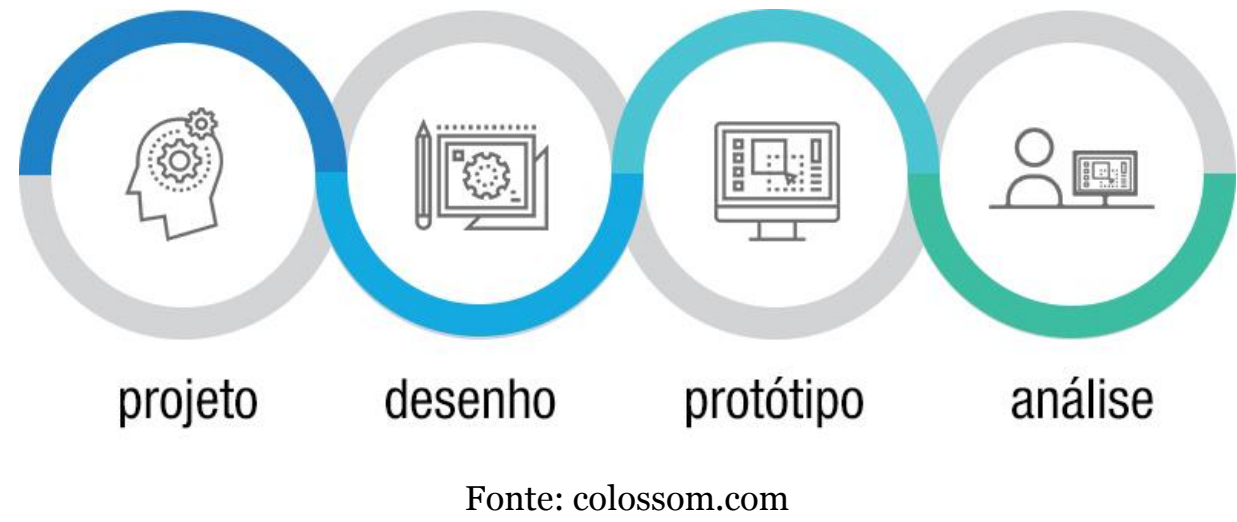

O design centrado no usuário é desenvolvido em etapas, as quais vão investigar primeiramente as necessidades, limitações, preferencias e expectativas dos usuários para em seguida criar soluções de design, que serão avaliadas (FIG. 20). As informações obtidas serão analisadas, possibilitando novas interações e iterações com o produto.

Neste ponto, os designers devem prestar muita atenção às avaliações dos
usuários, pois eles ajudarão a identificar critérios mensuráveis de usabilidade.
Os critérios de usabilidade mensuráveis abordam questões relacionadas à
eficácia, eficiência, segurança, utilidade, aprendizado e memorização (quanto
tempo leva para memorizar a realização das tarefas mais comuns) do
produto/artefato, além da satisfação subjetiva dos usuários com ele. Você
pode ver como seria difícil para os designers saber ou imaginar todos os
critérios de usabilidade que são importantes para os usuários. É apenas
através do feedback coletado em um processo iterativo e interativo envolvendo
usuários que produtos podem ser refinados. (ABRAS; MALONEY-
KRICHMAR; PREECE, 2004, tradução nossa).

Apesar de pesquisas serem predominantemente realizadas na área de desenvolvimento de sistemas, computação e design gráfico, como web, software, entre outros, o campo da arquitetura se utiliza com frequência desses processos, seja do PD ou UCD, principalmente em projetos de urbanismo, onde a participação da comunidade desempenha papel fundamental no desenvolvimento destes espaços, mas também no processo de projeto em arquitetura. A própria essência de um projeto residencial, por exemplo, é satisfazer as condições impostas pelos usuários alcançar os objetivos estabelecidos através da edificação.

Turan et al. (2016) descreve a experiência de redesenho de um parque urbano na cidade de Rize, Turquia, a partir de conceitos do design participativo. Para tanto, a comunidade participava durante o processo de concepção através de reuniões, questionários e entrevistas, ao escolher elementos, atividades e usos que eram 
preferíveis pela população. A pesquisa também procurou investigar os níveis de satisfação dos usuários antes e após a implementação quanto a variáveis como segurança, iluminação, paisagismo e uso do espaço e concluiu que estes aspectos foram melhorados com o redesenho do parque.

Bullinger et al. (2015) desenvolve um arcabouço conceitual para inserir o usuário no processo de projeto em arquitetura, utilizando-se de ambientes virtuais imersivos e conceitos do design centrado no usuário e design participativo (FIG. 21).

Figura 21 - uso de ambientes virtuais imersivos no processo de projeto em arquitetura

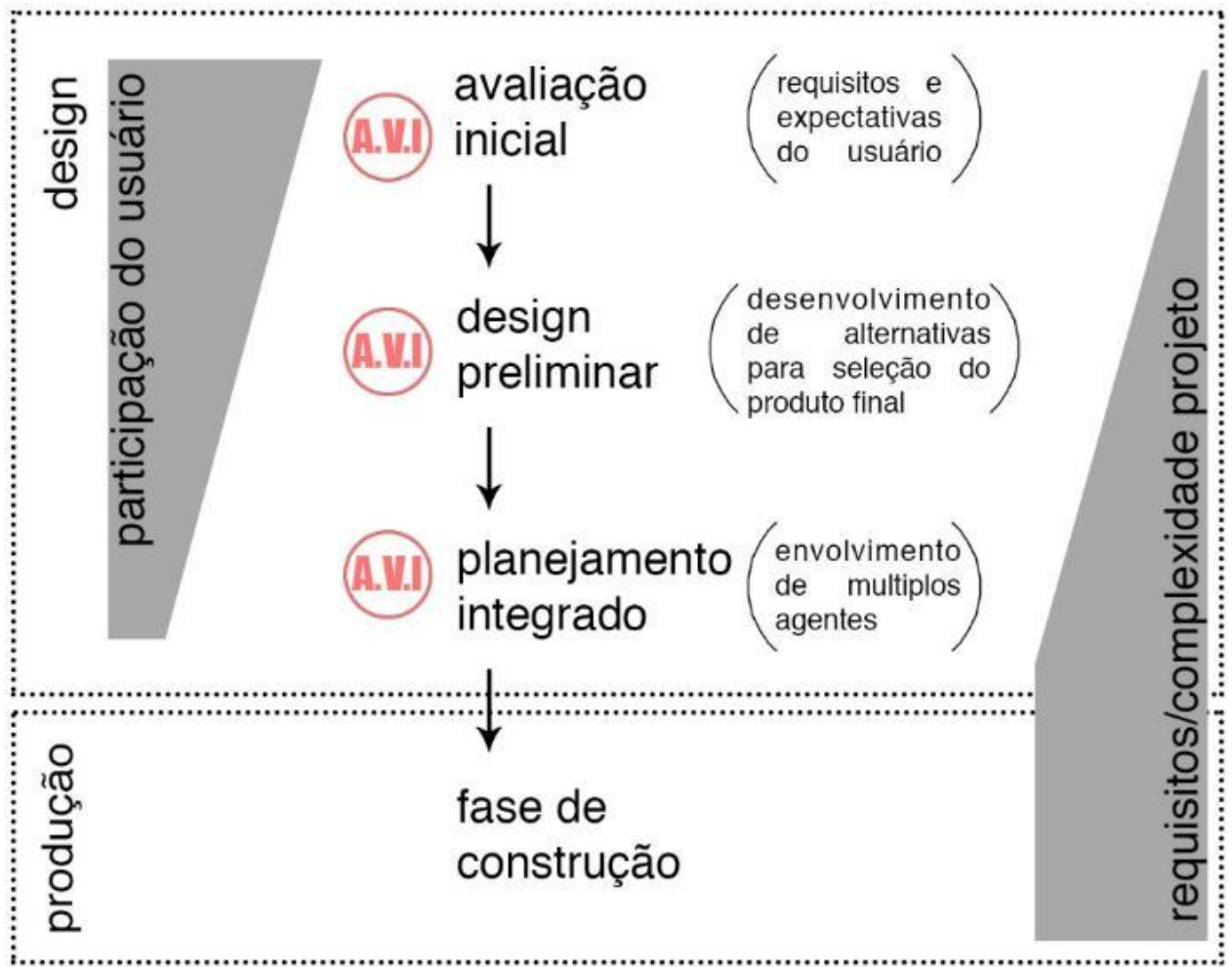

Fonte: adaptado de Bullinger et al. (2015)

Segundo os autores, o uso dos cenários tridimensionais deve facilitar vínculos de comunicação e troca de experiências entre profissionais e não profissionais. Os produtos resultantes do processo de projeto, como plantas baixas, maquetes volumétricas e desenhos esquemáticos, são pouco compreendidos aos olhos do usuário comum.

O próprio usuário final está envolvido desde o início na fase de avaliação básica para definir os requisitos do edifício, que incluem também o layout do volume geométrico. [...] A próxima etapa é o projeto preliminar que converge com o primeiro modelo geométrico do projeto. Aqui a maioria das variantes da forma são criadas pelo arquiteto e avaliadas com o contratante e o usuário 
final. [...] O modelo geométrico do projeto será entregue ao processo de planejamento integrado concomitante, em que diferentes especialistas fazem o planejamento detalhado [...] Quando o modelo deixa o domínio digital para ser construído, não são necessárias mais iterações no protótipo digital de projeto e o processo é encerrado. Esta é a grande diferença entre UCD para produtos de software e edifícios. (BULLINGER et al., 2015, p. 375-376, tradução nossa).

Com isto em mente, a simulação da experiência em um dado edifício e sua interação com o espaço são fundamentais para o usuário basear suas sugestões, participando do processo de projeto. Os autores descrevem a experiência prática deste arcabouço no processo de construção do laboratório de pesquisa em engenharia virtual na Fraunhofer IAO, onde os participantes utilizam-se da tecnologia da realidade virtual para avaliar desde a implantação no terreno até simulações térmicas (FIG.22).

Figura 22 - uso de ambientes virtuais imersivos durante experimento prático
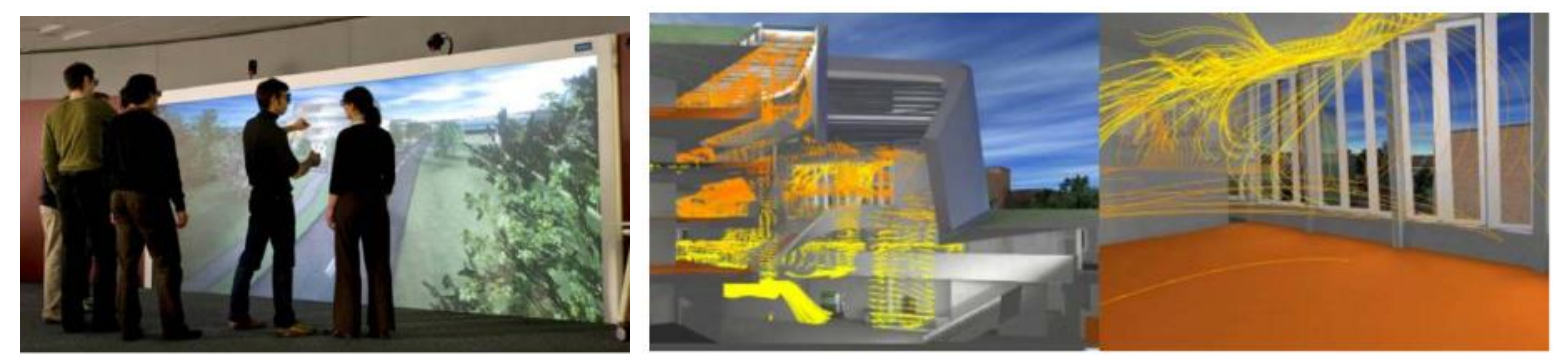

Fonte: Bullinger et al. (2015)

Em iluminação, o projeto é normalmente descrito através de desenhos esquemáticos, imagens digitais ou fotografias, onde o usuário possui pouca capacidade de interação. Também são criados modelos em escala real (1:1) ou reduzida, reproduzindo espaços tridimensionalmente, onde o usuário tem a possibilidade de interagir com o ambiente iluminado. Entretanto, o alto custo da criação destes espaços inviabiliza sua execução e uma alternativa a este problema são os ambientes virtuais imersivos. Todas estas formas de apresentação e representação estão contempladas no próximo capítulo.

Sendo assim, a presente pesquisa se insere no contexto do design centrado no usuário justamente na etapa da avaliação das alternativas de design. Ao serem traduzidos em projeto as necessidades e expectativas dos usuários em um espaço urbano, serão realizados experimentos visando compreender a percepção dos usuários inseridos nestes ambientes, cujos resultados trarão novas informações a respeito do processo, a fim de melhorar o produto final. 


\section{CAPÍTULO 2}

Modos de interação/representação do ambiente simulado 
O processo de projeto em iluminação ocorre através de associações mentais das intenções do lighting designer e as possibilidades que a luz pode causar em dado ambiente. Os chamados "efeitos de luz" (SKARLATOU, 2010) - definição de efeitos que são resultado da interação entre a luz e espaço, como por exemplo uplight, downlight, luz difusa, luz indireta - são imaginados pelo projetista, que combina características técnicas como temperatura de cor e brilho em uma composição espacial.

A partir da dualidade entre a técnica e a subjetividade, é comum os profissionais recorrerem a programas específicos de cálculo luminotécnico para verificação do projeto em termos de brilho, contraste, uniformidade, a fim de alcançar níveis adequados ao local (CYPRIANO, 2013). A composição dos efeitos de luz deverá trazer características estéticas, além de encargos psicológicos que causam nos usuários sensações e percepções em dado ambiente. Por não ser a luz uma matéria palpável, sua percepção é complexa, o que dificulta encontrar um meio que represente e comunique as intenções do projeto.

O resultado da iluminação, que perpassa desde a criação de conceitos, referências culturais, ideais e crenças do projetista, necessidades físicas e psicológicas dos usuários até o conhecimento técnico do campo de atuação, é observado em produtos do seu pensamento, como desenhos, conceitos e palavras, que serão organizadas a fim de transmitir da melhor forma ao cliente o que se pretende fazer.

Atualmente, a avaliação dos projetos tem um cariz essencialmente visual, onde a representação dos efeitos de luz e sombra é demonstrada através de recortes em catálogo de fabricantes, fotografias, imagens computadorizadas - privilegiando-se pontos de vista específicos - desenhos a mão, modelos em escala reduzida e escala real (mockups).

Este capítulo visa apresentar um panorama dos modos de representação/interação do ambiente iluminado encontrado na revisão bibliográfica. De acordo com Lau (1972), as técnicas de simulação podem ser divididas em dois tipos: Modelos tridimensionais e bidimensionais, hierarquizados a partir do parâmetro quantidade de informação (FIG. 23). 
Figura 23 - gráficos hierarquia estruturada quanto a disponibilidade de informação existente em cada meio de representação

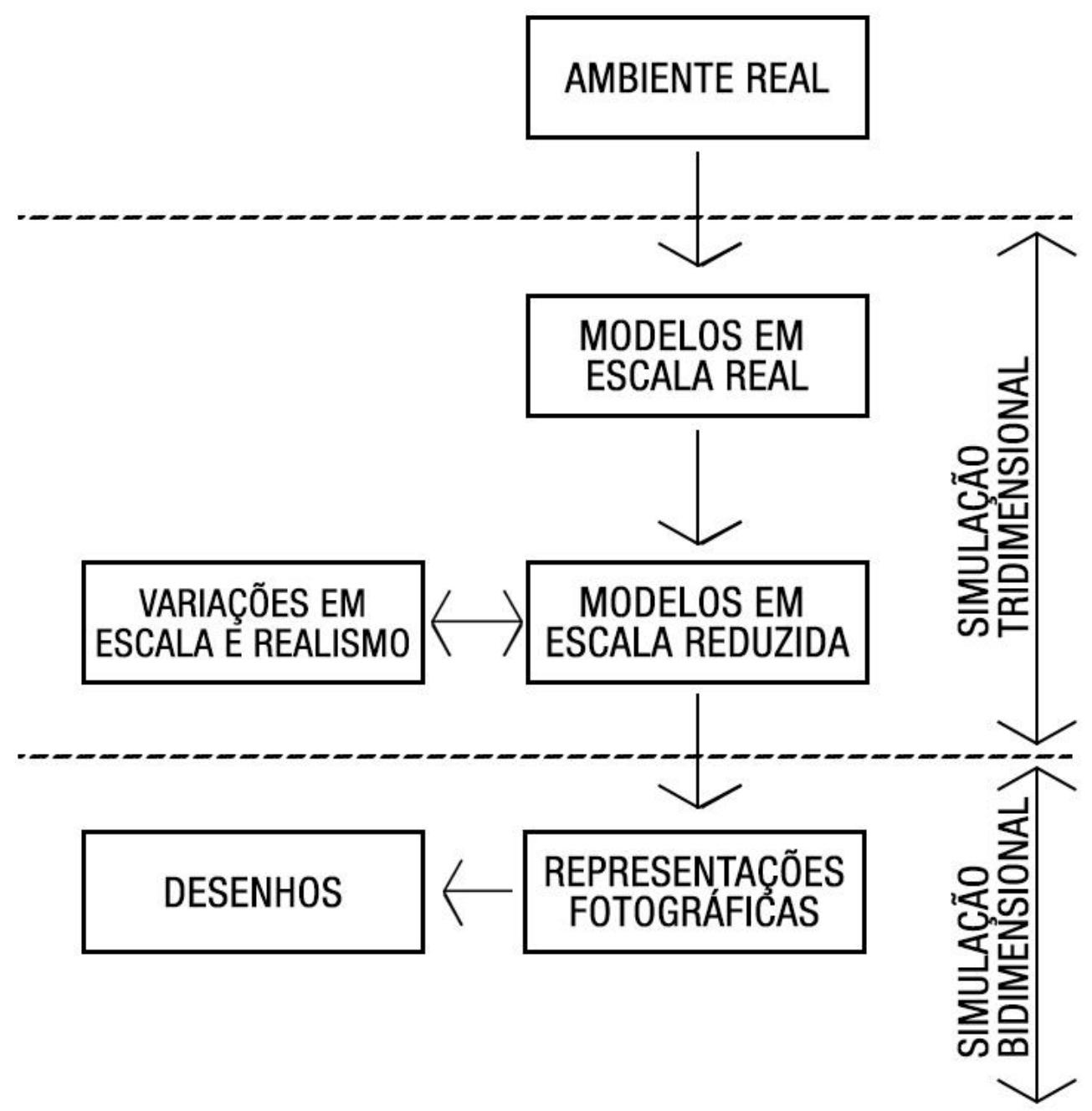

Fonte: Lau (1972), tradução nossa

À medida em que o ambiente real é reproduzido algumas características vão ser perdidas no processo - por exemplo, o contexto de certo elemento arquitetônico com seu entorno - em prol de outros fatores como redução de custos e viabilidade de execução.

Cada passo para baixo representa não só uma redução potencial no custo, mas muitas vezes também uma redução no conteúdo da informação. Por exemplo, tanto a técnica fotográfica como os desenhos custam menos do que modelos em escala reduzida e mockups em tamanho real, mas perdem parte da informação presente no ambiente real, que pode ou não ser representada com sucesso em uma configuração bidimensional. (LAU, 1972, p. 2, tradução nossa). 


\subsection{Mockups e modelos em escala}

A aplicação do mockup é recorrente em áreas que precisam realizar protótipos antes da finalização do produto, como forma de gerar melhores resultados otimização dos gastos, que vão desde a indústria automobilística à arquitetura e urbanismo e iluminação.

Um exemplo é a construção de mockups em ambientes hospitalares (FIG. 24). Segundo Dunston et al. (2011), com vistas a reduzir custos e melhorar o produto final, a inspeção realizada nestes ambientes pelos atores envolvidos no processo - equipe médica, arquitetos e administradores - possibilita identificar aspectos funcionais e qualitativos a serem revistos. Tendo em vista a complexidade de locais como salas de cirurgia ou a repetição de módulos, como quartos de pacientes, erros podem ser identificados antes da real construção. Esta justificativa é aplicável em diversos contextos, desde o planejamento de usinas nucleares à avaliação da performance e métodos construtivos (WHISKER et al., 2003; MAING, 2012).

Figura 24 - exemplos de mockups realizados na área hospitalar
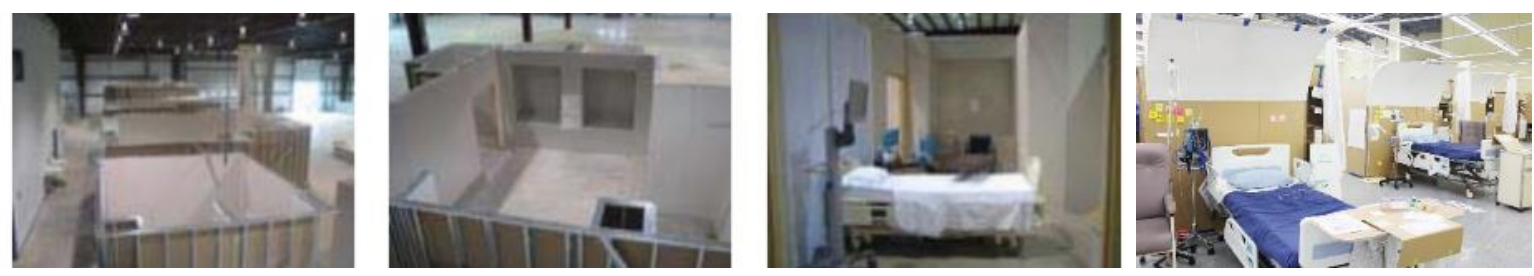

Fonte: Dunston et al. (2011)

Em iluminação, o uso de mockups é recorrente na área acadêmica. Para estudar os efeitos da iluminação no ambiente e na impressão do usuário, o trabalho de Flynn et al. (1973), descrito anteriormente, utiliza-se deste tipo de ambiente. Segundo justificam os autores, o aspecto laboratorial do mockup auxilia nas condições de pesquisa, tendo em vista o controle maior de variáveis que seriam difíceis de serem avaliadas em um ambiente real.

São criadas seis configurações, as quais serão avaliadas por 96 participantes. Os resultados mostram que a iluminação desempenha um papel fundamental na capacidade de modificar características do espaço e impressões do usuário - pode-se reforçar a sensação de relaxamento ao utilizar luz não uniforme - induzindo até variáveis comportamentais. 
Outros estudos envolvendo iluminação - predominantemente pesquisas em espaços internos como escritórios e lojas - fazem uso de mockups (HAWKES; LOE; ROWLANDS, 1979; VEITCH; NEWSHAM, 1998; VOGELS, 2008; VAN ERP, 2008).

Contudo, a avaliação com base em mockups enfrenta obstáculos para sua realização, envolvendo custo de material e instalação, procedimentos burocráticos e logísticos. Caso o ambiente estudado seja um espaço interno, por exemplo quartos de hospitais, a variação do custo de construção pode ser de centenas de milhares de dólares, desde a locação de galpão, equipamentos e construção do espaço e demolição após uso (DUNSTON et al., 2011).

Lam (1992) evidencia esta experiência ao descrever o processo de projeto da iluminação artificial para uma estação de metrô em Washington (FIG. 25), cuja técnica foi utilizada. Destaca que o custo do mockup pode ser justificado de forma a auxiliar também outras disciplinas envolvidas, como ar condicionado, design gráfico, estrutura e acabamentos. Por isso, recomenda cuidados na criação e detalhamento do modelo, tendo em vista a necessidade de refletir a realidade.

Porque todas as percepçães são holísticas, os mockups ainda mais do que
maquetes devem ser realisticamente mobilados, bem como tecnicamente
precisos em detalhes de iluminação. [...] Dois espaços idênticos, com
iluminação idêntica, um vazio e outro completamente mobilado, suscitarão
respostas bastante diferentes dos mesmos observadores. [...] seria
proibitivamente caro, por exemplo, construir uma maquete em escala real de
500 pés de comprimento de uma estação de metrô inteira, de modo que
construímos apenas um comprimento de 16 pés da estação usando os
materiais reais. O mockup foi decorado com um final de um trem real, pórticos
gráficos e outros equipamentos. [...] O uso de espelhos em ambas as
extremidades do mockup teria aumentado tanto o realismo do modelo como
a eficácia da utilização do equipamento, mas este refinamento caro foi
considerado desnecessário uma vez que os clientes foram capazes de avaliar o
efeito global a partir do modelo de escala muito realista. (LAM, 1992, p.92-93,
tradução nossa).

Os modelos em escala são similares aos mockups, ou seja, passíveis de ter variáveis controladas em um experimento laboratorial. Os benefícios do uso de modelos em escala são a facilidade de modificar parâmetros do modelo, tais como dimensões de aberturas para iluminação natural, por exemplo, e custo menor se comparado com modelos em escala real. Cauwerts (2013) relata a vantagem deste tipo de técnica para estudos de iluminação natural, pois a variabilidade das condições meteorológicas do ambiente real pode distorcer os resultados. 
Figura 25 - À direita, imagens do mockup do metrô em Washington. A esquerda, quarto de estudos, objeto de pesquisa em Lau (1972)
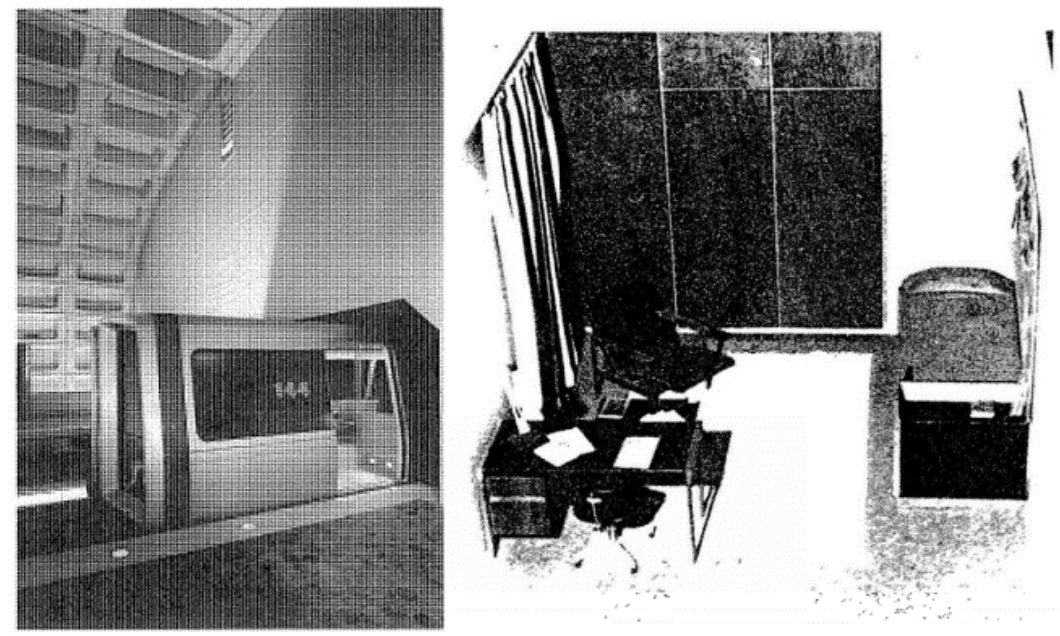

Fonte: Lam (1992) e Lau (1972)

O trabalho mais emblemático em estudos de iluminação diz respeito ao estudo realizado por Lau (1972) na investigação da validação de modelos em escala reduzida para avaliar percepções dos usuários. Na pesquisa, o autor se propõe a comparar os modelos em escala real (full-size mockup) e em escala 1:6 (FIG. 25) a fim de verificar se as impressões do usuário - respondidas através de questionários utilizando-se o conceito de escuridão (gloom) e prazer (pleasure) - são semelhantes entre si.

Para tanto, explora vários métodos em quatro experimentos - comparações entre os modelos, preferencias de cenários, avaliações diretas através de escalas semânticas - onde é possível estabelecer relações de semelhança e diferença entre os resultados dos participantes, além de possíveis distorções existentes principalmente no modelo em escala reduzida. Entretanto, algumas ressalvas são feitas pelo autor, sendo a primeira delas a escolha da escala adequada para representação do espaço.

Baseado nos limites de acomodação e convergência da visão humana, o autor sugere escalas entre 1:6 até o mínimo 1:20, pois além destas limitações, a experiência visual do espaço deve ser vista de dentro do modelo. O interior do modelo e seu nível de fidelidade deve ser definido de acordo com os objetivos do estudo, pois um ambiente altamente detalhado não deve ser menos custoso que um mockup. Além disto, o aspecto de miniaturização tende a desviar a atenção dos participantes (o modelo em escala reduzida foi percebido como mais bonito que o mockup). Outra ressalva do autor diz respeito a navegação pelo espaço. Em um dos experimentos esta capacidade foi 
relevante na comparação entre modelos, necessitando maiores estudos para validação. De maneira geral, os resultados mostraram correspondência entre ambos os modelos, ou seja, as percepções eram similares.

Outros estudos mais recentes utilizando-se de modelos em escala reduzida para avaliação de iluminação - artificial ou natural - também foram encontrados (LINDH, 2012; DUBOIS; CANTIN; JOHNSEN, 2007; ARSENAULT; HÉBERT; DUBOIS, 2012). Particularmente, o trabalho de Lindh investiga as impressões espaciais causadas pela iluminação artificial. Um modelo em 1:7.5 com 12 configurações luminosas foram criadas, visando compreender a influência do espaço iluminado na percepção de tamanho e enclausuramento sob o ponto de vista fenomenológico (FIG. 26).

Figura 26 - Modelo em escala 1:7.5 com diferentes posições de luminárias
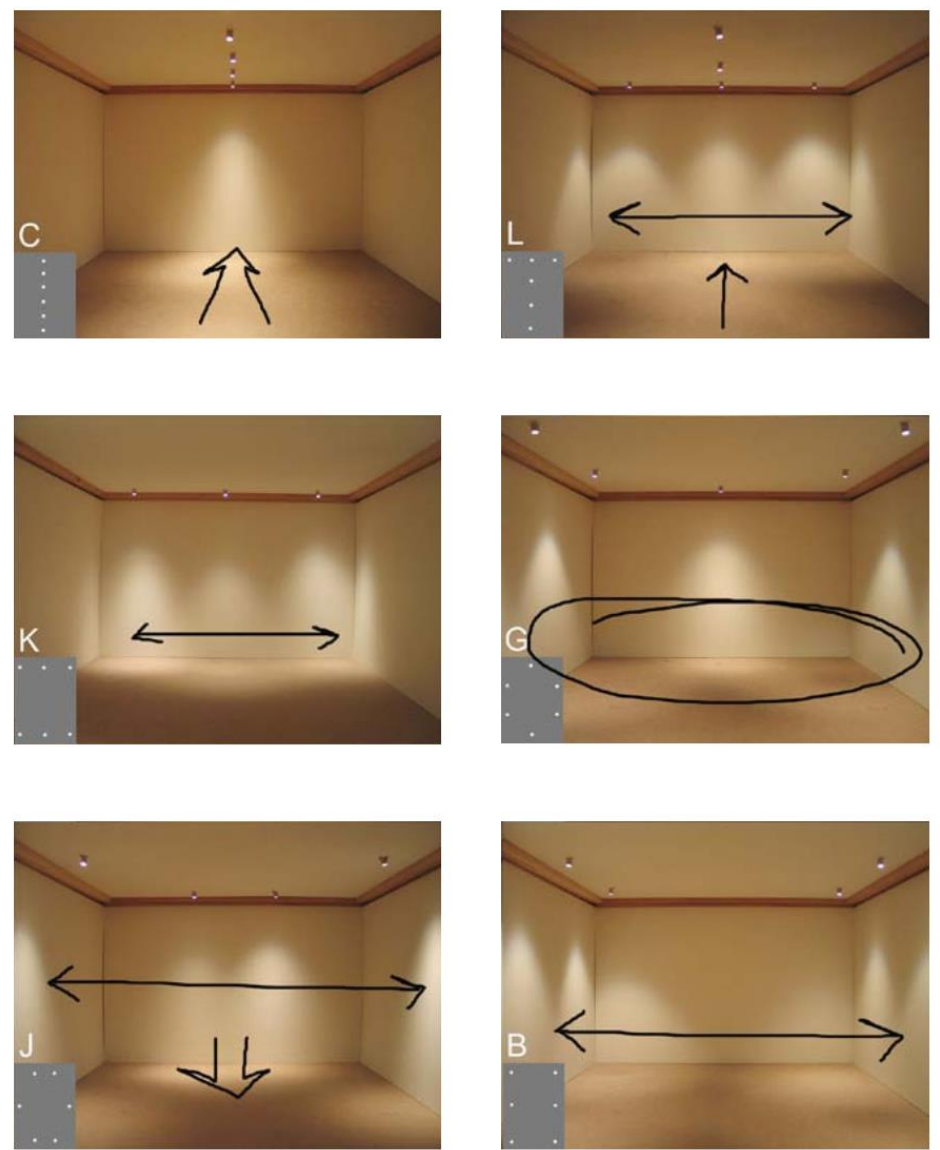

Fonte: Lindh (2012)

Os resultados demonstram que a distribuição da luz influencia a percepção de forma do espaço: "As zonas de luz composta e separada podem aumentar a profundidade ou largura, dependendo de como esses padrões de luz são lidos juntos no contexto espacial. " (LINDH, 2012, p. 84, tradução nossa). 


\subsection{Fotografias e imagens digitais}

Trabalhar com fotografias tendem a reduzir custos e melhorar a eficiência de um dado projeto ou pesquisa. Lau (1972) evidencia que a representação em duas dimensões possui desvantagens no sentido da perda de informações presentes no ambiente real, como a capacidade de navegação em dado espaço. Apesar disto, pesquisas procuraram comprovar se a reprodução de ambientes em fotografias produz resultados semelhantes ao espaço real.

Em psicologia ambiental, os estudos de Kaplan utilizam fotografias de cenários naturais e urbanos visando compreender o conceito de preferência, complexidade, coerência e mistério (KAPLAN; KAPLAN; WENDT, 1972; KAPLAN, 1985; KAPLAN, 1987) a partir da quantidade de informação existente na paisagem estudada e questões relacionadas ao processo de evolução do ser humano. A partir da análise dos resultados foi possível criar a teoria da preferência ambiental, utilizada desde então como uma das formas possíveis de sistematizar respostas emocionais dos usuários em ambientes urbanos e naturais.

Em iluminação, os estudos subsequentes de Flynn e sua equipe resultaram em experiências sobre o uso de fotografias como substitutos de modelos em escala real (mockup), para avaliação da influência da iluminação na impressão do usuário em espaços iluminados. Hendrick et al. (1977) replicam o mesmo experimento do estudo inicial (FLYNN et al., 1972), desta vez utilizando fotografias, visando dois objetivos.

O primeiro seria o uso de imagens ao invés de espaços reais para melhoria da eficiência e redução de custos na coleta de dados. O segundo refere-se à sistematização teórica sobre as diferenças e semelhanças na percepção do usuário, considerando o espaço tridimensional e sua reprodução bidimensional.

Para tanto, fotografias das seis configurações de iluminação do ambiente inicialmente estudado foram escolhidas como estímulo, e os participantes avaliaram o espaço de duas maneiras em dois experimentos, através de escalas semânticas e comparações entre pares. Participaram 185 alunos no primeiro experimento e 45 alunos no segundo.

Quando os alunos foram organizados para o experimento, o estudo foi explicado brevemente para eles. Todas os seis slides foram então mostrados durante cerca de 10 segundos cada para fins de familiarização. Então, cada slide foi apresentado individualmente; os alunos observaram o slide por 30 
segundos e, em seguida, avaliou-o em 34 escalas de diferencial semântica. O slide continuou ligado até que todos os alunos completaram as avaliações (geralmente cerca de cinco minutos, então o próximo slide era apresentado e avaliado). [...] $\mathrm{O}$ ambiente estava completamente escuro durante o período de observação de 30 segundos e apenas luz suficiente foi admitida no espaço durante o período de avaliação para que os alunos pudessem ver seus formulários de avaliação. (HENDRICK et al., 1977, p.496-497, tradução nossa).

As fotografias eram apresentadas por slides uma a uma em uma sala escura e após procedimentos estatísticos dos dados (principal component analysis - PCA), os fatores encontrados se mostraram similares ao estudo inicial de Flynn et al. (1973).

O segundo grupo de estudantes realizava 38 comparações entre pares de imagens apresentadas, variando em níveis de mudanças (o para "nenhuma mudança" e 10 representando "mudança muito grande"). Após procedimentos estatísticos (INDSCAL), apenas um fator foi obtido, claro/escuro, em detrimento de três fatores encontrados no estudo inicial de Flynn - claro/escuro, periférica/direta e uniforme/não uniforme - mostrando-se inadequado este método de análise de dados.

Como conclusão, os autores observaram que existem semelhanças na reprodução do conteúdo tridimensional para imagens bidimensionais, utilizando-se o método de escalas semânticas diferenciais para analisar impressões do espaço, e recomendaram mais estudos para validação dos dados. Mais tarde, ainda neste contexto, os trabalhos de Ünver (2009), Cortés e Morales (2010) e Casciani e Rossi (2014) tiveram como suporte teórico o trabalho de Hendrick et al. (1977), ao usar imagens fotográficas no processo de avaliação de percepções dos usuários em espaços urbanos noturnos iluminados (FIG. 27).

Figura 27 - variações de iluminação no cenário urbano noturno

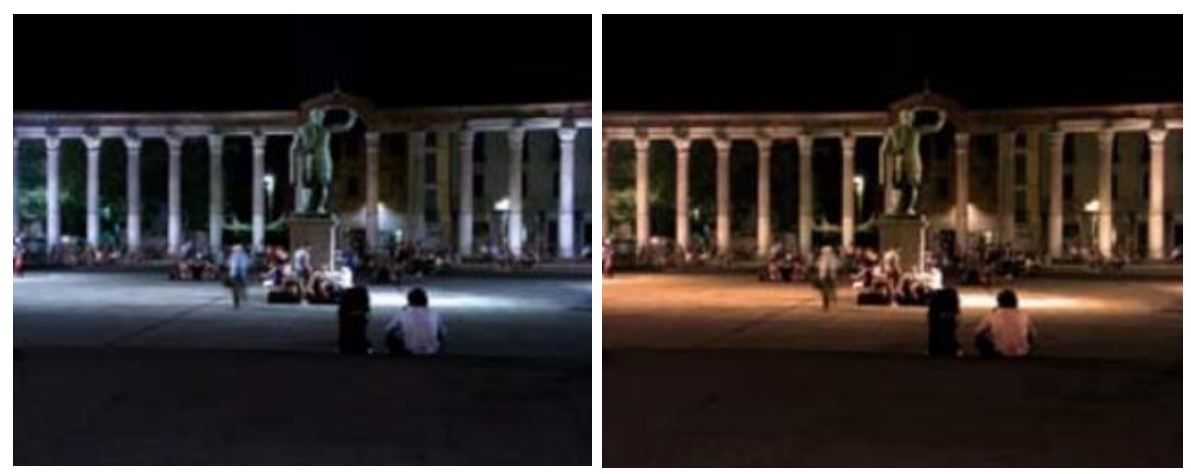

Fonte: Casciani e Rossi (2014) 
As imagens são parte integrante do processo de projeto em iluminação. Com o advento dos computadores e evolução na capacidade gráfica provenientes da indústria do cinema e jogos (ZARZYCKI, 2011), todas as áreas criativas se beneficiaram, à medida em que a qualidade da representação de materiais, efeitos e iluminação se tornam cada vez mais realísticas.

Essas representações são particularmente populares no processo arquitetônico para julgar as qualidades estéticas e a adequação de espaços projetados, além de comunicar com o cliente. Este tipo de imagem também é muito interessante para a avaliação subjetiva de ambientes luminosos, devido a uma grande diversidade de cenas que podem ser criadas. Além disso, ao contrário das fotografias, a renderização virtual não requer nem edifícios reais, nem maquetes ou modelos em escala. (CAUWERTS, 2013, p. 39, tradução nossa).

Ochoa, Aires e Hensen (2012) fazem uma revisão bibliográfica do estado da arte em simulações computacionais em iluminação e dividem em dois tipos de áreas existentes: visualizações fotorealísticas e visualizações físicas (também chamadas de preditivas).

A diferença entre os dois são simples de entender, de forma que o primeiro produz cenas a partir da percepção visual do ambiente real, sem necessariamente utilizar dados fotométricos e medições exatas. São imagens artísticas, cuja prioridade é a percepção visual e julgamentos estéticos. O segundo tipo lida com representações precisas e apuradas, baseadas nas leis e condições da física, utilizando-se de algoritmos capazes de gerar cenários virtuais tão reais e mensuráveis quanto no ambiente físico (FIG. 28).

Figura 28 - Diferentes algoritmos desempenham cálculo de iluminação preciso. Os mais utilizados são raytracing (a), radiosity (b) e photon map (c).

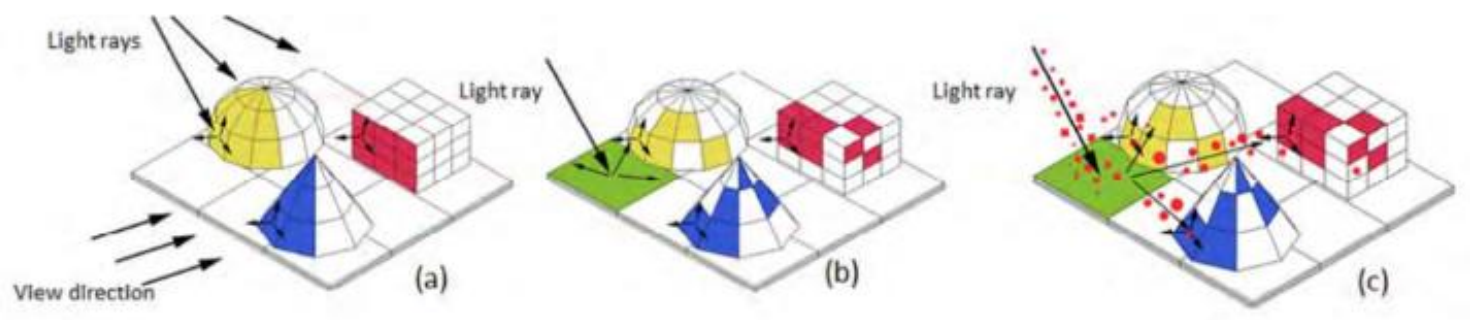

Fonte: Ochoa, Aires e Hensen (2012) 
Ambos coexistem entre si, e a necessidade do uso de cada uma delas dependerá dos objetivos do estudo, pois o gerenciamento de dados e produção de resultados terão focos diferentes. Por exemplo, para avaliações estéticas talvez não seja necessário o cálculo, mas sim o efeito causado.

Em contrapartida, ao avaliar a influência da iluminação no desempenho do usuário em escritórios, a necessidade de medições fotométricas torna-se inevitável, pois há aspectos importantes como ofuscamento e luminância, que podem ser estudadas a partir de imagens fisicamente baseadas. $\mathrm{O}$ artigo das autoras busca focar neste tipo de visualização, ao demonstrar ferramentas de simulação mais recorrentes, seus algoritmos utilizados e os estudos de validação desde início da década de 1990.

Uma série de trabalhos em que as visualizações digitais são parte fundamental da pesquisa são reunidas em Cauwerts (2013), cujo conteúdo são estudos sobre validações de imagens digitais e cenários reais, e também avaliações da percepção do usuário. Do ponto de vista da validação, Mahdavi e Eissa (2002) comparam dois grupos, o primeiro inserido em configurações de iluminação real e o outro visualizando a versão digital dos mesmos cenários. Em especial, questionam o uso de imagens estáticas em detrimento da dinâmica existente no espaço real.

O trabalho de Totir (2007) procura continuar os estudos de Flynn et al. (1973), Hendrick et al. (1977) e Flynn et al. (1979), a fim de investigar a validade do uso de imagens digitais de um espaço interno contendo três cenários de iluminação, a partir das dimensões encontradas pelos autores na década de 1970.

Os resultados indicam que apenas alguns fatores são semelhantes ao ambiente real e possíveis razões para as inconsistências encontradas devem ser relacionadas ao caráter bidimensional das imagens, tornando a imersão do usuário artificial. A autora relata que devido à complexidade do sistema visual, futuros trabalhos devem ser feitos a fim de investigar o processo de percepção e apresentação de imagens tridimensionais geradas por computador (FIG. 29). 
Figura 29 - Diferentes Cenários gerados por computador.
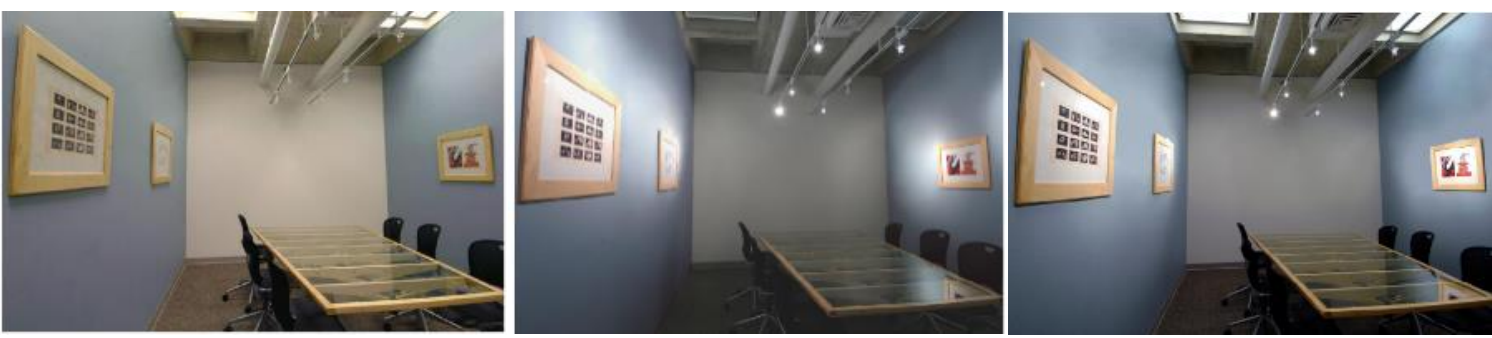

Fonte: Totir (2007)

Outras pesquisas utilizam imagens digitais para avaliar a qualidade dos ambientes a partir da preferência e percepção dos usuários. Os espaços hoteleiros, particularmente os quartos, são objeto de estudo de Fernandez (2012), que utiliza imagens digitais contendo opções de iluminação para identificar parâmetros relacionados a preferência dos usuários a partir de dois contextos: estéticos e situacionais. O primeiro diz respeito às características da luz e luminária, sua forma, cor e posição, enquanto o segundo busca identificar qual a melhor configuração luminosa para situações de chegada ao quarto e ao assistir tv (FIG. 30).

Figura 30 - Imagens digitais com configurações de iluminação diferentes.
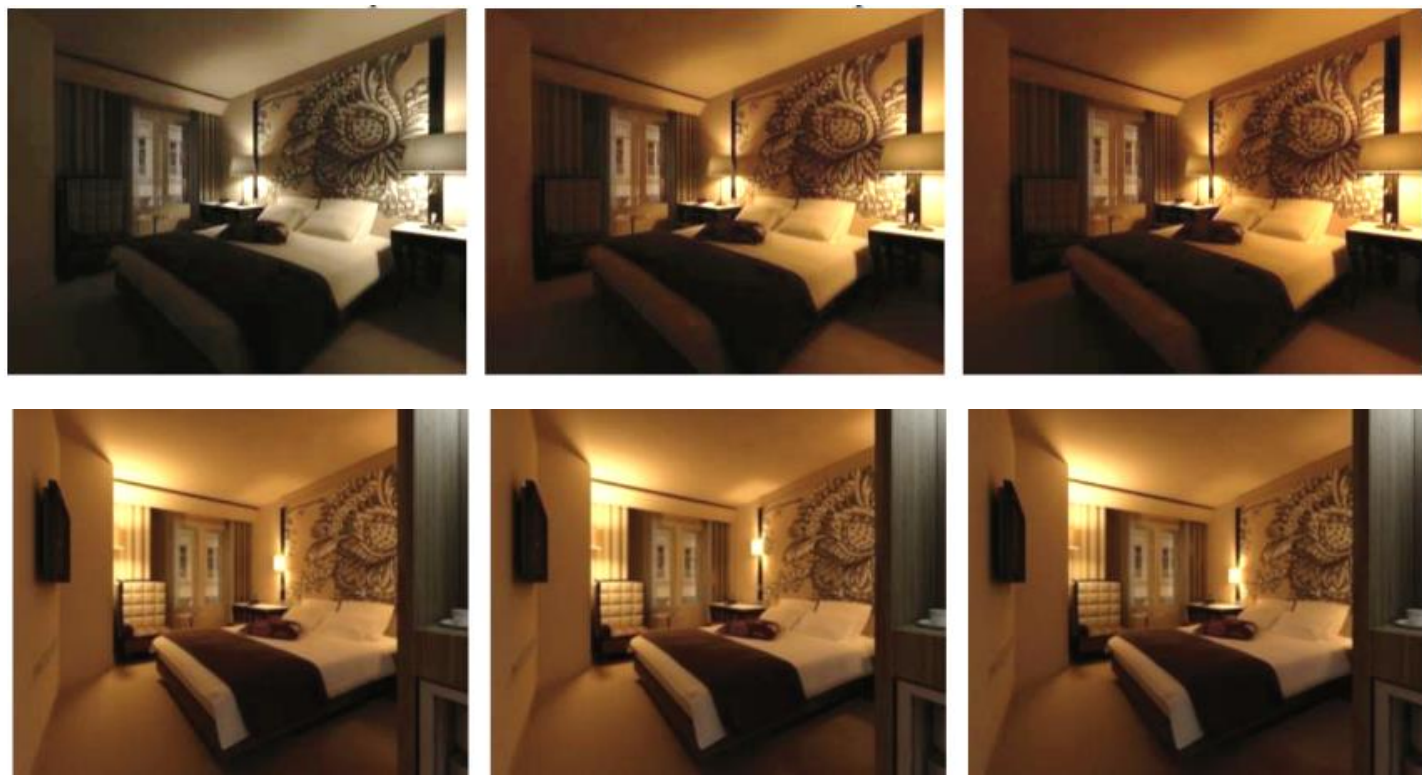

Fonte: Fernandez (2012)

De maneira geral, os resultados promoveram uma possível melhoria nas soluções em iluminação de um hotel ao mostrar que as variáveis estudadas influenciam na sensação de conforto do hóspede. A autora, entretanto, recomenda maiores estudos 
para a definição de parâmetros confiáveis à medida em que as condições de pesquisas foram limitadas pelo design de um quarto padrão de uma rede de hotéis.

Já Salters e Seuntiens (2011) investigam o uso de imagens computadorizadas na percepção do usuário a partir do conceito de atmosfera de Vogels (2008). Para tanto, os autores comparam o ambiente real genérico com sua reprodução digital a fim de descobrir diferenças e semelhanças na percepção da iluminação. Demonstram que as dimensões estudadas pelos autores resultaram em efeitos semelhantes na comparação entre o mundo real e virtual, implicando na possibilidade de uso das simulações computacionais (no caso dos autores, apresentados em uma tela LCD ou impressos em papel) para avaliações da atmosfera do ambiente iluminado (FIG. 31).

Figura 31 - Ambiente genérico utilizado para avaliação da atmosfera em ambientes virtuais (A) e reais (B).
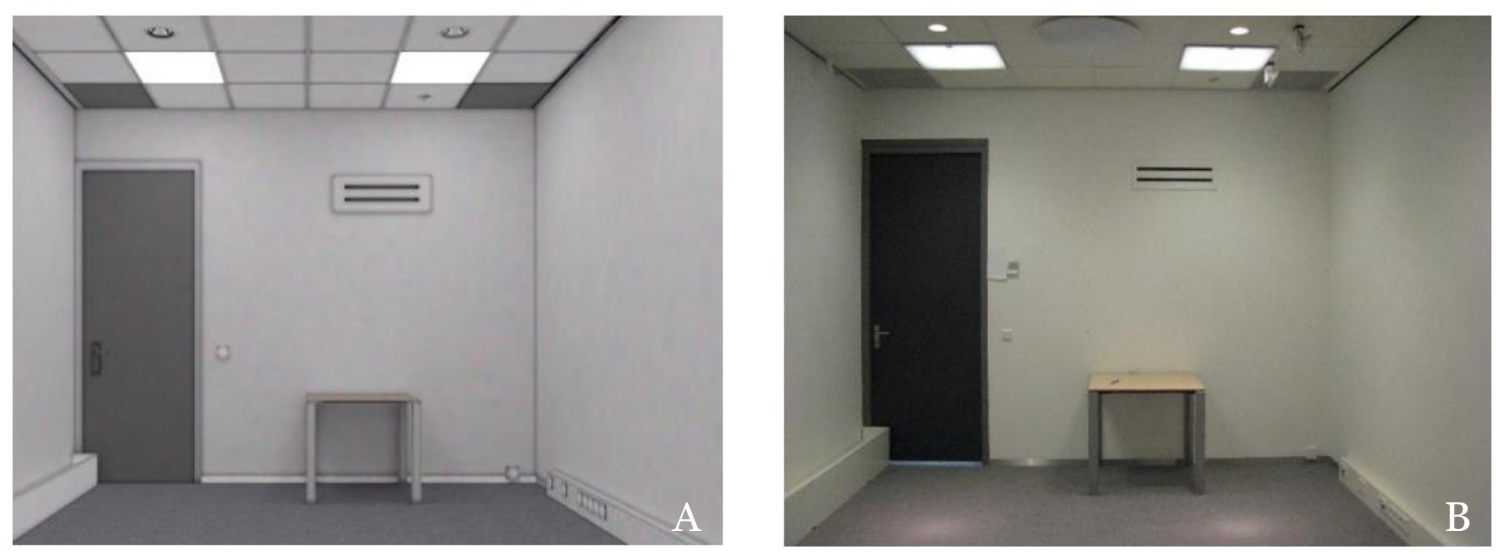

Fonte: Salters e Seuntiens (2011)

O meio no qual as imagens digitais são apresentadas podem influenciar a percepção do usuário no processo de avaliação de cenários, sejam criados via computação gráfica ou reproduções do ambiente real. Enquanto Hendrick et al. (1977) utilizam-se slides projetados em uma sala escura, Fernandez (2012) lança mão de uma tela de 20 polegadas para apresentação das opções de iluminação de um quarto de hotel, assim como Rankel (2014), que procede um questionário na web contendo imagens de cenários urbanos noturnos. Ünver (2009) já desenvolve a pesquisa a partir de questionários impressos, os quais contém 20 imagens de setores urbanos - edifícios, praças e parques, por exemplo - da cidade de Ankara, na Turquia. 
A imagem pode ser apresentada de diversas maneiras, desde trechos estáticos ou dinâmicos, como filmes. Pode ser apreciada através de cores ou em preto e branco. O aparato de apresentação perpassa desde o papel até as telas de computador, e através de ambientes imersivos, como a caverna digital (Cave Automatic Virtual Environment - CAVE) ou óculos/capacete de realidade virtual (head mounted display - HMD), onde fotografias panorâmicas e mundos virtuais vem sendo utilizados a fim de aumentar o realismo e deslocar o usuário do espaço real para o virtual.

\subsection{Ambientes virtuais imersivos}

Os cenários virtuais são representações sintéticas da realidade ou criações da imaginação viabilizados pela tecnologia computacional, cujas pesquisas datam desde 1960 e vem permitindo a troca de informações entre o sujeito e o meio virtual em tempo real, principalmente por meio de estímulos visuais (TORI; KIRNER, 2006). Como destaca Cauwerts (2013), a ilusão de profundidade através da estereoscopia é uma das características deste tipo de tecnologia.

\footnotetext{
A estereoscopia, também chamada de imagem 3D e desenvolvida nos anos 20, torna possível aumentar a ilusão de profundidade na criação da terceira dimensão em um meio bidimensional. Este método é baseado no fato de que os seres humanos têm visão binocular e cada olho não recebem informações idênticas. Assim, são formadas duas imagens ligeiramente diferentes nas retinas dos olhos, e essas diferenças participam da apreciação da profundidade e da avaliação das distâncias. (CAUWERTS, 2013, p.43, tradução nossa).
}

O meio de reprodução e interação nestes ambientes virtuais se dá através da realidade virtual (RV, ou Virtual Reality - VR). De acordo com Tori e Kirner (2006), a realidade virtual pode ser classificada em imersiva e não-imersiva. A diferença primordial está na capacidade de provocar a sensação de presença ou imersão dentro do mundo virtual. A versão não-imersiva é reproduzida através de projeção em um aparato, normalmente um monitor, transportando parcialmente o usuário para o mundo virtual, de forma que ao desviar o olhar para fora da tela, perde-se a referência do mundo virtual. Já a opção da realidade imersiva se vale de dispositivos multissensoriais - como óculos, controles, luvas ou as projeções em parede, teto e piso da CAVE - captando os movimentos do usuário, visando a interação com o mundo virtual (FIG. 32). 
Figura 32 - Meios de reprodução e interação em ambientes virtuais, como o CAVE (A), versão não-imersiva (B) e versão imersiva (C)
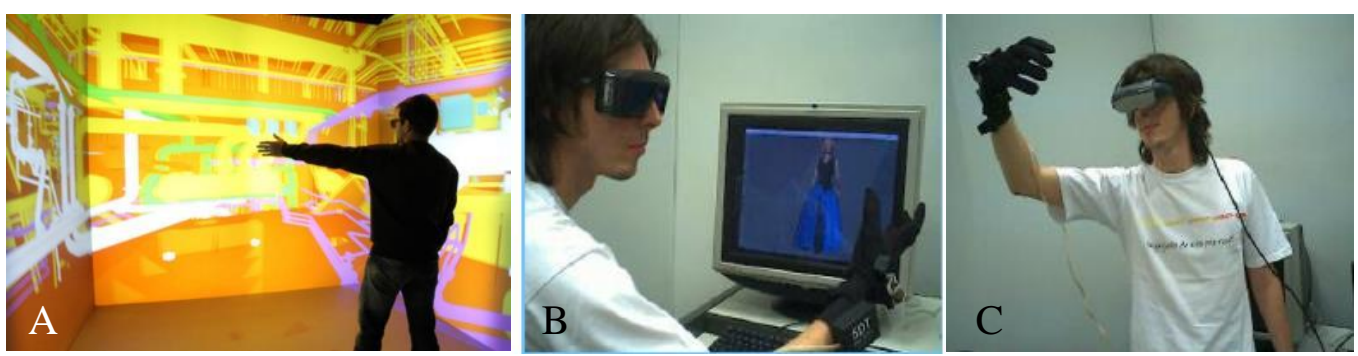

Fonte: Tori e Kirner (2006); google images

Os autores recomendam recursos adicionais para aumentar o realismo e melhorar a condição de imersão, como som espacial, dispositivos de navegação, além de estímulos ao tato, calor, vento. Cabe notar o trabalho de Luigi et al. (2015), que busca investigar o uso da sonorização nos ambientes virtuais ao compará-lo com o cenário real de uma cidade na Itália (FIG. 33). Com vistas a verificar a validade da realidade virtual imersiva, os resultados não diferiram no sentido da qualidade percebida (características visuais e acústicas do ambiente real e simulado) de ambos os espaços. De acordo com os autores, os efeitos do estímulo sonoro e visual na avaliação devem ser considerados juntos, e não separados - os dados suportam a ideia de que os efeitos subjetivos visuais e sonoros podem se transformar se considerados como tal - devido à percepção natural multissensorial do ser humano.

Figura 33 - Diagrama mostrando os procedimentos utilizados para a captação de áudio e reprodução em ambientes virtual imersivo.

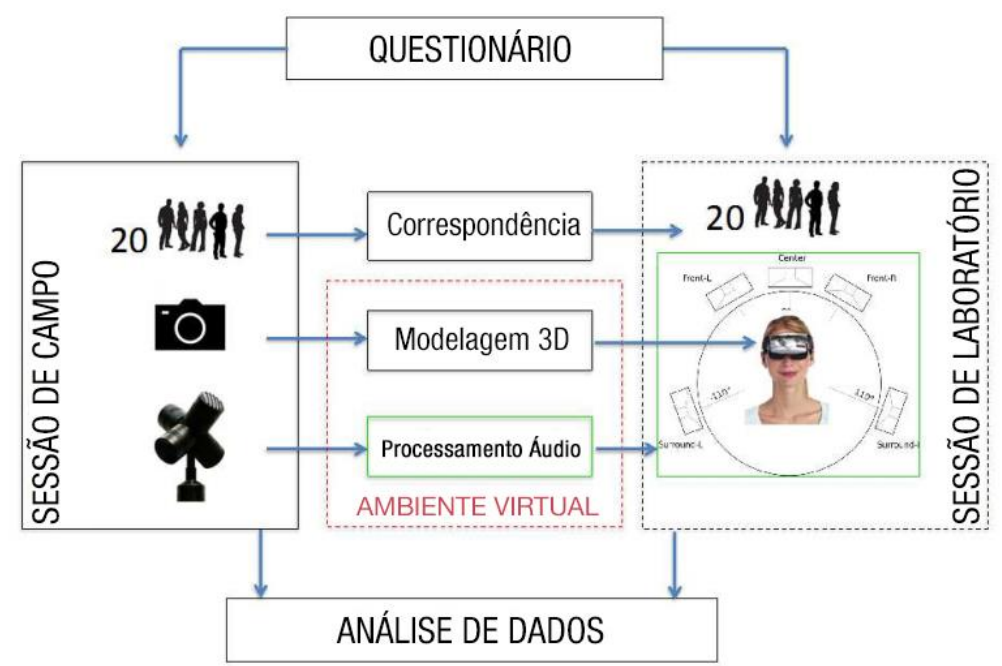

Fonte: LUIGI et al. (2015) 
Assim, a ferramenta permite a apropriação do espaço tridimensional e oferece maior controle sobre variáveis, as quais podem ser difíceis de serem controladas em ambientes reais, como a criação de cenário de luz em espaço público ou estudos de iluminação natural onde as condições meteorológicas podem distorcer os resultados. Kuliga et al. (2015) relatam a possibilidade de modificações e simulações de design de edifícios como um dos benefícios da ferramenta, ao auxiliar numa avaliação préocupação.

Embora seja difícil alterar substancialmente a configuração espacial em um edifício existente, o efeito de vários redesenhos no comportamento dos usuários pode ser simulado de forma eficiente na VR sem interromper o uso contínuo do edifício. [...] A realidade virtual pode suportar 'avaliação préocupação', uma avaliação ambiental da perspectiva dos usuários antes da ocupação de um edifício. (KULINGA et al., 2015, p. 363, tradução nossa).

Os ambientes virtuais fazem parte do escopo da arquitetura desde os anos 1990, através de estudos técnicos como processamento de dados e visualizações realísticas de superfícies em edifícios (BULLINGER et al., 2010).

Com o avanço da capacidade gráfica dos computadores pessoais e da indústria do vídeo game, novas funcionalidades e cenários mais sofisticados puderam ser criados, possibilitando pesquisas em campos específicos que exercem influência sobre a arquitetura, como melhorias em sombra, luz e vegetação (MANTLER et al., 2003 apud BULLINGER et al., 2010), além da interação e visualização de projetos em BIM (Building Information Modelling) pelos projetistas (YAN; CULP; GRAG, 2011).

Assim, permite a criação de modelos digitais para aplicações diversas, como avaliação da linha de montagem de um automóvel (SÁ; ZACHMANN, 1999), projeto e ensino de arquitetura (DUNSTON et al., 2011; ÂNGULO; VELASCO, 2014), e também como forma a auxiliar o processo de projeto em paisagismo e a participação de agentes importantes - arquiteto, público, administradores - no redesenho de uma praça (BALL; CAPANNI; WATT, 2007; DRETTAKIS et al., 2007). Outros trabalhos procuram validar o uso da realidade virtual ao compará-los com o ambiente real (FIG. 34), como exposto em Westerdahl et al. (2006) e Kuliga et al. (2015). 
Figura 34 - Ambientes virtuais imersivos utilizados para ensino de arquitetura (A, B), exploração do espaço (C) e avaliação de redesenho em projeto (D).
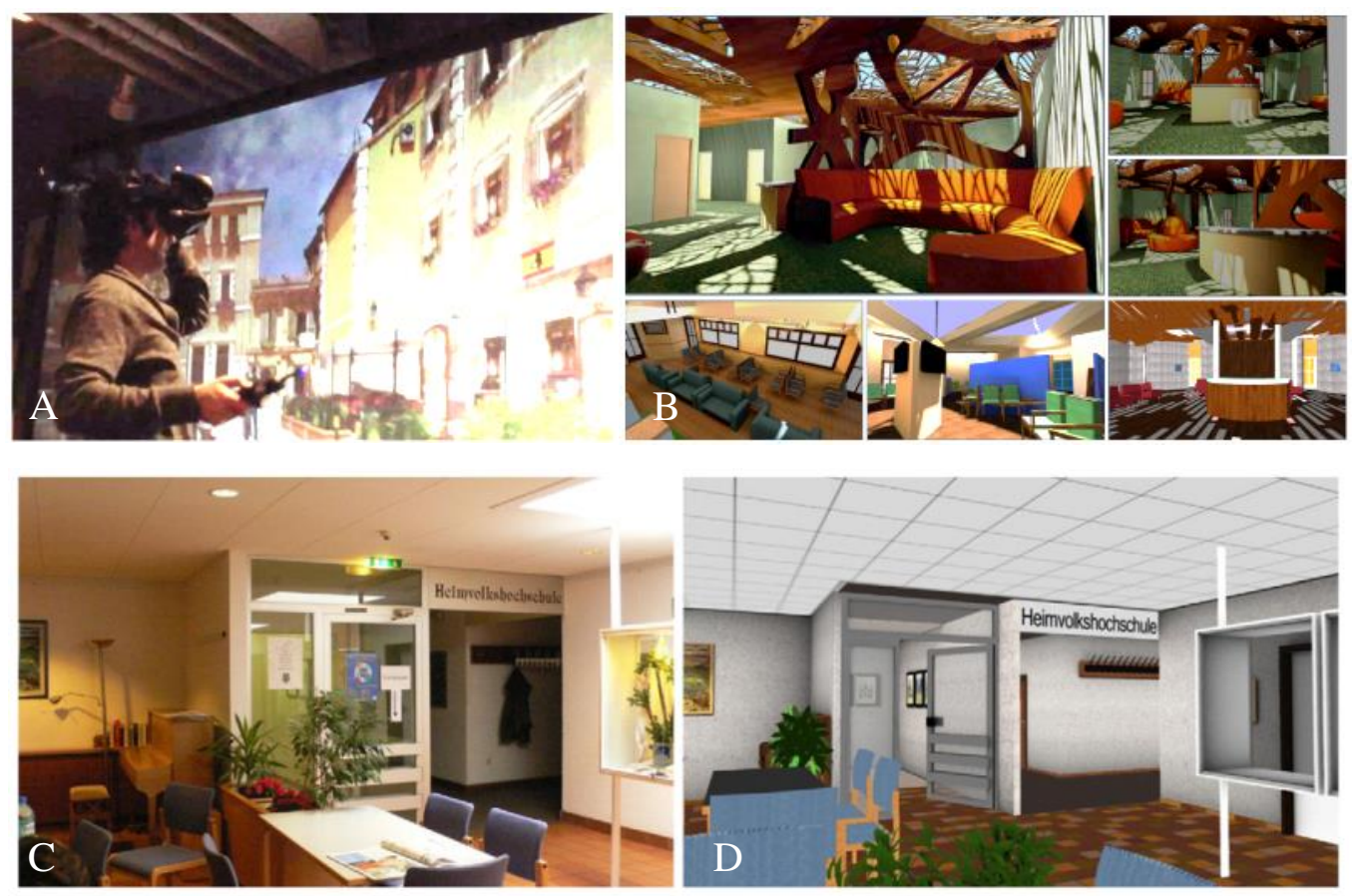

Fonte: Ângulo e Velasco (2014); Kuliga et al. (2015)

O trabalho de Drettakis et al. (2007) utiliza a RV como suporte no processo e tomada de decisão por parte dos atores envolvidos no projeto de intervenção na Praça Garibaldi, em Nice, França (FIG. 35). O VLT (Veículo Leve sobre Trilhos) atravessara sua extensão, e os arquitetos propuseram alternativas de desenho da praça - como a "Place d'armes" - a partir da manipulação de objetos como árvores, bancos e sombras. A plataforma de RV foi levada a reuniões importantes, como reunião na prefeitura, brainstorming entre arquitetos e a apresentação pública do projeto (as variações da Praça Garibaldi eram realizadas com a ajuda da ferramenta).

Figura 35 - Processo de projeto de praça utilizando-se ambientes virtuais imersivos
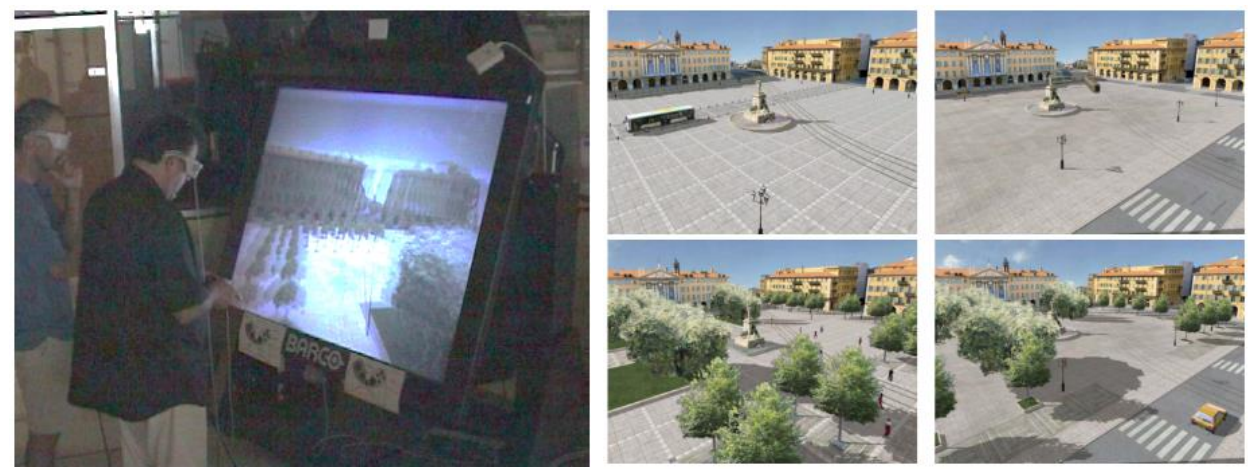

Fonte: Drettakis et al. (2007) 
Em iluminação, a realidade virtual é utilizada para analisar a preferência de usuários quanto ao controle lumínico em ambiente de escritório (HEYDARIAN et al., 2015a, 2015b, 2015c) e também como suporte de criação de cenários noturnos no Japão (FUKUDA et al., 2001).

Os trabalhos de Heydarian et al. (2015) buscam investigar o uso de ambientes virtuais imersivos na relação entre performance e iluminação em ambientes de escritórios, desde seu processo de validação - ao comparar um espaço real com o seu correspondente virtual - até estudos de preferencias de iluminação natural e artificial (FIG. 36). Segundo os autores, a realidade virtual pode influenciar decisões projetuais à medida que passa por uma avaliação ocupacional anterior ao edifício completado. A geometria e disposição de elementos arquitetônicos no espaço podem receber avaliações já nos primeiros estudos, de forma a melhorar o desempenho e design final do ambiente pensado nos usuários.

Figura 36 - Modelo da sala objeto de estudo. Ao lado, os participantes utilizando o aparato técnico
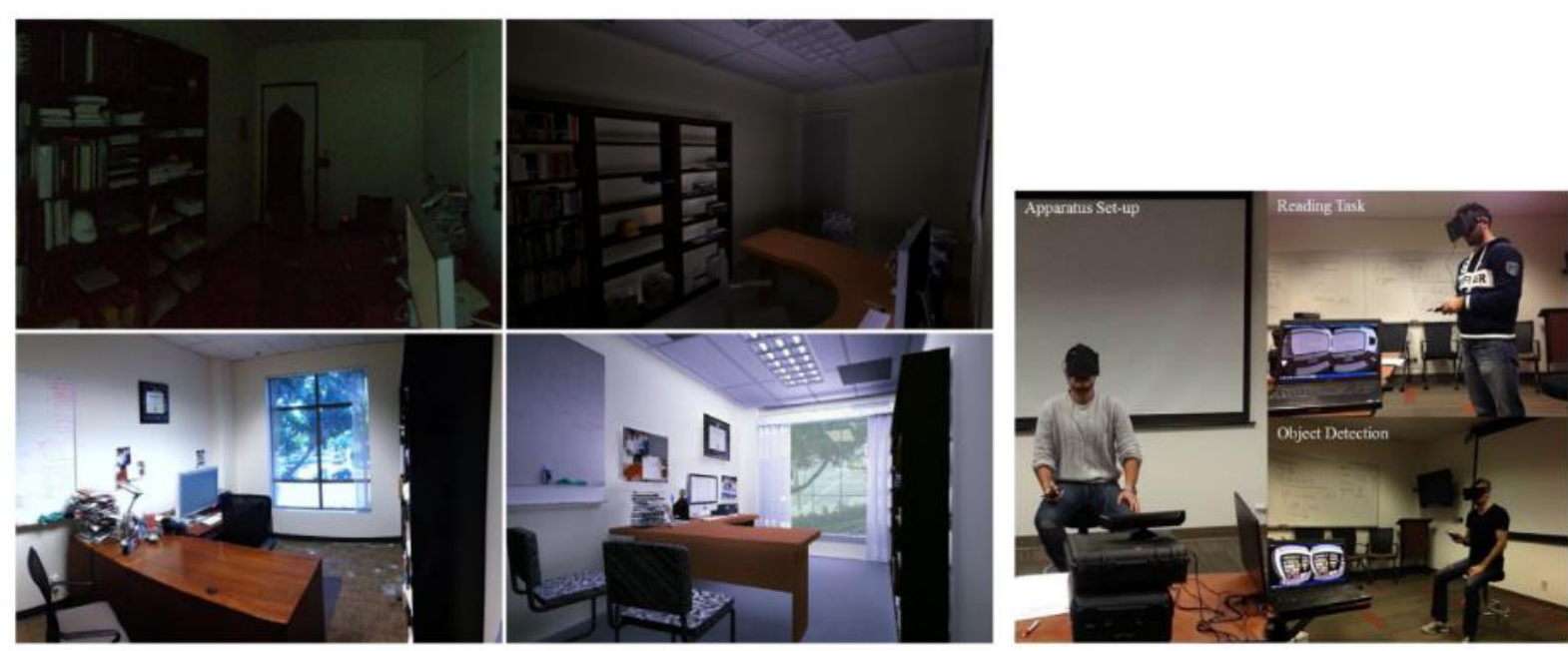

Fonte: Heydarian et al. (2015a)

Fukuda et al. (2001) desenvolve o sistema de realidade virtual para auxiliar os projetistas em todas as etapas, desde o planejamento até o detalhamento do projeto de iluminação do parque linear próximo ao rio Shinmachi, na cidade de Tokushima, no Japão (FIG. 37). 
Figura 37 - Ambientes virtuais utilizados para projeto de iluminação do trecho de rio urbano no Japão.
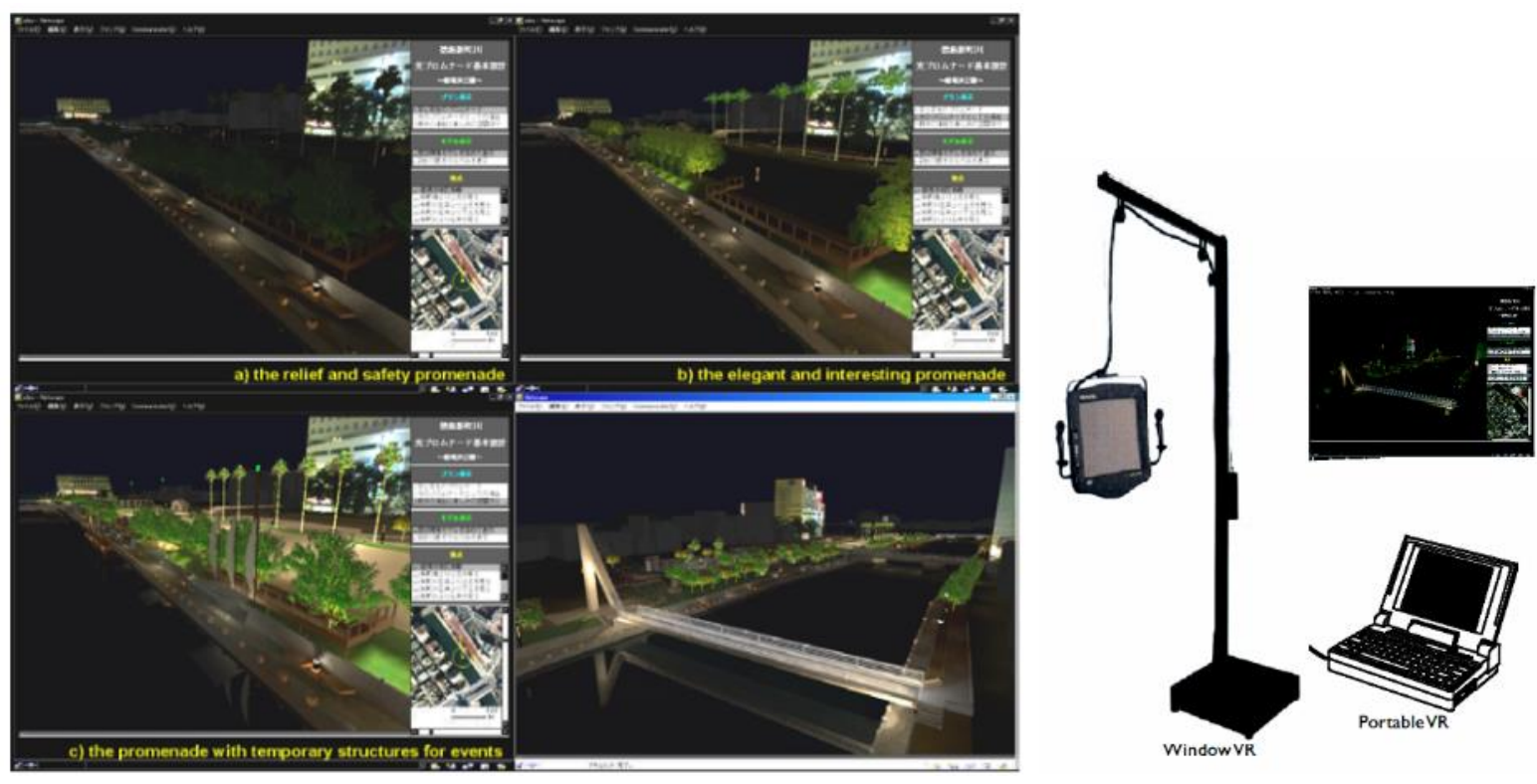

Fonte: Fukuda et al. (2001)

Assim, este projeto foi desenvolvido em formato de workshop, onde o envolvimento da comunidade, dos arquitetos e do governo foi fundamental para a escolha da melhor proposta.

O planejamento e o desenho esquemático foram desenvolvidos em workshop de Agosto de 1999 a Fevereiro de 2000. [...] participaram 343 participantes que não são apenas profissionais como arquitetos e lighting designers, mas também pessoas não profissionais como clientes e vizinhos. Nos workshops, os participantes realizaram uma pesquisa de campo, experimentação de iluminação, discussão e planejamento. [...] é esperado que os participantes possam entender o efeito de iluminação em nosso sistema de VR em desktop, e rever estes planos de forma concreta e clara. [...] na fase de detalhamento de desenhos, a alternativa de design foi revisada com a simulação em VR. (FUKUDA et al. 2001, p. 106, tradução nossa).

A realidade virtual é uma das opções existentes no processo de simulação e representação da iluminação, desde etapas preliminares até a apresentação final ao cliente. Também está diretamente associada aos mockups, principalmente quando relacionada a redução de custos, maior capacidade de modificações no processo de projeto e a predominância da percepção visual sobre outros sentidos, como interações táteis com superfícies (MAING, 2012).

Alguns fatores, contudo, podem dificultar a aceitação da ferramenta. A imersão do usuário, navegação pelo espaço e manipulação de objetos virtuais são feitos através 
de dispositivos auxiliares como óculos estereoscópicos (HMD) e controles. Longa exposição e erros como tremulações de imagem, rastreamento da posição do usuário e a sua atualização no cenário virtual podem causar desconforto e mal-estar (CARVALHO; COSTA; NARDI, 2011; LLORACH; EVANS; BLAT, 2014). Outro aspecto diz respeito ao manuseio do aparato tecnológico por parte dos usuários, cuja faixa etária e familiaridade com vídeo games podem influenciar no uso da realidade virtual (PORTMAN; NATAPOV; FISHER-GEWIRTZMAN, 2015).

Mesmo ao levar em consideração as limitações e fragilidades da ferramenta digital, seja no desempenho dos dispositivos de imersão, na capacidade de processamento de dados ou no manuseio do aparato tecnológico - o que pode gerar desconforto e influenciar nos resultados da pesquisa - o ambiente virtual tridimensional pode fornecer o suporte adequado para a reprodução de um cenário real ao qual será adicionada a iluminação, onde é permitido ao usuário explorar e interagir com o espaço por meio de uma interface virtual e equipamentos auxiliares.

O papel das tecnologias mencionadas neste capítulo é garantir que as ideias traduzidas em imagens e textos no processo de planejamento sejam transformadas em realidade antes da concretização do projeto.

A presente dissertação tem como suporte a utilização de visualizações fotorealísticas através da realidade virtual. Devido ao foco dado na percepção visual dos efeitos resultantes da luz no espaço e sua influência no usuário, as medições fotométricas no local de estudo não foram realizadas, mas sim a apreensão do espaço através de fotografias e visitas ao local para auxiliar na modelagem da iluminação. Assim, o ambiente virtual tridimensional se mostrou promissor, sendo a ferramenta selecionada para viabilizar a execução de experimentos sobre as qualidades subjetivas de espaços urbanos noturnos. Os usuários terão a possibilidade de gerar avaliações sobre suas impressões dos cenários desenvolvidos com base no projeto luminotécnico e na situação existente, além de contribuir como mediador no planejamento de uma melhor experiência noturna no espaço urbano. 


\section{CAPÍTULO 3}

Investigação sobre a percepção do espaço urbano: material, método e experimento 
Este capítulo trata da parte experimental da pesquisa, descrevendo as rotinas metodológicas desenvolvidas no trabalho e a noção de atmosfera percebida, seus termos e dimensões, fundamentais no embasamento dos questionários que foram aplicados no experimento, divididos em duas fases: estudo piloto e experimento consolidado. Tal opção justificou-se pelo caráter inovador da investigação, tanto em relação ao aparato tecnológico como pela abordagem qualitativa a ser aferida, e o estudo piloto serviu como teste e ajuste dos procedimentos que foram aplicados e aprimorados no experimento consolidado (VOLPATO, 2013, p. 223)

\subsection{Material e método}

O objetivo do presente estudo é mapear qualidades ambientais a partir de impressões subjetivas dos usuários inseridos no espaço urbano noturno. Para tanto, pesquisa concentra-se em duas vertentes: compreender as impressões percebidas em ambientes iluminados a partir do conceito de atmosfera, cunhada por Vogels (2008), e formular os recursos da realidade virtual para avaliação dos cenários pelos usuários. O ambiente simulado digitalmente possibilita a exploração do espaço e avaliação de cenários através do questionário da atmosfera percebida, que atribui descritores às qualidades projetadas e esperadas sobre o ambiente (FIG. 38).

Figura 38 -Mapa conceitual do experimento descrevendo as rotinas metodológicas desenvolvidas no trabalho

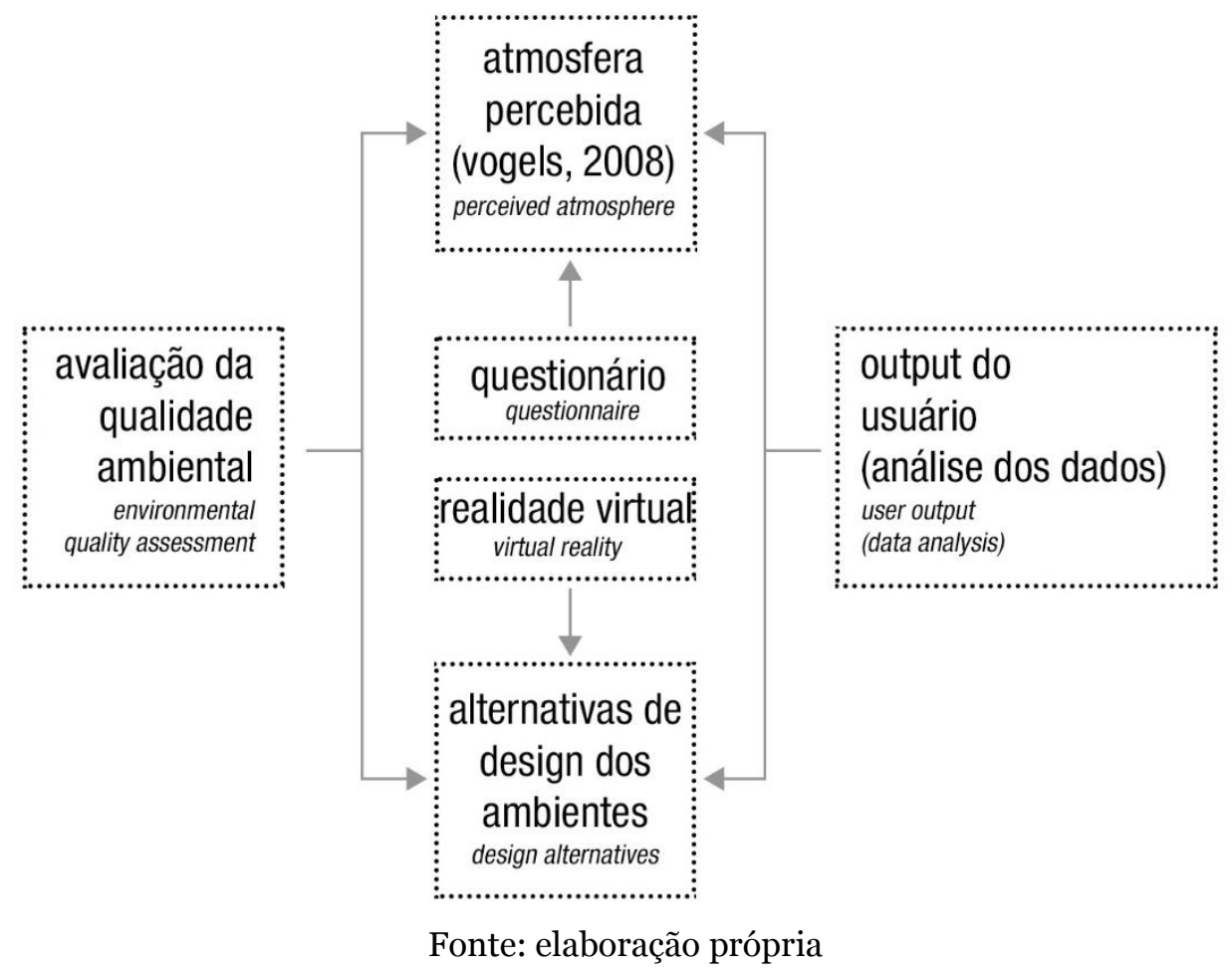


No processo de revisão bibliográfica e desenvolvimento metodológico, foi selecionado como base teórica o conceito de atmosfera do lugar desenvolvida por Vogels (2008), por entender a noção da percepção como uma avaliação do ambiente relacionada ao efeito esperado que dado espaço exerce no usuário, não necessariamente correspondendo ao real estado emocional. A autora justifica que apesar das emoções flutuarem de forma repentina, as qualidades projetadas sobre o ambiente permanecem mais estáveis. Em outras palavras, o ambiente pode ser considerado relaxante mesmo quando o usuário esteja se sentindo o oposto.

O experimento considera a criação de alternativas de cenário através do uso da realidade virtual, tendo em vista a viabilidade de execução da pesquisa. Na verdade, a utilização da realidade virtual permite a apropriação do espaço tridimensional ao oferecer maior controle sobre variáveis difíceis de serem controladas em condições reais, como a criação de cenário de luz em espaço público e a possibilidade de receber avaliações dos usuários e suas impressões - configurando uma avaliação pré-ocupação - em curto período de tempo.

De acordo com Vogels (2008), foram selecionados os termos que descrevem aspectos qualitativos dos ambientes, como espaços ora relaxantes, ora ameaçadores, ora inspiradores ou deprimentes, os quais foram captados através de questionários. Foram selecionados 22 dos 38 termos da atmosfera percebida analisados, os quais foram agrupados em quatro dimensões: aconchego, ânimo, tensão e distanciamento (coziness, liveliness, tenseness e detachment). Para a execução deste experimento, procedeu-se à análise e à adequação dos termos da língua original em Holandês para o Português, tendo em vista a tradução pela autora apenas para o Inglês (TAB. 9). 
Tabela 9 - Termos da atmosfera percebida de Vogels. (Em negrito os selecionados para o experimento)

\begin{tabular}{lll|rrr} 
Holandês & Inglês & Português & Holandês & Inglês & Português \\
\hline afstandelijk & detached & inamistoso & levendig & lively & vivaz \\
beangstigend & terrifying & assustador & luxueus & luxurious & luxuoso \\
bedompt & musty & abafado & mysterieus & mysterious & misterioso \\
bedreigend & threatening & intimidador & ongedwongen & uninhibited & desinibido \\
behaaglijk & cozy & acolhedor & ongemakkelijk & uncomfortable & desconfortável \\
beklemmend & oppressive & opressivo & onrustig & restless & agitado \\
deprimerend & depressed & deprimido & ontspannen & relaxed & relaxado \\
enerverend & exciting & excitante & persoonlijk & personal & intimo \\
formeel & formal & exclusivo & omantisch & romantic & romântico \\
gastvrij & hospitable & acolhedor & ruimtelijk & spatial & amplo \\
geborgen & safe & seguro & rustgevend & tranquil & tranquilo \\
gemoedelijk & pleasant & agradável & saai & boring & tedioso \\
gespannen & tense & estressante & sloom & lethargic & apático \\
gezellig & pleasant & sociável & stimulerend & stimulating & estimulante \\
inspirerend & inspiring & inspirador & toegankelijk & accessible & acessível \\
intiem & intimate & familiar & vijandig & hostile & hostil \\
Kil & chilly & ermo & vrolijk & cheerful & alegre \\
Knus & cool & frio & warm & warm & caloroso \\
Koud & zakelijk & business & pragmático
\end{tabular}

Fonte: adaptado de Vogels (2008)

A primeira dimensão chamada de aconchego (coziness) abrange termos que descrevem o ambiente como tranquilo, agradável, relaxante, romântico, seguro e acolhedor, e estão ligados diretamente a sensações positivas do ambiente.

Quanto à dimensão ânimo (liveliness), compreende termos qualitativos como vivaz, estimulante, agitado, alegre, inspirador e sociável, sendo descritores referidos a vitalidade do local. As características da dimensão de tensão (tenseness) dos ambientes, onde foram considerados termos como estressante, deprimido, assustador, intimidador, desconfortável e tedioso e são ligadas a aspectos negativos do espaço.

Por fim, última dimensão, distanciamento (detachment), inclui os termos acessível, familiar, exclusivo e desinibido, e tem aspectos relacionados ao comportamento e impressão do espaço que subjugam o usuário (Tabela 9). Um ambiente é considerado exclusivo ao entender que ele pressupõe padrões de comportamento e status. Um exemplo é o ambiente em uma loja de marca que induz a 
certa classe social e ao poder aquisitivo dos consumidores. O mesmo pode ocorrer em espaços urbanos, em intervenções como cerramento de áreas públicas através de grades.

\section{Área de estudo}

O espaço do Largo de São Frei Pedro Gonçalves (LSFPG), localizado em João Pessoa/PB foi o selecionado como objeto de estudo (FIG. 39). Situa-se no bairro do Varadouro, local de fundação da cidade a partir do Rio Sanhauá, e faz parte da chamada "cidade baixa", devido a sua topografia acidentada. Tombado em 2009 pelo Instituto do Patrimônio Histórico e Artístico Nacional (IPHAN), possui cerca de $7.000 \mathrm{~m}^{2} \mathrm{de}$ área (largo e edificações adjacentes). Tem como edificações importantes a Igreja que dá nome ao Largo, antigo hotel da cidade, além de um conjunto de casarios onde funcionam desde instituições a restaurantes.

Figura 39 -Localização do objeto de estudo

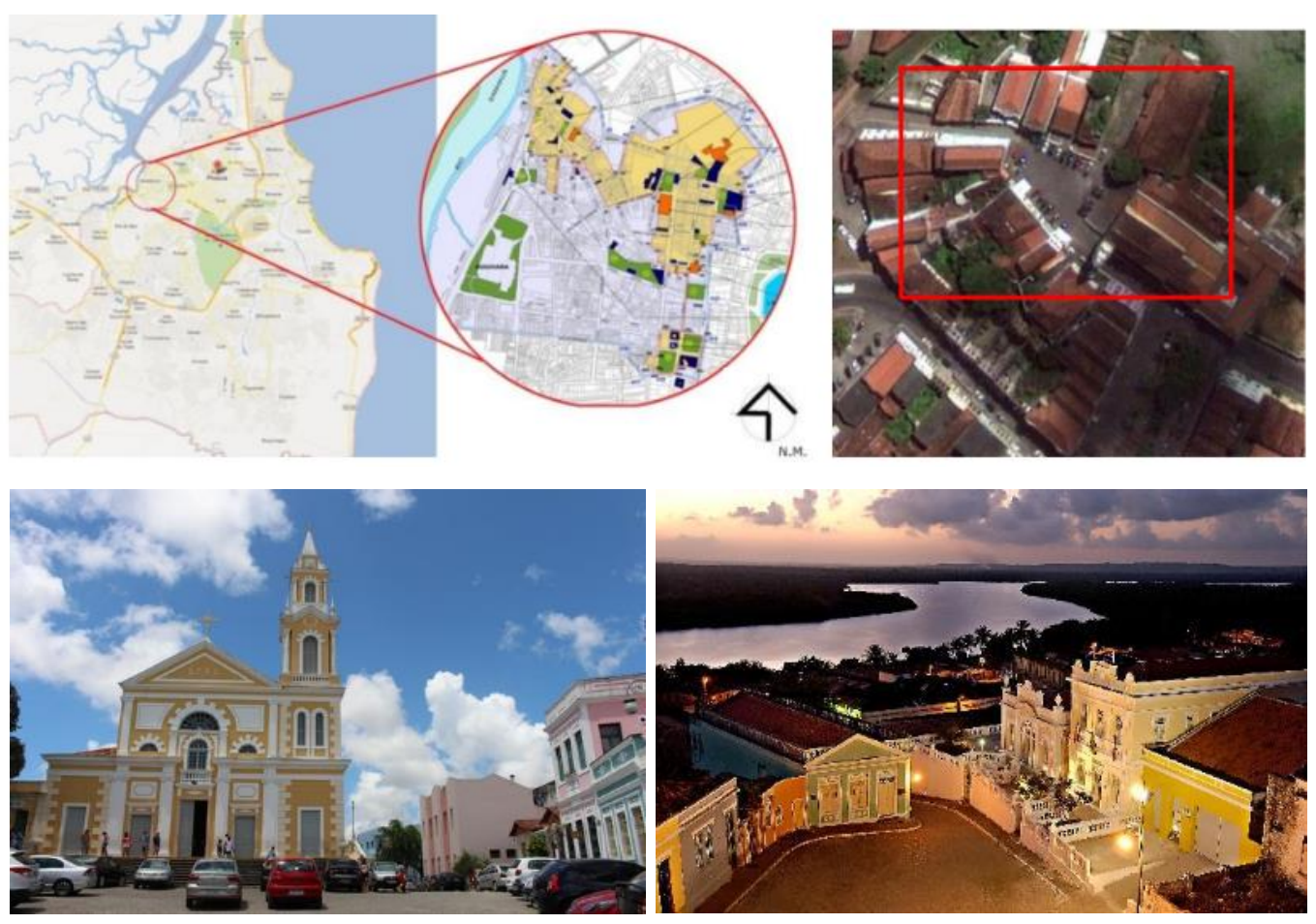

Fonte: elaboração própria; google images

Como relata Chaves (2010) a primeira construção do largo seria a Capela dos Navegantes, construída a partir de 1843, financiada pelos navegadores e comerciantes que se instalavam no porto da cidade, próximo ao local. Foi demolida para dar lugar ao atual edifício (concluída já no século XX, em 1916). Ainda segundo a autora, o Hotel Globo, um marco importante para a cidade e o local, passa a fazer parte do conjunto 
do largo em meados do século XX, a partir da transferência das suas instalações para o espaço em questão.

Os participantes eram solicitados a caminhar pelo ambiente virtual em cada um dos cenários para, em seguida, preencher um questionário a respeito das qualidades percebidas do espaço e sua atmosfera percebida apenas nos cenários noturnos.

\section{Modelo e recursos de imersão virtual}

O modelo tridimensional da área urbana (FIG. 40) foi reproduzido de acordo com as dimensões e texturas do ambiente físico, a fim de aproximar o ambiente virtual da realidade. Também foi criado com o objetivo de implantação de cenas noturnas, onde a iluminação desempenha papel importante na relação do usuário com as qualidades percebidas do espaço e suas impressões subjetivas.

Para o estudo em causa foram configurados três cenários com distintas soluções de iluminação: o Cenário o representando a versão diurna e dois cenários noturnos, um o Cenário 1 reproduzindo a situação existente e o Cenário 2 como uma simulação de projeto de iluminação para o espaço estudado.

Figura 40 - Imagens do Largo de São Frei Pedro Gonçalves. (A) vista aérea do modelo virtual tridimensional e (B) vista a partir da igreja

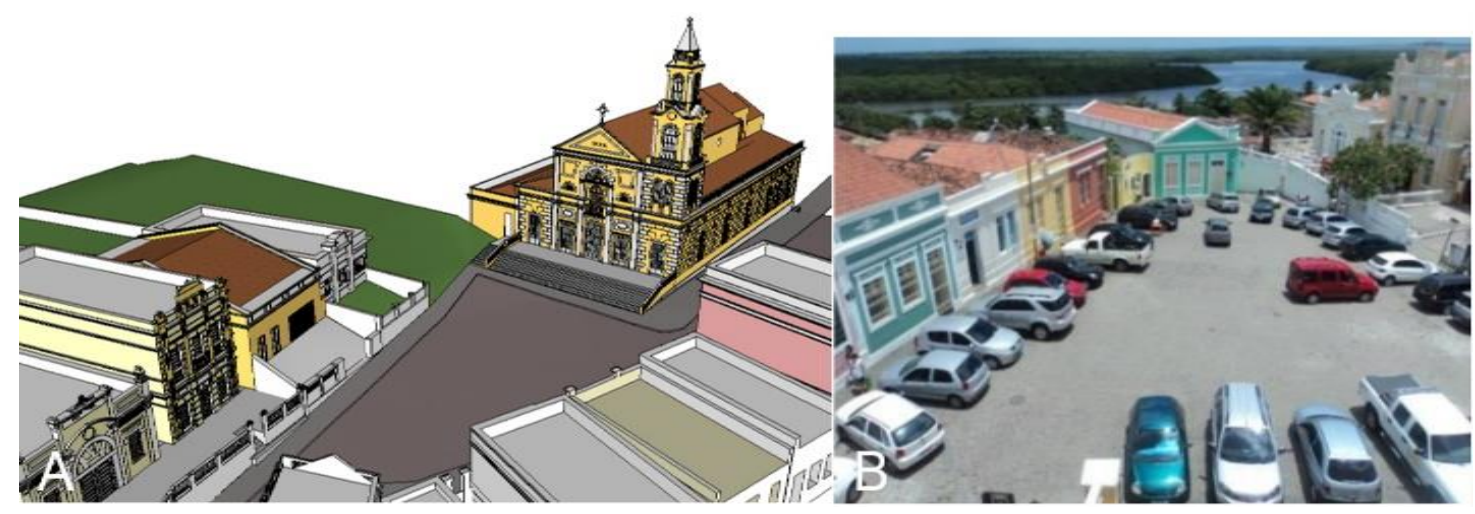

Fonte: elaboração própria

O processo de criação dos cenários de realidade virtual foi desenvolvido com base na modelagem da geometria do espaço urbano e dos edifícios e o mapeamento básico de texturas e cores no programa Trimble SketchUp. Em seguida o modelo foi exportado para o Autodesk 3DS Max via extensão “.FBX” para adequação da representação, tornando-a mais realista ao incluir iluminação dos cenários noturnos, sombras e mapeamento de texturas mais detalhado (FIG. 41). 
Figura 41 - Workflow e recursos de imersão virtual do experimento

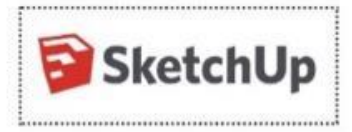

Modelo tridimensional

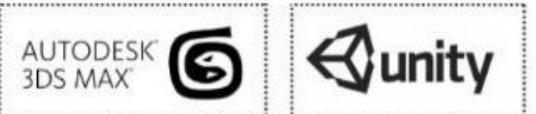

Mapeamento textura Interatividade lluminação Renderização

\section{Google Cardboard}

Head-mounted display

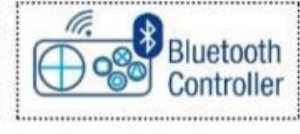

Navegação

Fonte: elaboração própria

Cuidados foram tomados para uma melhor experiência no ambiente virtual, tendo em vista que procedimentos errados podem causar desconforto nos usuários. Após, diversos testes foram realizados em modelo simplificado do pavilhão de Barcelona, onde foi criada uma rotina de ações, tarefas e comandos para atender os requisitos necessários, os cenários foram renderizados pelo chamado "Render to Texture" no próprio programa (FIG. 42). Este comando é capaz de decompor todo o modelo tridimensional em planos únicos, cuja iluminação e textura já estão aplicadas, melhorando o desempenho dos diversos processos em tempo real. Após este procedimento, o modelo está pronto para seguir a próxima etapa.

Figura 42 - utilização do comando "render to texture" gera um único material. Na imagem, o pavilhão de Barcelona foi utilizado como objeto de testes

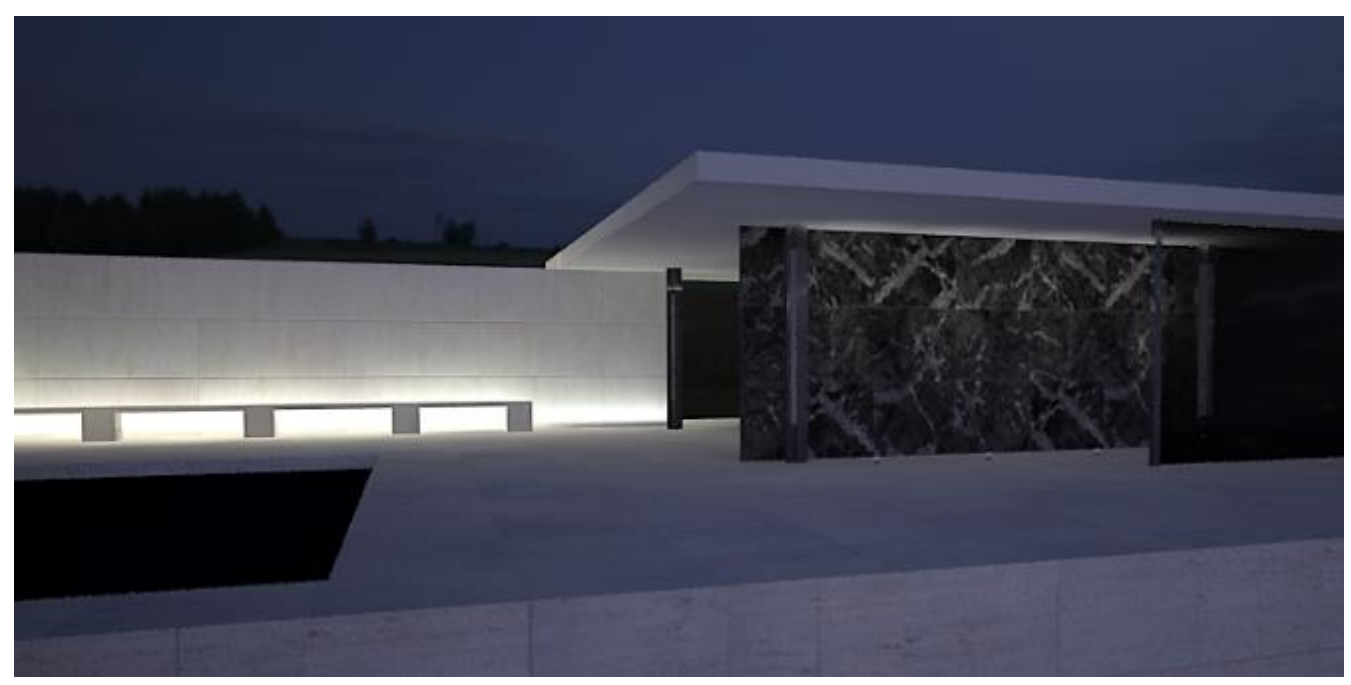




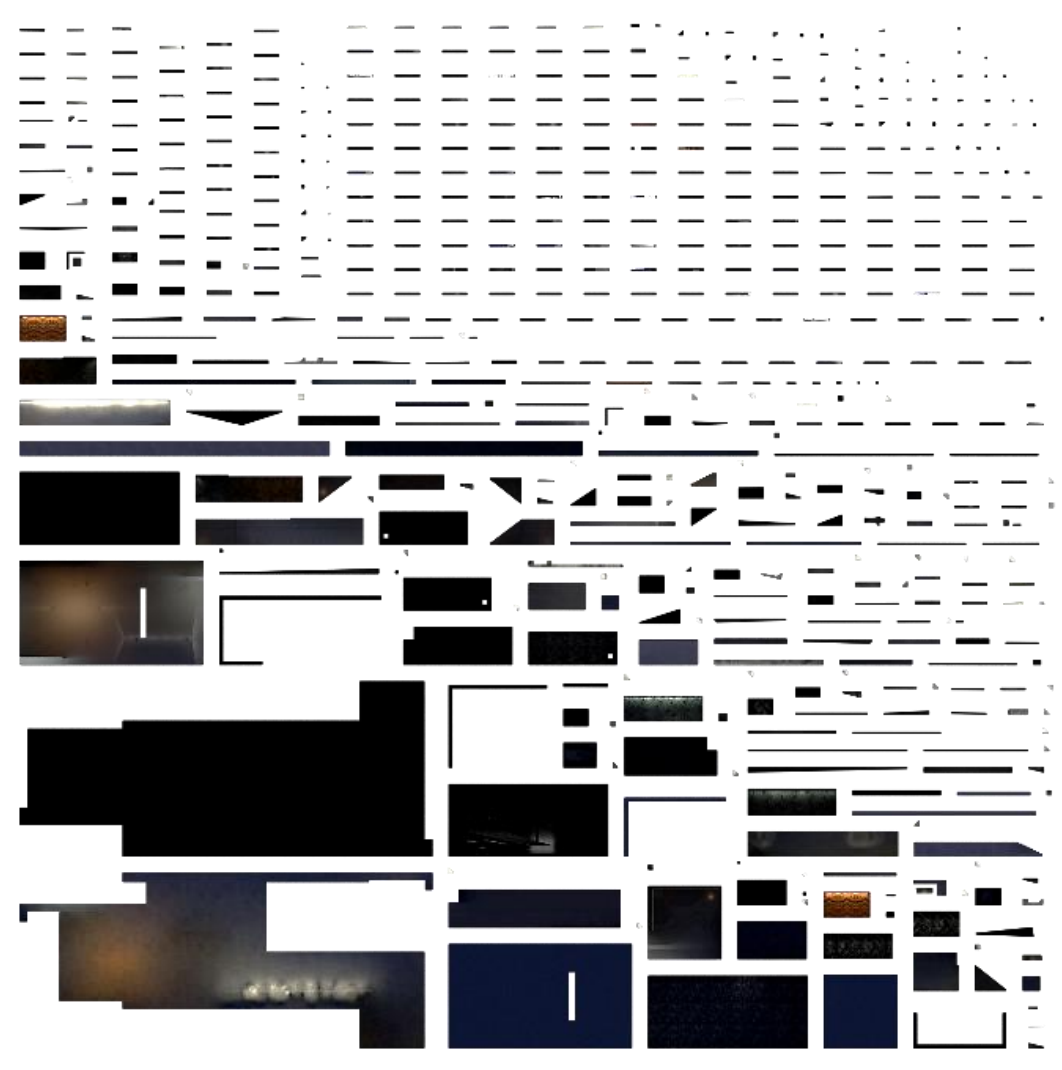

Fonte: elaboração própria

Os modelos renderizados foram então exportados para o Unity como extensão ".FBX", onde foram criados os parâmetros para a visualização e interação dentro do ambiente virtual. Dispositivos auxiliares foram utilizados (FIG. 43), como controle bluetooth para navegação e o Google Cardboard $\AA$ como head-mounted display (HMD) para permitir a imersão nos ambientes virtuais tridimensionais.

Figura 43-Modelo tridimensional e dispositivos auxiliares utilizados no experimento

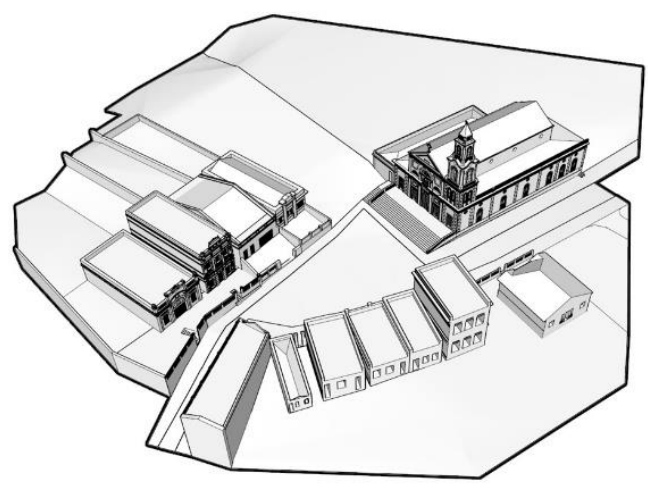

Modelo tridimensional (Sketchup + 3DS MAX + Unity)

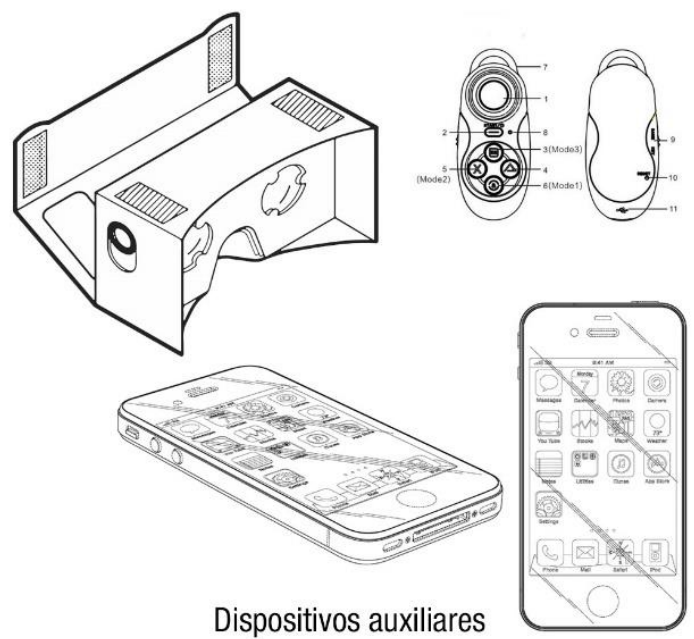

(Google cardboard + Smartphone + Controle Bluetooth)

Fonte: elaboração própria 


\section{Procedimentos de intervenção}

Os procedimentos de intervenção de um projeto de iluminação pública e de monumentos perpassam pelo entendimento das características do local e conjunto arquitetônico, seus usos e funções a partir das demandas dos usuários, bem como a atmosfera e ambiência percebida.

Neste trabalho considerou-se como área de estudo o projeto de iluminação da área de São Frei Pedro Gonçalves, sendo a Igreja homônima e todo seu conjunto arquitetônico. O recorte faz parte do objetivo de exemplificar a importância da iluminação na valorização dos centros históricos e no mapeamento de qualidades subjetivas dos usuários inseridos em espaços públicos.

O projeto luminotécnico para a Igreja de São Frei Pedro Gonçalves propõe uma série de efeitos, de iluminação rasante a elementos de destaque e fachadas com iluminação uniforme. O projeto de iluminação foi pensado evidenciando suas texturas e tridimensionalidade dos elementos arquitetônicos, como colunas, cornijas e frontão. Também privilegia os elementos transparentes, como as janelas e os vitrais coloridos, iluminando-os pelo interior, a fim de gerar a sensação de que a igreja esteja em funcionamento.

Como elemento principal do cenário urbano, a fachada oeste foi destacada por projetores simétricos que jogam luz nas suas colunas adossadas, enquanto que toda a base foi preenchida por luz através de projetores assimétricos embutidos no piso, num efeito wallwashing com temperatura de cor quente (300ok). Esta diferença de efeitos luminosos é percebida através de diferentes intensidades de luz, na qual as colunas foram mais iluminadas, porque marcam as entradas à nave da igreja.

As soluções de iluminação propostas à porção sul da igreja foram adotadas visando a percepção de uma fachada uniformemente iluminada pelo efeito wallwashing. No caso do casario do Largo foi utilizado o mesmo efeito da fachada em toda sua extensão, com projetores embutidos no piso de facho assimétrico, para dialogar com a igreja iluminada (FIG. 44). 
Figura 44-Modelo tridimensional e dispositivos auxiliares utilizados no experimento
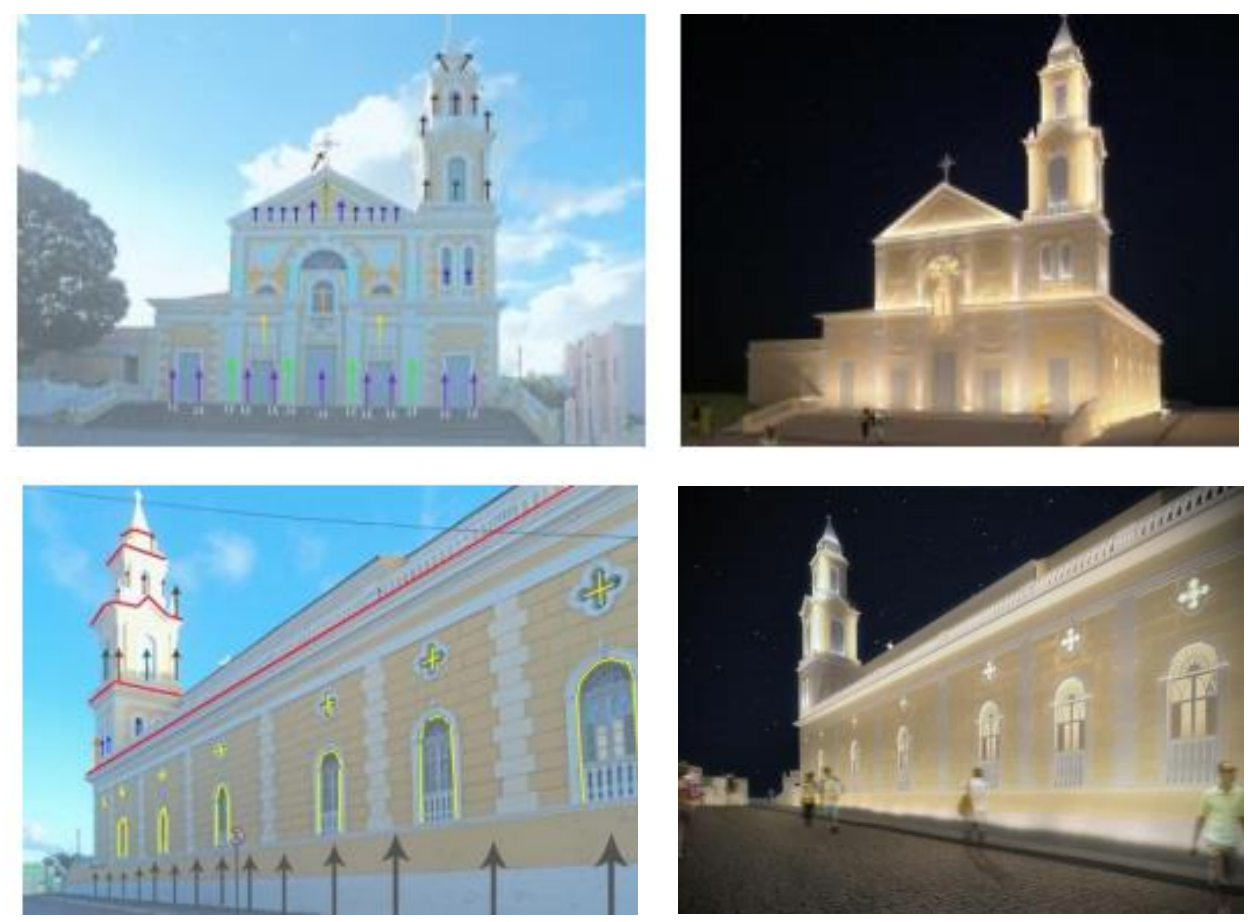

Fonte: elaboração própria

\subsection{Estudo piloto}

Considerando a pouca experiência com as técnicas e processos abordados, foi feito um ensaio prévio para eventuais adaptações e ajustes na metodologia (VOLPATO, 2013, p. 223).

Foram adotados 3 cenários: Cenário o; Cenário 1 e Cenário 2. O Cenário o foi admitido como referência para a configuração e ajuste das cores e propriedades das superfícies (transmissão e distribuição da luz) para os demais cenários. Uma vez que representa a situação diurna real com iluminação natural, o Cenário o foi criado a partir de fotografias digitais do local, cujo objetivo principal era auxiliar na aproximação visual das cores e texturas das fachadas dos edifícios e pisos existentes que compõem o espaço urbano na área em estudo.

Para a produção dos cenários com iluminação noturna (Cenário 1 e Cenário 2), utilizou-se o mesmo modelo produzido para o Cenário o, alterando-se apenas as condições de iluminação. A iluminação do Cenário 1 foi reproduzida a partir dos aspectos técnicos de temperatura de cor e intensidade das fontes luminosas existentes no local, de forma a torná-lo mais próximo possível da realidade. Quanto ao Cenário 2, partiu-se da proposta de um novo projeto de iluminação, utilizando-se do mesmo 
procedimento de modelagem do cenário anterior, tomando-se por base a temperatura de cor e intensidade da proposta de intervenção no espaço (FIG. 45).

Figura 45 - Imagem do Largo de São Frei Pedro Gonçalves nos cenários descritos. Em planta baixa a indicação do ponto de vista. (A) Cenário o; (B) Cenário 1; (C) Cenário 2
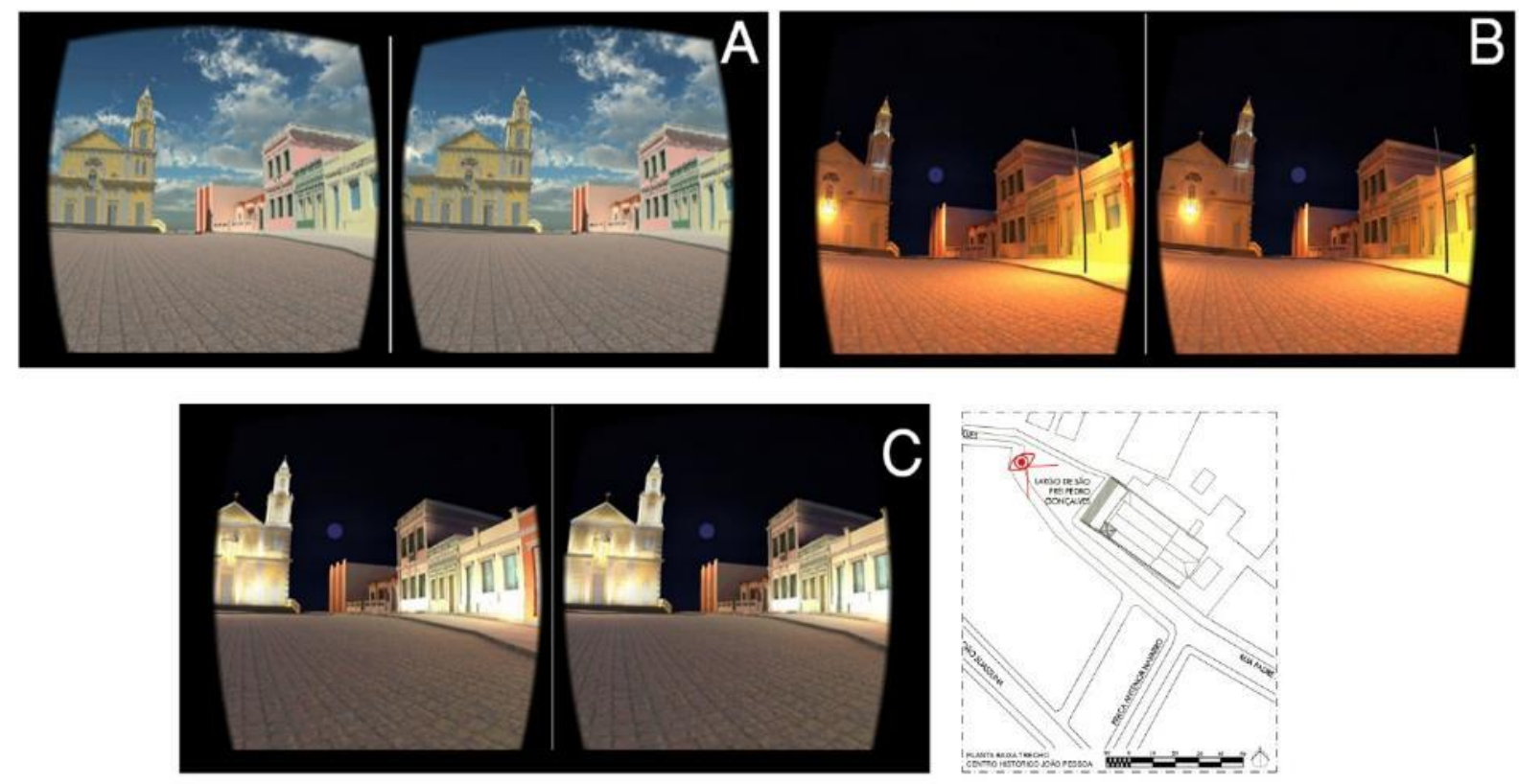

Fonte: elaboração própria

Antes de iniciar o experimento, os participantes que foram convidados a utilizar o sistema receberam instruções do funcionamento, navegação e interação. Nenhum dos participantes relatou experiências anteriores no uso da tecnologia. Ao todo foram convidadas 12 pessoas, com idades variando de 15 a 44 anos, sendo 6 pessoas do sexo feminino e 6 do sexo masculino, além da maioria (7 pessoas) declarar ser residente da cidade e conhecedor do local.

Do total de 12 participantes, 2 pessoas participaram de testes preliminares a fim de verificar as orientações a serem dadas aos participantes, tempo por pessoa e questionário. Para tanto, foi realizado o seguinte procedimento: os participantes inseriam os óculos de realidade virtual para a apreciação do espaço, enquanto o pesquisador os guiava através da narração do que eles precisavam fazer. A informalidade da narração gerava trajetos diferentes nos três cenários, além de não existir um limite de tempo. 
No momento de aplicação do questionário também não foi determinado um limite de termos a serem assinalados, o que causou contradições nos resultados preliminares. Estas ocorrências auxiliaram na otimização do processo de orientação ao usuário a partir da definição de um trajeto padrão, com ponto de partida ao lado da igreja (FIG. 45). Desta forma, foi possível estipular o limite de tempo de dois minutos na apreciação de cada cenário, para em seguida preencher o questionário, sendo definido o limite de até três termos entre seis alternativas. Estes testes preliminares foram descartados da análise final, restando 10 avaliações a serem analisadas.

O período de realização do experimento durou três dias em novembro de 2015 na cidade de João Pessoa/PB. Foi escolhido um ambiente interno para a execução, no sentido de minimizar influencias externas, como ruídos indesejáveis, que poderiam deturpar a avaliação do usuário. Levando isto em consideração, além da capacidade móvel do aparato tecnológico, o experimento foi realizado em dois locais: sala de aula no prédio de Arquitetura e Urbanismo da Universidade Federal da Paraíba (UFPB) e uma sala residencial no $12^{\circ}$ andar de edifício. Os ruídos urbanos eram minimizados ao fechar as esquadrias.

Ao longo do experimento, os usuários eram inseridos no ambiente virtual através do Cenário o como opção de treinamento, servindo de ajuda para se acostumarem com o aparato, com a navegação pelo ambiente e visualização dos espaços através dos óculos de realidade virtual, tendo como orientação as instruções dadas pelo pesquisador. Devido à possibilidade de visualização do cenário em $360^{\circ}$, os participantes preferiam ficar de pé.

Terminada a primeira fase de aprendizagem e teste da tecnologia, foi solicitada aos usuários a remoção do $H M D$ para descanso de 1 minuto. Esta pausa está relacionada com a possibilidade de desconforto - tonturas e náuseas - causado pela longa exposição ao ambiente virtual através do HMD (CARVALHO; COSTA; NARDI, 2011). Após esta fase, os participantes declararam não sentir incômodos provenientes da realidade virtual, e a navegação pelo ambiente foi considerada de fácil apreensão, semelhante a um vídeo game.

A próxima etapa foi a exploração do mesmo local, agora com cenários noturnos e para isso foi estabelecido o tempo limite de 2 minutos cronometrados, além do percurso básico para apreciação do espaço, no sentido de se ter múltiplas perspectivas 
do local. Também foi comunicado aos usuários que os cenários seguintes seriam objeto de questionário a respeito da atmosfera percebida.

Assim, primeiramente foi inserido o Cenário 1, no qual os participantes deveriam caminhar até o final da ladeira - uma linha reta em direção à casa verde - e voltar para o mesmo local, ao lado da igreja (FIG. 46). O mesmo procedimento foi então realizado no Cenário 2. Uma vez terminada a experiência nos três cenários, os participantes preenchiam o questionário.

Figura 46 - Vista aérea do Largo de São Frei Pedro Gonçalves demonstrando o percurso básico de apreensão do espaço urbano. À direita imagens dos participantes do experimento

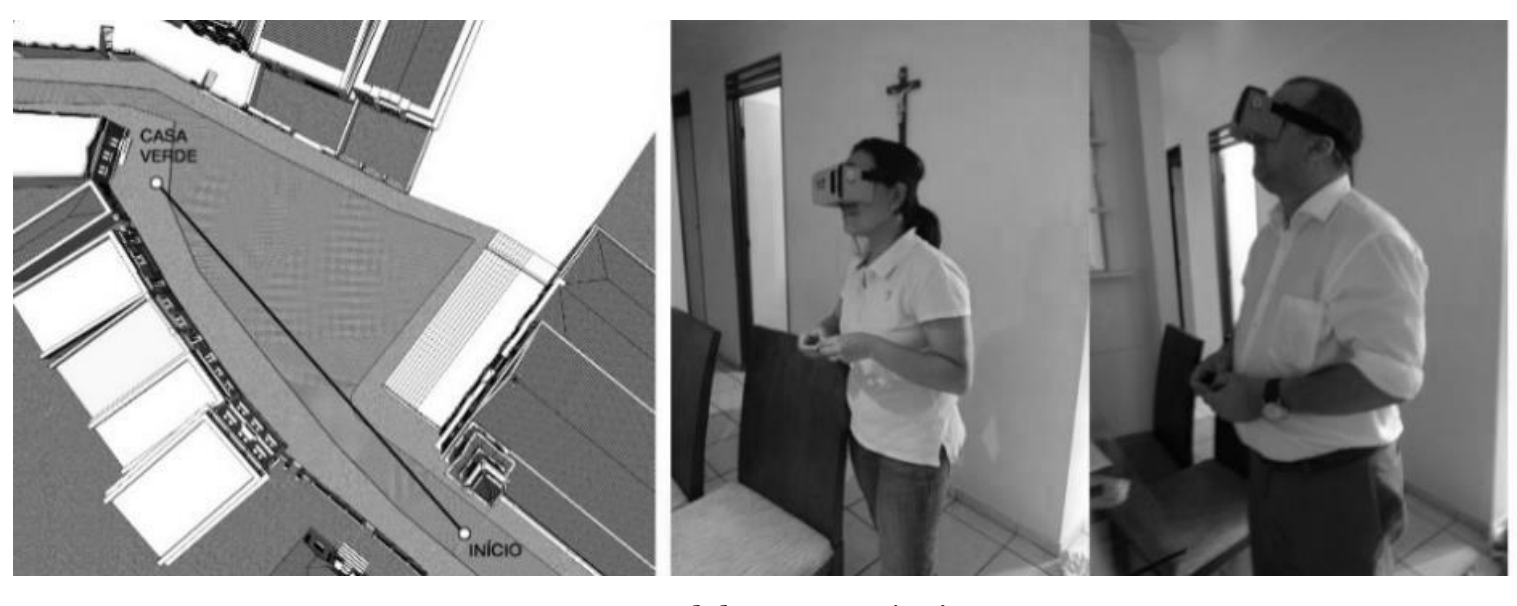

Fonte: elaboração própria

A etapa do questionário envolveu questões relacionadas às impressões subjetivas do usuário no espaço em que ele foi inserido virtualmente. Portanto, a fim de compreender as impressões subjetivas dos ambientes estudados, foi desenvolvido o questionário a partir das dimensões de atmosfera percebida desenvolvidas por Vogels (2008). Levando em consideração o tempo para a exploração dos cenários e o preenchimento do questionário pelos participantes, foi necessária a redução da quantidade de termos, passando de 38 para 22, separados pelas quatro dimensões de atmosfera percebida citadas anteriormente. Destes 18 termos os participantes deveriam assinalar aqueles que melhor descrevessem suas sensações em cada um dos ambientes.

Para o questionário foi previamente definido um limite de três termos, que poderiam ser marcados em cada dimensão, e caso o participante não se sentisse confortável em responder ou não soubesse como descrever, poderia deixar em branco 
ou acrescentar alguma observação na pergunta ao final do questionário. Foram solicitadas também informações sobre os participantes, como a idade, gênero, familiaridade com o local e com a tecnologia utilizada. Vale a pena salientar que no experimento não foi dito que o foco do trabalho eram pesquisas qualitativas em iluminação, assim não foram induzidos a prestar atenção em aspectos particulares do ambiente.

\section{Resultados preliminares}

O estudo piloto procurou medir qualitativamente como a qualidade ambiental é percebida através de mecanismos como a teoria da atmosfera percebida de Vogels, utilizando-se de ambientes virtuais imersivos. Apesar dos participantes selecionarem termos que descreviam a avaliação afetiva esperada que os cenários propostos promoviam, alguns obstáculos e limitações foram encontrados.

A pesquisa procurou utilizar equipamentos com custos acessíveis e facilmente disponíveis, como smartphones e controles, cujo desempenho é notadamente menor se comparado com aparatos mais sofisticados e mais caros, como o Oculus Rift. É importante compreender as necessidades do experimento para a adequação da tecnologia. O objetivo de mapear qualidades ambientais tornou-se possível através da tecnologia, devido aos recursos de tempo e custo disponíveis. Além da apreensão predominantemente visual e navegação exploratória, o aparato tecnológico possibilitava a execução do experimento em qualquer local, o que facilitou a participação de mais pessoas.

Entretanto, do ponto de vista técnico e operacional, alguns aspectos foram detectados a fim de serem melhor calibrados na próxima pesquisa, principalmente no tocante à interoperabilidade entre software e o desempenho dos dispositivos de imersão e interação de realidade virtual. Exemplo destas constatações são a navegação não otimizada através de bluetooth.

Outro fator foi o FPS (Frames per Second) baixo, causando movimentações de cabeça menos naturais, devido a performance do dispositivo móvel utilizado (google cardboard). Durante o experimento, este aspecto foi levado em consideração ao sugerir pausas entre cenários para descanso do participante. Procedimentos de melhorias e simplificações na geometria do espaço deverão favorecer uma melhor experiência na condução do experimento consolidado. 
Outros aspectos dizem respeito a consistência do questionário na captação de percepções do usuário e sua relação com atributos de iluminação (intensidade, direção da luz e temperatura de cor).

Devido ao curto período entre desenvolvimento do questionário execução do experimento, a partir da revisão bibliográfica concluiu-se que a atmosfera percebida deve ser melhor analisada através de escalas de concordância de termos (escalas Likert), ao invés de seleção de um ou mais termos, possibilitando maior variedade e robustez nos resultados. Para isto, também seria necessário um maior número de participantes.

A principal contribuição do estudo piloto foi o desenvolvimento de um processo metodológico de mapeamento de impressões dos usuários utilizando-se ambientes virtuais tridimensionais. A interação dos participantes com os dispositivos utilizados e o desempenho de software e hardware foram essenciais para a condução do experimento e a própria validação da tecnologia e metodologia. Também como contribuição está a avaliação de impressões por parte dos usuários ao utilizar três cenários distintos, tornando viável a utilização da ferramenta para esses fins, em prol de uma melhor paisagem noturna.

\subsection{Experimento consolidado}

Ao contrário do estudo piloto, o experimento foi conduzido apenas com cenários noturnos, por dois motivos. Primeiro, era necessária a adição de um novo cenário noturno para avaliar a influência de variáveis de iluminação na percepção do usuário sob o conceito da atmosfera, algo ainda incipiente no estudo piloto. O segundo motivo refere-se ao tempo despendido no experimento, tendo em vista que a duração por participante era de 20 a 25 minutos cada, por isso manteve-se três cenários noturnos.

Para a criação dos três cenários noturnos, procedeu-se à definição das variáveis de iluminação a serem utilizadas e modificadas, como temperatura de cor, intensidade e direção da luz, a fim de verificar diferenças entre cenários e as impressões dos usuários. O novo cenário toma por base o mesmo procedimento de modelagem do cenário de intervenção do espaço (cenário 2 do estudo piloto), modificando-se apenas a temperatura de cor da luz (FIG. 47). 
Figura 47 - visualização dos cenários noturnos a partir de dois pontos: com vista para a casa verde (A) e com vista para a igreja (B).
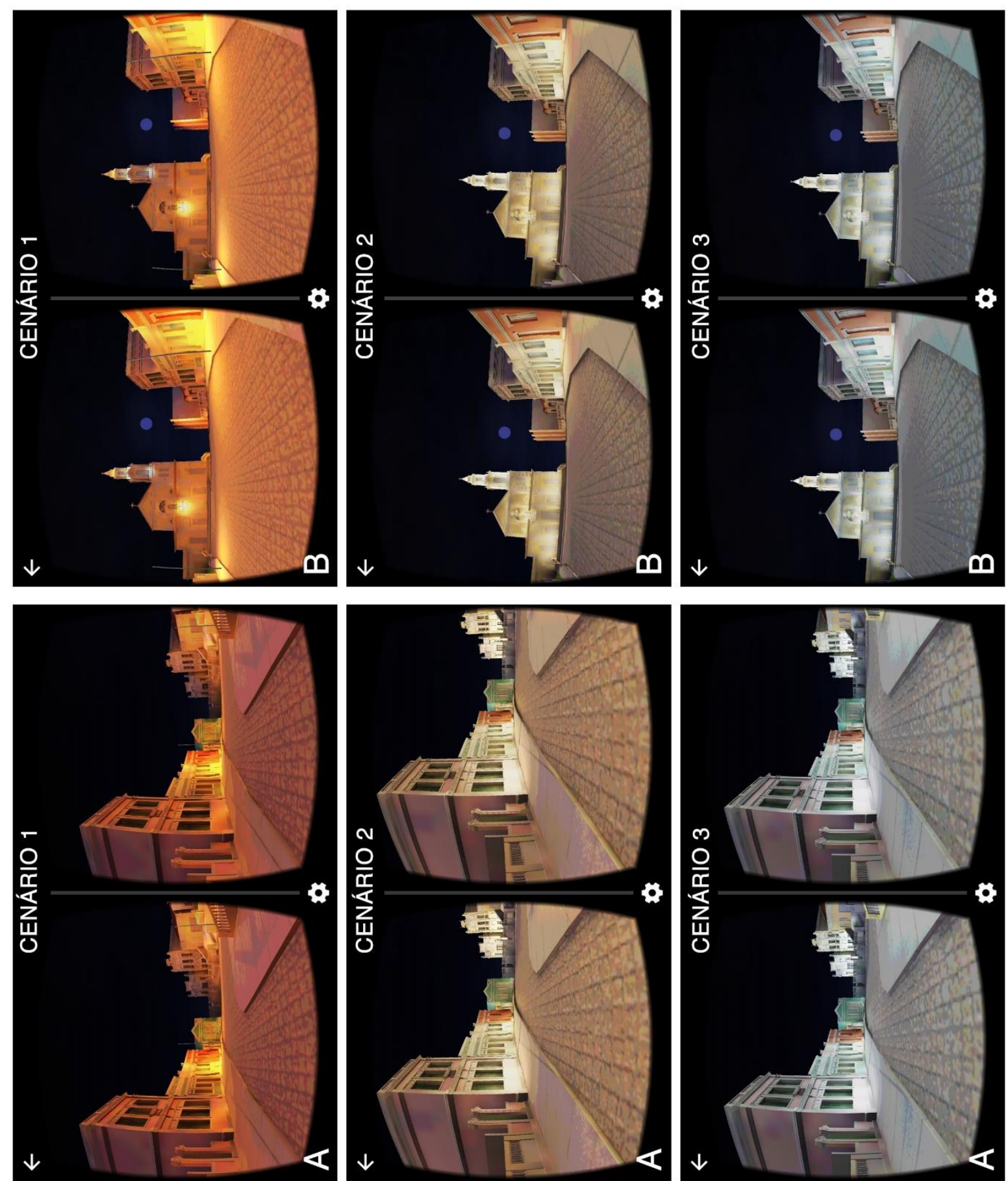

Fonte: elaboração própria 
A começar pelo cenário 1, correspondendo à situação existente, foi representado a partir de fotografias digitais do local, a fim de auxiliar na aproximação visual das cores, texturas das fachadas e pisos existentes do espaço urbano, e a iluminação reproduzida a partir dos aspectos técnicos de temperatura de cor e intensidade das fontes luminosas utilizadas no local, de forma a torná-lo o mais próximo possível da realidade (TAB. $10-1 \mathrm{a})$.

Tabela 10 - Resumo das quatro dimensões e respectiva abrangência de termos

\begin{tabular}{lccc}
\hline variável $\backslash$ cenário & $\mathbf{1}(\mathbf{a})$ & $\mathbf{2 ~ ( b )}$ & $\mathbf{3}$ (c) \\
\hline intensidade & baixa & alta & alta \\
\hline direção & $\begin{array}{c}\text { downlight } \\
\text { (postes e projetores) }\end{array}$ & $\begin{array}{c}\text { uplight } \\
\text { (projetores de piso) }\end{array}$ & $\begin{array}{c}\text { uplight } \\
\text { (projetores de piso) }\end{array}$ \\
\hline temperatura de cor & $2800 \mathrm{~K}$ & $3000 \mathrm{~K}$ & $6000 \mathrm{~K}$ \\
\hline
\end{tabular}

Fonte: elaboração própria

No cenário 2 foi criada uma nova iluminação para a área. Tomando como base as considerações anteriores e através de modificações das variáveis temperatura de cor, intensidade e direção da iluminação (TAB. 10 - 2b) foi realizada a proposta de intervenção, com cores quentes (3000K) e iluminação do plano vertical das fachadas. Os mesmos procedimentos foram replicados no terceiro cenário (cenário 3), mudando apenas a temperatura de cor (TAB. 10 - 1c) para 600oK, configurando-se assim nos três cenários noturnos de estudo.

\section{Caracterização do experimento e critérios de amostragem}

Antes do início do experimento, os participantes assinavam o termo de consentimento livre e esclarecido, preenchiam um questionário socioeconômico, contendo informações de idade, sexo, profissão, conhecimento da tecnologia e familiaridade com o local. Também era solicitado aos participantes responderem a seguinte pergunta: Para você, qual aspecto mais importante para melhor uso dos espaços a noite? Esta pergunta buscava identificar respostas recorrentes dos participantes - ao usarem o conhecimento existente, sem influência dos cenários estudados - quanto ao espaço público noturno. As alternativas foram baseadas em aspectos onde a iluminação desempenha papel fundamental, como conforto visual, orientação de caminhos, destaques de referências visuais, ambiências e sensação de segurança. 
Também era comunicado aos usuários que, após a interação com cada cenário, deveriam preencher um questionário a respeito da atmosfera percebida e outro sobre a qualidade ambiental de cada ambiente correspondente. A Tabela 11 demonstra a rotina de execução do experimento, desde os procedimentos preliminares até a navegação pelos cenários estudados.

Tabela 11 - Rotina de execução do experimento

\section{procedimentos preliminares}

O termo de consentimento livre e esclarecido (Apêndice A)

○ aplicação do questionário socioeconômico (Apêndice B)

○ identificação da função mais importante para uso dos espaços noturnos (Apêndice B)

○ orientação sobre os procedimentos do experimento e sobre o preenchimento dos questionários, divididos em duas abordagens:

a) atmosfera percebida (VOGELS, 2008); (Apêndice C)

b) qualidade ambiental (Apêndice D)

\section{experimento}

○ orientação de funcionamento, operação e navegação do aparato

○ navegação pelo cenário 1

○ remoção do aparato e descanso de um minuto

○ preenchimento dos questionários: a) atmosfera percebida; b) qualidade ambiental

○ navegação pelo cenário 2

○ remoção do aparato e descanso de um minuto

○ preenchimento dos questionários: a) atmosfera percebida; b) qualidade ambiental

○ navegação pelo cenário 3

○ remoção do aparato e descanso de um minuto

○ preenchimento dos questionários: a) atmosfera percebida; b) qualidade ambiental

Fonte: elaboração própria

Por razões operacionais, o período de realização do experimento foi dividido em dois momentos, o primeiro em maio e o segundo em setembro de 2016 na cidade de João Pessoa/PB. Esta opção não teve impacto no experimento, uma vez que foi desenvolvido em ambientes virtuais tridimensionais, cuja influência externa, por 
exemplo de condições meteorológicas, não era relevante, e quando a era, no caso de interferências acústicas durante o experimento, estas eram minimizadas.

Ao todo, 45 pessoas participaram do experimento consolidado, com idades entre 15 e 50 anos, sendo 25 (56\%) pessoas do sexo feminino e 20 (44\%) do sexo masculino. Do total de participantes, 32 pessoas $(71 \%)$ declaram não conhecer a tecnologia envolvida no experimento, enquanto 35 pessoas $(78 \%)$ informaram ter familiaridade com o local (FIG. 48).

Figura 48 - características demográficas dos participantes e níveis de familiaridade com o local e tecnologia
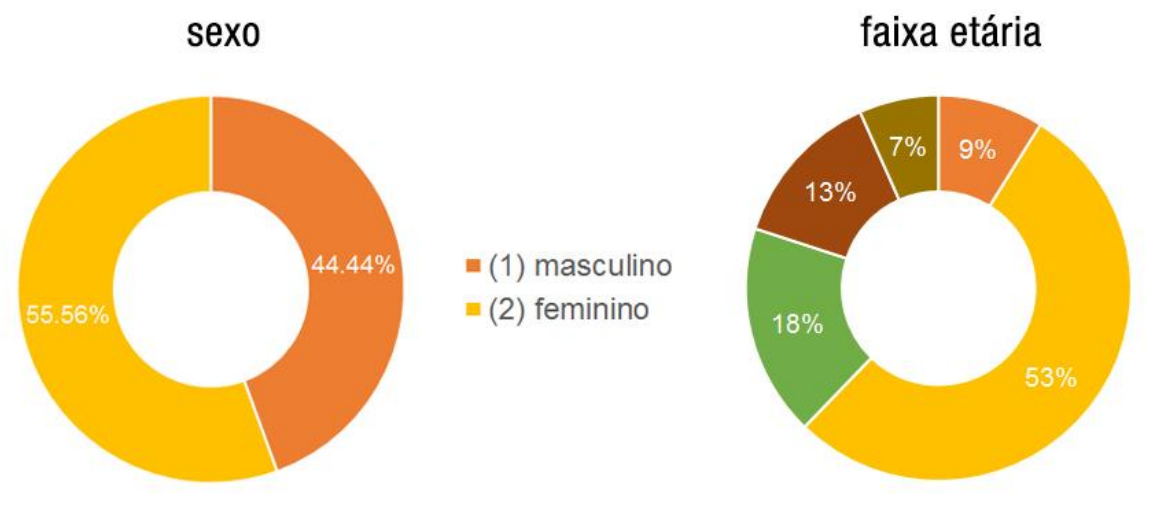

- (1) até 20 anos

- (2) 21 a 30 anos

- (3) 31 a 40 anos

- (4) 41 a 50 anos

- (5) mais de 50 anos

familiaridade com a tecnologia
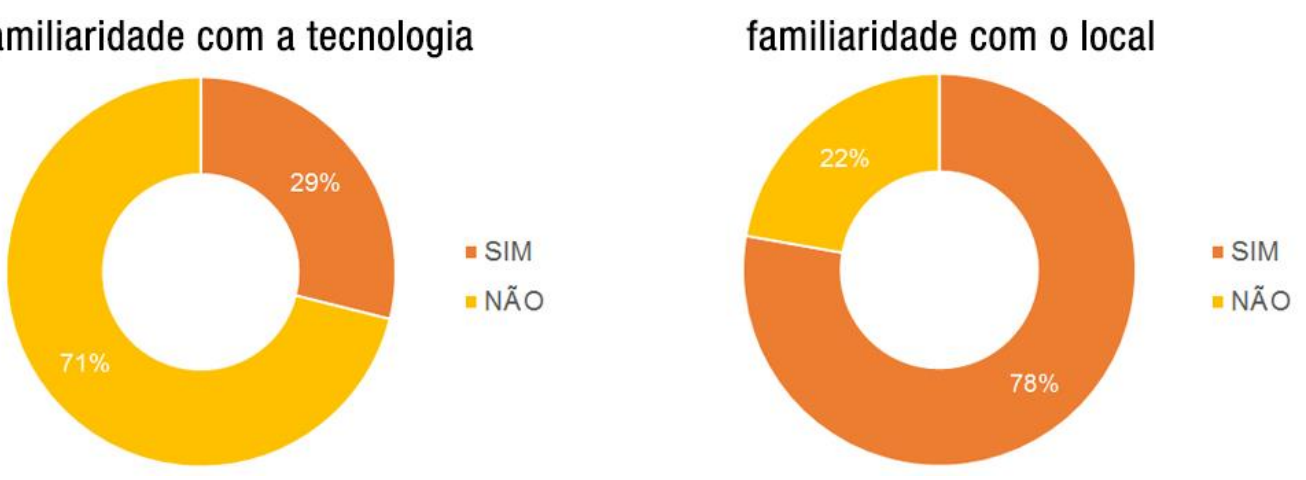

Fonte: elaboração própria

Após a etapa inicial, os participantes recebiam instruções do funcionamento do aparato, sua navegação pelo ambiente e visualização dos espaços através dos óculos de realidade virtual. Devido à possibilidade de visualização do cenário em 360 graus, era sugerido aos participantes ficarem em pé. Além disto, fones de ouvido - reproduzindo sons característicos do espaço urbano - foram disponibilizados para melhor imersão no espaço virtual. Vale salientar que para a adequada execução da pesquisa, os locais onde os experimentos aconteciam atendiam requisitos a fim de minimizar influencias 
externas e não perturbar a avaliação feita, como janelas fechadas para impedir ruídos indesejáveis e espaço livre de obstáculos.

Figura 49 - utilização do aparato tecnológico e trajeto básico de exploração do espaço

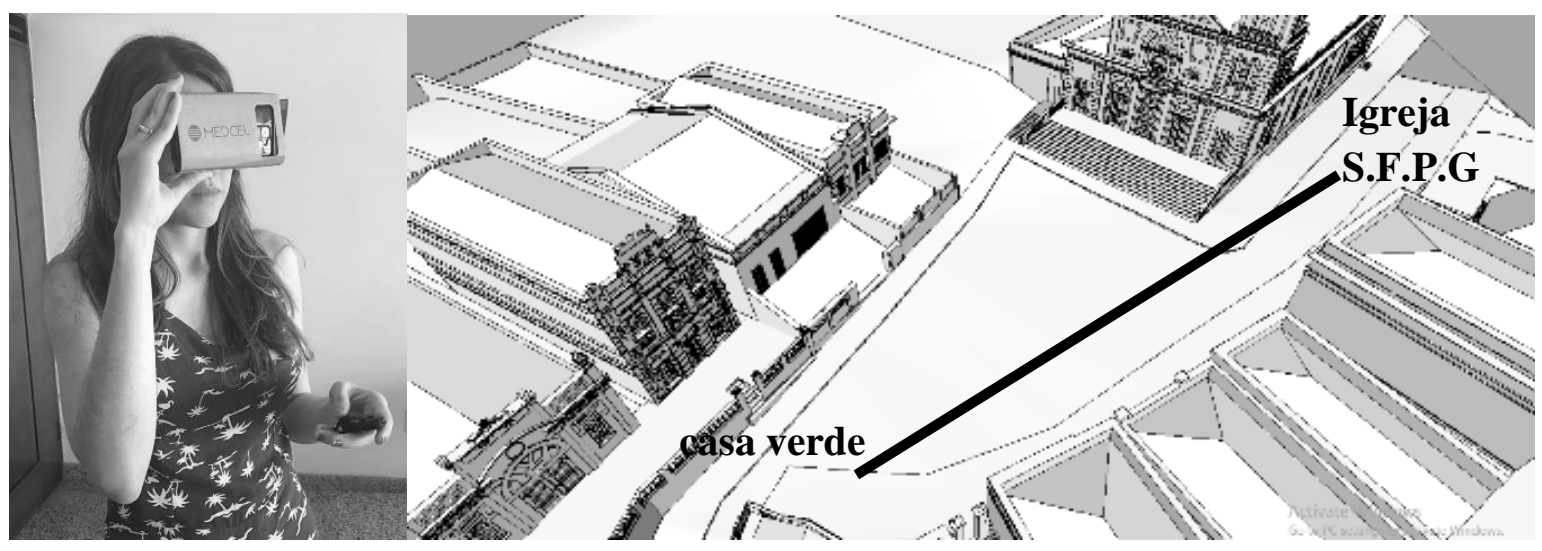

Fonte: elaboração própria

O dispositivo de realidade virtual foi utilizado de maneira semelhante ao estudo piloto, ou seja, exploração do local em período de tempo limite de 2 minutos, além de sugestão de percurso básico para apreciação do espaço. O trajeto tinha por objetivo a visualização de múltiplas perspectivas, desde o início até o final do largo - uma linha reta em direção à casa verde - para então voltar ao local de origem, junto à igreja de São Frei Pedro Gonçalves (FIG. 49).

Por fim, os usuários removiam o aparato para descanso de 1 minuto, e a cada cenário explorado era solicitado o preenchimento dos questionários correspondente. O processo repetia-se para os dois cenários restantes. A escolha do preenchimento do questionário logo após a visualização do espaço deu-se por dois motivos: a) alternância entre participantes, que poderiam participar do experimento no mesmo período, enquanto uma pessoa preenchia o questionário; b) minimizar a influência da comparação entre cenários, tendo em vista que o objetivo da pesquisa era a percepção do usuário para cada ambiente iluminado.

A etapa dos questionários teve duas abordagens. A primeira envolveu questões sobre as impressões do espaço onde o usuário estava inserido virtualmente, através do conceito de atmosfera desenvolvida por Vogels (2008). A segunda diz respeito à qualidade do espaço e da iluminação, lançando mão de termos que descrevem esteticamente o ambiente (agradável/desagradável, bonito/feio, atraente/não 
atraente) e termos referentes aos efeitos da luz na impressão dos usuários (claro/sombrio, monótono/interessante, quente/frio).

Os 22 termos selecionados em cada dimensão da atmosfera percebida, aplicados no estudo piloto, foram revisados pela literatura, e redistribuídos ao longo das quatro dimensões (TAB. 12), seguindo as recomendações de Van Erp (2008), cuja pesquisa segue os caminhos de Vogels (2008) ao investigar a atmosfera do lugar.

Tabela 12 - Resumo das quatro dimensões e distribuição entre tabelas estudo piloto

\begin{tabular}{ll|rr} 
aconchego & ânimo & tensão & distanciamento \\
\hline acolhedor & vivaz & estressante & acessivel \\
seguro & estimulante & assustador & familiar \\
romântico & agitado & deprimido & exclusivo \\
relaxado & alegre & intimidador & desinibido \\
agradável & inspirado & desconfortável & \\
tranquilo & sociável & tedioso &
\end{tabular}

experimento consolidado

\begin{tabular}{ll|rr} 
aconchego & ânimo & tensão & distanciamento \\
\hline acolhedor & vivaz & estressante & tedioso \\
seguro & estimulante & assustador & exclusivo \\
romântico & alegre & deprimente & acessível \\
relaxante & inspirador & intimidador & \\
agradável & & desconfortável & \\
tranquilo & & agitado & \\
sociável & & & \\
familiar & & & \\
desinibido & &
\end{tabular}

Fonte: elaboração própria

Assim, os participantes deveriam assinalar o grau de aplicabilidade dos termos que descrevessem as percepções em cada ambiente virtual. Para isto, foi utilizada a escala Likert de 5 pontos com respostas variando entre $-2 \mathrm{a}+2$, correspondendo desde fortemente inaplicável a fortemente aplicável, respectivamente (FIG. 50) 
Figura 50 - questionário utilizado com os termos de atmosfera percebida e escala Likert

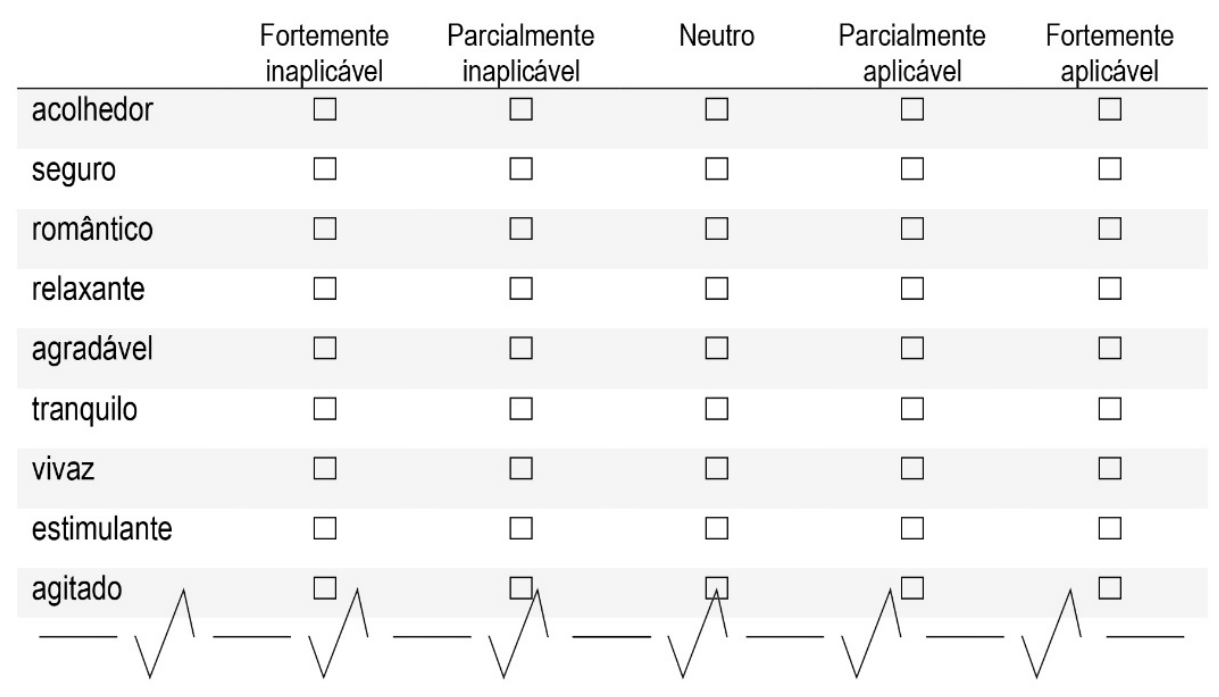

Fonte: elaboração própria

Caso o participante não se sentisse confortável em responder ou não soubesse como descrever o ambiente a partir dos termos existentes, poderia marcar a opção neutro (o) ou acrescentar alguma observação na pergunta ao final do questionário.

Na segunda abordagem do questionário, é tratado aspectos relacionados à qualidade do cenário explorado, utilizando-se da escala semântica diferencial, que busca investigar como os usuários percebem o ambiente do ponto de vista da preferência ambiental e do entendimento quanto a iluminação do espaço estudado (FIG. 51). São termos com significados opostos variando de -2 a +2, como por exemplo bonito/feio, claro/sombrio, quente/frio. 
Figura 51 - questionário da qualidade ambiental e qualidade da iluminação

\begin{tabular}{lcccccc}
\hline & -2 & -1 & 0 & +1 & +2 & \\
\hline desagradável & $\square$ & $\square$ & $\square$ & $\square$ & $\square$ & agradável \\
\hline não atraente & $\square$ & $\square$ & $\square$ & $\square$ & $\square$ & atraente \\
\hline feio & $\square$ & $\square$ & $\square$ & $\square$ & $\square$ & bonito \\
\hline
\end{tabular}

Avaliação das qualidades da iluminação em escala de 5 pontos contendo palavras com significados opostos

\begin{tabular}{lcccccr}
\hline & -2 & -1 & 0 & +1 & +2 & \\
\hline sombrio & $\square$ & $\square$ & $\square$ & $\square$ & $\square$ & claro \\
\hline monótono & $\square$ & $\square$ & $\square$ & $\square$ & $\square$ & interessante \\
\hline frio & $\square$ & $\square$ & $\square$ & $\square$ & $\square$ & quente
\end{tabular}

Fonte: elaboração própria

Os questionários aplicados são complementares à medida em que o conceito de atmosfera percebida se relaciona com a qualidade do ambiente, ao verificar que a iluminação tem capacidade de melhorar do espaço. A relação entre os termos de Vogels e parâmetros estéticos também é importante, de forma a investigar conexões entre um espaço agradável, bonito e um ambiente acolhedor e seguro. Quanto aos efeitos de luz, da mesma forma pode-se verificar se os participantes compreendiam os termos os quais estavam atribuindo valores ou se as variáveis de iluminação surtiam efeito nas respostas da atmosfera. Por exemplo, existe correspondência entre as respostas aos termos quente/frio e à temperatura de cor utilizada nos cenários?

A análise dos resultados permite ao pesquisador (ou ao projetista) identificar aspectos que influenciam a qualidade do ambiente a partir do que o usuário estabelece como agradável, interessante ou monótono. Do ponto de vista da luz, estudos indicam que variáveis de iluminação desempenham papel fundamental na percepção (VEITCH, 2001). Também, o entendimento do participante sobre estes aspectos deve guiar tendências e criar potencialidades na área de pesquisa. 
CAPÍTULO 4

Resultados 
A partir da análise da atmosfera nos três cenários noturnos foi possível verificar tendências sobre a influência da iluminação na percepção dos usuários e como estes dados podem auxiliar na tomada de decisões em projeto de iluminação no espaço urbano.

\subsection{Procedimentos preliminares}

Do ponto de vista da qualidade ambiental, a leitura dos gráficos demonstra como os participantes percebiam os cenários explorados a partir de termos como agradável/desagradável, claro/sombrio, quente/frio. Esta etapa do questionário tornase fundamental à medida em que se consegue estabelecer relações com a atmosfera percebida do ambiente, por exemplo ao comparar o parâmetro quente e frio com os cenários de temperaturas de cor diferentes, dito cenário 2 e 3 e verificar se há correspondência na compreensão dos termos.

Antes do experimento, foi detectada a expectativa dos participantes a partir da questão: qual aspecto mais importante para melhor uso dos espaços a noite? A resposta mais recorrente é a sensação de segurança, com pouco mais da metade da preferência dos usuários (53,3\%), enquanto as ambiências provocadas (17,78\%) e conforto visual (15,56\%) configuram no segundo e terceiro lugar, respectivamente (FIG. 52).

Figura 52 - opiniões sobre o aspecto mais importante para melhor uso dos espaços à noite

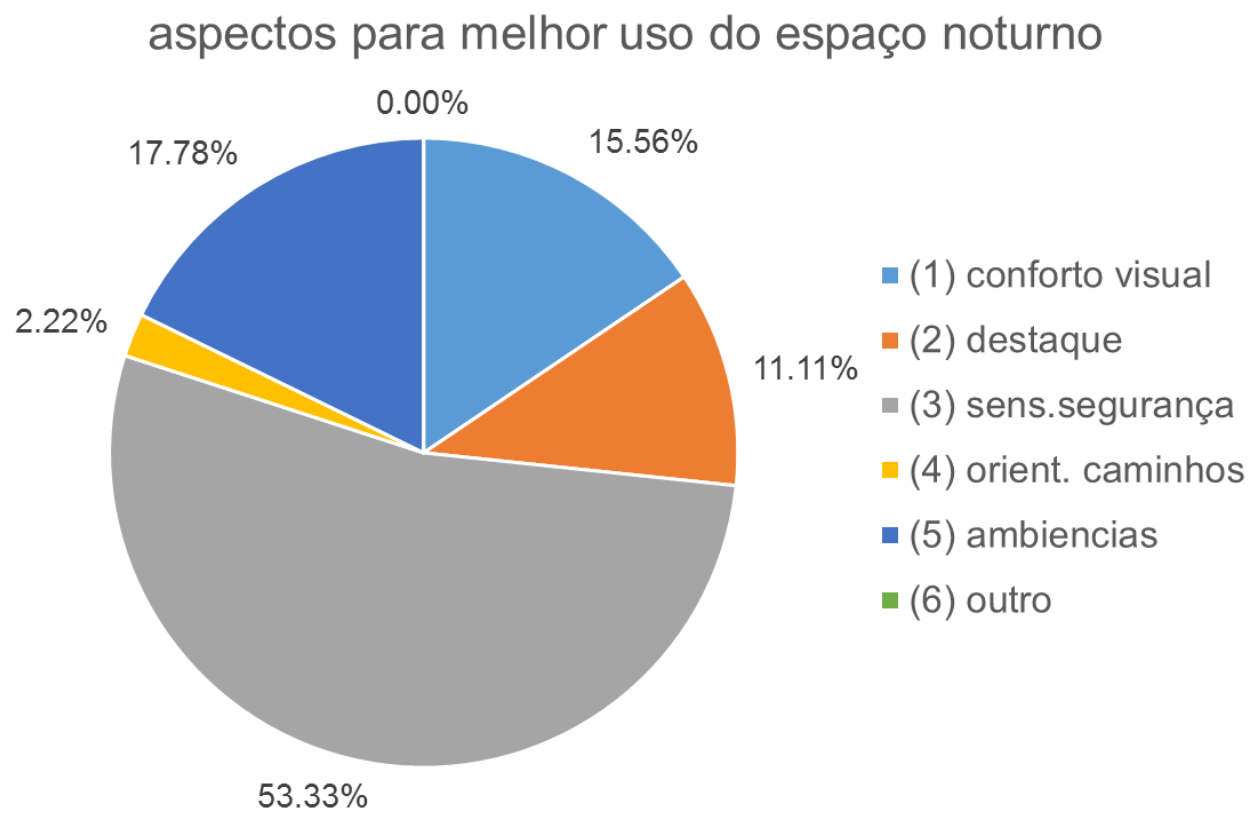

Fonte: elaboração própria 
Estes dados configuram-se como necessidades e expectativas dos usuários perante o espaço público noturno, algo que os projetistas almejam alcançar através da intervenção pela iluminação no espaço público.

\subsection{Atmosfera percebida (Vogels)}

Definidos em Cenário 1, Cenário 2 e Cenário 3, respectivamente ambiente com iluminação atual, ambiente com iluminação proposta em temperatura de cor quente e ambiente com iluminação proposta em temperatura de cor fria, as dimensões de atmosfera percebida de Vogels foram obtidas.

Para a melhor compreensão das informações, possibilitando a fácil visualização dos dados, os resultados dos 45 participantes do experimento foram analisados a partir da média de cada termo de atmosfera. Este procedimento possibilitou não só a criação de gráficos comparativos entre cenários para cada um dos termos, mas também do gráfico síntese da atmosfera percebida, visualizada sob as dimensões aconchego (coziness), ânimo (liveliness), tensão (tenseness) e identidade/pertencimento (detachment).

Os valores apresentados nos gráficos dizem respeito ao nível de aplicabilidade do termo ao ambiente em questão, ou seja, quanto mais próximo ao $-2 \mathrm{ou}+2$, o termo é caracterizado como "fortemente inaplicável" ou "fortemente aplicável", respectivamente. Os gráficos devem ser lidos como uma escala de intensidade, ou seja, quanto maior o nível em dado termo, mais aplicável ele demonstra ser para o cenário correspondente.

\subsubsection{Primeira dimensão: Aconchego}

A primeira dimensão, aconchego (coziness), compreende termos que descrevem o ambiente positivamente, desde "acolhedor", "seguro", "romântico", "relaxante", "agradável, "tranquilo", "sociável", "familiar" e "desinibido", e através da análise notam-se aspectos importantes na percepção dos usuários inseridos nos três cenários noturnos (FIG. 53). 
Figura 53 - gráfico da dimensão aconchego

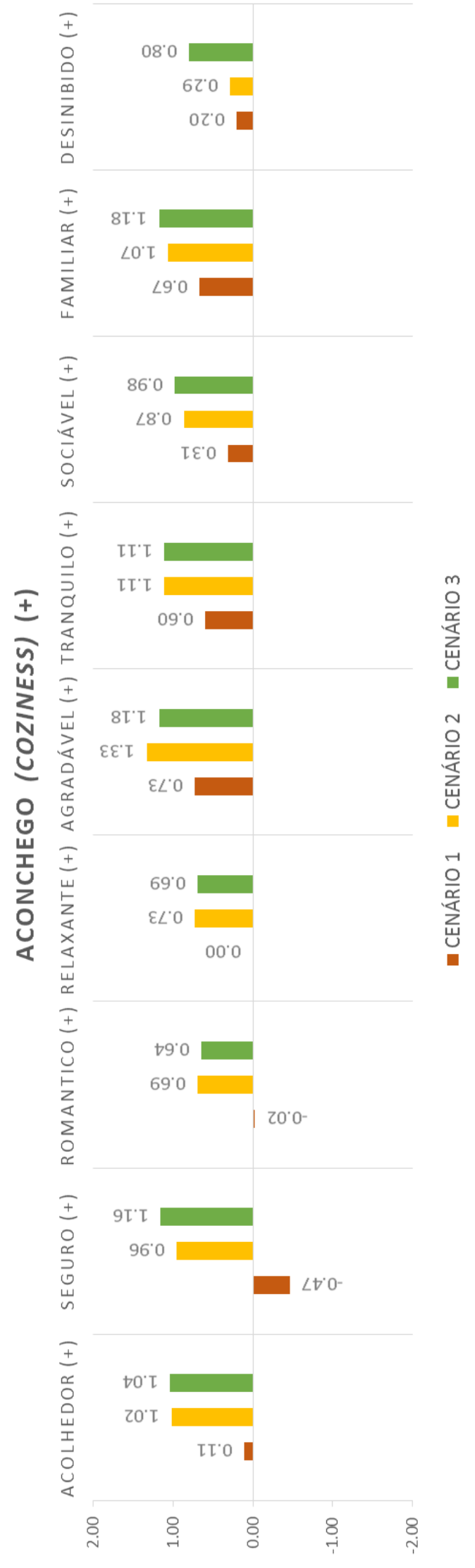

Fonte: elaboração própria 
De maneira geral, o cenário 1 apresenta valores desfavoráveis se comparado com os cenários 2 e 3, o que significa que o ambiente é considerado menos agradável do que os outros. Um caso importante está no termo "seguro", com valor negativo, enquanto os cenários restantes possuem médias maiores para o termo em questão. Visto isto, a mudança de iluminação funcionou como um fator relevante para melhoria do espaço.

Também, é interessante verificar como apesar de agradável, familiar e tranquilo (talvez porque de dia assim o aparenta), os resultados demonstram que o sentimento que transmite é de insegurança. Esta situação é contornada nos restantes cenários, os quais aparentam ser mais homogêneos e coerentes, com o termo relacionado com a segurança apresentando valores semelhantes à tranquilidade, romantismo, relaxamento, acolhimento. A mudança de variáveis de iluminação em comparação com a situação existente corrobora a sensação de segurança e agradabilidade encontrada em pesquisas a respeito da relação entre estes dois parâmetros (FOTIOS; CHEAL; BOYCE, 2005; KNIGHT, 2010).

Particularmente, a maior sensação de segurança foi reconhecida no cenário 3, cuja iluminação com temperatura de cor fria é apresentada com maior percepção de luz devido a fatores fisiológicos da luz no olho humano (PEÑA-GARCÍA, HURTADO E AGUILAR-LUZÓN, 2015), apesar de o aspecto da relação fisiologia e iluminação não ser contemplada nesta pesquisa.

O termo familiar, no sentido de sensação de intimidade e respeito mútuo, foi considerado em maior grau nos cenários com iluminação proposta (2 e 3) em detrimento da condição real (1). Aqui se conectam alguns descritores, como romântico e agradável. Por fim, o termo "desinibido" possui relação com a capacidade de interações sociais, que sugerida pela influência da iluminação na paisagem tem no cenário 3 seu maior nível.

\subsubsection{Segunda dimensão: Ânimo}

As características da dimensão ânimo (liveliness) seguem a mesma linha dos termos anteriormente citados, através da capacidade do ambiente em promover interações sociais e manifestações culturais. O cenário 1 não satisfaz os participantes na maioria dos termos avaliados, enquanto os outros cenários seguem uma constante homogênea. Entretanto, aqui os indicadores parecem mais precisos, favorecendo a análise dos resultados. (FIG. 54) 
Figura 54 - gráfico da dimensão ânimo

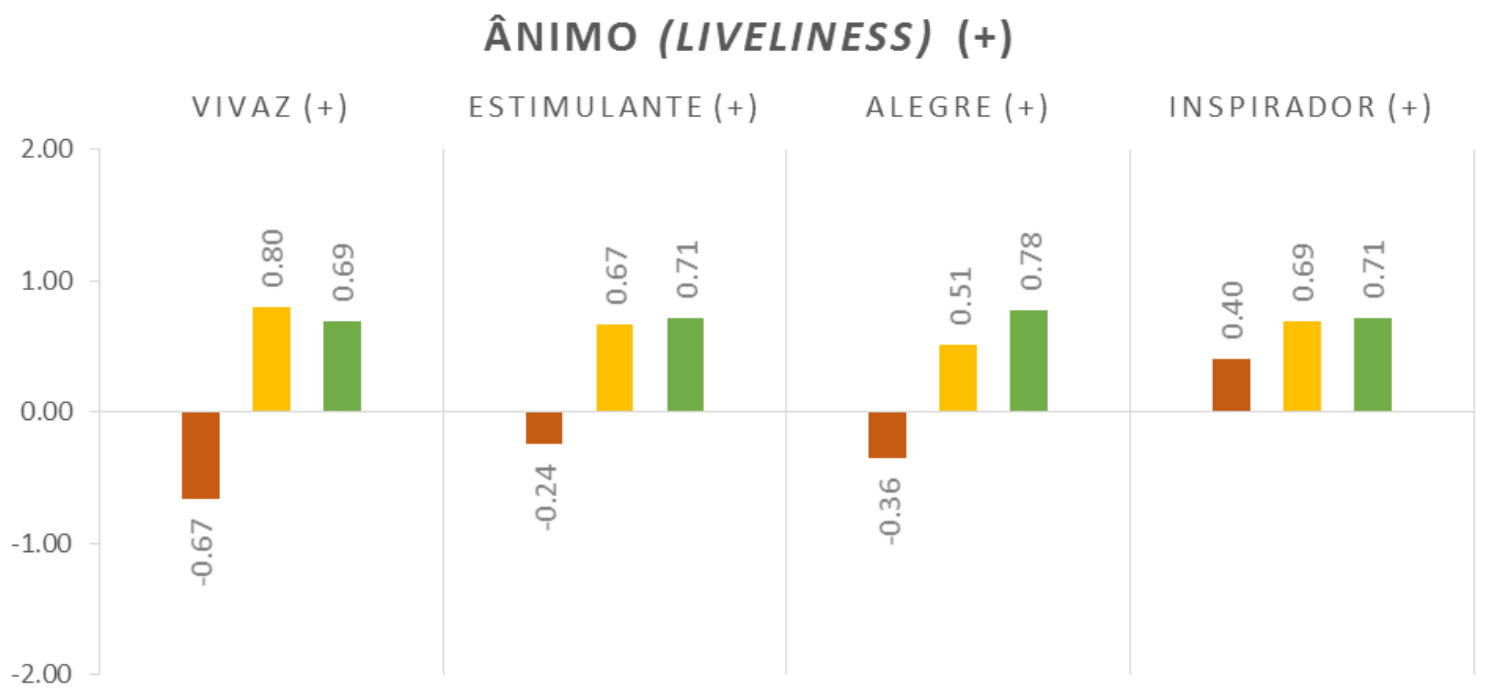

- CENÁRIO 1 -CENÁRIO 2 -CENÁRIO 3

Fonte: elaboração própria

Os cenários 2 e 3, que possuem cuidados de projeto, foram mais bem avaliados para os termos da dimensão ânimo do que a situação existente. Particularmente, estes termos relacionam-se com aspectos de urbanidade, caracterizada pela diversidade de perfis, gêneros e classes sociais, coexistindo na dinâmica da cidade noturna. Aguiar (2012) descreve o conceito de como um tipo de espacialidade, ao relacionar o espaço e as pessoas. Refere-se ao modo como os espaços públicos e coletivos acolhem as pessoas, sejam elas habitantes ou estranhos, pois "para que estranhos se interessem em passar por ali é evidente que o lugar tem que ter alguma atratividade [...] Portanto, configuração e atratores se complementam na realização da urbanidade" (AGUIAR, 2012).

A iluminação funciona como um fator de atratividade, se planejada a partir de necessidades e expectativas das pessoas que usufruem do espaço. O termo estimulante, por exemplo, ao ser mais bem avaliado nos cenários propostos, denota um espaço noturno com grau de interação elevado, tendo em vista que o cenário existente é caracterizado pela baixa capacidade de promover tais atividades (GEHL, 2010).

Os resultados também demonstram que ao passo que há uma melhora nos termos analisados entre os cenários propostos (2 e 3) e a situação existente, (1) o cenário 1 apresenta-se como inspirador enquanto se configura como um espaço pouco vivaz, alegre e estimulante. O termo inspirador pode se relacionar aos de Kaplan 
(1987), que descreve o ambiente a partir da quantidade de informação existente, como mistério e complexidade, estimulando o usuário a um engajamento para obter mais informações sobre o lugar. A iluminação revela uma variedade de elementos presentes no cenário, de forma a facilitar compreensão imediata de um todo coerente.

\subsubsection{Terceira dimensão: Tensão}

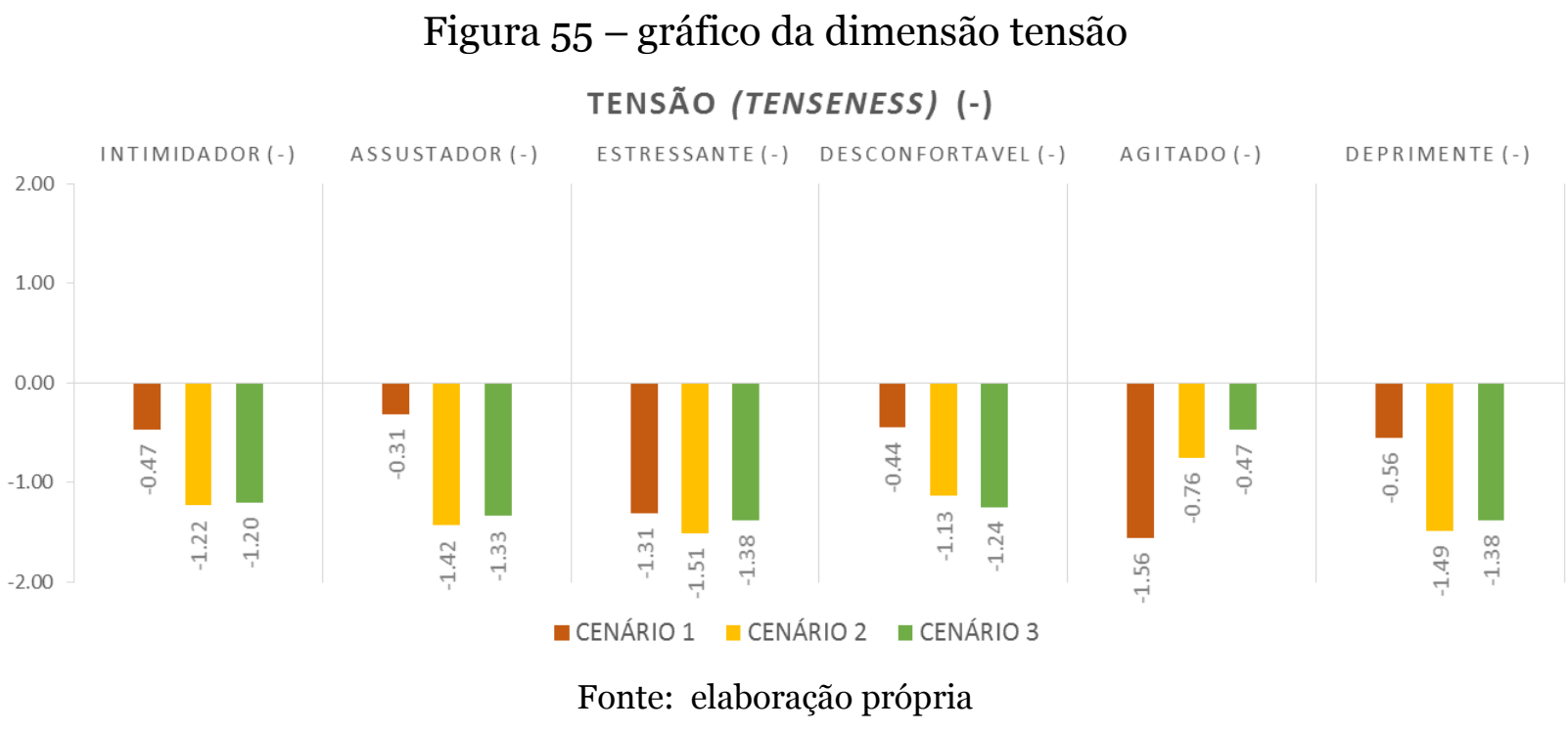

Termos que descrevem o ambiente negativamente são categorizadas sob a dimensão tensão (tenseness). Em nenhum cenário foi constatada a dimensão tensão para caracterizar o ambiente, pois todos os termos apresentaram valores negativos, o que resulta em uma avaliação positiva para o ambiente em função do sinal negativo da própria dimensão (FIG. 55). Comparativamente, a análise dos dados mostra o cenário 1 com níveis de tensão superiores aos cenários 2 e 3. Isto é natural, tendo em vista que a dimensão aconchego funciona como a face oposta da tensão. Deste modo, a ligação que é possível fazer diz respeito à sensação de segurança, relevante na primeira dimensão (onde o cenário 1 apresentou valor negativo, ou seja, não aplicável), através de termos como intimidador e deprimente, justificando de certa maneira a percepção dos usuários neste sentido.

Os resultados da primeira dimensão descrevem o cenário existente (1) como sendo um espaço agradável, tranquilo e familiar, em menor grau se comparado com os cenários propostos. Entretanto, existe significativa diferença nos termos da dimensão tensão, intimidador, assustador, desconfortável e deprimente, cujos resultados demonstram um sentimento de insegurança e desconforto ao mesmo tempo em que é 
considerada agradável. Esta situação torna-se mais coerente na análise dos cenários onde foi realizada a intervenção da iluminação (2 e 3)

Também, vale salientar a relevância do termo agitado, onde o cenário 1 é mais bem avaliado do que os cenários 2 e 3, ou seja, a percepção dos usuários é de que este ambiente é menos agitado do que os outros. Pode ser o caso de palavras com sentidos ambíguos, que foram mal compreendidas pelos participantes. Especificamente, este termo pode ter a conotação oposta, se for considerado que o espaço é agitado por conter aspectos que promovam agitação positivamente (algum evento efêmero, por exemplo). Esta interpretação dos sentidos pode estar associada à parâmetros como idade dos participantes e contexto local (KNEZ, 1995; FERNANDEZ, 2012).

\subsubsection{Quarta dimensão: Identidade/Pertencimento}

A última dimensão, identidade/pertencimento (detachment), tem aspectos relacionados ao comportamento e impressão que o espaço subjuga ao usuário.

Figura 56 - gráfico da dimensão identidade/pertencimento

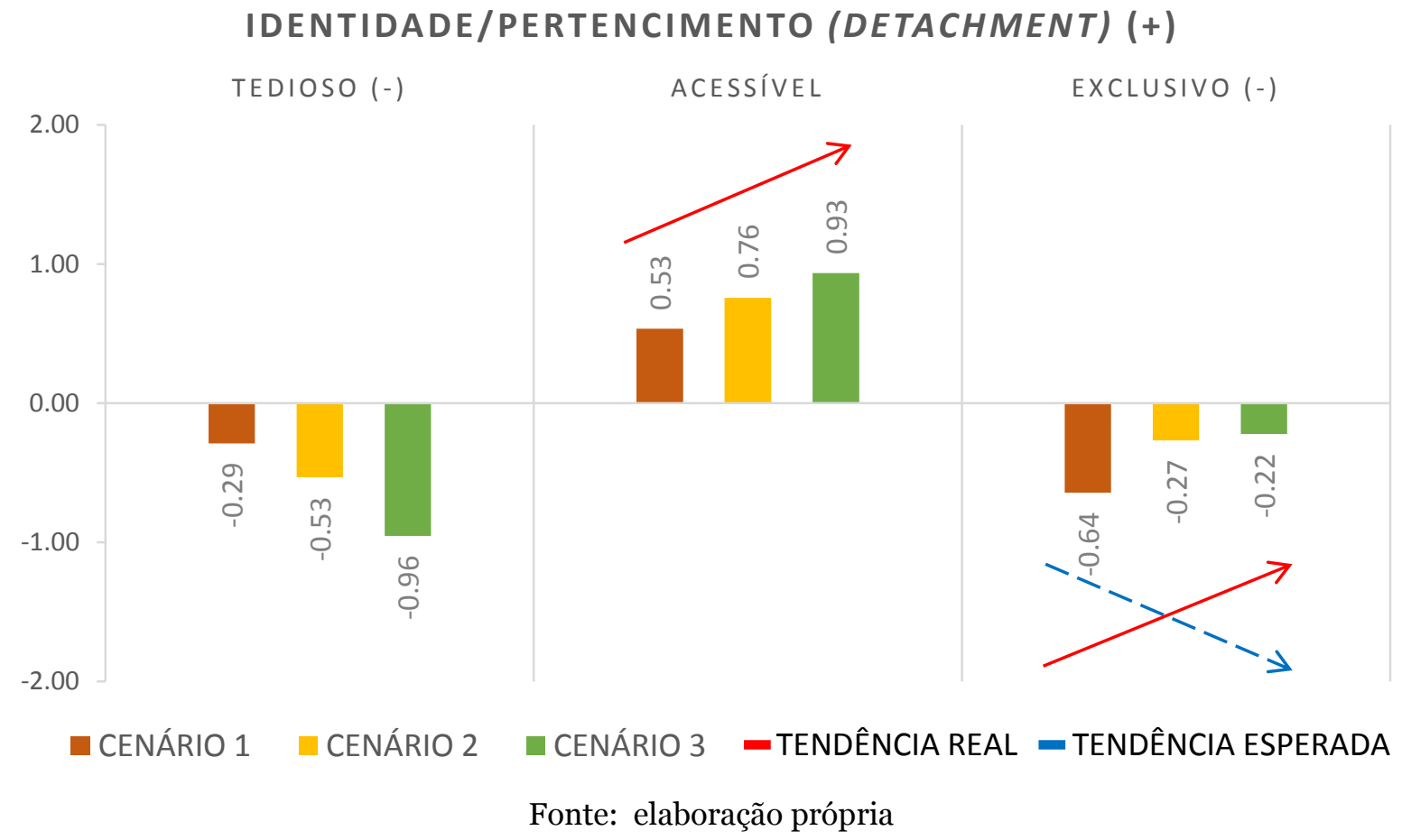

Originalmente, identidade/pertencimento continha três termos que descrevem o ambiente segundo esta dimensão, sendo eles tedioso, acessível e exclusivo (FIG. 56). Entretanto, observa-se que os termos acessível e exclusivo possuem significados antagônicos, contrariando-os, cujos resultados apresentam-se diferente do esperado. 
Por exemplo, o cenário 3 é avaliado como mais acessível ao mesmo tempo em que é mais exclusivo se comparado com os cenários restantes. De acordo com a figura, a tendência esperada seria caracterizada justamente pelo oposto, ou seja, o terceiro cenário ser menos exclusivo.

Durante a análise dos dados, este fenômeno foi encontrado, sendo necessário revisa-lo à luz das considerações dos autores que trabalham com o conceito de atmosfera percebida. Van Erp (2008), a partir de procedimentos estatísticos (análise fatorial), encontra as quatro dimensões e distribui seus termos de acordo com valores obtidos. Enquanto que os termos exclusivo e tedioso alcançaram pontuações satisfatórias para serem incluídas em identidade/pertencimento, o mesmo não se pode dizer do termo acessível, onde o pouco impacto nesta dimensão ocasionou sua exclusão. Portanto, esta dimensão contém os dois termos restantes, que não se anulam, e caracteriza-se por ativar comportamentos específicos no usuário inserido no espaço.

Um ambiente é considerado exclusivo, por exemplo, ao entender que ele pressupõe padrões de comportamento e status. É o ambiente em uma loja de marca que induz a certa classe social e poder aquisitivo dos consumidores. O mesmo pode ocorrer em espaços urbanos abertos, em intervenções como cerramento de áreas públicas através de grades.

Figura 57 - gráfico da dimensão identidade/pertencimento

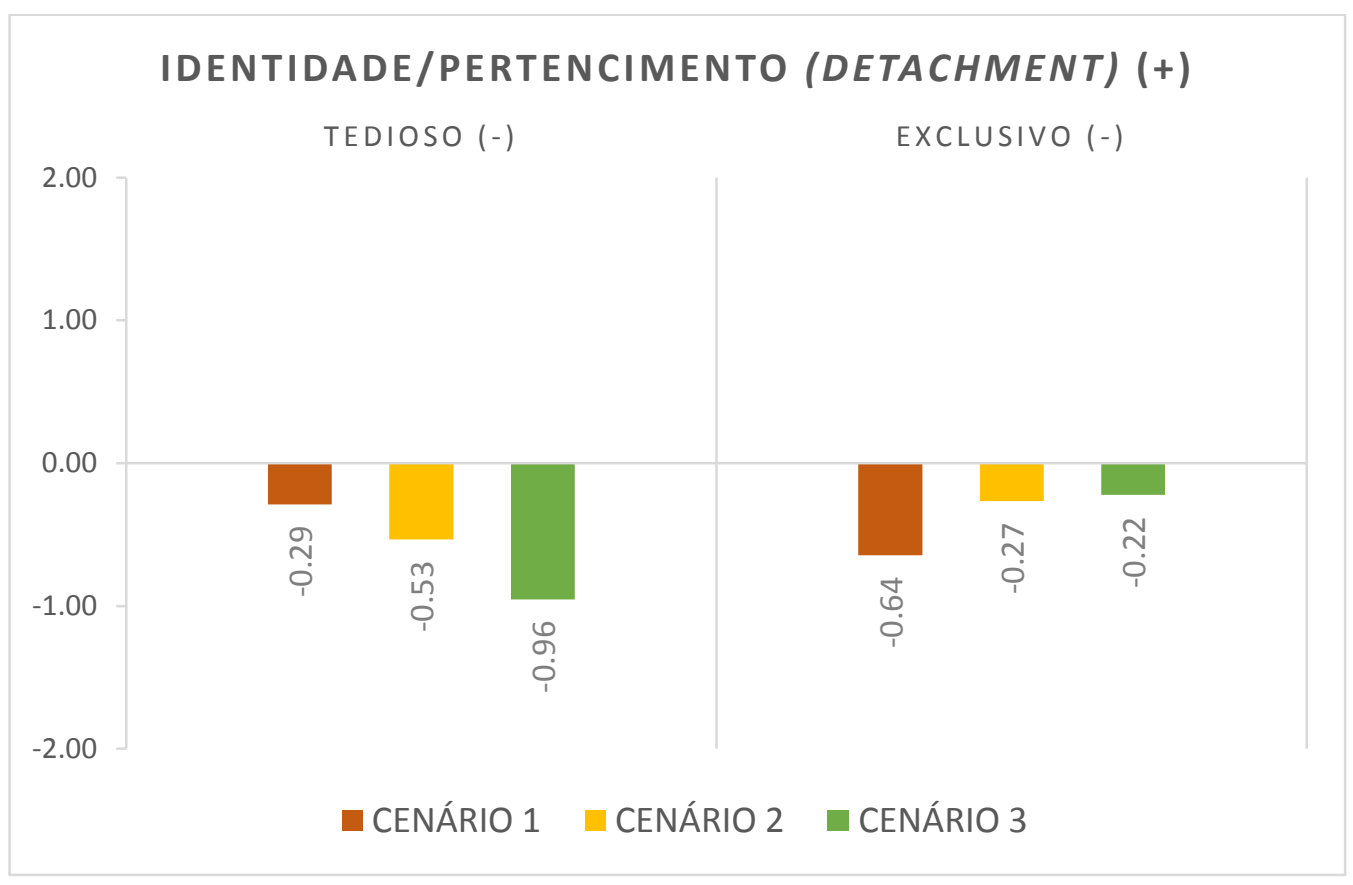

Fonte: elaboração própria 
De acordo com os resultados (FIG. 57), ainda houve tendências inversas entre os termos da dimensão, de tal sorte que o cenário 3 é mais bem avaliado no quesito tedioso, ou seja, foi considerado com mais opções de atratividade pelos participantes se comparado com o cenário existente (1). Mesmo assim, os termos não se contrariam, e os resultados foram analisados. O inverso acontece no termo seguinte, exclusivo, onde o cenário 1 é mais bem avaliado do que os cenários propostos.

Vale salientar, portanto, a relevância da correta interpretação dos termos estudados, como exposto anteriormente sobre o termo agitado na dimensão tensão. Aqui, percebe-se que a compreensão do termo acessível é de maior precisão do que exclusivo, tendo em vista seus significados (uma no sentido de exclusão e outra no sentido de exclusividade), o que pode indicar a interpretação pelos participantes não esperada pelo pesquisador. Também, em prol do rigor científico e coerência, esta pesquisa baseou-se no arcabouço teórico existente, lançando mão de procedimentos metodológicos corretos, a fim de não favorecer a análise das dimensões, influenciando o resultado final.

\subsubsection{Síntese da Atmosfera percebida}

O gráfico síntese das dimensões avaliadas possibilita a visualização das impressões dos participantes de maneira generalizada e ampla, de maneira a verificar se as intenções de projeto refletem as expectativas dos usuários no tocante às dimensões aconchego, ânimo, tensão e identidade (FIG. 58).

Figura 58 - gráfico síntese da atmosfera percebida

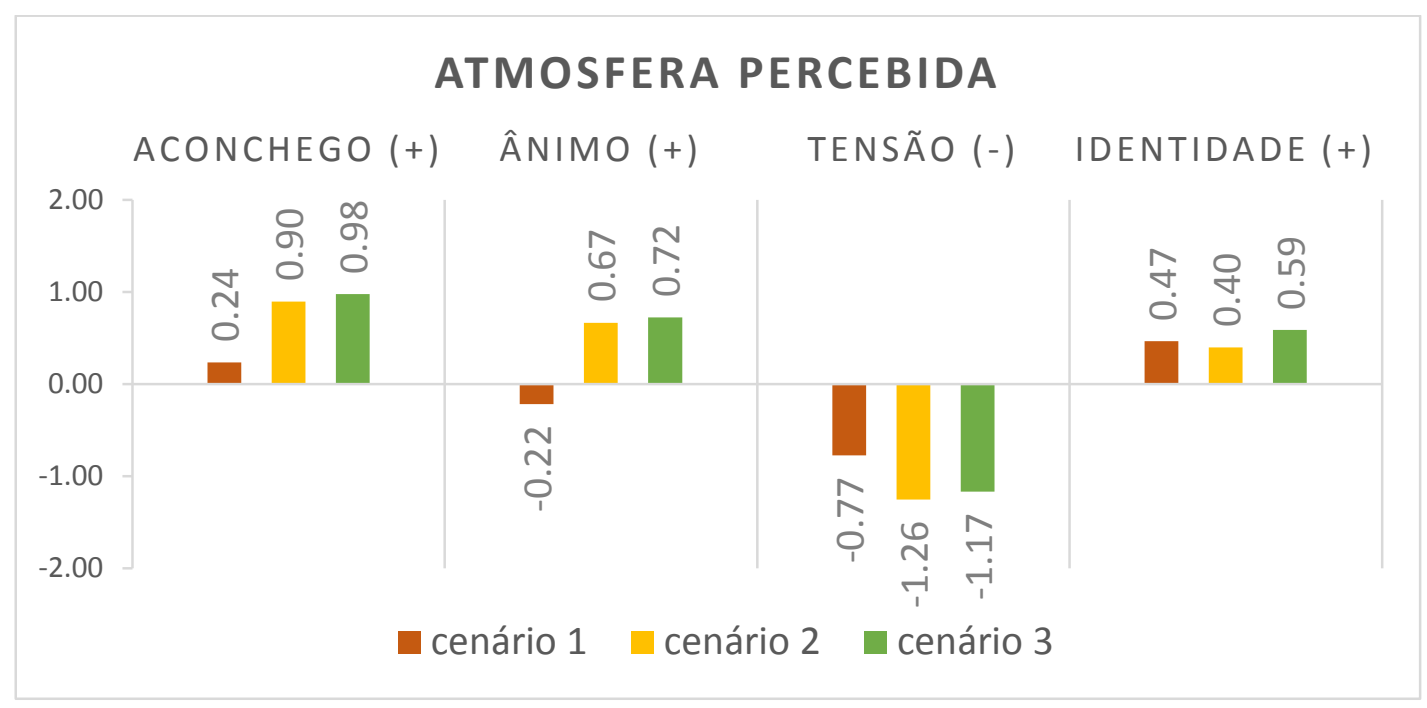

Fonte: elaboração própria 
Sendo assim, os ambientes demonstraram qualidades positivas em relação ao cenário da situação existente (Cenário 1), sendo evidente o melhor desempenho dos espaços urbanos onde existiram cuidados de projeto (cenários 2 e 3). Principalmente no tocante à segurança, inseridos sob a dimensão aconchego, é importante notar que a iluminação promoveu melhorias nestes quesitos, almejado pelos participantes quando responderam sobre a pergunta do aspecto mais importante para melhor uso dos espaços a noite. Houve também melhores avaliações em questões relacionadas a sociabilização e agradabilidade do ambiente, corroborando com pesquisas recentes que descrevem a iluminação como fator fundamental no processo de dinamização do espaço público noturno (CASCIANI, 2014). Nota-se no gráfico síntese a coerência entre os cenários com projeto de iluminação, particularmente o cenário 3, caracterizado como o mais aconchegante e animador, ao passo que o cenário 1 é verificado com mais tensão e identidade.

Quanto a dimensão de tensão, notadamente os valores diminuíram nos cenários propostos (2 e 3), demonstrando a importância da iluminação para a melhoria do aspecto da paisagem à noite. De certa forma, as intenções do projetista em minimizar qualidades negativas do espaço foram alcançadas quando se investiga a dimensão tensão. Em identidade/pertencimento, é demonstrado uma dimensão difícil de compreender através dos cenários.

Percebe-se uma leve melhora no cenário 3 em comparação com o 1, enquanto o segundo cenário os valores foram mais baixos. Isto pode estar relacionado, de um lado, com a característica que este cenário tem de ser mais exclusivo, ao estimar que a temperatura de cor promoveu esta impressão, sendo motivo de reflexão para o projetista no processo de planejamento da luz. Por outro lado, deve-se refletir sobre a interpretação dos termos que integram esta dimensão pelos participantes, e a sua influência em outro contexto cultural, que no processo de tradução e adequação das palavras para a língua portuguesa, pode-se ter perdido certas nuances características da língua original.

As contradições identificadas na análise de cada dimensão refletem a complexidade das avaliações e a importância das dinâmicas inerentes ao espaço público como fator relevante para transpor ao ambiente virtual, não só em aspectos visuais, mas também sonoros e dinâmicos, para adequá-las à percepção do impacto da iluminação na paisagem noturna. 


\subsection{Qualidade ambiental dos cenários estudados}

Do ponto de vista da qualidade ambiental, a leitura dos gráficos demonstra como os participantes percebiam os cenários explorados a partir de termos como agradável/desagradável, claro/escuro, quente/frio. Esta etapa do questionário tornase fundamental à medida em que se consegue estabelecer relações com a atmosfera percebida do ambiente, por exemplo ao comparar o parâmetro quente e frio com os cenários de temperaturas de cor diferentes, dito cenário 2 e 3, e verificar se há correspondência na compreensão dos termos.

Os valores apresentados nos gráficos são gerados através de escalas semânticas diferenciais, ou seja, uma atribuição de valor entre conceitos antagônicos. Assim, termos como claro/escuro variam entre +2 e -2 , respectivamente.

O primeiro gráfico diz respeito à categoria agradável/desagradável (FIG. 59). O cenário 1 apresenta valores inferiores em comparação com os cenários restantes, onde houve a proposta de intervenção no espaço através da iluminação.

Figura 59 - gráfico correspondente aos termos agradável/desagradável

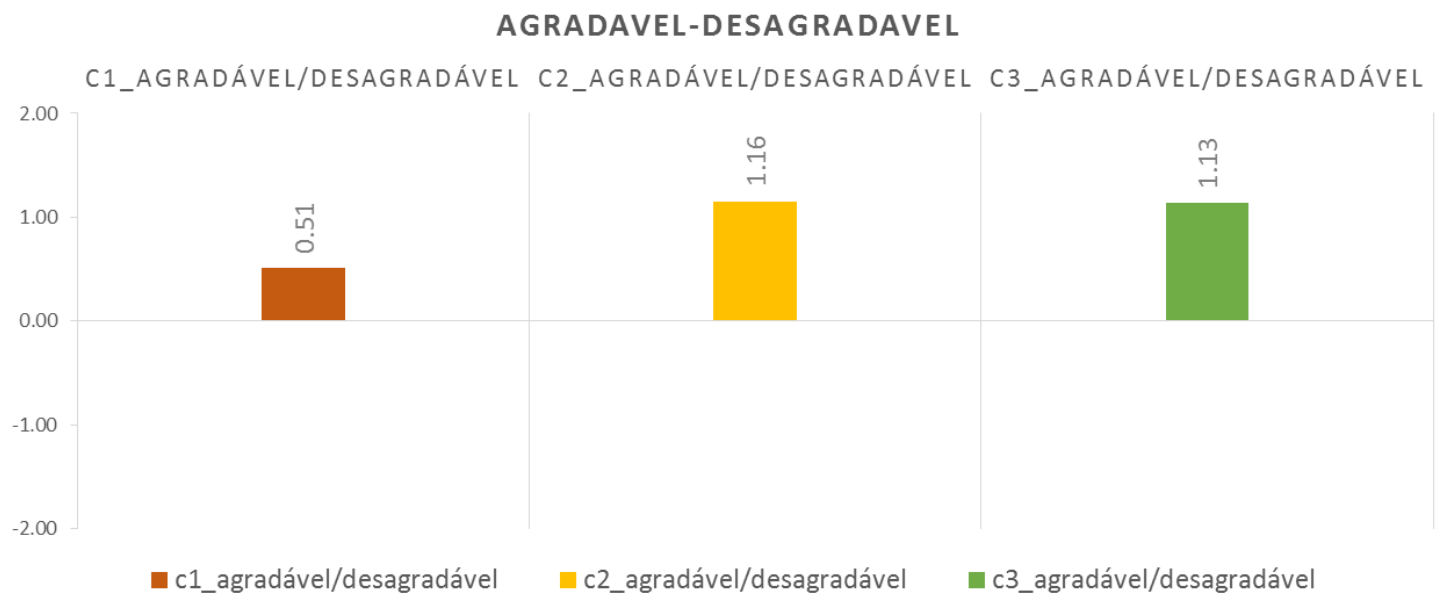

Fonte: elaboração própria

Os cenários propostos apresentaram melhoria em comparação com a situação existente (cenário 1), podendo-se inferir que ambos foram considerados agradáveis, com leve variação para o cenário 2 (para validações mais precisas, deve-se executar testes estatísticos a fim de verificar se a diferença entre cenários é significativa). Esta avaliação do ponto de vista dos participantes tende a justificar a preferência por ambientes iluminados adequadamente, mas também, esta preferência é importante no imaginário coletivo. 
Segundo Del-Negro (2012) e Skarlatou (2010), cenários que possuem fontes quentes representam maior aconchego e conforto devido a predominância destas fontes ao logo do século XX. Historicamente, eram utilizadas em áreas urbanas, como lampiões a óleo e gás a lâmpadas incandescentes, e ainda são muito lembradas em detrimento de lâmpadas com temperaturas frias, cujas lembranças tendem a ser locais onde são requeridas acuidade visual, performance e atenção, como escritórios e ambientes hospitalares.

A tendência se repete nos gráficos seguintes, atraente/não atraente e bonito/feio (FIG. 60). A preferência estética pelos cenários também é um aspecto importante para a compreensão holística dos resultados, visto que o projeto de iluminação deve aliar características que promovam interações sociais, seja aconchegante, minimizem questões relacionadas a tensão e denotem identidade e pertencimento ao ambiente.

Figura 60 - gráficos correspondentes aos termos atraente/não atraente e bonito/feio

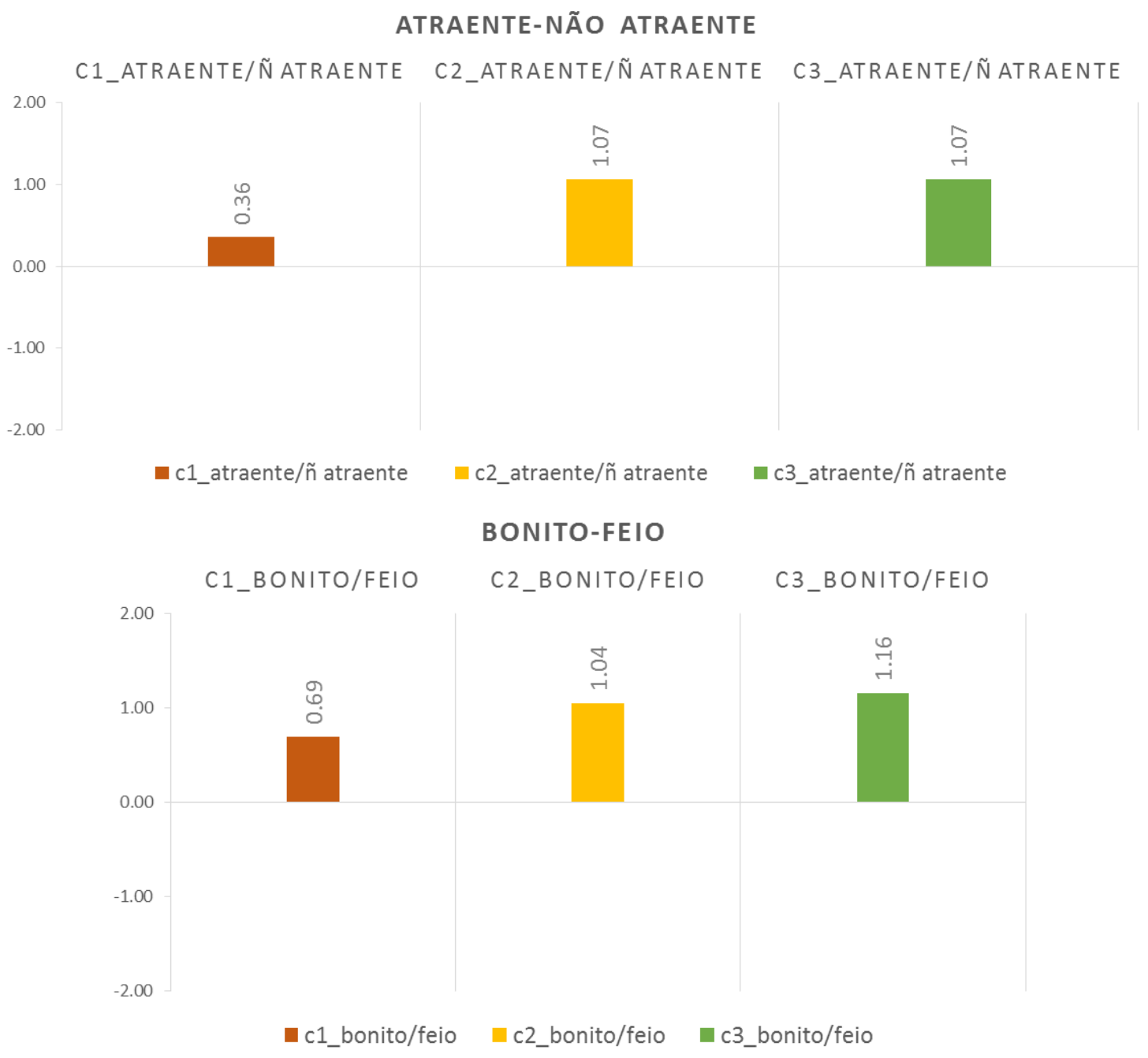

Fonte: elaboração própria 
Da mesma forma, esteticamente, este projeto deve prover sensação de agradabilidade, e, portanto, preencher o mínimo de requisitos no sentido de tornar o espaço bonito, legível, com graus de complexidade e coerência estabelecidos (KAPLAN, 1987). Aqui, os resultados servem como base para explorar estas questões, resultando de maneira geral na ampliação de características positivas quando comparados os cenários.

Quanto às características relacionadas a iluminação, os gráficos mostram aspectos interessantes a serem observados. Após a análise dos dados sobre os termos claro/escuro (FIG. 61), o cenário 1 foi considerado mais escuro entre os três ambientes, enquanto houve uma tendência à mudança de percepção nos cenários restantes, onde ambos possuem mesmo nível de iluminação, porém com temperatura de cor diferente. Assim, os cenários propostos apresentaram-se mais claros, em especial o cenário 3.

Figura 61 - gráfico correspondente aos termos claro/escuro

\section{CLARO-ESCURO}

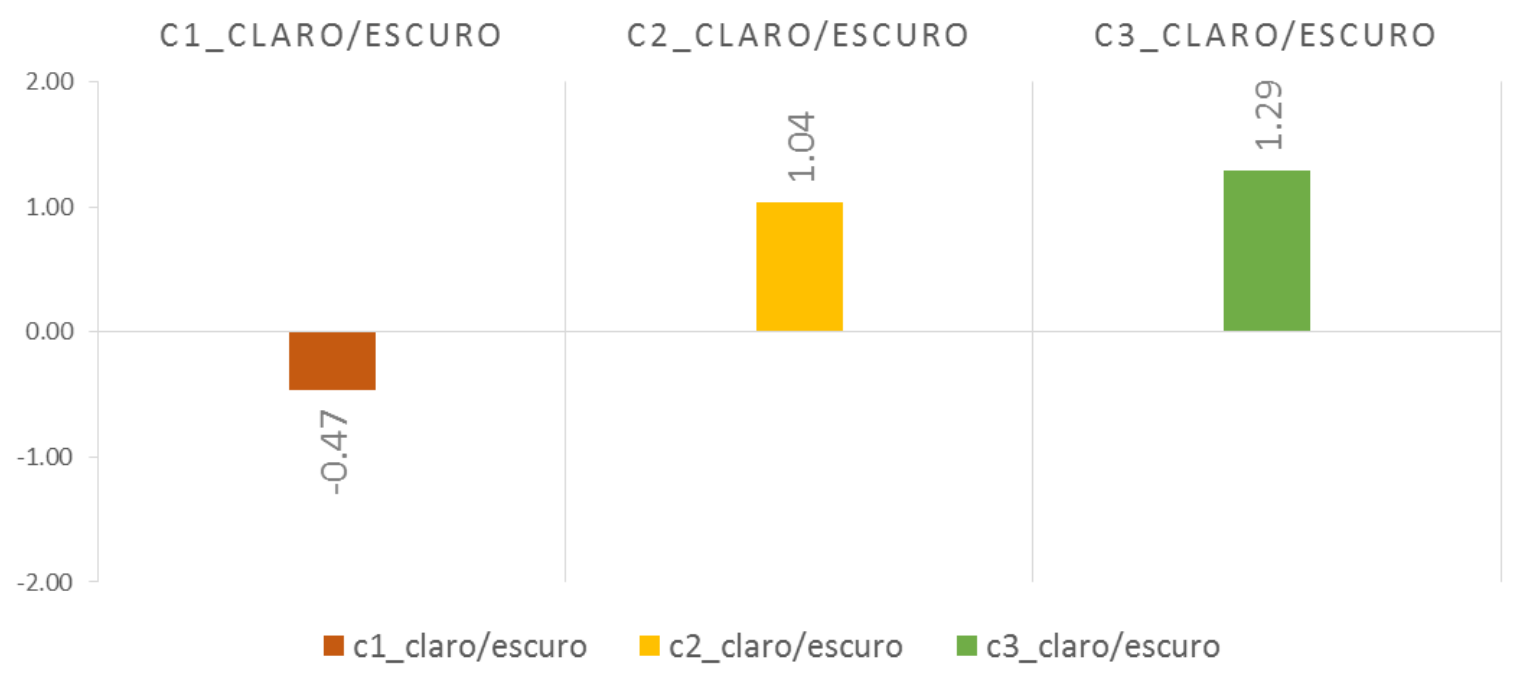

Fonte: elaboração própria

Os resultados se relacionam com estudos de Peña-García, Hurtado e AguilarLuzón (2015) e Ylinen et al. (2011) que descrevem o fenômeno físico da luz no espaço. Segundo os autores, ambientes com fontes luminosas em maiores quantidades de azul são percebidas como mais claros, devido as características fisiológicas do olho humano - a curva mesópica é ativada em locais onde baixos índices de iluminância geralmente são encontrados, como na iluminação pública (YLINEN et al., 2011) - sendo favoráveis para a percepção visual dos usuários nesse tipo de ambiente. 
Sob outro ponto de vista, o estudo de Flynn et al. (1973) e (1979) sugere uma série de efeitos que podem ser utilizados a fim de satisfazer uma impressão de espaço específica, como amplitude ou intimidade. Por exemplo, os requisitos para o ambiente aparentar ser mais claro e espaçoso são o uso de iluminação uniforme e periférica, semelhante ao apresentado nos cenários 2 e 3, quando se ilumina verticalmente as fachadas do conjunto arquitetônico.

De maneira semelhante, o gráfico correspondente aos termos interessante/monótono (FIG. 62) demonstra que houve mudanças de percepção, sugerindo melhorias no espaço pela intervenção em iluminação. De acordo com os participantes, os cenários 2 e 3, apresentados de forma muito parecidas, são mais interessantes e menos monótonos que a situação existente, reproduzida no cenário 1.

Figura 62 - gráfico correspondente aos termos interessante/monótono

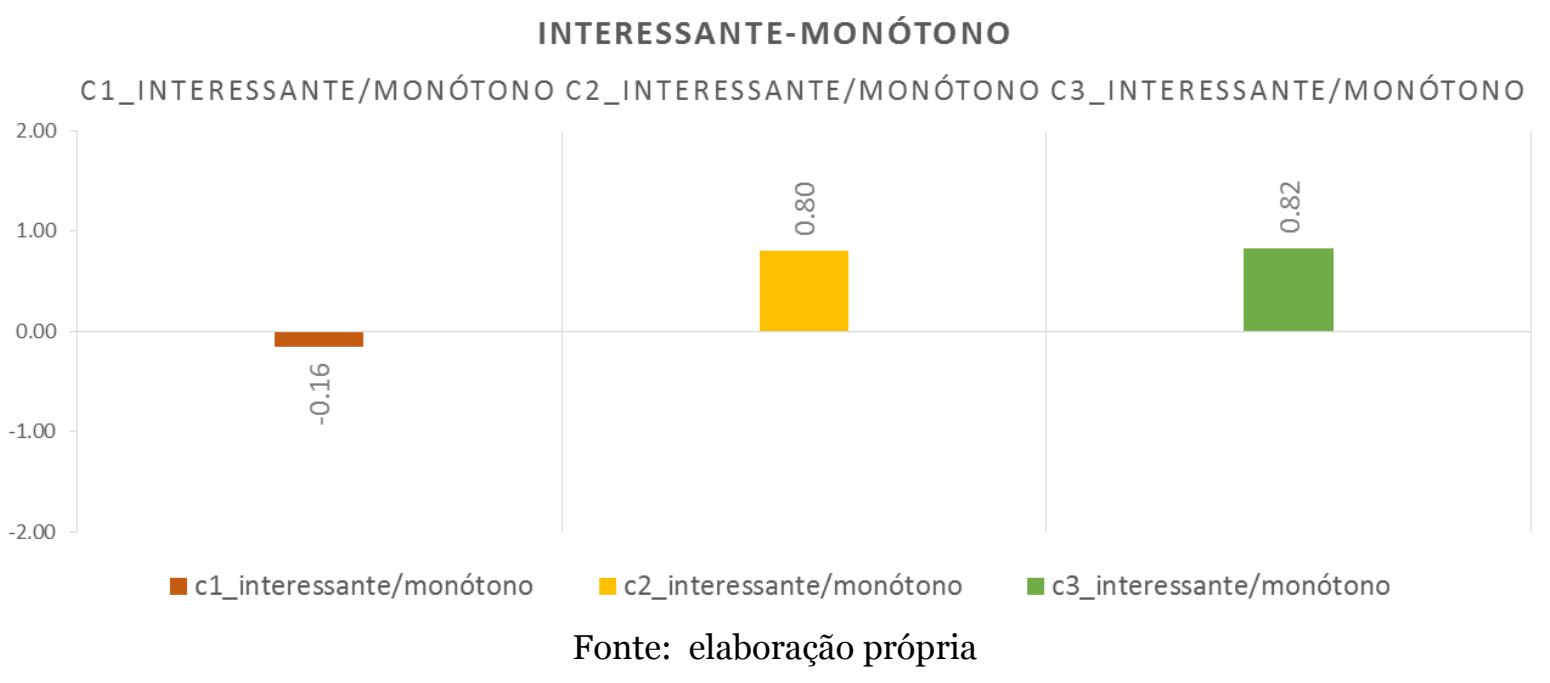

A preferência pelo interessante pode ser relacionada às características do projeto e às percepções geradas por ela. Ao imaginar as pesquisas de Flynn et al. (1973), conceitos de Kelly (1952, apud SKARLATOU, 2010) e Kaplan (1987), é possível descrever os cenários através de efeitos luminosos que possibilitam, de maneira geral: a) atenção a elementos importantes, gerando legibilidade; b) iluminação geral e difusa, gerando sensação de segurança e c) efeitos que podem estimular a curiosidade.

Os resultados dos termos quente/frio (FIG. 63) tinham por objetivo principal investigar, do ponto de vista do usuário, se existiria correspondência na relação entre compreensão dos termos e temperatura de cor dos cenários explorados, de forma que, 
como explicitado no capítulo 1, este atributo de iluminação é de fundamental importância no processo de percepção do espaço.

Figura 63 - gráfico correspondente aos termos quente/frio

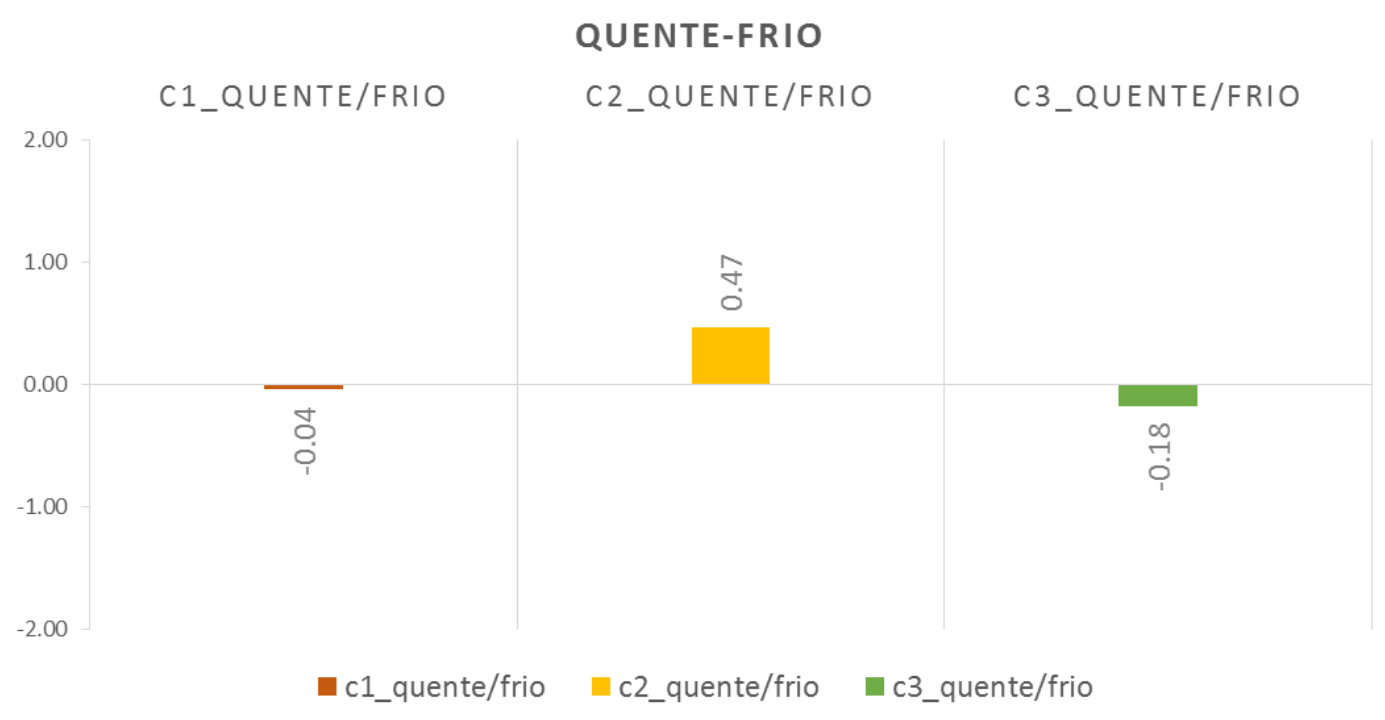

Fonte: elaboração própria

De maneira geral, os usuários perceberam diferenças no aspecto estudado, principalmente se compararmos os cenários 2 e 3, cuja variação de temperatura de cor é maior. A partir dos resultados, o cenário 1 valor negativo próximo de zero, com leve tendência para o termo frio, quando na realidade a reprodução do ambiente atual possuía temperatura de cor quente. Este desvio pode ter sido causado pelo fato de o cenário ser o primeiro avaliado pelo participante, que, sem possuir precedentes para fins de comparação, preferia responder neutro ao questionário.

O cenário 2 apresentou-se com 0.47 , portanto considerado quente, que se assemelha com as intenções do projeto de iluminação neste ambiente; por fim, o cenário 3 teve valores correspondentes ao termo frio, assemelhando-se ao projeto de iluminação deste cenário, que utilizou temperatura de cor fria. Sendo assim, os cenários projetados foram percebidos como quentes ou frios a depender da temperatura de cor escolhida no projeto. 


\section{CAPÍTULO 5 Considerações finais}


A luz e suas ambiências estão intimamente ligadas à percepção que se tem dado ao espaço, seja ele externo ou interno. A pesquisa teve como objetivo geral a verificação da influência da iluminação na percepção do espaço urbano e na relação do usuário com o ambiente noturno. Para tanto, espaços urbanos noturnos simulados digitalmente foram analisados a fim de gerar um mapeamento de qualidades subjetivas sob o ponto de vista do usuário.

Os resultados sugerem que a iluminação funciona como fator fundamental na qualidade dos cenários noturnos, cuja dinâmica da cidade pode ser modificada por variáveis técnicas como intensidade, direção e temperatura de cor, gerando assim qualidades projetadas diferentes e que precisam ser mais bem compreendidas.

Um dos objetivos específicos da pesquisa, que procura investigar de que forma a luz exerce influência na percepção visual do espaço urbano, é levada em consideração no processo de desenvolvimento da parte teórica da pesquisa. Consequentemente, a necessidade de sistematizar este conhecimento sobre percepção em iluminação e seu registro tornou-se essencial para melhor compreensão do viés qualitativo da iluminação.

De acordo com o arcabouço teórico levantado da revisão bibliográfica, existe um campo multidisciplinar de atuação na área de iluminação, onde pesquisadores utilizam-se de métodos e procedimentos relacionados à psicologia ambiental, ciências sociais e arquitetura e urbanismo a fim de investigar como o registro das percepções dos usuários é realizado. Estas percepções são investigadas a partir de parâmetros específicos, como gênero, idade ou aspectos culturais onde a pesquisa se desenvolveu, que auxiliam no mapeamento das qualidades subjetivas da iluminação em dado contexto, seja para ambientes internos ou externos.

Do ponto de vista experimental, a pesquisa procura investigar sob a ótica do design centrado no usuário, a participação das pessoas no processo de projeto, ao traduzir suas necessidades e expectativas em forma de intervenção urbana luminosa (cenários 2 e 3), gerando assim percepções qualitativas dos ambientes. Estas impressões, resultante da avaliação dos usuários ao explorar os espaços urbanos noturnos digitalmente - através da realidade virtual - serve como retroalimentação para verificação das intenções de projeto em iluminação pública, num ciclo iterativo, com objetivo de otimizar o produto final. 
O planejamento da luz visa melhorar a qualidade da paisagem noturna e a dinâmica da cidade. Neste sentido, o objetivo específico da pesquisa de estudar como dados de percepção visual pode alimentar o processo em iluminação, foi atingido. Como contribuição deste processo, foi possível compreender como a participação coletiva no processo de projeto é analisada, ao utilizar na pesquisa os dados qualitativos gerados pelos participantes durante a execução dos experimentos, levando em consideração suas necessidades e expectativas. Vale salientar que esta é apenas uma das formas de participação coletiva, havendo a possibilidade de maiores aprofundamentos em trabalhos futuros.

O desenvolvimento do experimento procurou, criar cenários noturnos e compará-los através do conceito de atmosfera percebida, desenvolvido por Vogels (2008), de forma a compreender o papel da iluminação entendida sob o ponto de vista psicológico, subjetivo e estético, cujos conceitos vem tendo crescente interesse por parte de pesquisadores no âmbito da iluminação. Também buscou-se superar obstáculos logísticos e financeiros, decorrentes da dificuldade de execução de testes de luz em ambientes públicos, particularmente em bens tombados, como é o caso da área de estudo, aliado ao custo elevado de produção de maquetes em escala real (mockups).

Utilizando-se da realidade virtual enquanto suporte à criação de cenários noturnos em ambientes tridimensionais, foi desenvolvido um processo metodológico envolvendo aspectos técnico-operacionais (uso dos óculos de realidade virtual e controles sem fio) e virtuais (modelagem tridimensional dos cenários estudados), cuja avaliação qualitativa desses ambientes era realizada através dos questionários. O objetivo de verificar a influência da iluminação na percepção do espaço urbano e na relação do usuário com o ambiente noturno tornou-se possível através da tecnologia, devido aos recursos de tempo e custo disponíveis.

Assim, o aparato tecnológico possibilitou a apropriação do espaço tridimensional (ao assemelhar-se com o ambiente real e tornando viável a execução da pesquisa) pelos participantes, cuja apreensão predominantemente visual e navegação exploratória foram essenciais para o processo de imersão no espaço virtual tridimensional, causando impressões e gerando dados qualitativos dos usuários.

Como observado no experimento, as dimensões aconchego, ânimo, tensão e identidade/pertencimento sugerem que existe ligação entre iluminação e as 
percepções dos usuários, e desempenham um papel importante na relação entre pessoas e os espaços urbanos, conforme observam diversos autores (KAPLAN, 1987; UNVER, 2009; CASCIANI, ROSSI, 2012; CASCIANI, 2013; CASCIANI, 2014). Neste sentido, o planejamento dos efeitos de luz pode engajar visitantes a permanecerem no espaço noturno, além de estimular funções como turismo e comércio, algo que os cenários 2 e 3 almejaram alcançar, além da melhoria das qualidades percebidas nos ambientes sob a ótica dos participantes, através do termo "sociável" e "familiar", características positivas para melhor usufruto dos espaços (GEHL, 2010).

Palavras como "vivaz", "estimulante" e "alegre" parecem justificar a teoria de que o espaço público deve possibilitar novas formas de convívio, interação e identificação entre a cidade e seus usuários, e é através da iluminação que estes ambientes se desvelam no período noturno (CORTÉS; MORALES, 2010; GONÇALVES, 2006).

É interessante observar como algumas dimensões foram mais bem indicativas das diferenças entre qualidades subjetivas dos cenários, enquanto outras podem ser aprimoradas, talvez pela adequação dos termos selecionados a um dado contexto ou melhorias na qualidade do estímulo (nesta pesquisa utilizou-se os ambientes virtuais tridimensionais). Na dimensão "tensão", considerações sobre termos como agitado, estressante e tedioso (este da dimensão identidade/pertencimento) são responsáveis pela avaliação da consistência do ambiente virtual quanto à sua fidelidade como espaço público. Apesar da sonorização aplicada aos cenários, contendo sons característicos do meio urbano, os participantes entendiam que, já que não foram inseridos elementos que favorecessem interações e movimentos, por exemplo pessoas inseridas no ambiente (chamados de avatares), o ambiente virtual faltava algo para fazer além de caminhar no espaço, o que pode ter influenciado a avaliação dos cenários estudados.

Entretanto, deve-se salientar algumas limitações a respeito do experimento. Esta pesquisa utilizou-se como aporte teórico o conceito de atmosfera de Vogels (2008). Originalmente em holandês, os termos referentes ao trabalho da autora precisaram ser traduzidos para a língua portuguesa. Neste processo de tradução, e devido a nuances linguísticos, algumas palavras devem ser discutidas sob a luz do contexto brasileiro, refletindo em uma melhor compreensão de termos. Um exemplo disto está no termo familiar: seu original (intiem) pode ser também traduzido como 
íntimo. Da mesma forma, o termo exclusivo pode ser também traduzido do original (formeel) como formal/oficial.

Outras limitações referem-se aos aspectos técnicos do experimento. Ao utilizar equipamentos com custos acessíveis e disponíveis a todos, como smartphones e controles bluetooth, o desempenho e processamento de dados é menor, se comparado com aparelhos específicos para a utilização de realidade virtual. Como consequência, recorre-se a simplificações de geometria e redução do conteúdo informacional do modelo, tendo em vista sua otimização. Assim, devido à complexidade de elementos e dinâmicas existentes no ambiente urbanos abertos, deve-se estabelecer com clareza quais são os objetivos da pesquisa, pois o aparato tecnológico a ser utilizado pode não suportar as condições necessárias.

Na presente pesquisa, o desenvolvimento dos cenários urbanos foi baseado nas condições tecnológicas e recursos financeiros disponíveis. Devido à complexidade envolvida no espaço público, houve a necessidade de simplificar elementos sempre que possível, porém sem perder informações importantes, como cores, texturas e a própria iluminação. Considerando que o aspecto da exploração e navegação pelos ambientes era essencial para apreensão do espaço urbano noturno, outras possibilidades de interação não foram utilizadas, como manipulação de elementos virtuais (por exemplo, mudar a iluminação de lugar) e programação de cenas (ligar e desligar trechos do projeto de iluminação), além da utilização de personagens dinâmicos (avatares).

Da mesma forma, particularmente importante, uma das contribuições da metodologia é o envolvimento da comunidade no processo de projeto, fornecendo os subsídios para que as intenções do projetista possam atender as expectativas e necessidades dos usuários. Incluem-se também como contribuição o desenvolvimento de protocolos de avaliação das qualidades subjetivas de espaços urbanos utilizando-se de ambientes virtuais tridimensionais imersivos e também, do ponto de vista técnico, a interação entre softwares e hardwares na formulação do aparato tecnológico e a criação de um fluxo de trabalho, sistematizando a criação dos cenários noturnos em ferramentas computacionais.

Em relação a pesquisas futuras, os procedimentos expostos vislumbram caminhos para novos estudos, sendo importante a replicação do processo metodológico em outros contextos urbanos a fim de compreender o impacto do projeto 
de iluminação na qualidade ambiental percebida, além da possibilidade de utilização das contribuições coletivas como auxiliadores do processo de planejamento urbano participativo. Do ponto de vista teórico, novos estudos são necessários para a sistematização de métodos para caracterização de termos adequados ao contexto brasileiro, suas peculiaridades e nuances linguísticos, a fim de gerar um mapeamento de impressões orientadas ao objeto de estudo, sejam espaços urbanos ou interiores.

Outras considerações para desenvolvimentos futuros dizem respeito ao uso de ambientes virtuais imersivos, sendo importante investigar até que ponto a inserção de estímulos diversos - interação com avatares e novas formas de estímulo aos sentidos influenciam a percepção do espaço urbano noturno digitalmente simulado.

Também, em estudos futuros há a possibilidade ramificações da pesquisa em diferentes localidades do país. Tendo em vista o caráter multicultural do país, deve-se investigar se existem ocorrências de percepções diferentes quando há mudança de contexto, seja outra cidade ou outro estado.

Os estudos realizados neste sentido mostram a relevância do tema para a área da iluminação, onde pesquisas são focadas tradicionalmente no aspecto técnico da luz, sua performance e eficiência na utilização de luz artificial, e não tratam das expectativas dos usuários. Assim, buscou-se nesta pesquisa uma abordagem mais humanista, alinhada com as pesquisas atuais de conforto ambiental, que ressaltam a importância de olhar para os usuários, invertendo a questão da quantidade para a qualidade dos espaços investigados. 


\section{Referências bibliográficas}


ABRAS, C.; MALONEY-KRICHMAR, D.; PREECE, J. User-centered design. In: BAINBRIDGE, W. S. Berkshire Encyclopedia of Human-Computer Interaction. 1 ed. Massachusetts: Berkshire Publishing Group, 2004, p. 763-768.

ACKING, C., KULLER, R. Presentation and judgement of planned environment and the hypothesis of arousal. Environmental Design Research, v. 1, p. 72-83, 1973.

AGUIAR, D. Urbanidade e a qualidade da cidade. Arquitextos, a. 12, n. 141.o8, mar. 2012

ÂNGULO, A.; VELASCO, G. V. Immersive Simulation of Architectural Spatial Experiences. In: CONFERENCE OF THE IBEROAMERICAN SOCIETY OF DIGITAL GRAPHICS, 17., 2014, Valparaiso. Proceedings... São Paulo: Blucher, 2014, p. 495499

ARNHEIM, R. Arte e percepção visual: uma psicologia da visão criadora: nova versão. Tradução Terezinha de Faria. São Paulo: Pioneira Thomson Learning, 2005.

ARSENAULT, H., HÉBERT, M.; DUBOIS, M.-C. Effects of glazing colour type on perception of daylight quality, arousal, and switch-on patterns of electric light in office rooms. Building and Environment, v. 56, p. 223-231, 2012.

BAKKER, I.; VAN DER VOORDT, T.; VINK, P.; BOON, J. Pleasure, Arousal, Dominance: Mehrabian and Russell revisited. Current Psychology, v. 33, n. 3, p. 405-421, 2014.

BALL, J.; CAPANNI, N.; WATT, S. Virtual Reality for Mutual Understanding in Landscape Planning. International Journal of Social, Behavioral, Educational, Economic, Business and Industrial Engineering, v.1, n. 11, p. 661-671, 2007.

BARON, R. A.; REA, M. S.; DANIELS, S. G. Effects of indoor lighting (illuminance and spectral distribution) on the performance of cognitive tasks and interpersonal behaviors: The potential mediating role of positive affect. Motivation and Emotion, v. 16, n. 1, p. 1-33, 1992.

BASSO, R. L. R. Plano diretor de iluminação do Centro histórico de São Paulo: uma nova ambiência e atmosfera para os calçadões. 2008. 215 f. Dissertação 
(Mestrado em Arquitetura e Urbanismo) - Faculdade de Arquitetura e Urbanismo, Universidade de São Paulo. São Paulo, São Paulo, 2008.

BONAIUTO, M.; FORNARA, F.; BONNES, M. Indexes of perceived residential environment quality and neighbourhood attachment in urban environments: a confirmation study on the city of Rome. Landscape and Urban Planning, v. 65, n. 1-2, p. 41-52, 2003.

BOYCE, P.; CUTTLE, C. Effect of correlated colour temperature on the perception of interiors and colour discrimination performance. Lighting Research and Technology, v. 22, n. 1, p. 19-36, 1990.

BOYCE, P.; EKLUND, N.; HAMILTON, B.J.; BRUNO, L.D. Perceptions of safety at night in different lighting conditions. Lighting Research and Technology, v. 32, n. 2, p. 79-91, 2000.

BOYCE, P. R. Human factors in lighting. London: Taylor \& Francis, 2003.

BULLINGER, H.; BAUER, W.; WENZEL, G.; BLACH, R. Towards user centred design (UCD) in architecture based on immersive virtual environments. Computers in Industry, v. 61, n. 4, p. 372-379, 2010.

CARVALHO, M. R.; COSTA, R. T; NARDI, A. E. Simulator Sickness Questionnaire: tradução e adaptação transcultural. Jornal Brasileiro de Psiquiatria, Rio de Janeiro, v. 60, n.4, p. 247-252, 2011.

CASCIANI, D.; ROSSI, M. ELSE: Experience of Lighting Sustainability in the Environment. In: CUMULUS CONFERENCE, 2012, Helsinki. Proceedings... Helsinki: Aalto University, 2012.

CASCIANI, D. Are citizens interested in their lit cities? A series of urban lighting impressions. In: PROFESSIONAL LIGHTING DESIGN CONVENTION, 4., 2013, Copenhagen. Proceedings... Copenhagen: VIAVerlag, 2013, p. 50-53.

CASCIANI, D. Urban Social Lighting: Exploring the social dimension of urban lighting for more sustainable urban nightscapes. 2014. Tese (Doutorado em Design) Faculdade de Design, Politecnico di Milano, Milão, 2014. 
CASCIANI, D.; ROSSI, M. An applied research to assess the experience of the colour of urban lighting: a pilot study in Milano downtown. Journal of the International Colour Association, v. 13, p. 14-26, 2014

CAUWERTS, C. Influence of presentation modes on visual perceptions of daylit spaces. 2013. 285 f. Tese (Doutorado em Ciencias da Engenharia) - Faculté d'architecture, d'ingénierie architecturale, d'urbanisme, Université catholique de Louvain, Louvain, 2013.

CHAVES, L. M. Era uma vez... Um Largo chamado São Pedro Gonçalves. In: ENCONTRO DA ASSOCIAÇÃO NACIONAL DE PESQUISADORES EM ARTES PLÁSTICAS, 20., 2011, Rio de Janeiro. Anais... Rio de Janeiro: ANPAP, 2011, p. 30743086

CORTÉS, A. B. C.; MORALES, L. E. F. Emotions and the Urban Lighting Environment: A Cross-Cultural Comparison. SAGE Open, v. 6, n. 1, p. 1-8, 2016

CUSTERS, P.; KORT, Y.; IJSSELSTEIJN, W.A.; KRUIFF, M. Lighting in retail environments: Atmosphere perception in the real world. Lighting Research and Technology, v. 42, n. 3, p. 331-343, 2010.

COLOMO-PALACIOS, R.; CASADO-LUMBRERAS, C., SOTO-ACOSTA, P.; GARCÍACRESPO, A. Using the affect grid to measure emotions in software requirements engineering. Journal of Universal Computer Science, v. 17, n. 9, p. 1281-1298, 2011.

CUTTLE, Christopher. Lighting Design: A Perception-Based Approach. 1 ed. New York: Routledge, 2015

CYPRIANO, A. Iluminação artificial na percepção da arquitetura: considerações sobre aspectos quantitativos e qualitativos no processo de projeto. 2013. 203 f. Dissertação (Mestrado em Arquitetura e Urbanismo) - Faculdade de Arquitetura e Urbanismo, Universidade de São Paulo, São Paulo, 2013.

DAVIS, R. Lighting Psychology: Cognitive and Emotional Responses to Lighting. 2013. Disponível em: <http://www.ledinside.com/knowledge/2013/12/lighting_psychology_cognitive_an d_emotional_responses_to_lighting>.Acesso em: 14 jul. 2016. 
DEL-NEGRO, D. Arquitectura em Luz: A Iluminação Exterior do Patrimônio. Lisboa: Caleidoscópio, 2012.

DONOFF, E. Giving Definition. 2013. Disponível em: <http://www.archlighting.com/industry/comment/giving-definition_o>. Acesso em: 20 jan. 2017.

DONOVAN, R. J.; ROSSITER, J. R. Store Atmosphere: An Environmental Psychology Approach. Journal of Retailing, v. 58, n. 1, p. 34-57, 1982.

DRETTAKIS, G.; ROUSSOU, M.; RECHE, A; TSINGOS, N. Design and Evaluation of a Real-World Virtual Environment for Architecture and Urban Planning. Presence: Teleoperators and Virtual Environments, Massachusetts, v. 16, n. 3, p. 318-332, 2007.

DUNSTON, P. S.; ARNS, L. L.; MCGLOTHLIN, J. D.; LASKER, G. C; KUSHNER, A. G. An Immersive Virtual Reality Mock-Up for Design Review of Hospital Patient Rooms. In: WANG, X; TSAI, J. J. (Ed.). Collaborative Design in Virtual Environments. 1st ed. Netherlands: Springer, 2011, p. 167-176.

DUBOIS, M-C.; CANTIN, F.; JOHNSEN, K. The effect of coated glazing on visual perception: a pilot study using scale models. Lighting Research and Technology, v. 39, n. 3, p. 289-304, 2007.

FERNANDEZ, P. La perception des environnements lumineux de chambres d'hotels: Effets de l' eclairage, de l'usage et des caract' eristiques individuelles sur le jugement d'appr'eciation en situation r'eelle. 2014. 276 f. Thèse (Doctorat en Neurosciences et cognition) - École Doctorale Neurosciences et Cognition, Université Claude Bernard Lyon 1, Lyon, 2012.

FLYNN, J. E.; MILLS, S. M. The design medium: lighting systems in the architectural environment. Architectural Lighting Graphics, p. 24, 1962.

FLYNN, J. E.; SPENCER, T.; MARTYNIUK, O.; HENDRICK, C. Interim study of procedures for investigating the effect of light on impression and behavior. Journal of the Illuminating Engineering Society, v. 3, p. 87-94, 1973. 
FLYNN, J. E.; SPENCER, T.; MARTYNIUK, O.; HENDRICK, C. A guide to methodology procedures for measuring subjective impressions in lighting. Journal of the Illuminating Engineering Society, p. 95-110, 1979.

FONSECA, R. R. K.; DUARTE, O. F. P.; D’AVILA, M. R. Iluminação nos espaços públicos de habitação de interesse social. In: CONGRESSO INTERNACIONAL ESPAÇOS PÚBLICOS, 1., 2015, Porto Alegre. Anais... Porto Alegre, 2015.

FOTIOS, S.; CHEAL, C.; BOYCE, P. Light source spectrum, brightness perception and visual performance in pedestrian environments: a review. Lighting Research and Technology, v. 37, n. 4, p. 271-291, 2005.

FOTIOS, S.; GOODMAN, T. Proposed UK guidance for lighting in residential roads. Lighting Research and Technology, v. 44, n. 1, p. 69-83, 2012.

FOTIOS, S.; UNWIN, J.; FARRALL, S. Road lighting and pedestrian reassurance after dark: A review. Lighting Research and Technology, v. 47, n. 4, p. 449-469, 2014.

FUKUDA, T.; NAGAHAMA, R.; KAGA, A.; OH, S.; SASADA, T. Collaboration support system for nightscape design based on VR technology. In: CONFERENCE ON COMPUTER AIDED ARCHITECTURAL DESIGN RESEARCH IN ASIA, 6., 2001, Sydney. Proceedings... Sydney: CAADRIA, 2001, p. 103-111.

GEHL, Jan. Cidades para pessoas. São Paulo. Editora Perspectiva. 2010.

GONÇALVES, A. L. A. Iluminação urbana de conjuntos históricos e tradicionais: adequação do projeto à ambiência. Uma metodologia para planos diretores de iluminação. O caso do bairro histórico de Paraty. 2005. v.1 334 f. e v.2 132 f. Tese (Doutorado em Arquitetura e Urbanismo) - Faculdade de Arquitetura e Urbanismo, Universidade de São Paulo, São Paulo, 2005.

GONÇALVES, A. L. A. Iluminação Urbana: A construção da paisagem noturna de sítios históricos. Lume Arquitetura, São Paulo, v.20, p.10-14, 2006.

GUILHERMINO, L. A. Atmosferas arquitetônicas: projeto e percepção na obra de Peter Zumthor. 2015. 213 f. Dissertação (Mestrado em Arquitetura e Urbanismo) Faculdade de Arquitetura e Urbanismo, Universidade Federal do Rio Grande do Norte, Natal, 2015 . 
HAWKES, R. J.; LOE, D. L.; ROWLANDS, E. Note towards the understanding of lighting quality. Journal of the Illuminating Engineering Society, v. 8, p. 111120, 1979.

HENDRICK, C.; MARTYNIUK, O.; SPENCER, T. J.; FLYNN, J. E. Procedures for investigating the effect of light on impression: Simulation of a Real Space by Slides. Environment and Behavior, v. 9, n. 4, p. 491-510, 1977.

HEYDARIAN, A.; CARNEIRO, J. P.; GERBER, D.; BECERIK-GERBER, B. Towards Understanding End-user Lighting Preferences in Office Spaces by Using Immersive Virtual Environments. Computing in Civil Engineering, p. 475-482, jun. 2015.

HEYDARIAN, A.; CARNEIRO, J. P.; GERBER, D.; BECERIK-GERBER, B. Immersive virtual environments, understanding the impact of design features and occupant choice upon lighting for building performance. Building and Environment, v. 89, p. 217-228, 2015 .

HEYDARIAN, A.; CARNEIRO, J. P.; GERBER, D.; BECERIK-GERBER, B.; HAYES, T; \& WOOD, W. Immersive virtual environments versus physical built environments: A benchmarking study for building design and user-built environment explorations. Automation in Construction, v. 54, n. 7, p. 116-126, 2015.

HONG, O. S. Design Basis to Quality Urban Lighting Masterplan. 2007. 243f. Thesis (Master of Arts) - School of Design and Environment, National University of Singapore, Singapore, 2007

JOHANSSON, M.; ROSEN, M.; KULLER, R. Individual factors influencing the assessment of the outdoor lighting of an urban footpath. Lighting Research and Technology, v. 43, n. 1, p. 31-43, 2011.

JOHANSSON, M.; PEDERSEN, E.; MALEETIPWAN-MATTSSON, P.; KUHN, L.; LAIKE, T. Perceived outdoor lighting quality (POLQ): A lighting assessment tool. Journal of Environmental Psychology, v. 39, p. 14-21, set. 2014.

KANG, M.; CHOO, P.; WATTERS, C. E. Design for experiencing: participatory design approach with multidisciplinary perspectives. Social and Behavioral Sciences, v. 174, p. 830-833, 2015. 
KAPLAN, S.; KAPLAN, R.; WENDT, J. S. Rated preference and complexity for natural and urban visual material. Perception and Psychophysics, v. 12, n. 4, p. 354-356, 1972.

KAPLAN, R. The analysis of perception via preference: A strategy for studying how the environment is experienced. Landscape Planning, v. 12, n. 2, p. 161-176, 1985.

KAPLAN, S. Aesthetics, Affect, and Cognition: Environmental Preference from an Evolutionary Perspective. Environment and Behavior, v. 19, n. 1, p. 3-32, 1987.

KNEZ, I. Effects of indoor lighting on mood and cognition. Journal of Environmental Psychology, v. 15, n. 1, p 39-51, 1995.

KNIGHT, C. Field surveys of the effect of lamp spectrum on the perception of safety and comfort at night. Lighting Research and Technology, v. 42, n.3, p. 313-329, set. 2010.

KUHN, L.; JOHANSSON, M.; LAIKE, T.; GOVÉN, T. Residents' perceptions following retrofitting of residential area outdoor lighting with LEDs. Lighting Research and Technology, v. 45, p. 568-584, 2013.

KULIGA, S. F.; THRASH, T.; DALTON, R. C.; HOLSCHER, C. Virtual reality as an empirical research tool - Exploring user experience in a real building and a corresponding virtual model. Computers, Environment and Urban Systems, v. 54, p. 363-375, 2015 .

KULLER, R. Environmental assessment from a neuropsychological perspective. In: GARling, T.; EVANS, G. W. (Ed.) Environment, Cognition, and Action: An Integrated Approach. New York: Oxford University Press, 1991. p. 111-147.

KULLER, R.; WETTERBERG, L. Melatonin, cortisol, EEG, ECG and subjective comfort in healthy humans: Impact of two fluorescent lamp types at two light intensities. Lighting Research and Technology, v. 25, n.2, p.71-81, 1993.

LINDH, U. W. Light Shapes Spaces: Experience of Distribution of Light and Visual Spatial Boundaries. 2012. 295 f. Thesis (Doctor of Philosophy in Design) - Faculty of Fine, Applied and Performing Arts, University of Gothenburg, Gothenburg, 2012. 
LAM, W. M. C. Perception and Lighting as Formgivers for Architecture. New York: Van Nostrand Reinhold, 1992.

LAU, J. J. H. Use of scale models for appraising lighting quality. Lighting Research and Technology, v. 4, n. 4, p. 254-262, 1972.

LIN, I. Y. The interactive effect of Gestalt situations and arousal seeking tendency on customers' emotional responses: matching color and music to specific servicescapes. Journal of Services Marketing, v. 24, n. 4, p. 294-304, 2010.

LLORACH, G.; EVANS, A.; BLAT, J. Simulator sickness and presence using HMDs: comparing use of a game controller and a position estimation system. In: ACM SYMPOSIUM ON VIRTUAL REALITY SOFTWARE AND TECHNOLOGY, 20., 2014, Edinburgh. Proceedings... Edinburgh: ACM, 2014, p. 137-140.

LOE, D. L.; MANSFIELD, K. P.; ROWLANDS, E. Appearance of lit environment and its relevance in lighting design: Experimental study. Lighting Research and Technology, v. 26, n. 3, p. 119-133, 1994.

LUIGI, M.; MASSIMILIANO, M.; ANIELLO, P.; GENNARO, R.; VIRGINIA, P. R. On the Validity of Immersive Virtual Reality as tool for multisensory evaluation of urban spaces. In: INTERNATIONAL BUILDING PHYSICS CONFERENCE, 6., 2015, Turin. Proceedings... Turin: IBPC, 2015, p. 471-476

LYNCH, Kevin. A imagem da cidade. São Paulo: Martins Fontes, 1980.

MAHDAVI, A.; EISSA, H. Subjective evaluation of architectural lighting via computationally rendered images. Journal of the Illuminating Engineering Society, v. 31, n.2, p. 11-20, 2002.

MAING, M. Virtual Mock-Up Modeling As Study Model Of Building Envelope, Performance And Design. In: SIMBUILD, 2012, Wisconsin. Proceedings... Wisconsin: IBPSA, 2012, p. 75-82.

MASCARÓ, L. (Org.) A Iluminação do Espaço Urbano. Masquatro Ed., P.A., 2006.

MEHRABIAN, A.; RUSSEL, J. A. An approach to environmental psychology. Cambridge: MIT Press, 1974 
MINAYO, M. C. de S.; SANCHES, O. Quantitativo-qualitativo: oposição ou complementaridade?. Cad. Saúde Pública, Rio de Janeiro, v. 9, n. 3, p. 237-248, set. 1993.

OCHOA, C. E.; ARIES, M. B. C.; HENSEN, J. L. M. State of the Art in Lighting Simulation for Building Science: A Literature Review. Journal of Building Perfomance Simulation, v. 5, p. 209-233, 2012.

OLASCOAGA, J. F. Development of a New Approach for Appraising the Aesthetic Quality of Cities. 2003. $288 \mathrm{f}$. Thesis (Doctor of Philosophy) - Faculty of Land-Use Planning, Management and Design, Texas Tech University, Texas, 2003.

OSGOOD, C.; SUCI, G.; TANNENBAUM, P. The measurement of meaning. 1st ed. Illinois: University of Illinois Press, 1957.

PEÑA-GARCÍA, A.; HURTADO, A.; AGUILAR-LUZÓN, M.C. Impact of public lighting on pedestrians' perception of safety and well-being. Safety Science, v. 78, p. 142-148, 2015 .

PORTMAN, M.E.; NATAPOV, A.; FISHER-GEWIRTZMAN, D. To go where no man has gone before: virtual reality in architecture, landscape architecture and environmental planning. Computers, Environment and Urban Systems, v. 54, p. 376-384, 2015 .

RANKEL, S. Future lighting and the appearance of cities at night: A case study. Urbani izziv, v. 25, n. 1, p. 126-141, 2014.

REA, M. The Lighting Handbook: Reference and Application. 9. ed. Nova York: Illuminating Engineering, 2000.

ROIZENBLATT, I. Critérios da iluminação elétrica urbana. 2009. 209 f. Tese (Doutorado em Arquitetura e Urbanismo) - Faculdade de Arquitetura e Urbanismo, Universidade Presbiteriana Mackenzie, São Paulo, 2009.

RUSSEL, J. A. A Circumplex Model of Affect. Journal of Personality and Social Psychology, v. 39, n. 6, p. 1161-1178, 1980.

SÁ, A. G.; ZACHMANN, G. Virtual reality as a tool for verification of assembly and maintenance processes. Computers \& Graphics, v. 23 n. 3, p. 389-403, 1999. 
SALTERS, B.; SEUNTIENS, P. A comparison of perceived lighting characteristics in simulations versus real-life setup. In: HUMAN VISION AND ELECTRONIC IMAGING XVI, 2011, San Francisco. Proceedings... San Francisco: SPIE, 2011.

SANDERS, E. From User-Centered to Participatory Design Approaches. In: FRASCARA, J. (Ed.) Design and the Social Sciences: Making Connections. New York: Taylor \& Francis, 2002, cap. 1, p. 1-8.

SIlVA, E. L.; MENEZES, E. M. Metodologia da Pesquisa e Elaboração da Dissertação. Florianópolis: UFSC, 2005.

SKARLATOU, A. Light Effects in the Design Process: A theoretical investigation of designers' perceptions of light effects and an empirical study of how they use them in architectural lighting design. 2010. 543 f. Thesis (Doctor of Philosophy) - Bartlett Faculty of the Built Environment, University College London, London, 2010

TEJERA, F. P. Diferencias entre los usuarios de seis parques públicos en Barcelona según el nivel de seguridad percibida en el barrio. Athenea Digital, v. 12, n. 1, p. 5566, 2012.

TIEN, J.M.; O'DONNELL, V. F.; BARNETT, A.; MIRCHANDANI, P.B. Street Lighting Projects: National Evaluation Program. Phase 1 Report. Washington, DC: National Institute of Law Enforcement and Criminal Justice, 1977, 102 P. Relatório técnico apresentado ao Departamento de Justiça.

TORI, R.; KIRNER, C. Fundamentos de Realidade Virtual. In: TORI, R.; KIRNER, C.; SISCOUTO, R. (Ed.). Fundamentos e Tenologia de Realidade Virtual e Aumentada: Livro do Pré-Simpósio VIII Symposium on Virtual Reality. 1a ed. Belem: SBC, 2006, cap. 1, p. 02-21.

TOTIR, C. D. The potential of computationally rendered images for the evaluation of lighting quality in interior spaces. 2007. $90 \mathrm{f}$. Thesis (Master of Fine Arts) - College of Design, Iowa State University, Iowa, 2007.

TU, K.-J.; LIN, L.-T. Evaluative structure of perceived residential environment quality in high-density and mixed-use urban settings: An exploratory study on Taipei City. Landscape and Urban Planning, v. 87, p. 157-171, 2008. 
TURAN, S. O.; PULATKAN, M.; BEYAZLI, D.; OZEN, B. S. User Evaluation of the Urban Park Design Implementation with Participatory Approach Process. Social and Behavioral Sciences, v. 216, p. 306-315, 2016.

UNVER, A. People's Experience of Urban Lighting in Public Space. 2009. 199 f. Thesis (Master of Urban Design in City and Regional Planning) - Graduate School of Natural and Applied Sciences, Middle East Technical University, Ancara, 2009.

VAN ERP, T. The effects of lighting characteristics on atmosphere perception. 2008. Thesis (Masters in Human Technology Interaction) - Department of Technology Management, Eindhoven University of Technology, Eindhoven, 2008.

VEITCH, J.; NEWSHAM, G. Lighting quality and energy-efficiency effects on task performance, mood, health, satisfaction, and comfort. Journal of the Illuminating Engineering Society, v. 27, p. 107-129, 1998.

VEITCH, J. Psychological processes influencing lighting quality. Journal of the Illuminating Engineering Society, v. 30, p. 3-16, 2001.

VIEIRA, V. A. Meta-Análise do Modelo Teórico "E-O-R" de Mehrabian e Russel (1974). In: ENCONTRO DA ASSOCIAÇÃO NACIONAL DE PÓS-GRADUAÇÃO E PESQUISA EM ADMINISTRAÇÃO, 32., 2008, Rio de Janeiro. Anais... Rio de Janeiro: ANPAD, 2008.

VOGELS, I. Atmosphere Metrics: Development of a Tool to Quantify Experienced Atmosphere. In: WESTERINK, J.; OUWERKERK, M.; OVERBEEK, T.J.M.; PASVEER, W. F. (Ed.). Probing Experience: From Assessment of User Emotions and Behaviour to Development of Products. Netherlands: Springer, 2008 , cap. 1 , v. 8, p. 25-41.

VOLPATO, G. L. Ciência: da filosofia à publicação. 6 ed. São Paulo: Cultura Acadêmica, 2013.

WATSON D.; CLARK L.A.; TELLEGEN, A. Development and validation of brief measures of positive and negative affect: the PANAS scales. Journal of Personality and Social Psychology, v. 54, n. 6, p. 1063-1070, 1988.

WESTERDAHL, B.; SUNESON, K.; WERNEMYR, C.; ROUPÉ, M.; JOHANSSON, M.; ALLWOOD, C. M. Users' evaluation of a virtual reality architectural model compared 
with the experience of the completed building. Automation in Construction, v. 15, n. 2, p. 150-165, 2006.

WHISKER, V. E.; BARATTA A. J.; YERRAPATHRUNI, S.; MESSNER J. I.; SHAW, T. S.; WARREN, M. E; ROTTHOFF, E. S. Using Immersive Virtual Environments to Develop and Visualize Construction Schedules for Advanced Nuclear Power Plants. In: INTERNATIONAL CONGRESS ON ADVANCES IN NUCLEAR POWER PLANTS, 2003, Córdoba. Proceedings... Córdoba: ICAPP, 2003, p. 3271-3278.

YAN, W.; CULP, C.; GRAG, R. Integrating BIM and gaming for real-time interactive architectural visualization. Automation in Construction, v. 20 n. 4, p. 446-458, 2011.

YLINEN, A.; TAHKAMO, L.; POULAKKA, M.; HALONEN, L. Road lighting quality, energy efficiency, and mesopic design: LED street lighting case study. Journal of the Illuminating Engineering Society, v. 8, n. 1, p. 9-24, 2011

ZARZYCKI, A. Epic video games: Narrative spaces and engaged lives. International Journal of Architectural Computing, v. 14, n. 3, p. 201-211, 2016.

ZUMTHOR, Peter. Atmosferas. 5. ed. São Paulo: Gustavo Gili, 2009 
Apêndices 


\section{APÊNCIDE A - Termo de Consentimento Livre e Esclarecido TERMO DE CONSENTIMENTO LIVRE E ESGLARECIDO}

Título do projeto: Iluminação urbana e sua influência no espaço noturno: como percepções do usuário podem auxiliar no processo de planejamento da luz

Objetivos da pesquisa: as informações fornecidas neste questionário visam investigar como a influência da luz impacta na percepção do espaço urbano e compreender como dados de percepção alimentam o processo de projeto. Também faz parte da pesquisa contribuir com os estudos qualitativos em ambientes noturnos e sua relação com a melhoria da paisagem nas cidades brasileiras.

Descrição dos procedimentos: o pesquisador deve solicitar autorização para o participante realizar o experimento. Em seguida, deverá ser explicada a pesquisa, seus objetivos e o questionário utilizado, além de solicitar o consentimento através deste documento. Uma vez aceito, o experimento deverá se estender por aproximadamente 15 minutos e será realizada no local escolhido pelo participante, sem ser preciso se deslocar para um lugar específico.

Possíveis riscos envolvidos: o participante pode sofrer o chamado "simulator sickness", causando náuseas, tonturas e dores de cabeça após longa exposição aos ambientes virtuais.

Trata-se de participação voluntária, sem benefício direto para o participante. As informações obtidas neste questionário serão analisadas em conjunto, não existindo a possibilidade de identificação de nenhum usuário e garantindo confidencialidade. Também é garantida a desistência do experimento a qualquer momento e a retirada do termo de consentimento. 


\section{APÊNCIDE B - Questionário Socioeconômico}

Esta pesquisa desenvolveu o modelo tridimensional do Largo de São Frei Pedro Gonçalves em João Pessoa/PB, e criou-se momentos distintos para visualização e exploração do espaço em realidade virtual. Preencha o formulário abaixo dedicado à avaliação das impressões dos cenários estudados.

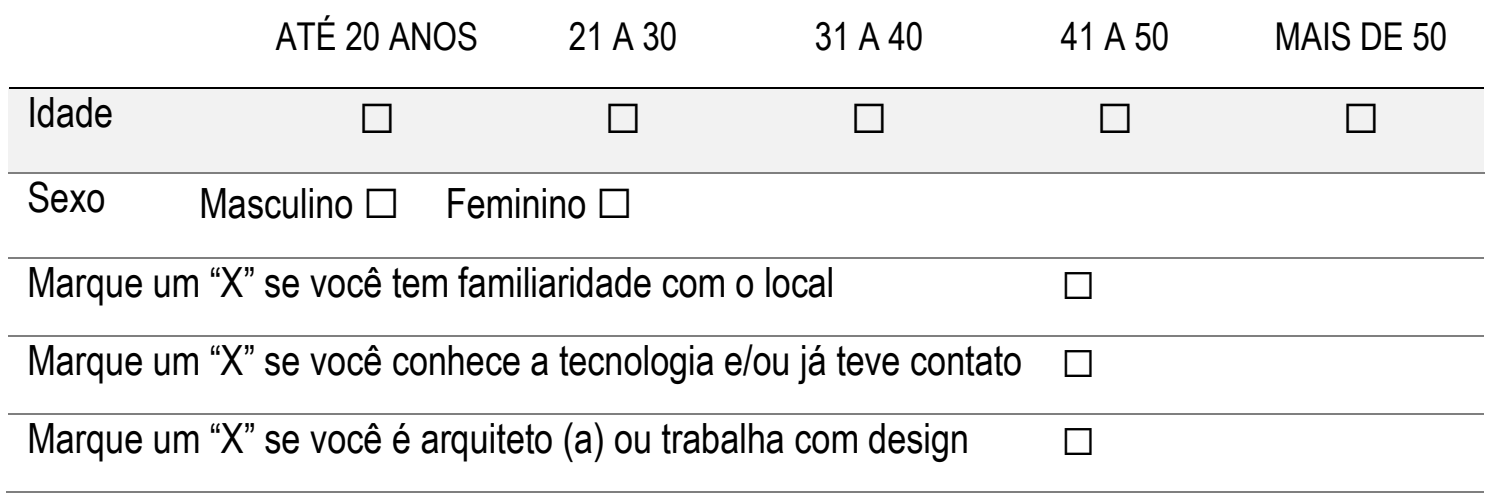

Para você, qual aspecto mais importante para melhor uso dos espaços a noite?

\begin{tabular}{lll}
\hline$\square$ conforto visual & $\square$ orientação de caminhos \\
\hline$\square$ destaque de referências visuais & $\square$ ambiências \\
\hline$\square$ sensação de segurança & $\square$ outro \\
\hline
\end{tabular}


APÊNCIDE C - Questionário da atmosfera percebida

\section{CENÁRIO NOTURNO 01 \\ QUESTIONÁRIO ATMOSFERA}

Cada palavra que descreve 0 ambiente deverá ser avaliado através de uma escala que varia desde "fortemente inaplicável" a "fortemente aplicável".

\begin{tabular}{lccccc} 
& $\begin{array}{c}\text { Fortemente } \\
\text { inaplicável }\end{array}$ & $\begin{array}{c}\text { Parcialmente } \\
\text { inaplicável }\end{array}$ & Neutro & $\begin{array}{c}\text { Parcialmente } \\
\text { aplicável }\end{array}$ & $\begin{array}{c}\text { Fortemente } \\
\text { aplicável }\end{array}$ \\
\hline acolhedor & $\square$ & $\square$ & $\square$ & $\square$ & $\square$ \\
seguro & $\square$ & $\square$ & $\square$ & $\square$ & $\square$ \\
romântico & $\square$ & $\square$ & $\square$ & $\square$ & $\square$ \\
relaxante & $\square$ & $\square$ & $\square$ & $\square$ & $\square$ \\
agradável & $\square$ & $\square$ & $\square$ & $\square$ & $\square$ \\
tranquilo & $\square$ & $\square$ & $\square$ & $\square$ & $\square$ \\
vivaz & $\square$ & $\square$ & $\square$ & $\square$ & $\square$ \\
estimulante & $\square$ & $\square$ & $\square$ & $\square$ & $\square$ \\
agitado & $\square$ & $\square$ & $\square$ & $\square$ & $\square$ \\
alegre & $\square$ & $\square$ & $\square$ & $\square$ & $\square$ \\
inspirador & $\square$ & $\square$ & $\square$ & $\square$ & $\square$ \\
sociável & $\square$ & $\square$ & $\square$ & $\square$ & $\square$ \\
estressante & $\square$ & $\square$ & $\square$ & $\square$ & $\square$ \\
assustador & $\square$ & $\square$ & $\square$ & $\square$ & $\square$ \\
deprimente & $\square$ & $\square$ & $\square$ & $\square$ & $\square$ \\
intimidador & $\square$ & $\square$ & $\square$ & $\square$ \\
desconfortável & $\square$ & $\square$ & $\square$ & $\square$ \\
tedioso & $\square$ & $\square$ & $\square$ & $\square$ \\
acessível & $\square$ & $\square$ & $\square$ & $\square$ \\
exclusivo & $\square$ & $\square$ & $\square$ & $\square$ \\
familiar & $\square$ & $\square$ & $\square$ & $\square$ \\
desinibido & $\square$ & $\square$ & $\square$ & $\square$ \\
& $\square$ & $\square$ & $\square$ & $\square$ \\
\hline
\end{tabular}

Tem algum termo/comentário sobre o ambiente que não consta no questionário? preencha o espaço abaixo: 
APÊNCIDE D - Questionário da qualidade ambiental e da iluminação QUESTIONÁRIO QUALIDADE DO AMBIENTE

Avaliação das qualidades do ambiente em escala de 5 pontos contendo palavras com significados opostos.

\begin{tabular}{lcccccr}
\hline & -2 & -1 & 0 & +1 & +2 & \\
\hline desagradável & $\square$ & $\square$ & $\square$ & $\square$ & $\square$ & agradável \\
\hline não atraente & $\square$ & $\square$ & $\square$ & $\square$ & $\square$ & atraente \\
\hline feio & $\square$ & $\square$ & $\square$ & $\square$ & $\square$ & bonito
\end{tabular}

Avaliação das qualidades da iluminação em escala de 5 pontos contendo palavras com significados opostos

\begin{tabular}{llllllr}
\hline & -2 & -1 & 0 & +1 & +2 & \\
\hline sombrio & $\square$ & $\square$ & $\square$ & $\square$ & $\square$ & claro \\
\hline monótono & $\square$ & $\square$ & $\square$ & $\square$ & $\square$ & interessante \\
\hline frio & $\square$ & $\square$ & $\square$ & $\square$ & $\square$ & quente
\end{tabular}

